NUREG/CR-6285

INEL-94/0016

\title{
Severe Accident Natural Circulation Studies at the INEL
}

Manuscript Completed: November 1994

Date Published: February 1995

Prepared by

P. D. Bayless, D. A. Brownson, C. A. Dobbe, K. R. Jones,

J. E. O'Brien, D. J. Pafford, L. D. Schlenker, V. X. Tung

Idaho National Engineering Laboratory

Managed by the U.S. Department of Energy

Lockheed Idaho Technologies Company

Idaho Falls, ID 83415

Prepared for

Division of Systems Research

Office of Nuclear Regulatory Research

U.S. Nuclear Regulatory Commission

Washington, DC 20555-0001

NRC Job Code L1675 


\section{DISCLAIMER}

This report was prepared as an account of work sponsored by an agency of the United States Government. Neither the United States Government nor any agency thereof, nor any of their employees, make any warranty, express or implied, or assumes any legal liability or responsibility for the accuracy, completeness, or usefulness of any information, apparatus, product, or process disclosed, or represents that its use would not infringe privately owned rights. Reference herein to any specific commercial product, process, or service by trade name, trademark, manufacturer, or otherwise does not necessarily constitute or imply its endorsement, recommendation, or favoring by the United States Government or any agency thereof. The views and opinions of authors expressed herein do not necessarily state or reflect those of the United States Government or any agency thereof. 


\section{DISCLAIMER}

Portions of this document may be illegible in electronic image products. Images are produced from the best available original document. 


\begin{abstract}
Severe accident natural circulation flows have been investigated at the Idaho National Engineering Laboratory to better understand these flows and their potential impacts on the progression of a pressurized water reactor severe accident. Parameters affecting natural circulation in the reactor vessel and hot legs were identified and ranked based on their perceived importance. Reviews of the scaling of the 1/7-scale experiments performed by Westinghouse were undertaken. RELAP5/MOD3 calculations of two of the experiments showed generally good agreement between the calculated and observed behavior. Analyses of hydrogen behavior in the reactor vessel showed that hydrogen stratification is not likely to occur, and that an initially stratified layer of hydrogen would quickly mix with a recirculating steam flow. An analysis of the upper plenum behavior in the Three Mile Island, Unit 2 reactor concluded that vapor temperatures could have been significantly higher than the temperatures seen by the control rod drive lead screws, supporting the premise that a strong natural circulation flow was likely present during the accident. SCDAP/RELAP5 calculations of a commercial pressurized water reactor severe accident without operator actions showed that the natural circulation flows enhance the likelihood of ex-vessel piping failures long before failure of the reactor vessel lower head.
\end{abstract}

FIN L1675-Natural Circulation in PWRs During Severe Accidents. 


\section{CONTENTS}

ABSTRACT $\ldots \ldots \ldots \ldots \ldots \ldots \ldots \ldots \ldots \ldots \ldots \ldots \ldots \ldots \ldots \ldots \ldots \ldots \ldots \ldots \ldots \ldots \ldots \ldots \ldots$

LIST OF FIGURES $\ldots \ldots \ldots \ldots \ldots \ldots \ldots \ldots \ldots \ldots \ldots \ldots \ldots \ldots \ldots \ldots \ldots \ldots \ldots \ldots \ldots \ldots$

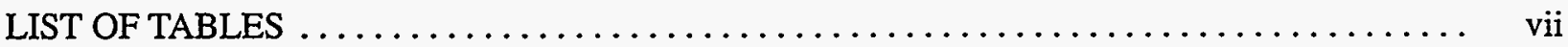

EXECUTIVE SUMMARY $\ldots \ldots \ldots \ldots \ldots \ldots \ldots \ldots \ldots \ldots \ldots \ldots \ldots \ldots \ldots \ldots \ldots \ldots \ldots \ldots \ldots$

ACKNOWLEDGMENTS $\ldots \ldots \ldots \ldots \ldots \ldots \ldots \ldots \ldots \ldots \ldots \ldots \ldots \ldots \ldots \ldots \ldots \ldots \ldots \ldots \ldots \ldots$

ACRONYMS $\ldots \ldots \ldots \ldots \ldots \ldots \ldots \ldots \ldots \ldots \ldots \ldots \ldots \ldots \ldots \ldots \ldots \ldots \ldots \ldots \ldots \ldots \ldots$

1. INTRODUCTION $\ldots \ldots \ldots \ldots \ldots \ldots \ldots \ldots \ldots \ldots \ldots \ldots \ldots \ldots \ldots \ldots \ldots \ldots \ldots \ldots \ldots \ldots \ldots$

1.1 Description of Natural Circulation Flows $\ldots \ldots \ldots \ldots \ldots \ldots \ldots \ldots \ldots \ldots \ldots \ldots$

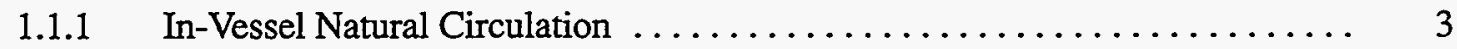

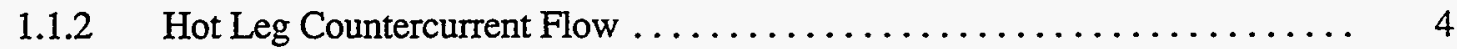

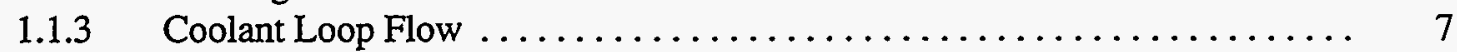

1.2 Importance of Natural Circulation Flows $\ldots \ldots \ldots \ldots \ldots \ldots \ldots \ldots \ldots \ldots \ldots$

1.3 Description of Scenarios Leading to Natural Circulation $\ldots \ldots \ldots \ldots \ldots \ldots \ldots$

2. PHENOMENA IDENTIFICATION AND RANKING TABLES $\ldots \ldots \ldots \ldots \ldots \ldots \ldots$

2.1 In-Vessel Natural Circulation $\ldots \ldots \ldots \ldots \ldots \ldots \ldots \ldots \ldots \ldots \ldots \ldots \ldots \ldots \ldots \ldots \ldots$

2.2 Hot Leg Natural Circulation $\ldots \ldots \ldots \ldots \ldots \ldots \ldots \ldots \ldots \ldots \ldots \ldots \ldots \ldots \ldots \ldots \ldots \ldots$

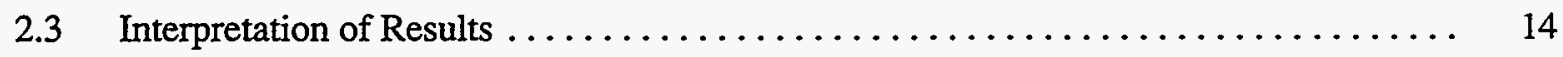

3. EXPERIMENTS AND SEPARATE EFFECTS ANALYSES $\ldots \ldots \ldots \ldots \ldots \ldots \ldots \ldots$

3.1 Westinghouse U-Tube Steam Generator Experiments $\ldots \ldots \ldots \ldots \ldots \ldots \ldots \ldots$

3.1.1 Experiment Description and Results . . . . . . . . . . . . . . . . 16

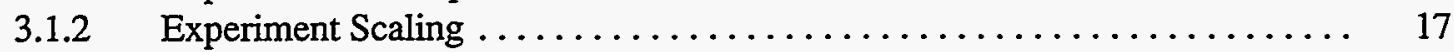

3.1.3 RELAP5/MOD3 Experiment Calculations . . . . . . . . . . . . 19

3.2 Natural Circulation Flow Disruption $\ldots \ldots \ldots \ldots \ldots \ldots \ldots \ldots \ldots \ldots \ldots \ldots \ldots \ldots \ldots \ldots$

3.2.1 Upper Plenum Hydrogen Stratification and Mixing . . . . . . . . . . . 19

3.2.2 Hydrogen Blocking of the Steam Generator Tubes $\ldots \ldots \ldots \ldots \ldots \ldots \ldots 20$

3.3 Natural Circulation in the TMI-2 Accident $\ldots \ldots \ldots \ldots \ldots \ldots \ldots \ldots \ldots \ldots \ldots \ldots$

4. COMMERCIAL PLANT ANALYSES $\ldots \ldots \ldots \ldots \ldots \ldots \ldots \ldots \ldots \ldots \ldots \ldots \ldots$

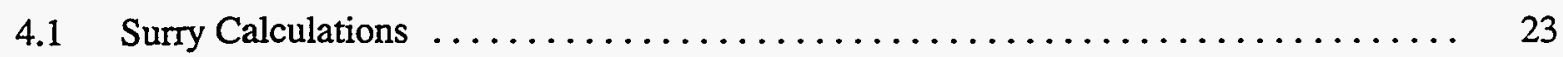


4.1.1 Modeling Natural Circulation Flows $\ldots \ldots \ldots \ldots \ldots \ldots \ldots \ldots \ldots \ldots \ldots \ldots$

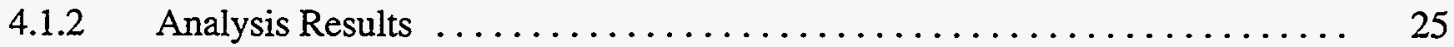

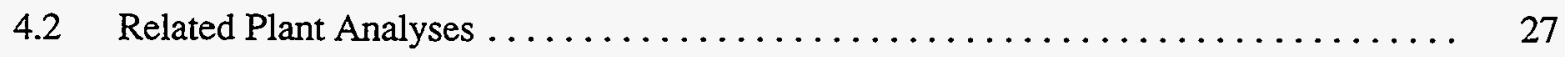

4.3 Extension of Results to Other PWRs $\ldots \ldots \ldots \ldots \ldots \ldots \ldots \ldots \ldots \ldots \ldots \ldots \ldots \ldots$

5. SUMMARY AND CONCLUSIONS $\ldots \ldots \ldots \ldots \ldots \ldots \ldots \ldots \ldots \ldots \ldots \ldots \ldots \ldots \ldots \ldots \ldots \ldots \ldots \ldots$

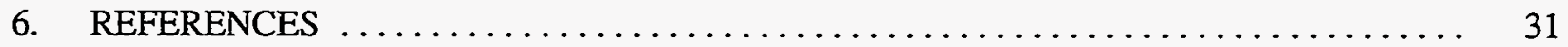

Appendix $\mathrm{A}-\mathrm{Natural}$ Circulation Parameter Importance Evaluation $\ldots \ldots \ldots \ldots \ldots \ldots \ldots$ A-1

Appendix B-Scaling Review of the Westinghouse Test Apparatus and Natural

Circulation Experiments $\ldots \ldots \ldots \ldots \ldots \ldots \ldots \ldots \ldots \ldots \ldots \ldots \ldots \ldots \ldots \ldots \ldots \ldots \ldots \ldots \ldots \ldots$

Appendix C-Reevaluation of Scaling Considerations for the Westinghouse 1/7-Scale

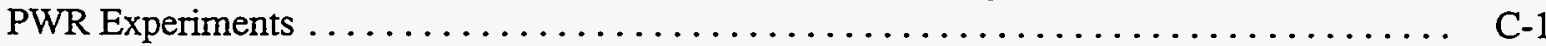

Appendix D-RELAP5 Analysis of Natural Circulation Flow in the Westinghouse

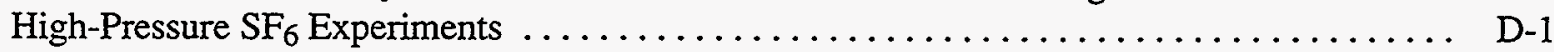

Appendix E-Effects of Hydrogen Generation on Severe Accident Natural Circulation $\ldots . . . \quad$ E-1

Appendix F-Evaluation of the Capability of RELAP5/MOD3 to Calculate Hydrogen

Blockage Effects in U-Tube Steam Generators $\ldots \ldots \ldots \ldots \ldots \ldots \ldots \ldots \ldots \ldots \ldots$ F-1

Appendix G-Examination of the Lead Screw Temperatures in the Upper Plenum of TMI-2 . . . G-1

Appendix H-Evaluation of Heat Transfer Uncertainties for Hot Leg Natural Circulation . . . . . . H-1

Appendix I-Plant Categorization Based on the Potential for Unintentional Depressurization

Resulting from Failure of Ex-Vessel Components $\ldots \ldots \ldots \ldots \ldots \ldots \ldots \ldots \ldots \ldots \ldots \ldots \ldots$ 


\section{LIST OF FIGURES}

1. Severe accident natural circulation flows $\ldots \ldots \ldots \ldots \ldots \ldots \ldots \ldots \ldots \ldots \ldots \ldots \ldots \ldots \ldots \ldots \ldots$

2. Hot leg natural circulation stream flows $\ldots \ldots \ldots \ldots \ldots \ldots \ldots \ldots \ldots \ldots \ldots \ldots \ldots \ldots \ldots \ldots \ldots$

3. Typical nodalization of the hot leg and steam generator for SCDAP/RELAP5 calculations with hot leg natural circulation $\ldots \ldots \ldots \ldots \ldots \ldots \ldots \ldots \ldots \ldots \ldots \ldots \ldots \ldots$

4. Nodalization of the reactor vessel for the Surry SCDAP/RELAP5 calculations with in-vessel natural circulation

\section{LIST OF TABLES}

1. Priority rankings for in-vessel natural circulation phenomena $\ldots \ldots \ldots \ldots \ldots \ldots \ldots \ldots \ldots$

2. Priority rankings for hot leg natural circulation phenomena $\ldots \ldots \ldots \ldots \ldots \ldots \ldots \ldots$ 


\section{EXECUTIVE SUMMARY}

Severe accident natural circulation flows have been investigated at the Idaho National Engineering Laboratory to gain insight into the influence these flows have on the accident progression in a pressurized water reactor. Efforts have included an assessment of the importance of various parameters associated with natural circulation, benchmarking of the RELAP5/MOD3 code against experiments performed by Westinghouse, reviews of the scaling of those experiments, analyses of phenomena that could disrupt natural circulation flow, and simulations of commercial pressurized water reactor severe accidents. Possible natural circulation during the Three Mile Island, Unit 2 accident was also investigated.

The investigations described here focused on two primary flow patterns: in-vessel and hot leg natural circulation flows. In-vessel natural circulation is the result of vapor being heated in the core and cooled in the upper plenum. The vapor flows up through the center of the core, is cooled by the internal structures in the upper plenum, and flows back down into the periphery of the core. Hot leg natural circulation is a countercurrent flow of vapor in the hot leg, with hotter vapor flowing from the reactor vessel to the steam generators along the top of the pipe, while cooler vapor returns to the vessel along the bottom of the pipe. U-tube steam generators provide a very large heat sink, and can remove about $20 \%$ of the core decay energy.

Natural circulation flows are important because they transfer energy from the core to other regions of the reactor coolant system. As these structures heat up, they may fail. A failure of the reactor coolant system pressure boundary would allow the system to depressurize. If the failure occurs early enough or is large enough, the system pressure at the time of vessel lower head failure may be low enough to avoid a highpressure melt ejection, thus mitigating the effects of direct containment heating. If the failure occurs in the steam generator tubes, a containment bypass path is established that would allow fission products released from the fuel to travel directly to the environment.

Transferring energy to other regions of the reactor coolant system also slows the core heatup. This can influence the core damage progression by allowing more complete oxidation of the cladding while it is still in the core, resulting in a later core relocation and minimizing the amount of metallics in the melt. A faster core heatup may allow early failure and relocation of the core, with more unoxidized materials.

Parameters that affect the in-vessel and hot leg natural circulation flows were identified. Phenomena identification and ranking tables were then developed to estimate the relative importance of the various phenomena. The rankings can be used to guide sensitivity or experimental studies, or code development and improvement efforts.

For in-vessel natural circulation, the phenomena were ranked based on their perceived influence on the vapor temperature at the hot leg nozzle. The higher-ranked phenomena were water draining from the hot legs back into the reactor vessel, the reactor vessel water level, and convective heat transfer in the upper plenum and core. The lower-ranked phenomena were radiative heat transfer in the core and upper plenum, fission product behavior, and noncondensible gas effects.

For hot leg natural circulation, the phenomena were ranked based on their perceived influence on creep rupture failure of the hot leg, pressurizer surge line, or steam generator tubes. The higherranked phenomena were relief valve cycling, liquid draining from the pressurizer, steam generator secondary side conditions, reactor coolant system pressure, and heat transfer from the vapor to the structures. The lower-ranked phenomena included hot leg countercurrent flow, vapor-tovapor heat transfer, noncondensible gas effects, fission product behavior, material properties, steam generator inlet plenum mixing and the hot leg circumferential temperature gradient in the 
U-tube steam generator plants, and hot leg flow cells in the vertical section of Babcock \& Wilcox plants.

Westinghouse performed natural circulation experiments in a $1 / 7$-scale facility using water and $\mathrm{SF}_{6}$. An order-of-magnitude review of the scaling of those experiments was performed. The hot leg countercurrent flow was judged to be scaled fairly well in the high-pressure $\mathrm{SF}_{6}$ tests, but not well in the low-pressure tests. The flow in the model steam generator will be much greater than in the plant, and the flow through the core will also be higher in the experiment. Fluid heating in the core will be higher in the plant because of radiation heat transfer. Thermal inertia in the steam generator is well scaled, but is too high in the upper plenum. On an order-of-magnitude basis, the scaling of the high-pressure tests was found to be adequate for code assessment, with the exception of the effects of radiative heat transfer in the core and the boundary condition supplied to the hot leg by the steam generator.

Calculations of two of the high-pressure, $\mathrm{SF}_{6}$ steady-state experiments were performed with the RELAP5/MOD3 computer code. The calculations showed generally good agreement with the measured results, providing some confidence that the code and modeling philosophy could be applied to commercial plant simulations. Vapor temperatures were slightly overpredicted in the hot legs and steam generators, and the core temperatures were overpredicted in downflow and underpredicted in upflow.

Two analyses were performed to investigate the effects of hydrogen stratification in the reactor vessel and steam generators. The concern is that the hydrogen may reduce or inhibit heat transfer in those locations, thereby reducing the structure heatup rates and increasing the core heatup rate. In the reactor vessel, it was determined that a stratified layer of hydrogen in the upper plenum is not likely to form. Even with an initially stratified layer in the upper plenum, the recirculating steam will quickly incorporate the lighter gas into the natural circulation flow.
In the steam generators, a study was performed to investigate the capability of the RELAP5 code to model the concentration of hydrogen caused by condensation of steam in the steam generator tubes. The study concluded that should such condensation occur, RELAP5 should be capable of simulating the behavior.

One of the questions raised concerning natural circulation flows during severe accidents involves the accident at Three Mile Island. The metallurgical examinations of the control rod guide lead screws from the upper plenum indicated that the temperatures were much lower than would be predicted with in-vessel natural circulation occurring. An analysis of the upper plenum behavior was performed that considered axial conduction along the lead screws, radiation and convection between the vapor and the structures, and buoyancy-driven flow within the control rod guide housings. It was calculated that the upper plenum vapor temperatures could have been $700-800 \mathrm{~K}\left(1,250-1,450^{\circ} \mathrm{F}\right)$ higher than the temperatures of the lead screws. This indicates that a vigorous in-vessel natural circulation flow was likely occurring during the accident.

Analyses of severe accident behavior in the Surry plant were performed. Calculations of the response to a station blackout transient were performed with the SCDAP/RELAP5 code, with both in-vessel and hot leg natural circulation flows modeled. The initial calculations predicted that creep rupture failure of the surge line would occur at about the same time as initial fuel rod relocation. This happens more than 1 hour before predicted lower head failure, allowing sufficient time for the reactor coolant system to depressurize and mitigate the effects of direct containment heating.

Calculations were also performed to determine the sensitivity of the results to uncertainties in the phenomena associated with the natural circulation flows. Changes in the reactor vessel loss coefficients, steam generator inlet plenum mixing, and heat transfer coefficients in the piping and upper plenum, as well as modeling heat loss through the piping or heat transfer between the counterflowing vapor in the hot leg, had little 
effect on the transient. Surge line failure was still predicted to occur near the time of the initial fuel rod relocation, leaving ample time for the system to depressurize before lower head failure.

Operator actions, which were not modeled in these analyses, could result in sufficient cooling of the ex-vessel piping to allow the reactor vessel lower head to fail first. This was observed in the Three Mile Island accident, where there was no evidence of ex-vessel piping heatup despite the extensive core damage.

An attempt was also made to determine whether plants could be categorized based on their potential for ex-vessel failures. If successful, this effort would allow the use of a few selected plant analyses in predicting the response of many plants. The possible failure locations considered were the relief valves, surge line and hot leg piping, steam generator tubes, and reactor coolant pump seals. These failures were considered to have the potential to reduce the reactor coolant system pressure sufficiently to mitigate direct containment heating. It was found that differences in plant hardware, a lack of applicable component failure data, and variations in the accident progression result in large enough uncertainties that groupings of plants could not be made, and that the results of the Surry analyses cannot be realistically applied to determine how and when ex-vessel failures would occur in other plants during a severe accident. The only possible exception was for reactor coolant pump seal failures, where those plants with the older Westinghouse seal design might be grouped separately from the rest of the pressurized water reactors; these seals are more likely to fail than those of other pump manufacturers because they require continuous cooling. 



\section{ACKNOWLEDGMENTS}

The authors gratefully acknowledge the many valuable contributions to the natural circulation investigations made by D. J. Hanson. Additional support in the various analyses has been provided by C. M. Allison, A. N. Brown, S. A. Chavez, S. V. Chmielewski, G. L. Hawkes, G. A. Mortensen, J. L. Rempe, and L. J. Siefken.

Guidance and support for the project has been provided by C. R. Troutman and D. E. Bessette of the Nuclear Regulatory Commission.

The reviews of various portions of the work provided by P. Griffith, R. Viskanta, and $\mathrm{S}$. Ostrach, as well as by W. Lyon, are appreciated by the authors. 



\section{ACRONYMS}

$\begin{array}{llll}\text { AHP } & \text { analytical hierarchy process } & \text { PD } & \text { pressurizer draining } \\ \text { B\&W } & \text { Babcock \& Wilcox } & \text { PIRT } & \begin{array}{l}\text { phenomena identification and ranking } \\ \text { table }\end{array} \\ \text { CC } & \text { countercurrent } & \text { PORV } & \text { power-operated relief valve } \\ \text { CE } & \text { Combustion Engineering } & \text { PWR } & \text { pressurized water reactor } \\ \text { DCH } & \text { direct containment heating } & \text { RCS } & \text { reactor coolant system } \\ \text { HL } & \text { hot leg } & \text { SG } & \text { steam generator } \\ \text { HT } & \text { heat transfer } & \text { SRV } & \text { safety relief valve } \\ \text { INEL } & \text { Idaho National Engineering } & \text { TML-2 } & \text { Three Mile Island, Unit } 2 \\ & \text { Laboratory } & \text { UP } & \text { upper plenum }\end{array}$




\section{Severe Accident Natural Circulation Studies at the INEL}

\section{INTRODUCTION}

The U.S. Nuclear Regulatory Commission (NRC) sponsored a parallel experimental and analytical effort that enhanced the understanding of severe accidents following the accident at Three Mile Island, Unit 2 (TMI-2). This research effort culminated in the "Reassessment of the Technical Bases for Estimating Source Terms," NUREG-0956, ${ }^{1}$ which described the current state of knowledge in the severe accident area and identified eight major areas of uncertainty. The "Reactor Risk Reference Document," NUREG-1150, ${ }^{2}$ used the source term methodology in NUREG-0956 to provide a basis for new estimates of reactor risk.

NUREG-0956 identified natural circulation in the reactor coolant system (RCS) as one of the areas of major uncertainty. Phenomenological analyses that contributed to the draft version of NUREG-1150, however, did not account for the natural circulation flows. The initial Idaho National Engineering Laboratory (INEL) analyses performed for the NRC in this area investigated the effects of various types of natural circulation on the transient, severe accident response of the Surry nuclear power plant. ${ }^{3}$ Of particular interest were changes in the events that occur, in event timings, and in the extent of core damage.

Subsequent analyses have been performed at the INEL to develop a more extensive understanding of natural circulation behavior. These efforts assessed the importance of various parameters associated with natural circulation, benchmarked the RELAP5/MOD3 code against experiments performed by Westinghouse, and analyzed phenomena that could disrupt natural circulation flow. Further code calculations of the Surry plant were also performed to address additional limitations and uncertainties in the modeling approach.
The remainder of this chapter describes natural circulation flows and their significance in pressurized water reactor (PWR) severe accidents. Chapter 2 describes and presents results from the development of phenomena identification and ranking tables (PIRTs) for severe accident natural circulation behavior. Scaled experiments performed by Westinghouse are summarized in Chapter 3, as are the results of RELAP5 calculations of two of those experiments. Chapter 3 also contains separate effects analyses related to possible disruption of natural circulation flows, and a brief discussion of natural circulation during the TMI-2 accident. Results from commercial plant analyses are presented in Chapter 4. Chapter 5 summarizes results and conclusions from the various analyses. References are listed in Chapter 6. The appendices contain more detailed descriptions of the analyses discussed in the body of the report.

\subsection{Description of Natural Circulation Flows}

Three natural circulation flows can be important during severe accidents: in-vessel, hot leg countercurrent flow, and flow through the coolant loops. Figure 1 illustrates these flows. Each of these flows may be present during a high-pressure boiloff transient such as the TMLB' sequence. (The TMLB' sequence refers to a transient in which all ac power is lost and no steam-driven auxiliary feedwater is supplied to the steam generators.)

The primary effect of the natural circulation flows is to redistribute the energy being generated in the core. This energy redistribution will slow the heatup of the core, which in turn may affect the damage progression or the extent of the core damage. Slowing the core damage would allow more time for systems to be recovered to mitigate or terminate the accident. However, the energy 
Introduction

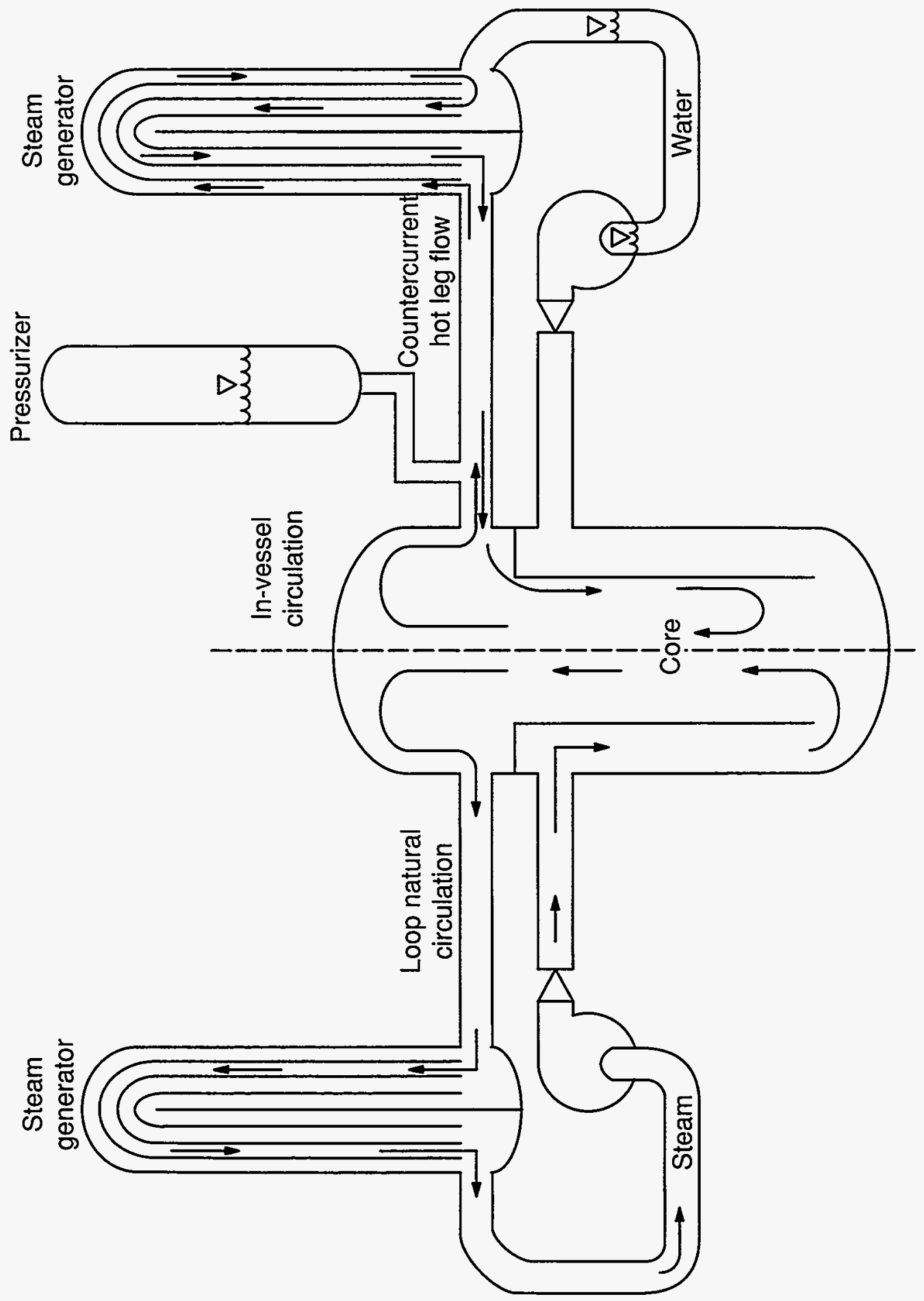

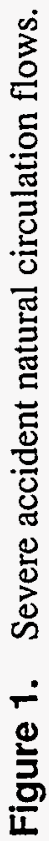


removed from the core will affect the structures in which it is deposited, in both the upper plenum and the coolant loops. The discussions below address the basic phenomena associated with the three types of natural circulation being considered, together with how the transient progression may be affected by the coolant flow.

\subsubsection{In-Vessel Natural Circulation. In-} vessel natural circulation begins when the core heatup begins. Because the center part of the core is at a higher power than the periphery, the superheated steam there is hotter and less dense, and a radial density gradient is established. The denser vapor in the outer part of the core tends to flow toward the center, replacing the hot vapor that rises into the upper plenum. This vapor plume rises to the top of the upper plenum, where it is turned radially outward to the core barrel, and then back down toward the top of the core. Heat transfer to the structures in the upper plenum cools the vapor, reinforcing the density gradient between the center of the vessel and the periphery. The cooler steam reenters the core through the top of the peripheral fuel assemblies. As core uncovering continues and the liquid level drops, the recirculating flow extends farther down into the core. Depending on the axial power profile, the flow may eventually extend to the bottom of the core. The density gradient in the upper plenum also establishes a recirculating flow within the upper plenum.

In reality, many natural circulation cells will probably be established in the core, especially during the core damage portion of the transient. These cells will exist between fuel assemblies, between parts of fuel assemblies, and even between subchannels. Wherever a radial temperature gradient exists, a natural convection flow may be established. The rapid increases in local temperature associated with the accelerated oxidation of the zircaloy fuel rod cladding, at a temperature around $1,850 \mathrm{~K}\left(2,870^{\circ} \mathrm{F}\right)$, will in particular result in the establishment of these relatively small natural circulation cells. These smaller flow cells are believed (assumed) to exist within larger overall natural convection cells involving the entire core. It is these core-wide patterns that are being investigated and discussed in these analyses, because it is the global core behavior that is of interest, not the behavior of individual fuel rods or assemblies.

The in-vessel natural circulation flow may affect the cladding oxidation. Because steam is being recirculated from the upper plenum back into the core, it is less likely that the oxidation reaction will become steam-starved. The slower cladding heatup caused by the removal of some of the core energy to the upper plenum structures, combined with a steam-rich environment, may result in more extensive oxidation of the cladding at lower temperatures. This in turn may lead to smaller amounts of unoxidized zircaloy melting as the temperature increases, which could delay relocation of molten material and cause less dissolution of the fuel pellets.

Increased heating of the upper plenum structures resulting from the natural circulation flow could also lead to their oxidation or melting. This could add to the hydrogen generated in the RCS before vessel failure, and could add more material to the melt that flows from the vessel at the time of lower head failure.

Both the smaller amount of fuel dissolved by liquid zircaloy and the higher upper plenum structure temperatures affect the fission product behavior. The smaller amount of dissolved fuel may delay the release of many of the fission products until the fuel melts. At this later time, which will be closer to the time of vessel failure, there will be less time for the fission products to be retained on surfaces in the RCS, which may result in more fission products in the containment. The higher structure temperatures would tend to reduce the amount of fission products retained in the upper plenum, causing them to be deposited elsewhere or released to the containment.

Higher vapor temperatures in the upper plenum will also make hotter vapor available to the hot legs. Flow through the hot leg and surge line to the pressurizer power-operated relief valves (PORVs) will heat the piping. If the pipe temperatures are high enough, creep rupture failure of these pipes may become a concern. Failure of the 
RCS piping before the vessel fails could allow the system to depressurize, initiating accumulator injection. If the depressurization continues far and fast enough, the RCS pressure at the time of vessel failure may be low enough to preclude direct containment heating.

\subsubsection{Hot Leg Countercurrent Flow. Single-}

phase countercurrent flow in the hot leg is much more significant in PWRs with U-tube steam generators than in those with once-through steam generators because the U-tube steam generators participate in the natural circulation flow and heat transfer, but the once-through steam generators do not. The following paragraphs discuss the basic considerations of the flow.

Superheated vapor enters the top of the hot leg, displacing saturated vapor, which then flows back to the reactor vessel along the bottom of the hot leg. When the hotter vapor enters the steam generator inlet plenum, it will rise toward the steam generator tubes. Vapor enters some of the tubes, displacing the cooler steam that was in the tubes. The displaced vapor enters the outlet plenum, then reenters other steam generator tubes, forcing vapor into the inlet plenum. A density gradient is thus established between tubes. This density gradient then pulls more hot vapor into the tubes, displacing additional cooler steam. The process continues until a steady flow is established, with hot vapor flowing from the inlet plenum to the outlet plenum through some of the steam generator tubes, and cooler vapor returning to the inlet plenum through the remaining tubes.

Now consider the flow streams shown in Figure 2. The hot $\left(T_{h}\right)$ and cold $\left(T_{c}\right)$ fluid temperatures at three locations will be examined: the hot leg nozzle (1), the steam generator end of the hot leg (2), and the inlet to the steam generator tubes (3). At each of the locations, the hotter fluid flows from the reactor vessel toward the steam generator outlet plenum, and the colder fluid flows toward the reactor vessel.

The hot vapor entering the hot leg from the reactor vessel flows toward the steam generator along the top of the pipe. As it flows, heat is transferred to both the hot leg piping and the returning cooler fluid stream. There may also be some mass transfer between the two fluid streams. The result is that $T_{h, 1}>T_{h, 2}$. As the flow enters the steam generator inlet plenum, some of it mixes with the fluid in the plenum and with the cold flow exiting from some of the steam generator tubes. The mixing reduces the temperature of the steam entering the steam generator tubes, and $T_{h, 3}<T_{h, 2}$. Heat is transferred to the tubes as the steam flows through the steam generators. When the flow returns to the inlet plenum, some of it mixes with the hot leg flow. This mixing raises the temperature of the steam returning through the hot leg, so that $T_{c, 2}>T_{c, 3}$. As the flow proceeds along the bottom of the hot leg to the reactor vessel, heat transfers from the hotter fluid above into this cooler steam, and from this cooler steam to the hot leg pipe. Whether these energy transfers result in a net heating or cooling of the return flow has not been quantified, but the vapor temperature will probably not change significantly along the bottom of the hot leg. Also unaccounted for in this discussion is the effect of circumferential heat transfer in the hot leg piping, in which heat would be conducted from the hot upper part of the hot leg to the cool lower part.

Assuming a steady flow, the total energy transfer in the coolant loop is the product of the hot leg mass flow rate, the average heat capacity of the flowing vapor, and the temperature difference between the opposing flows at the hot leg nozzle. The analyses associated with the Westinghouse natural circulation experiments ${ }^{4}$ showed that the hot leg mass flow rate is a function of geometric parameters, the fluid density, and the square root of the temperature difference $\left(T_{h, 1}-T_{c, 1}\right)$. Thus, the heat transferred by the hot leg natural circulation flow depends on the temperature difference at the nozzle, and interactions that tend to increase the cooler vapor temperature will reduce the flow rate and the heat transfer. Both the mixing in the steam generator inlet plenum and heat transfer from the hotter vapor above act to increase the temperature of the returning vapor.

Similarly, the heat transfer in the steam generator tubes is the product of the mass flow rate through the tubes, the average vapor heat 
u

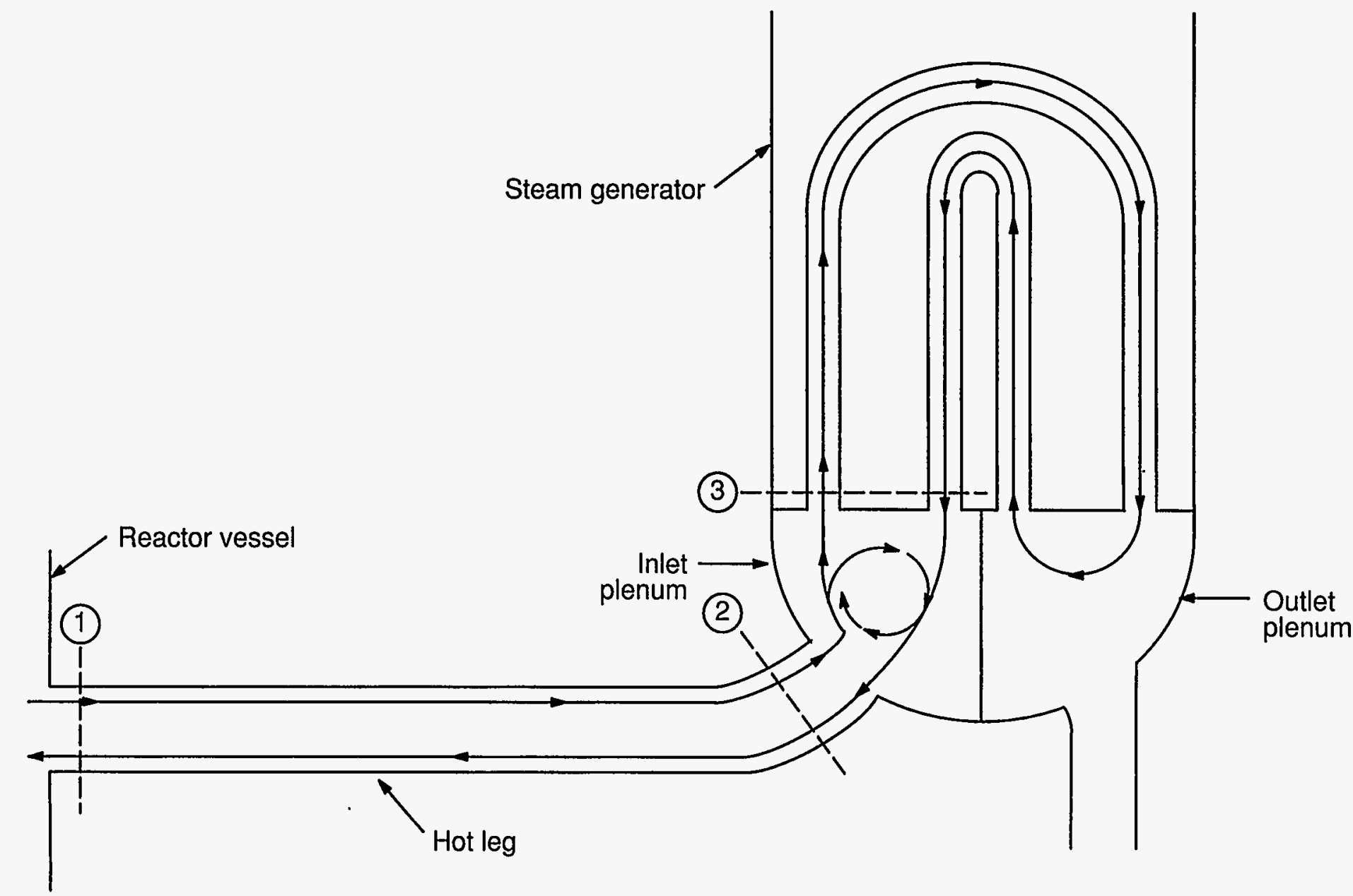

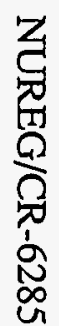

LF94 0130

Figure 2. Hot leg natural circulation stream flows. 
capacity, and the temperature difference $\left(T_{h, 3}-T_{c, 3}\right)$. The heat transfer in the tubes will be affected by interactions that alter either of these temperatures. Again, the mixing in the inlet plenum tends to reduce $T_{h, 3}$, thereby limiting the heat transfer in the steam generators.

Now consider the case in which there is no mixing in the steam generator inlet plenum. The hot vapor temperatures in the hot leg will change little; a lower temperature in the cooler vapor (in the bottom of the hot leg) will increase the amount of heat transferred between the opposing flow streams slightly. However, $T_{h, 3}=T_{h, 2}$. The higher temperature fluid entering the steam generator tubes will result in increased heat transfer to the tubes. The absence of mixing also means that $T_{c, 2}=T_{c, 3}$, so that the flow returning through the hot leg is colder. Since the flow is driven by the temperature difference between the hot and cold fluid streams in the hot leg, the mass flow will increase. The higher mass flow rate will increase the heat transfer in the loop, slowing the core heatup. The higher steam generator tube temperatures will also change the relative energy deposition between the hot leg and the tubes, with more energy being transferred to the tubes.

Mixing in the steam generator plenum is a controlling phenomenon for the hot leg natural circulation flow. It limits the mass flow in the hot leg by increasing the temperature (and lowering the density) of the vapor returning from the steam generator along the bottom of the hot leg. It limits the heat transfer in the steam generator by reducing the temperature of the hot vapor entering the tubes. While accurate modeling of the mixing is important in providing a realistic simulation of the hot leg flow behavior, neglecting the mixing in the steam generator inlet plenum in the analyses will yield steam generator tube temperatures and hot leg mass flow rates that are higher than would be expected.

Hot leg countercurrent flow can affect the structural integrity of the RCS piping. Heating of the pipes and steam generator tubes may lead to melting or creep rupture failure of those components. Steam generator tubes are very thin compared to the loop or surge line piping, and can be quickly heated if exposed to high temperature vapor. Should the tubes fail, a direct path outside of containment (through the steam line relief valves) becomes available to any fission products carried in the coolant. While flow through pressurizer relief valves in some transients will draw hot vapor into the hot leg and surge line, the countercurrent flow may accelerate the heating and possible failure of these pipes. For lower pressure transients in which relief valves are not open, the hot leg countercurrent flow may result in hot leg piping failures that would not otherwise be expected to occur.

Fission product behavior may also be affected by the flow to the steam generators. An extremely large surface area is available on the steam generator tubes for deposition of fission products. If the tubes remain cool, deposited species may remain there and not be released from the RCS. If the tubes continue to heat up so that revolatilization occurs, the flow may simply carry the resuspended fission products to cooler parts of the tubes, where they would again be deposited. The mixing in the steam generator inlet plenum may also play a part in the fission product behavior. If gaseous fission products are carried with the hot vapor along the top of the pipe, the sudden cooling associated with interaction with the cooler fluid in the inlet plenum may result in the condensation of the vapors, either on existing aerosols or as newly generated aerosols. In liquid form, these fission products would be deposited more quickly, and probably in the inlet plenum rather than in the tubes. The countercurrent flow in the hot leg itself may also affect the fission product transport. If gravitational settling is an important mechanism for fission product deposition in the hot leg, fission products falling from the flow that is heading toward the steam generators would enter the return vapor stream, where they would be carried back toward the reactor vessel, rather than away from it. This phenomenon is beyond the capability of current analytical methods, which are for one-dimensional flows. However, the magnitude of the effect should be calculable for a given analysis since the amount of deposition caused by gravitational settling 
should be known from the fission product transport calculation. (Fission product transport was not modeled in the analyses presented in this report.)

The discussion up to this point has described hot leg countercurrent flow in PWRs with U-tube steam generators. Plants designed by Babcock \& Wilcox (B\&W) do not have U-tube steam generators; they use once-through steam generator tubes in which the primary coolant is cooled in downflow through straight tubes. To accommodate this steam generator, the hot leg geometry is significantly different as well. After the horizontal run from the reactor vessel, the hot leg has a long upward vertical run before turning over into another short horizontal section, followed by a downward-oriented vertical pipe that connects to the steam generator inlet plenum.

The most significant feature of this "candy cane" hot leg design as far as the hot leg countercurrent flow is concerned is that the steam generators are precluded from participating in the hot leg countercurrent flow. Any vapor that is cooled in the steam generator has no path for returning directly to the hot leg; it has to enter the cold leg first.

Hot leg countercurrent flow will be initiated in the same manner as for PWRs with U-tube steam generators. Superheated vapor will enter the hot leg, displacing cooler vapor and establishing a temperature gradient in the horizontal section of the hot leg, with hotter vapor on the top of the pipe and cooler vapor along the bottom. When the hotter vapor reaches the vertical section, some plumes of hot vapor will be established, with cooling along the pipe walls returning cooler vapor to the horizontal piping. This flow pattern is likely to be more transient in nature than that found in the U-tube steam generators. As one region of the vertical piping section is heated, the heat transfer to it is reduced, and another cooler region of the piping may be preferentially heated. Overall, the relatively small amount of heat transfer surface area provided by the hot leg piping (compared to a steam generator) will result in much less energy being transferred from the reactor vessel to the hot leg in this design than in plants with U-tube steam generators. The hot leg flow rate, which is determined by the density gradient between the counterflowing streams, will likewise be much smaller than that in the U-tube steam generator plants.

1.1.3 Coolant Loop Flow. Should the loop seals clear of liquid during a transient with the reactor coolant pumps off and the steam generators removing heat from the RCS, loop natural circulation would be reestablished. In contrast to the natural circulation that occurs following the reactor coolant pump coastdown early in a transient, the fluid flowing through the coolant loops would now be superheated vapor. Loop natural circulation flow is a buoyancy-driven onedimensional flow with heat addition in the core and heat rejection primarily in the steam generators. However, in this situation heat would be transferred to the piping throughout the coolant loops. Because of the resulting large vapor density differences and the height of the steam generators, this flow is generally large enough that it disrupts any multidimensional natural circulation flows that might exist in the hot leg or reactor vessel.

The high flow rate and large amount of metal structures available as heat sinks result in a much slower core heatup. The slower heatup rate could result in complete oxidation of the cladding before any of the zircaloy melts. Fuel rod relocation would be delayed for several hours. Failure of the piping anywhere in the RCS is possible, although the steam generator tubes would be particularly susceptible because they are much thinner than the hot or cold legs. Heating of all the piping will also tend to reduce the extent of fission product retention in the RCS.

Because it is fairly well characterized, loop natural circulation was not directly addressed in the investigations described later in this report.

\subsection{Importance of Natural Circulation Flows}

The significance of natural circulation flow in severe accidents is that it transfers energy from 
the core to other regions of the RCS. This energy transfer both slows the core heatup, delaying fuel damage, and increases the temperature of structures elsewhere in the RCS (upper plenum, hot leg and surge line piping, steam generator tubes, etc.) so that they may get hot enough to melt or fail.

Slowing the core heatup provides additional time for system recovery or operator actions, either of which could terminate the transient by returning the core to a covered, cooled state. The core heatup rate also affects the composition of the molten core. A slower core heatup allows more complete oxidation of the fuel rod cladding in place, so that the melt contains mostly ceramic material. A thick oxide shell builds up in the cladding, preventing relocation until ceramic melting temperatures are reached. A rapid core heatup allows cladding melt and relocation much earlier, as molten zircaloy dissolves the thinner oxide shell. The relocating material in this case contains more metallic cladding, which can still be oxidized in either the molten pool or in containment through core/concrete interaction.

If the upper plenum structures melt, their mass is added to the core debris that may eventually reach the lower head. If the RCS piping gets hot enough to fail, either through melting or creep rupture, a breach of the RCS pressure boundary results that would allow the system to blow down to the containment. This could significantly alter the containment response at the time of vessel melt-through, in that the dispersion of molten core material is minimized if there is no pressure difference between the RCS and the containment [no direct containment heating (DCH)]. Thus, while intentional depressurization of the RCS is being considered as an accident management strategy, ${ }^{5}$ natural circulation flows may result in unintentional depressurization of the RCS by causing failures of the surge line or hot leg. If the failure location is the steam generator tubes, a containment bypass path is established. Fission products released from the fuel can flow through the failed tubes to the secondary side of the steam generator, and from there through atmospheric dump valves or safety relief valves to the environment, bypassing the containment.

While all PWRs will experience similar invessel natural circulation, only those with U-tube steam generators will have vigorous hot leg natural circulation. The B\&W "candy cane" hot leg design with once-through steam generators does not allow the steam generators to participate as significant heat sinks unless the loop seals clear of liquid. The countercurrent hot leg flow would be driven only by heat transfer to the hot leg piping, which has a very small heat transfer surface area and heat capacity compared to the steam generators.

\subsection{Description of Scenarios Leading to Natural Circulation}

While there are innumerable accident sequences that lead to core damage, not all of them can or will result in natural circulation playing an important role in the accident progression. Those in which natural circulation will be significant do have several characteristics in common.

The reactor coolant pumps cannot be running, because forced flow through the RCS will preclude the existence of natural circulation flows. Along a similar vein, there should be no pumped emergency core coolant injection. While the initial injection of liquid may increase the natural circulation flow because there is now more steam being generated in the core, the temperature of the steam exiting the core will decrease as the core continues to be cooled. The decreasing temperature will result in a reduced temperature difference between the hot and cooler vapor, thereby reducing the driving potential for natural circulation flows. Heat transfer from the now hotter structures in the RCS to the cooler steam leaving the core will also tend to reduce the natural circulation flow. Additionally, the presence of pumped injection flow likely means that the accident is being terminated, so that further core damage will not occur.

There should be no large breaks in the system. For example, opening of the safety relief valves 
(SRVs) or PORVs on the pressurizer draws enough flow through the surge line that hot leg countercurrent flow is disrupted, although invessel circulation is not. Small enough breaks will still allow natural circulation flows to exist in the reactor vessel and the hot legs. For example, pump seal leaks are not large enough to preclude hot leg natural circulation flow.

As examples, two transients that would result in significant natural circulation flows are designated the TMLB' and $S_{2} D$ sequences. The TMLB' station blackout sequence has traditionally been used in severe accident natural circula- tion studies. The steam generators receive no feedwater, there is no ac power available for the duration of the accident, and the core undergoes a high-pressure boiloff with relief valves cycling. If reactor coolant pump seal leaks are considered, the RCS pressure will depend on the size of the leak. The pressure may still be controlled by the relief valves, or it may approach and fall below the accumulator pressure. The $S_{2} D$ sequence is a small break loss of coolant accident with no highpressure coolant injection. This transient will result in a core boiloff somewhere above the accumulator pressure, with the RCS pressure depending on the size of the break. 


\section{PHENOMENA IDENTIFICATION AND RANKING TABLES}

Phenomena identification and ranking tables (PIRTs) for the in-vessel and hot leg countercurrent flows were developed. The purpose of these tables is to provide an indication of the relative importance of various parameters. This information can then be used to guide sensitivity studies, direct model development, or suggest experiments to be performed. Ideally, there is feedback between these efforts over the course of an investigation, so that information gained from activities such as code sensitivity studies can be factored back into the PIRT, either confirming the previous importance ranking or altering it. Appendix A contains more details on the PIRT development process and on the tables developed for severe accident natural circulation flows. This chapter summarizes and interprets the results of the PIRT development.

PIRTs are developed using the analytical hierarchy process. Phenomena are ranked based on their perceived influence on some event or parameter, such as failure of the steam generator tubes or peak fuel cladding temperature. The rankings are done in a pair-wise manner, with each phenomenon being compared to the others, one at a time. The comparisons are based on whether one phenomenon is of greater, equal, or lesser importance than the second phenomenon in affecting the event or parameter of interest. The pair-wise rankings are then statistically processed to provide a measure of the relative importance of each of the phenomena with respect to the event or parameter of interest.

The rankings are performed without regard for probabilities, as long as they are non-zero. A particular phenomenon may have a very low probability of occurrence during a particular transient, but its ranking is based on the assumption that it does occur. It is in the interpretation and application of the results of the ranking effort that probabilities are considered. For example, a new code model might be developed for a particular phenomenon, but not for an equally important phenomenon that has a very small probability of occurrence.
While the process will provide relative rankings of phenomena, with associated numerical values, it nevertheless represents the opinions of the experts gathered to perform the rankings. The results can be influenced not only by the people performing the rankings, but also by the personalities of the people involved. A strong personality may be able to dominate the process, so that the rankings can sometimes represent one person's opinion, rather than the consensus of a group of analysts.

To make the problem more manageable, a transient is often broken up into different phases, with phenomena rankings made for each phase. This allows phenomena that may be unique to a particular time in the transient to be evaluated separately from phenomena that do not apply. It also reduces the size of the matrix being developed, and removes phenomena that do not come into play. For this effort, the accident was divided into four phases, based on peak core temperature: temperatures up to $1,500 \mathrm{~K}\left(2,200^{\circ} \mathrm{F}\right)$ (roughly from initiation through core uncovering, with some cladding oxidation); temperatures from 1,500 to $2,100 \mathrm{~K}\left(2,200\right.$ to $\left.3,300^{\circ} \mathrm{F}\right)$ (includes rapid oxidation and melting of metals); temperatures from 2,100 to $2,500 \mathrm{~K}\left(3,300\right.$ to $\left.4,000^{\circ} \mathrm{F}\right)$ (relocation of metallics); and peak core temperatures above $2,500 \mathrm{~K}\left(4,000^{\circ} \mathrm{F}\right)$ (melting and relocation of ceramic core materials).

Divisions were also made for different regions of the plant. In-vessel and hot leg natural circulation were treated separately. Failure of the reactor vessel lower head was also addressed. While it is of interest, lower head failure is not directly related to natural circulation flows in severe accidents. It was included because of the interest in determining whether the RCS pressure boundary fails first in the piping outside the reactor vessel, or in the vessel itself as molten corium attacks the lower head. This concern goes directly to the issue of direct containment heating. No further discussion of lower head failure will be presented. 
The evaluation process also addressed the PWR designs separately, where the designs deviated significantly. In-vessel and hot leg natural circulation are expected to be similar in Westinghouse and Combustion Engineering (CE)-designed plants, but different in B\&W plants because of the reactor vessel vent valves and the once-through steam generators.

The PIRTs were developed after the initial set of natural circulation calculations and sensitivity analyses had been completed, and thus had the results of that work available.

\subsection{In-Vessel Natural Circulation}

The priority rankings for in-vessel natural circulation for all vendors and all phases of the transient are summarized in Table 1 . The priority values have been grouped into those phenomena judged to be of relatively high importance and those with lower importance. Without a large body of supporting experimental and analytical evidence, it is a mistake to attach too much significance to the exact numerical values of the rankings presented in Appendix A. The basis for the ranking was the perceived influence of the phenomenon on the temperature at the reactor vessel/ hot leg interface. This parameter was selected because of the interest in high ex-vessel structure temperatures that may result in component failures and subsequent depressurization of the RCS before lower head failure.

For all plants in all transient phases, water draining from the hot leg into the reactor vessel, the reactor vessel water level, and upper plenum convective heat transfer were judged to have a relatively high importance. Core convective heat transfer was also generally of higher importance than most phenomena, but was ranked lower during the later phases of the transient, when the intact core geometry has been lost. Radiative heat transfer in the upper plenum and core, fission product behavior, and noncondensible gas effects were all judged to be of low priority in all phases of the transient, for all PWR designs.
The reactor vessel water level is important because it determines the coolability of the core, and the extent of the natural circulation in the core. The natural circulation flow will exist above the water level. When the water level is near the top of the core, there will not be significant superheating of the vapor leaving the core. As the water level decreases, the core exit temperatures increase because more of the decay heat is going into heating the vapor rather than boiling the liquid.

Water draining from the hot leg into the reactor vessel can affect the temperature at the hot leg/ vessel interface in several ways. The saturated or subcooled liquid will allow heat transfer from superheated vapor in the upper plenum near the hot leg, reducing the temperature at the interface. It may also provide additional steam in the core, which could either reduce the temperature of the vapor leaving the core (and entering the upper plenum) or could promote additional cladding oxidation and higher temperatures in a steamstarved environment. The water draining into the vessel will also increase the liquid level in the vessel, with the impacts described above, unless all of the liquid is boiled before it can be added to the liquid pool in the vessel.

There are several potential sources for water to enter the reactor vessel from the hot leg. The initial liquid inventory in the hot legs and steam generator tubes, up to the top of the U-tubes or the $\mathrm{B} \& \mathrm{~W}$ "candy cane," will drain during the initial stages of the transient, before the core is uncovered. Because of this timing, this draining will not impact the temperature at the interface, since it will be saturated vapor. The most likely source of water during the core damage portion of the transient is liquid draining from the pressurizer. Another potential source is liquid from the secondary side of the steam generators, if the RCS pressure is low enough and there have been tube ruptures. Hot leg safety injection could also provide liquid. While it is not the normal system configuration, most if not all U.S. PWRs can be aligned to provide emergency core coolant to the hot legs. 
Table 1. Priority rankings for in-vessel natural circulation phenomena.

\begin{tabular}{|c|c|c|c|c|c|c|}
\hline \multirow[b]{2}{*}{ Parameter } & \multicolumn{3}{|c|}{ Westinghouse and CE } & \multicolumn{3}{|c|}{$B \& W$} \\
\hline & Phase I & Phase II & Phases III, IV & Phase 1 & Phase II & Phases III, IV \\
\hline $\begin{array}{l}\text { Water draining } \\
\text { from the hot leg }\end{array}$ & Higher & Higher & Higher & Higher & Higher & Higher \\
\hline $\begin{array}{l}\text { Reactor vessel } \\
\text { water level }\end{array}$ & Higher & Higher & Higher & Higher & Higher & Higher \\
\hline $\begin{array}{l}\text { Upper plenum } \\
\text { convective heat } \\
\text { transfer }\end{array}$ & Higher & Higher & Higher & Higher & Higher & Higher \\
\hline $\begin{array}{l}\text { Upper plenum } \\
\text { radiative heat } \\
\text { transfer }\end{array}$ & Lower & Lower & Lower & Lower & Lower & Lower \\
\hline $\begin{array}{l}\text { Core convective } \\
\text { heat transfer }\end{array}$ & Higher & Higher & Lower & Higher & Higher & Lower \\
\hline $\begin{array}{l}\text { Core radiative } \\
\text { heat transfer }\end{array}$ & Lower & Lower & Lower & Lower & Lower & Lower \\
\hline $\begin{array}{l}\text { Core power } \\
\text { distribution }\end{array}$ & Higher & Lower & Lower & Lower & Lower & Lower \\
\hline $\begin{array}{l}\text { Loss of core } \\
\text { geometry }\end{array}$ & Lower & Lower & Higher & Lower & Lower & Higher \\
\hline $\begin{array}{l}\text { Fission product } \\
\text { behavior }\end{array}$ & Lower & Lower & Lower & Lower & Lower & Lower \\
\hline $\begin{array}{l}\text { Noncondensible } \\
\text { gas behavior }\end{array}$ & Lower & Lower & Lower & Lower & Lower & Lower \\
\hline System pressure & Lower & Lower & Lower & Lower & Lower & Lower \\
\hline
\end{tabular}

Heat transfer in the core and upper plenum is the driving force for the in-vessel natural circulation flow; heat is added to the vapor in the core and removed from it in the upper plenum, establishing the density gradient necessary for natural circulation flow. The relative values of the heat addition and removal will determine the vapor temperatures in the upper plenum.

Despite the high temperatures present in severe accidents, radiation heat transfer in the core and upper plenum were ranked low, while convective heat transfer in both those locations was ranked high. Analyses described in Section 3.1.2 suggest that inclusion of the radiation heat transfer may affect the heat transfer coefficient in the steam generator tubes by about $25 \%$. This indicates that convection is still the major heat transfer mech- anism, with radiation a smaller, but not negligible, contributor.

\subsection{Hot Leg Natural Circulation}

Table 2 presents the rankings for hot leg natural circulation flow for all of the vendor designs. Some of the phenomena are unique to one design or the other; inlet plenum mixing is only a concern in the U-tube steam generators, and only the $\mathrm{B} \& \mathrm{~W}$ design has a vertical hot leg section. The rankings were based on how the phenomena were perceived to influence creep rupture failure of the surge line, hot leg, or steam generator tubes.

The rankings were quite similar for the two vendor groupings. Both showed PORV operation, 
Table 2. Priority rankings for hot leg natural circulation phenomena.

\begin{tabular}{lll}
\hline \multicolumn{1}{c}{ Parameter } & Westinghouse/CE & B\&W \\
\hline PORV operation & Higher & Higher \\
Pressurizer draining & Higher & Higher \\
Steam generator secondary conditions & Higher & Higher \\
RCS pressure & Higher & Higher \\
Vapor-to-structure heat transfer & Higher & Higher \\
Hot leg countercurrent flow & Lower & Lower \\
Vapor-to-vapor heat transfer & Lower & Lower \\
Noncondensible gas effects & Lower & Lower \\
Fission product behavior & Lower & Lower \\
Material properties & Lower & Lower \\
Steam generator inlet plenum mixing & Lower & NR \\
Hot leg circumferential temperature & Lower & NR \\
gradient & & \\
Hot leg flow cells-vertical section & NR & Lower \\
& & \\
NR-not ranked for that design because it is not applicable. & \\
\hline
\end{tabular}

liquid draining from the pressurizer, steam generator secondary conditions, RCS pressure, and heat transfer from the vapor to the structures to be the higher priority phenomena. The remaining phenomena were of lesser importance: hot leg countercurrent flow, vapor-to-vapor heat transfer, noncondensible gas effects, fission product behavior, material properties, steam generator inlet plenum mixing and the hot leg circumferential temperature gradient in the U-tube steam generator plants, and hot leg flow cells in the vertical section of the $B \& W$ plants.

Relief valve cycling is important because it interrupts the hot leg natural circulation flow. When the relief valves are open, the flow in all of the hot legs is toward the surge line. This is also the major mechanism for heating of the surge line piping. Liquid draining from the pressurizer will provide cooling of the surge line and of part of the hot leg. Heat transfer from the vapor in the hot leg may reduce the temperatures in the hot leg, in turn affecting both the structure temperatures and the density gradient driving the natural circulation flow. It may also have an indirect effect on the vapor temperatures in the loops by adding liquid to the core, thereby providing cooler vapor in the upper plenum and at the hot leg inlet.

The steam generator secondary side conditions are particularly important if feedwater becomes available. The increased heat transfer through the tubes may be sufficient to remove the core heat, thereby terminating the transient. Increased heat transfer alone could have a significant impact on the natural circulation flow. The RCS pressure is highly ranked because it affects the stresses in the piping and steam generator tubes. The higher the pressure, the higher the stress and the faster the creep rupture of the piping will occur. If the system pressure is very low, the piping will fail by melting rather than creep rupture, which requires a much higher structure temperature [about $1,700 \mathrm{~K}\left(2,600^{\circ} \mathrm{F}\right)$ rather than $1,200 \mathrm{~K}$ $\left.\left(1,700^{\circ} \mathrm{F}\right)\right]$. The vapor-to-structure heat transfer 
addresses the other part of the structural integrity issue, the metal temperature.

While PORV operation in the Westinghouse design has been shown experimentally to influence the hot leg countercurrent flow, this has not been demonstrated for the $B \& W$ design. While the B\&W PORVs are much smaller than those in the Westinghouse plants, the hot leg natural circulation flow is also weaker, so that the natural circulation flow may be disrupted by the flow through the PORV. (While not a natural circulation concern, the more important effect of an open PORV is that it will draw hot vapor from the reactor vessel through the hot leg and surge line, heating the piping in the flow path.) Additionally, in station blackout analyses for the Bellefonte plant, ${ }^{6}$ the PORV remained open while the pressure was controlled by the cycling SRVs; the SRVs are easily large enough to disrupt the hot leg natural circulation. Some CE plants do not have PORVs, only SRVs on the pressurizer. The PORV operation phenomenon should be interpreted as applying to SRV operation as well.

One might expect the mixing in the steam generator inlet plenum to be very highly ranked, since this is the controlling parameter for hot leg countercurrent flow. While it is true that the amount of energy deposited in the steam generators, and hence steam generator tube failure, depends on the mixing, failure of the surge line and hot leg do not. The sensitivity calculations for the Surry plant described in Chapter 4 showed that whether the mixing was complete or zero, the surge line still failed near the time that initial fuel rod relocation occurred. Even with no mixing modeled, steam generator tube failure was not predicted to occur until after surge line and hot leg failure. Since the relative timing of the first RCS pressure boundary failure and initial fuel rod relocation was insensitive to the inlet plenum mixing, the low ranking of the mixing for how it affects any ex-vessel failure seems justified.

\subsection{Interpretation of Results}

One of the features of the PIRTs is that the more important phenomena are identified from a larger list of contributing phenomena. The credibility of an analysis depends on the ability to adequately represent the governing phenomena.

The commercial plant analyses performed at the INEL have used the SCDAP/RELAP5 computer code. ${ }^{7}$ The capabilities of that code to model the in-vessel and hot leg natural circulation flow phenomena will be addressed in the following discussion.

For in-vessel natural circulation, the highly ranked phenomena were liquid draining from the hot leg, convective heat transfer in the core and upper plenum, and the reactor vessel water level. All of these are essentially one-dimensional phenomena that the code should be able to adequately represent. Liquid draining is a transient-specific phenomenon that will usually depend on the modeling of the surge line/ pressurizer interface. The code has models for countercurrent flow limitation that could be applied at that location, as vapor drawn into the pressurizer from the surge line by open relief valves may be flowing at a sufficiently high rate to prevent liquid from draining back into the surge line.

Several items that would be difficult for the code to model were judged to be of low priority. Radiation heat transfer in the upper plenum from the vapor to the structures is beyond the current scope of the code. How the core geometry changes as the relocation progresses is highly uncertain, and that uncertainty is inherent in code calculations. Fission product behavior models are in the code, but have not been extensively tested or used. Again, however, this is a lower-ranked phenomenon that should not have a significant impact on the transient calculation.

For the hot leg natural circulation, the highly ranked phenomena were PORV operation, pressurizer draining, steam generator secondary conditions, RCS pressure, and heat transfer from the vapor to the structures. PORV operation depends only on the RCS pressure and the critical flow through the valves, both of which are calculable by the SCDAP/RELAP5 code. Pressurizer draining was discussed above. The steam 
generator secondary side conditions are transient dependent, but are determined by flow rates and heat transfer coefficients that are within the capability of the code. Heat transfer from the vapor to the structures will include both convective and radiative heat transfer; the former is within the realm of the code, while the latter is not.

Many of the lower-ranked hot leg natural circulation phenomena cannot be modeled because of the one-dimensional nature of the code. A specific nodalization is used to simulate the threedimensional nature of the inlet plenum mixing. The hot leg is generally split into two pieces, one allowing vapor to flow from the vessel to the steam generators, and the other carrying the return flow, since a one-dimensional code cannot model single-phase countercurrent flow within a control volume. This physical separation of the flows also does not allow simple modeling of the vapor-to-vapor heat transfer between the counterflowing streams. Similarly, the one-dimensional heat conduction model in the code will not allow modeling of the hot leg circumferential temperature gradient.

In general, the SCDAP/RELAP5 code contains models that describe the natural circulation phenomena judged to be the most important. While this suggests that the code can be applied to severe accident natural circulation simulations, it does not establish whether it can adequately represent the expected phenomena. Code assessment against applicable experiments and sensitivity studies are needed to establish the credibility of the code for this application. Chapter 3 describes assessment of the RELAP5/MOD3 code against Westinghouse natural circulation data, and Chapter 4 presents the results of several sensitivity studies. 


\section{EXPERIMENTS AND SEPARATE EFFECTS ANALYSES}

Experiments were performed to investigate the nature of severe accident natural circulation flows in PWRs with U-tube steam generators. These experiments, and analyses of them, are briefly described in the following section.

Given the potential significance of natural circulation flows in severe accidents, it is of interest to know how natural circulation flows might be disrupted. Several separate effects analyses were performed that investigated the likelihood of noncondensible gases being able to prevent or diminish natural circulation during a severe accident.

An analysis was also performed to try to reconcile the upper plenum temperature data from the TMI-2 accident with the belief that in-vessel natural circulation should have been present. Additional discussion of natural circulation during the TMI-2 accident is also presented in the final section.

\subsection{Westinghouse U-Tube Steam Generator Experiments}

Experiments were conducted by Westinghouse in an electrically heated, 1/7-scale model of a reactor vessel and two hot legs with U-tube steam generators. Reviews of the experiment scaling were conducted. Two of the steady-state experiments were used to assess the capability of the RELAP5 code to model severe accident natural circulation flows.

\subsubsection{Experiment Description and} Results. Several series of experiments were conducted by Westinghouse to investigate natural circulation flows in the reactor vessel and hot legs during a severe accident. 4,a These experiments used water, low-pressure $\mathrm{SF}_{6}$, and high-pressure

a. W. A. Stewart, A. T. Pieczynski, and V. Srinivas, Natural Circulation Experiments for PWR HighPressure Accidents, EPRI Project No. RP2177-5 Final Report (draft), 1992.
$\mathrm{SF}_{6}$ as the working fluids. The objective of the Westinghouse experiments was to experimentally determine flow patterns, flow rates, and temperatures of natural circulation flows in PWRs during severe accidents such as station blackout and small-break loss of coolant accident (TMLB' and $\left.S_{2} D\right)$ events.

Although much effort was expended to make the model as representative of the full-scale plant as possible, compromises had to be made. The full lower plenum geometry was not modeled, nor was that of the reactor vessel upper head. Cooling flow was used to simulate thermal capacity in the upper head, upper plenum, and steam generators. Reynolds and Grashof numbers in the lowpressure tests were several orders of magnitude below those expected in the plant. These dimensionless flow parameters were better reproduced in the high-pressure tests, as is discussed in the experiment scaling review section.

The low-pressure tests showed, by using dye in the fluid, that a stable countercurrent flow was present in the hot legs, with very little turbulence at the interface between the two flow streams. They also showed that the natural circulation flow in the hot legs is robust. When the PORVs were opened, the flow was interrupted. But when the valves were closed, the flow was quickly reestablished.

While the low-pressure experiments displayed the basic nature of the natural circulation phenomena, the high-pressure experiments provided scaling that was closer to the behavior expected in a commercial plant. While some transient tests were conducted, most of the high-pressure experiments were conducted with steady cooling of the reactor vessel upper internals and steam generators. These steady-state tests allowed a more thorough investigation of the natural circulation flows than did the transient tests. In all, five series of experiments with high-pressure $\mathrm{SF}_{6}$ were conducted; these are described below.

The first series of experiments included 14 steady-state tests with $\mathrm{SF}_{6}$ vapor between 
1.379 and 3.179 $\mathrm{MPa}$ (200 and $461 \mathrm{psia}$ ) and the core heating between 10.3 and $30 \mathrm{~kW}$. Besides varying the system pressure and core power, these tests included cases with and without cooling by the steam generators, and three of the tests simulated fission product heating in the left hot leg. All fourteen tests had upper plenum cooling. Vapor temperatures were recorded in the reactor vessel, the hot legs, and at the steam generator tube sheet.

The second series consisted of eight transient tests with peak pressures of 2.068 to $2.758 \mathrm{MPa}$ (300 to 400 psia) and core heating ranging from 22 to $30 \mathrm{~kW}$. No upper plenum or steam generator cooling was included in these tests. Periodic and continuous venting methods were used to maintain system pressure. The recorded data for these tests included selected structure temperatures as a function of time. Vapor temperatures were recorded only at the termination of the test.

The third series of experiments included eight tests which focused on the temperatures and flow conditions in the steam generator inlet plenums and hot legs. The steam generator inlet plenum instrumentation included a rake of thermocouples that measured the vapor temperatures in the plenum. Vapor temperatures in the reactor vessel were not recorded in these tests. Four of these tests were steady-state and four transient. For these tests, the system pressure was varied from 2.068 to $2.758 \mathrm{MPa}$ (300 to $400 \mathrm{psia}$ ) and the core heating varied from 22 to $30 \mathrm{~kW}$. These tests were otherwise identical to the steady-state and transient tests of the first two series.

The fourth series of tests examined the short time transient response of fluid temperatures to safety valve venting cycles. All of these tests began at a pressure of $2.068 \mathrm{MPa}$ (300 psia) and $22 \mathrm{~kW}$ of core heating.

Finally, two tests were performed to study the transient effects of initially stable stratified hydrogen in the vessel upper plenum and upper head regions. Helium was used to simulate hydrogen.
Temperature measurements in the steam generator inlet plenum and tube inlets indicated that the fluid in the inlet plenum was fairly well mixed. In none of the experiments was there any indication that hotter fluid from the hot leg flowed directly into any of the steam generator tubes. In the highpressure $\mathrm{SF}_{6}$ Test $\mathrm{S} 9$, for example, the vapor exiting the hot leg was near $412 \mathrm{~K}\left(282^{\circ} \mathrm{F}\right)$, while the hottest vapor measured in the steam generator tubes was $361 \mathrm{~K}\left(190^{\circ} \mathrm{F}\right)$; the vapor returning to the reactor vessel along the bottom of the hot leg was near $340 \mathrm{~K}\left(152^{\circ} \mathrm{F}\right)$. This experiment had the highest hot leg temperature of any of the steadystate tests. Temperatures were measured in 51 out of 216 tubes, with the lower-most instruments located $0.025 \mathrm{~m}$ (1 in.) from the inlet plenum.

The major deficiency of the experiments was the low temperature of the fluid. In a severe accident, temperatures in excess of $1,000 \mathrm{~K}$ $\left(1,340^{\circ} \mathrm{F}\right)$ are expected, and radiation heat transfer may play an important role. Such high temperatures cannot be achieved in this experiment facility without destroying it. Of particular concern is how the hot leg countercurrent flow will be affected. Heat transfer between the counterflowing streams will tend to reduce the temperature and density differences between them, reducing the flow rate and hence the amount of heat that is being removed from the reactor vessel and deposited in the hot legs and steam generators.

\subsubsection{Experiment Scaling}

One of the major concerns with any experimental facility is the scaling rationale employed, and how well that scaling preserves the phenomena of interest. Westinghouse performed a scaling study for their experiments. As part of the INEL effort, a review of the experiment scaling was conducted.

An initial scaling review was performed by Tung, and his findings are included as Appen$\operatorname{dix} \mathrm{B}$. He looked at the scaling in several different areas of the reactor vessel, hot leg, and steam generator. The results of his study are summarized below. 
Thermal conditions in the hot leg countercurrent flow are not well simulated in either the water tests or the low-pressure $\mathrm{SF}_{6}$ tests. Higher heat transfer will occur between the two fluid streams in the full-scale plant because of the presence of radiative heat transfer. This tends to reduce the average temperature and density differences between the two streams, and hence the driving force for the countercurrent flow in the hot leg. Consequently, extrapolation of the model data to conditions in the full-scale plant may result in overprediction of the mass flow rate through the hot leg. At the higher Reynolds numbers typical of the high-pressure $\mathrm{SF}_{6}$ tests (about $10^{5}$ ), however, heat transfer from convection overwhelms radiation and the tests appear to be properly scaled even when the effects of radiative heat transfer are included.

Conversion from buoyant (potential) energy to kinetic energy in the model steam generator is a factor of 36 higher than that in the full-scale steam generator because of geometrical differences and the absence of radiative heat transfer in the model. Nonetheless, if the scaled steam generator is considered to be a boundary condition for the hot leg, the overall scaling is fairly good.

Friction factors in the model core are a factor of 2 to 3 lower than those in the full-scale core for both vertical and horizontal directions. As a consequence, the natural circulation flow rate through the actual core will be lower than that predicted from the behavior of the model. The dominant flow resistance to natural circulation occurs in the vertical core segments. Consequently, distortion of the radial flow resistance will have a lesser effect on the model performance.

The combined radiation/convection term in the fluid energy equation is about 2 orders of magnitude higher in the core region of the full-scale plant than in the model because of the effects of radiative heat transfer. Therefore, the heating rate of the fluid in the actual core may be faster than the rate indicated by the Westinghouse data.
The ratio of the heated perimeter to the nonheated perimeter is a factor of 14 higher in the full-scale plant than in the model. As a result of this difference and the distortion in the radiation/ convection coefficient, the scaled temperature in the heated region of the actual core may be lower than that of the model for the same heat source.

The boundary conditions for the high-pressure $\mathrm{SF}_{6}$ tests are similar to those in the water and lowpressure $\mathrm{SF}_{6}$ tests. The thermal inertia of the upper plenum internals is about 2 orders of magnitude higher in the model than in the plant, while that of the upper plenum core barrel is about 1 order of magnitude high in the model. This will cause these components to heat up more slowly compared to other components in a transient test. The difference in the thermal inertia of the upper plenum core barrel, however, is not critical because of the relatively small magnitude of its heat sink compared to the total heat dissipation. Thermal inertia of the full-scale steam generator is well represented by that of the model steam generators.

The overall conclusion of the scaling review was that the high-pressure $\mathrm{SF}_{6}$ experiments would be adequate for code assessment, with the exception of the effects of radiative heat transfer in the core.

An independent review of Tung's scaling analysis was performed by three consultants, P. Griffith (Massachusetts Institute of Technology), S. Ostrach (Case Western Reserve University), and R. Viskanta (Purdue University). Their primary concern with Tung's work related to the treatment of radiation heat transfer. A more rigorous treatment of the radiation heat transfer effects was applied by O'Brien, who also reevaluated Tung's report. O'Brien's findings are contained in Appendix C. This review of the earlier work generally confirmed the previous findings about the adequacy of the experiment scaling. The one exception was in the steam generator, where it was concluded that the boundary condition supplied by the steam generator to the hot leg was less adequate than had been previously believed.

As part of this second review, calculations were made with the FIDAP computer $\operatorname{code}^{8}$ to 
determine the impact of radiation on the overall heat transfer. An analysis of the radiation heat transfer in the steam generator tubes was performed. Steam was modeled as entering the tubes at a temperature of $1,000 \mathrm{~K}\left(1,340^{\circ} \mathrm{F}\right)$. Heat transfer to the tubes was calculated, and an effective heat transfer coefficient determined. Calculations were performed with and without radiation modeled. With radiation included, the effective heat transfer coefficient was about $25 \%$ higher than without. Based on this, it is concluded that while convection remains the major heat transfer mechanism, radiation is not negligible.

\subsubsection{RELAP5/MOD3 Experiment Calcula-}

tions. Calculations of two of the steady-state, high-pressure $\mathrm{SF}_{6}$ experiments were performed with the RELAP5/MOD3 code. ${ }^{9}$ The purpose of these calculations was to assess the capability to model the experiments and the natural circulation flows that were present. If the experiments can be modeled adequately, confidence is provided in the modeling approach used to describe the plant and experiment facility. Confidence is also provided in the full plant simulation of phenomena that occurred in the experiments. (The experiments did not reproduce all of the phenomena or conditions expected during a PWR severe accident, such as high vapor and structure temperatures and items related to core damage progression.) A detailed description of the analysis and results is contained in Appendix D.

To model the experiments, it was necessary to add $\mathrm{SF}_{6}$ fluid properties to the code. A model of the experiment facility was then developed, using the same nodalization approach that is used in commercial plant input models. Finally, calculations of steady-state Tests S6 and S7 were performed. These tests both had a core power of $20.5 \mathrm{~kW}$, with system pressures of $1.65 \mathrm{MPa}$ (240 psia) and 2.17 $\mathrm{MPa}$ (315 psia) for Tests S6 and S7, respectively. Cooling water was provided to the upper internals and the steam generators, and the tests were terminated after steady-state conditions were established. These particular experiments were selected because they provided the data necessary to benchmark the code calculations, and had smaller discrepancies in the measured energy balances than the other steadystate experiments.

The calculated vapor flow rates and temperatures in the hot legs and steam generators were in generally good agreement with the experiment data, although the temperatures were overpredicted by 4 to $14 \%$. Similarly, the vapor temperatures in the core and upper plenum were comparable to those in the experiments. The heating of the vapor as it flowed from the upper plenum down the periphery of the core was overpredicted, while the temperature of the vapor flowing up the center of the core was underpredicted. Overall, it appeared that the code did a reasonable job of predicting the flow patterns and thermal response of the experiments, providing some confidence in the application of the code to natural circulation during severe accidents in fullscale plants.

It should be remembered that these applications are attempting to model three-dimensional behavior with a one-dimensional code, so that the phenomena will not be explicitly reproduced. Uncertainties in the modeling and phenomena should be addressed in performing plant analyses. It is also important that the experiments, and the calculations of them, did not get into hightemperature or core damage regimes.

\subsection{Natural Circulation Flow Disruption}

A consideration in examining natural circulation flow phenomena is what could cause the flows to stop, or not be set up in the first place. Since natural circulation flows are driven by a heat source in one location and at least one heat sink in another, one mechanism for disrupting the flow would be for the heat sinks to become ineffective. Two such mechanisms involve stratification of noncondensible gases, in either the reactor vessel upper plenum or the steam generator tubes. These mechanisms, and analyses of them, are discussed in the following sections.

3.2.1 Upper Plenum Hydrogen Stratification and Mixing. It has been postulated that 
hydrogen stratification in the upper plenum may result in insulating the structures from the hot vapor exiting the core. If this occurs, the reduced heat transfer in the upper plenum would result in a decreased natural circulation flow rate, leading to a faster core heatup and earlier fuel melting. It would also change the relative timing of core relocation and ex-vessel component failures, if the latter still existed.

An analysis of mixing times for an initially stratified upper plenum was performed. Details of the analysis are presented in Appendix E. The analysis showed that the mixing times are very short, so that stratification of hydrogen in the upper plenum would not occur. The presence of hydrogen in the vapor mixture actually enhanced heat transfer to the structures, so that a more vigorous natural circulation flow would be maintained.

This conclusion is consistent with the results of several Westinghouse experiments in which helium was used as a hydrogen simulant. Those experiments showed that even with an initially stratified layer in the upper plenum, the helium and $\mathrm{SF}_{6}$ became well mixed, and the in-vessel natural circulation extended to the top of the upper plenum. (The ratio of molecular weights for $\mathrm{SF}_{6}$ to $\mathrm{He}$ is 36 , while that for steam to hydrogen is 9. This indicates that it should be easier for mixing to occur with steam and hydrogen than for $\mathrm{SF}_{6}$ and helium.)

\subsubsection{Hydrogen Blocking of the Steam Generator Tubes. Similarly to the upper ple-} num, it may be possible for hydrogen to collect in the upper portion of the steam generator U-tubes. This may be able to prevent flow through the tubes, which would in turn remove the steam generators as heat sinks in the transient. With no heat transfer in the steam generators, there would be no hot leg countercurrent flow. This again would increase the core heatup rate, and may reduce the likelihood of ex-vessel failures.

The process involved in the steam generators usually involves condensing the steam from the steam/hydrogen mixture, leaving only the lighter hydrogen, which then collects in the tops of the U-tubes. Unable to displace the hydrogen, steam flow through the steam generators then stops, removing the generators as heat sinks for the RCS. However, to condense the steam, cooling water is required on the secondary side of the steam generators. In many severe accidents, all feedwater flow to the steam generators is lost. If some feedwater capability is restored, then condensation could occur.

An analysis was performed to assess the RELAP5/MOD3 code's capability to model the condensing of steam from a multicomponent mixture, thereby concentrating hydrogen in the tops of the U-tubes. The details of this analysis are presented in Appendix F.

A RELAP5 model of a steam generator was used in the study. A steam/hydrogen mixture with $1 \%$ hydrogen was introduced to the steam generator tubes. Cooling water on the secondary side caused steam to condense. As steam was condensed, additional vapor (1\% hydrogen, $99 \%$ steam) was made available to the steam generator inlet and outlet plena. A concentration gradient was established in the tubes, with higher hydrogen concentrations at the tops of the U-tubes. The hydrogen concentration in each of the volumes gradually increased, until it was nearly pure hydrogen. The study concluded that the RELAP5/MOD3 code is capable of calculating this behavior, although there is some sensitivity to the level of detail in the nodalization of the steam generator tubes; increasing the number of calculational cells by a factor of four yielded a more well-behaved calculation, although the basic response was unchanged.

Although the RELAP5 code may be able to calculate the concentrating of hydrogen in the U-tubes, that does not mean that natural circulation flow will be terminated by a hydrogen bubble. Blockage of the tubes by a lighter gas was addressed indirectly in the Westinghouse experiments. A large amount of helium was injected into the system in the core. This helium flowed to the hot legs and steam generators, where it temporarily interrupted the natural circulation flow. However, as the experiment continued, the flow 
patterns in the hot legs were reestablished, and countercurrent flow between the reactor vessel and the steam generators resumed. As was pointed out in the previous section, the ratio of molecular weights for $\mathrm{SF}_{6}$ and $\mathrm{He}$ is four times larger than that for steam and hydrogen, so that resumption of the natural circulation flow pattern in the experiment indicates that it should also occur in the plant.

\subsection{Natural Circulation in the TMI-2 Accident}

The only commercial PWR severe accident data are from the accident that occurred in March 1979 at TMI-2. Postulated severe accident phenomena must be justified in light of the data collected during and after the accident, although those data are somewhat limited.

One of the major areas of contention has been how much natural circulation flow occurred during the event. Theoretical discussions of the robustness and significance of the in-vessel natural circulation flows that will occur in a PWR during a severe accident did not appear to be borne out by the TMI- 2 data. While some of the upper end boxes were melted and showed extensive damage, others did not. Of particular concern was reconciling the temperatures inferred from the metallurgical examination of the control rod drive lead screws. These structures, located in the upper plenum, indicated that the peak temperatures in the upper plenum were well below those that would be predicted if in-vessel natural circulation were occurring. If the lead screws accurately reflected the upper plenum vapor temperatures, then the models of natural circulation are not providing adequate representations of the phenomena. However, if the lead screws did not represent the upper plenum vapor temperatures, then perhaps an analysis would indicate how these data might be used to validate the natural circulation flow models being used.

Temperatures inferred from postaccident examination of two lead screws were used in the analysis described below. Peak temperatures were given for three axial locations on each lead screw. The lead screw at core position B8 had a peak temperature at the bottom of $1,033 \mathrm{~K}$ $\left(1,400^{\circ} \mathrm{F}\right)$, at $0.99 \mathrm{~m}(3.2 \mathrm{ft})$ above the bottom of $911 \mathrm{~K}\left(1,180^{\circ} \mathrm{F}\right)$, and at $3.0 \mathrm{~m}(9.8 \mathrm{ft})$ above the bottom of $723 \mathrm{~K}\left(842^{\circ} \mathrm{F}\right)$. The lead screw at position $\mathrm{H} 8$ had a peak temperature at the bottom of $1,255 \mathrm{~K}\left(1,799^{\circ} \mathrm{F}\right)$, at $2.3 \mathrm{~m}(7.5 \mathrm{ft})$ above the bottom of $710 \mathrm{~K}\left(818^{\circ} \mathrm{F}\right)$, and at $3.0 \mathrm{~m}(9.8 \mathrm{ft})$ above the bottom of $666 \mathrm{~K}\left(739^{\circ} \mathrm{F}\right)$.

An analysis was performed to investigate how well the lead screw temperatures would reflect the vapor temperatures in the upper plenum, and whether these data supported or refuted the existence of in-vessel natural circulation during the TMI-2 accident. This analysis is described in more detail in Appendix G. The investigation, which considered conduction and radiation heat transfer, as well as natural circulation flow within the guide tubes, found that the maximum vapor temperature in the upper plenum can be on the order of $1,300-1,500 \mathrm{~K}\left(1,900-2,200^{\circ} \mathrm{F}\right)$, even though the observed lead screw temperatures near the top of the upper plenum were only 666-723 $\mathrm{K}\left(739-842^{\circ} \mathrm{F}\right)$. This conclusion means that a strong natural circulation flow likely existed in TMI-2, as the current models and experiments would suggest.

Axial conduction along the lead screw was found to be unimportant in determining the lead screw temperatures for locations near the top of the upper plenum. A bounding analysis estimated the time required for conduction alone to heat the lead screws from the saturation temperature of $560 \mathrm{~K}\left(548^{\circ} \mathrm{F}\right)$ to the deduced temperatures given above, assuming the bottom of the lead screw was its maximum temperature. This calculation indicated it would take from 75 to 219 hours to heat the higher regions of the lead screws to their maximum temperatures. Since this is much longer than the time scale of the accident, axial conduction does not play an important role in determining the temperatures of the lead screws.

A similar bounding analysis was performed for radiation heat transfer from the guide tubes. The guide tubes were assumed to be at the temperature of the bottom of the lead screws. The 
times required to heat the lead screws ranged from 0.5 to $4.9 \mathrm{~min}$, indicating that radiation exchange between the guide tube and the lead screw may be important.

A gravity-driven recirculating flow can be established in the enclosure between the guide tube and the lead screw, with the buoyancy term arising from the temperature difference between these two structures. Calculations of the upper plenum vapor temperature based on the lead screw temperatures and this flow pattern indicate that the vapor temperatures could be nearly $800 \mathrm{~K}\left(1,450^{\circ} \mathrm{F}\right)$ higher than the lead screw temperatures.

The PORV was closed during the core damage phase of the TMI-2 accident. With the PORV closed, no flow would be expected to enter the surge line and pressurizer from the hot leg. Additionally, the configuration of the surge line, with a loop seal to trap liquid, would tend to keep the surge line cooled. The design of the hot legs, with the steam generators located downstream and below the top of the "candy canes," is not conducive for establishing hot leg countercurrent flow, as was discussed in Chapter 1. A weak natural circulation flow may have existed, driven by heat transfer to the hot leg pipe in both the horizontal and vertical sections. This flow would provide some heating of the hot leg, but would not remove much energy from the reactor vessel.

A strong in-vessel natural circulation flow likely existed during the core damage portion of the TMI- 2 accident. The low temperatures experienced by the control rod drive lead screws in the upper plenum are consistent with a vigorous natural circulation flow, as the guide tubes provided significant thermal shielding from the high vapor temperatures in the upper plenum. A weak natural circulation flow may have existed in the hot legs. Such a flow would remove little energy from the reactor vessel, and would not have a noticeable effect on the transient. 


\section{COMMERCIAL PLANT ANALYSES}

A number of commercial plant severe accident analyses have been performed that modeled invessel and hot leg natural circulation flow. Many of these analyses were specifically directed at investigating natural circulation flow phenomena to gain insight into the effects of natural circulation on severe accident damage progression and event timings. Sensitivity analyses were also performed that addressed parameters related to natural circulation flows. Other plant analyses investigated different issues, but included the natural circulation flows.

The commercial plant calculations were for idealized station blackout transients. No operator actions were considered. Systems and components, such as the relief valves, were assumed to continue operating as designed indefinitely; this will not likely be the case.

The plant analyses are described in the following sections. Also included are the results of attempts to group plants according to their likelihood for ex-vessel failures.

\subsection{Surry Calculations}

Investigative and sensitivity analyses concerning severe accident natural circulation flows have used the Surry plant in calculations with the SCDAP/RELAP5 computer code. Surry is a three-loop, Westinghouse designed PWR with a rated power of $2,441 \mathrm{MW}$. The discussions that follow will briefly describe the specific modeling of the natural circulation flows and results of plant analyses.

\subsubsection{Modeling Natural Circulation Flows.} One of the challenges in analyzing commercial plant response to severe accidents is modeling multidimensional natural circulation flows with a one-dimensional computer code. In the reactor vessel, the crossflow junctions provide an approximation of the multidimensional flow. In the hot leg, the situation is countercurrent, singlephase flow. To model this behavior, the hot legs were divided into top and bottom halves. The top half provided the flow path for hot vapor to move from the reactor vessel to the steam generators, while the cooler vapor flowed from the steam generators back to the reactor vessel through the bottom half of the hot leg pipe. Figure 3 shows a representative nodalization of the hot leg and steam generators for modeling hot leg countercurrent flow (control volume numbers are shown). This nodalization is typical of that used in all of the commercial plant analyses.

Because the hot leg flows are artificially separated, some of the interactions between the hot and cool vapor are not modeled. These interactions include mixing and heat transfer between the two flow streams. Dividing the pipe into halves also separates the pipe heat structures, so that large temperature gradients can occur between the top and bottom of the pipe, with no heat transfer between them. One would expect conduction and radiation to tend to equalize the temperatures of the top and bottom halves of the piping.

The steam generator tubes were also separated into two groups. One group was established to allow the hot vapor to flow from the inlet plenum toward the outlet plenum, while the remainder provided the path for flow from the outlet plenum to return to the inlet plenum. The division of the tubes into the two groups was based on results of the low-pressure Westinghouse experiments, which showed that approximately $35 \%$ of the tubes had flow from the inlet plenum toward the outlet plenum.

The steam generator inlet plenum modeling was also changed from a single control volume to simulate the mixing that occurs. Most of the plenum volume was contained in a mixing volume that allowed the hot vapor from the hot legs and the cool vapor from the steam generator tubes to mix. While the mixing volume provided most of the flow to the hot steam generator tubes and to the bottom of the hot leg, there were also smaller volumes used to allow hot vapor from the top of the hot leg to pass directly to the hot flowing 


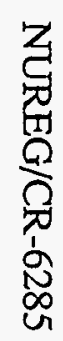

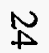

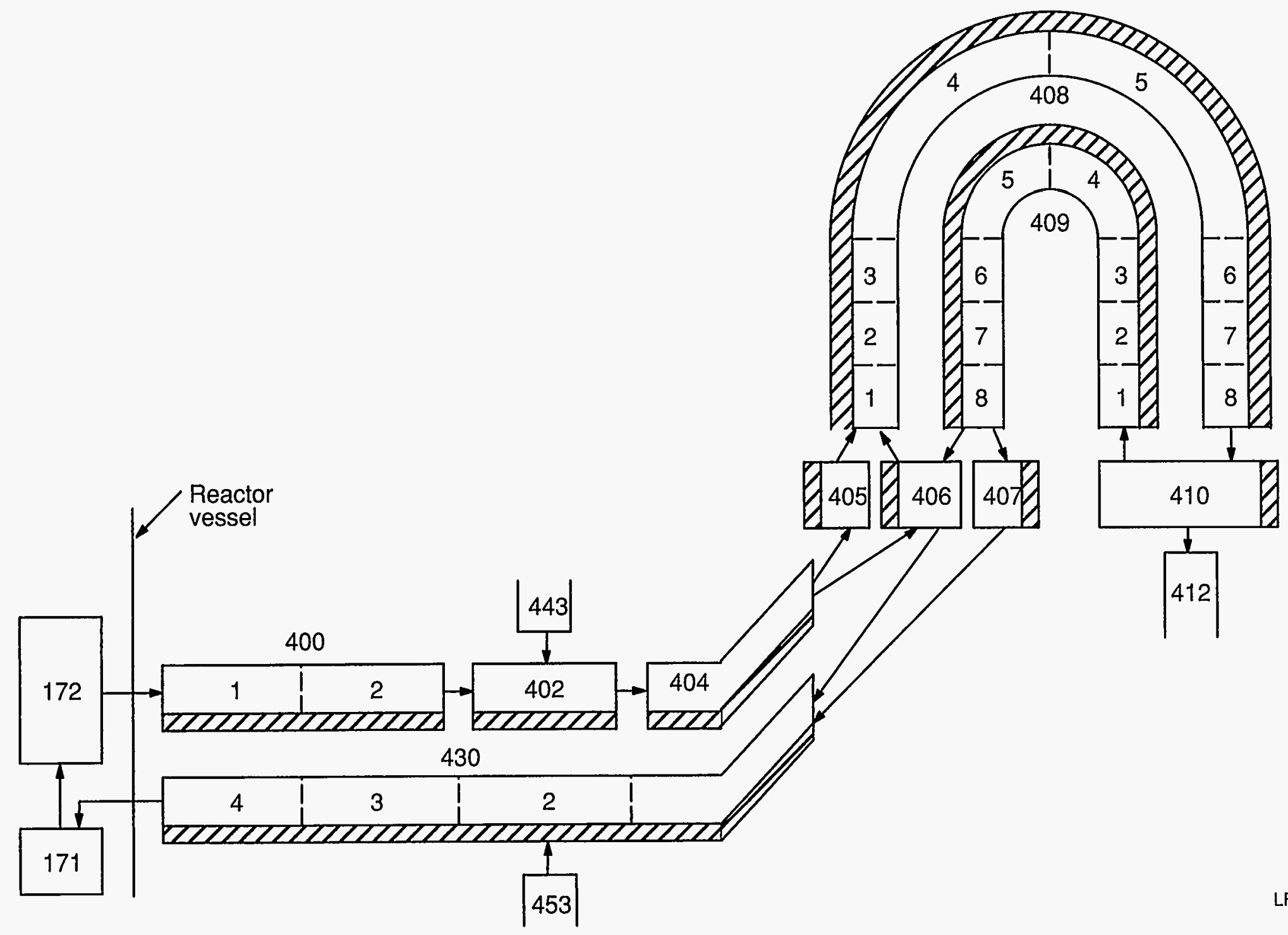

Figure 3. Typical nodalization of the hot leg and steam generator for SCDAP/RELAP5 calculations with hot leg natural circulation. 
steam generator tubes, and to allow cool vapor returning to the inlet plenum from the steam generator tubes to flow directly to the bottom of the hot leg.

To establish the flow characteristics of the SCDAP/RELAP5 model, a transient heatup calculation was performed with both the COMMIX ${ }^{10}$ and SCDAP/RELAP5 computer codes. The COMMIX calculation provided information on the heat transfer, flow rates, and temperatures in the coolant loop and steam generator. The piping loss coefficients and flow areas associated with the steam generator inlet plenum mixing volumes were adjusted in the SCDAP/ RELAP5 model so that the total heat transfer in the loop was the same for a given hot leg inlet temperature as calculated by COMMIX. This step was necessary because the SCDAP/RELAP5 model was developed before the Westinghouse high-pressure $\mathrm{SF}_{6}$ experiment data were available. Previous analyses of the low-pressure experiments with the COMMIX code had shown good agreement with the measured data. ${ }^{11}$

Figure 4 shows a typical nodalization for the reactor vessel for modeling in-vessel natural circulation. The core is divided into three parallel channels. Crossflow junctions at each axial elevation allow the channels to communicate with each other. The radial division of the core is based on the relative powers of the fuel assemblies in each region, with like-powered assemblies being grouped together. The radial division from the core is carried into the upper plenum, again with crossflow junctions interconnecting the three flow channels. In this particular illustration, the top-most axial nodes are not cross-connected, because the deep beam weldments were judged to provide a large enough obstruction that crossflow between the channels would not occur or would be very small.

Another consideration is that the nodalization must prevent unphysical behavior. For example, when the PORVs open, the flow from the reactor vessel will move from the hot leg to the surge line, along both the top and the bottom of the hot leg. If the surge line is attached to the top of the pipe, the inclination would be to model it as connected only to the top half of the pipe. However, this will result in an unphysical flow through the bottom of the hot leg when the PORVs open. Flow will move from the reactor vessel through the bottom half of the hot leg to the steam generator inlet plenum, then back to the surge line through the top half of the hot leg. This is clearly not realistic. To prevent this behavior, the bottom of the hot leg must also be connected to the surge line, even though this does not quite represent the physical connections in the plant.

4.1.2 Analysis Results. Past efforts in the natural circulation area are described in Reference 3. Those analyses looked at the effect on the Surry plant response to a station blackout transient by incrementally adding in-vessel and hot leg countercurrent natural circulation flows to the input model. With no natural circulation modeled, the core retained nearly all of the heat being generated, with virtually no heatup above saturation temperatures outside the reactor vessel. Adding in-vessel natural circulation allowed much hotter steam to exit the vessel, such that the surge line and hot leg piping between the vessel and the surge line heated up significantly. High enough temperatures were reached that creep rupture failure of the surge line and hot leg could occur. Including the hot leg natural circulation as well further slowed the core heatup, as heat was deposited in the steam generators. Again, temperatures were high enough that creep rupture failure of the surge line was predicted to occur at about the same time that the initial fuel rod relocation took place.

This timing is significant in that it allows several hours for the RCS to depressurize through a piping failure before molten core attack on the lower head would result in vessel failure. That is sufficient time for the RCS to depressurize to near the containment pressure, thus avoiding highpressure melt ejection and $\mathrm{DCH}$.

One of the concerns is how sensitive the results are to the modeling. There are uncertainties inherent in the modeling approach, since a onedimensional code cannot directly model multidimensional effects, especially the single-phase 
Commercial Plant Analyses

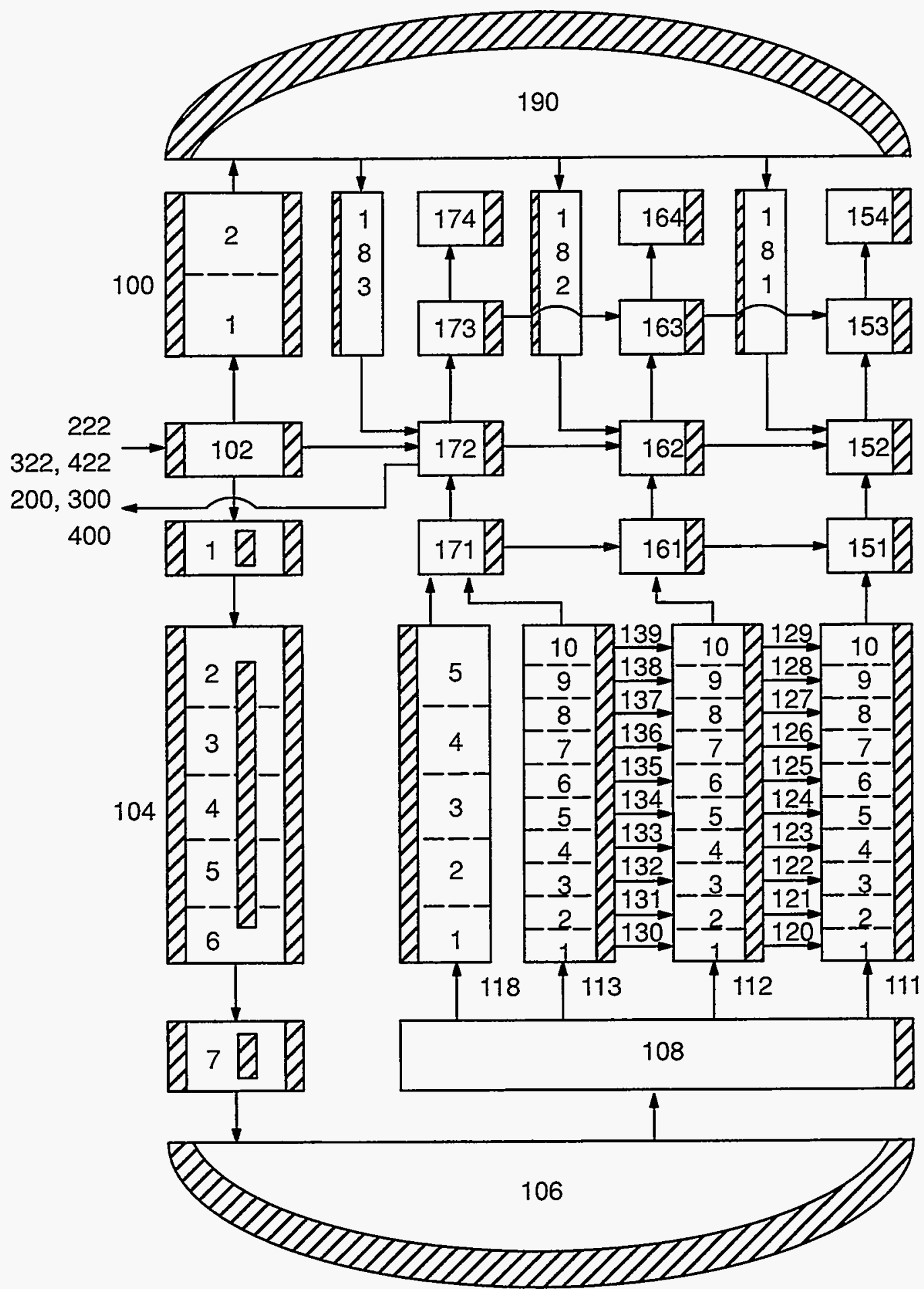

LF94 0127

Figure 4. Nodalization of the reactor vessel for the Surry SCDAP/RELAP5 calculations with in-vessel natural circulation. 
countercurrent flow in the hot legs. To address these uncertainties, sensitivity calculations were performed that addressed the major areas that control the in-vessel and hot leg natural circulation flows. Areas investigated were the axial power profile in the core, loss coefficients in the core and upper plenum, mixing in the steam generator inlet plenum, and heat loss through the hot leg and surge line piping. In all cases, predicted failure of the surge line occurred near the same time that the initial relocation of fuel within the core occurred. Only the steam generator inlet plenum mixing sensitivity calculation had a significant effect on the absolute timing of the core damage; with no mixing in the plenum, the RCS piping failure and initial core damage were delayed about 1 hour compared to the base case.

Additional sensitivity calculations have been performed recently to address other uncertainties and parameters of concern; a more detailed description of these analyses is contained in Appendix $\mathrm{H}$. Five calculations were performed to investigate the impact of uncertainties in the heat transfer coefficients on the plant response. Heat transfer coefficients in the upper plenum and steam generators were separately increased and decreased by $20 \%$, and heat transfer coefficients in the hot leg were decreased by $20 \%$. These calculations showed that the changes in the heat transfer coefficients had negligible effects on the predicted plant response. The timing of the surge line failure was virtually unchanged from the base case with nominal heat transfer coefficients, and the heatup rates in the core and ex-core structures showed little change from the base case.

The $20 \%$ increase in the steam generator tube heat transfer coefficients approximated the estimated effect of radiation heat transfer in the steam generator tubes. In Section 3.1.2, it was found that inclusion of radiative heat transfer from the vapor to the wall would result in a $25 \%$ increase in the effective heat transfer coefficient. That particular sensitivity calculation therefore approximated the effects of radiation heat transfer in the steam generator tubes, and indicated that the effects on the overall plant response are not significant.
One of the major deficiencies identified in the original work was the lack of a model for heat transfer between the hot and cold flows within the hot leg. Radiation heat transfer from the hot vapor to the cooler vapor was simulated to determine how much reduction in the heat transferred to the coolant loops might occur. Appendix $\mathrm{H}$ provides more details on how the radiation heat transfer was modeled. While this is a simplified approach to a much more complex heat and mass transfer process, it did provide insight into how the core and piping heatup may be affected by this heat transfer. The results of the calculations showed that the modeled radiation heat transfer had a negligible effect on the timing of the ex-vessel piping failures. Creep rupture of the surge line and hot leg occurred within $1 \mathrm{~min}$ of the calculated failure time for the base case (223 $\mathrm{min}$ for the surge line, $242 \mathrm{~min}$ for the pressurizer loop hot leg, and $245 \mathrm{~min}$ for the other two hot legs) without the vapor-to-vapor heat transfer modeled. Most of the creep damage occurred before radiation heat transfer was a significant contributor to the heat transfer from the vapor. The calculated radiation heat flux peaked after the surge line failure was predicted to occur.

The conclusion that failure of the surge line will occur near the time of initial fuel rod relocation must be tempered with the realization that this is for a specific transient without operator intervention. As the TMI-2 accident showed, operator actions can have a profound influence on the transient progression. When the TMI- 2 accident was terminated, the reactor vessel lower head was close to failure, but there was no indication of any significant heatup of any ex-vessel piping. Operator actions in an actual transient may result in cooling or quenching of the hot legs, surge line, or steam generator tubes while the core damage progression continues. Ex-vessel failures may occur in some severe accidents, but they will not occur in all of them.

\subsection{Related Plant Analyses}

Other commercial plant transient analyses have been performed that considered natural circulation flows during severe accidents. Although these analyses were not performed specifically to 
investigate the natural circulation flow behavior and effects, they do provide some information on the impact of the natural circulation flows.

Calculations of the Surry and Zion plants were performed as part of an investigation into the effects of direct containment heating. ${ }^{12,13}$ These calculations used the SCDAP/RELAP5 computer code. The Surry model was the same as that used in the analyses described in the previous section. The Zion model was similar, although that plant has four coolant loops rather than the three in Surry and a proportionately higher power. Another difference between Zion and Surry is that Zion is a downcomer bypass plant, while Surry is a core bypass plant. This means that the flow between the core baffle plates and the core barrel is normally parallel to the downcomer flow, and is connected at the top to the downcomer in Zion; in Surry, this flow is normally parallel to the core flow, and the opening at the top of the gap between the barrel and baffle is to the upper plenum. Analyses for both plants addressed the station blackout transient, with and without reactor coolant pump seal leakage and failure modeled.

The Surry calculations with no pump seal leaks predicted that creep rupture failure of the surge line occurred near the time of initial fuel rod cladding failure, whether or not the hot leg countercurrent flow was modeled. This result is consistent with the results of the Surry natural circulation analyses described in the previous section. However, the core damage progression was greatly affected. Surge line failure occurred about $140 \mathrm{~min}$ before vessel failure in the base case, and $45 \mathrm{~min}$ before vessel failure without the hot leg natural circulation flow. The hot leg natural circulation flow results in about $20 \%$ of the core decay and oxidation energy being deposited in the steam generators. Without this flow modeled, this energy remains in the core, causing a much faster core heatup and a more rapid progression from initial fuel rod relocation to vessel failure.

With a pump seal leak of $0.016 \mathrm{~m}^{3} / \mathrm{s}$ (250 gpm) per pump, the surge line and hot leg were predicted to fail about $100 \mathrm{~min}$ after the first fuel melting, but still more than 1 hour before relocation of molten core material to the lower head. With a maximum pump seal leak of $0.030 \mathrm{~m}^{3} / \mathrm{s}$ (480 gpm) per pump, no ex-vessel failures were predicted. While the pump seal leaks did not disrupt the hot leg natural circulation flow, they did divert some of the energy away from the hot legs, resulting in lower structure temperatures in the hot legs and surge line. They also allowed the reactor coolant system to depressurize sufficiently that the PORVs were not cycling and drawing hot vapor into the pressurizer surge line.

The Zion station blackout calculation without reactor coolant pump seal leaks predicted that the surge line would fail $8 \mathrm{~min}$ after the first fuel cladding failure, and $84 \mathrm{~min}$ before core relocation. Cases were also run with pump seal leaks of 0.016 and $0.030 \mathrm{~m}^{3} / \mathrm{s}$ (250 and $480 \mathrm{gpm}$ ) per pump. Neither of these calculations predicted failure of ex-vessel structures, although the hot leg natural circulation flow was not disrupted.

These analyses showed that even though hot leg natural circulation is present, a large enough break in the cold leg (reactor coolant pump seal in this case) may be sufficient to prevent failure of the hot leg or surge line piping. Energy is diverted away from the hot legs toward the break, resulting in slower heatups of the hot leg and surge line piping, and of the steam generator tubes. The lower RCS pressure alleviates the need for opening of the PORVs, so that hot steam is not drawn into the surge line. However, the likelihood of DCH is also reduced (compared to an intact RCS pressure boundary) because the RCS is depressurizing through the break.

\subsection{Extension of Results to Other PWRs}

Given the time and expense involved in performing severe accident analyses, it would be helpful if the results of a few plant analyses, such as the Surry and Zion calculations, could be extended to other PWRs, so that calculations would not have to be made for each plant. Accordingly, a study was undertaken to see if plants could be categorized for their susceptibility 
to ex-vessel failures. Appendix I contains a detailed description of that effort, which is summarized below.

Attempts were made to group plants based on their potential for unintentional depressurization; that is, the failure of an ex-vessel component. Areas examined included the PORVs (failure by overheating), surge line and hot leg piping, steam generator tubes, and reactor coolant pump seals. These failures were considered to have the potential to reduce the RCS pressure sufficiently to mitigate DCH.

Ex-vessel component failures can occur when structures are exposed to high-temperature fluid that originates in the reactor vessel. If relief valves are operating, forced flow in the hot legs and surge line will strongly influence the heat transfer from the hot fluid to the piping. If the RCS pressure is below the setpoint for relief valve operation, or during periods when the relief valves are closed, natural circulation flow will allow heat transfer to the piping or steam generator tubes. In both of these situations, many system parameters influence the temperature of the fluid that is in contact with the pipe or tubes, the fluid flow rates, and the structure stored energy capacity. Consequently, a simple set of parameters could not be identified that would characterize PWRs according to their potential for unintentional depressurization resulting from temperature-induced failure of ex-vessel piping.

Relief valves may fail in an open position if hot fluid passing through the valve heats valve components above their failure limits. The potential for failure of relief valves would depend strongly on their design and temperature qualifications. Consequently, PWR plants could be categorized according to the potential for failure of relief valves based on the valves installed in the plant. However, there are no data on the failure modes of relief valves under conditions similar to those expected during a severe accident. Without extensive failure mode testing and analysis of the data, plants cannot be categorized according to the potential for relief valve failure.

The likelihood of a reactor coolant pump seal failure is considered to be higher for plants with Westinghouse pumps because they must rely on continuous seal cooling. Since Combustion Engineering and Babcock \& Wilcox plants use other manufacturers' pumps (Bingham International, Byron Jackson, or Klein, Schanzlin, and Becker), unintentional depressurization as a result of pump seal failure is considered to be less likely. However, Westinghouse has recently developed a pump seal design that would be less likely to fail under high-temperature conditions. As a result, some Westinghouse PWRs may now be using, or are planning to use, the new pump seal design. Plants could be categorized into two groups, those with Westinghouse pumps that have the old seal design and those that have the new seal design or that do not have Westinghouse pumps. Plants with the old Westinghouse seal design would be more likely to experience unintentional depressurization.

The conclusion is that it is not possible to categorize the plants. Differences in hardware, a lack of applicable component failure data, and variations in the accident progression result in large enough uncertainties that the results of the Surry analyses cannot be realistically applied to determine how and when RCS failures would occur in other plants during a severe accident. 


\section{SUMMARY AND CONCLUSIONS}

Analyses have been performed at the INEL to investigate severe accident natural circulation phenomena. The efforts have included developing PIRTs for natural circulation flow, review and analysis of scaled experiments, and full-scale plant calculations using the SCDAP/RELAP5 code.

Natural circulation in severe accidents redistributes energy from the core to structures in the upper plenum and coolant loops. This energy transfer not only slows the heatup of the core, it also contributes to potential failure of the RCS piping. Such a failure, if it occurs early enough in the transient, may allow the RCS sufficient time to depressurize before lower head failure (following molten core attack) that high-pressure melt ejection will not occur, minimizing the effects of direct containment heating.

Analyses and experiments have shown that the natural circulation flow is robust and hard to disrupt. Hydrogen generated in the core will not stratify in the upper plenum, thereby insulating the upper plenum structures and reducing the invessel natural circulation. Hydrogen bubbles in the steam generators, caused by steam being condensed in the tubes, are also not likely to disrupt heat transfer to the steam generators.

The analyses of the Westinghouse experiments showed that the RELAP5 code, and the typical nodalization used for commercial plants, were able to model the experiments reasonably well. Vapor temperatures were slightly overpredicted in the hot legs and steam generator tubes, and the core vapor temperatures were overpredicted in downflow and underpredicted in upflow. These results provided some confidence that the plant calculations are exhibiting reasonable behavior.

The plant analyses have shown that while the in-vessel and hot leg natural circulation flows are important in predicting whether the ex-vessel piping will fail, the timing of the failures is relatively insensitive to variations in parameters affecting the natural circulation flows. Changing loss coefficients, steam generator inlet plenum mixing, heat transfer coefficients in the vessel and piping, and modeling heat transfer between the counterflowing vapor in the hot leg had little effect on the transient; surge line failure still occurred near the time of initial fuel rod relocation. This occurs more than 1 hour before vessel failure is predicted, allowing time for the RCS to depressurize and minimize the effects of DCH.

An analysis of the TMI-2 upper plenum indicated that vapor temperatures in the upper plenum could be substantially higher [700-800 K $\left.\left(1,250-1,450^{\circ} \mathrm{F}\right)\right]$ than those of the control rod lead screws. This result supports the presence of in-vessel natural circulation during the TMI-2 accident; this had been questioned because of the low temperatures observed in the lead screws.

Operator actions can affect the progression of a severe accident sufficiently that high-pressure melt ejection and subsequent DCH cannot be ruled out. Actions taken during the TMI-2 accident resulted in low ex-vessel piping temperatures, so that the reactor vessel lower head would have been the location of the first RCS pressure boundary failure. 


\section{REFERENCES}

1. M. Silberberg, J. A. Mitchell, R. O. Meyer, and C. P. Ryder, Reassessment of the Technical Bases for .Estimating Source Terms, NUREG-0956, July 1986.

2. U.S. Nuclear Regulatory Commission, Reactor Risk Reference Document, NUREG-1150, December 1990.

3. P. D. Bayless, Analyses of Natural Circulation During a Surry Station Blackout Using SCDAPI RELAP5, NUREG/CR-5214, EGG-2547, October 1988.

4. W. A. Stewart, A. T. Pieczynski, and V. Srinivas, "Experiments on Natural Circulation Flows in Steam Generators During Severe Accidents," Proceedings of the International ANSIENS Topical Meeting on Thermal Reactor Safety, San Diego, CA, February 2-6, 1986.

5. D. A. Brownson, L. N. Haney, and N. D. Chien, Intentional Depressurization Accident Management Strategy for Pressurized Water Reactors, NUREG/CR-5937, EGG-2688, April 1993.

6. P. D. Bayless, C. A. Dobbe, and R. Chambers, Feedwater Transient and Small Break Loss of Coolant Accident Analyses for the Bellefonte Nuclear Plant, NUREG/CR-4741, EGG-2471, March 1987.

7. C. M. Allison et al., SCDAP/RELAP5/MOD2 Code Manual, Volumes 1, 2, and 3, NUREG/CR-5273, EGG-2555, June 1989.

8. Englemann, M. S., FIDAP 7.0 Theory Manual, Fluid Dynamics International, Evanston, II.

9. K. E. Carison et al., RELAP5/MOD3 Code Manual, NUREG/CR-5535, EGG-2596, June 1990. (Draft available from Lockheed Idaho Technologies Company).

10. H. M. Domanus and W. T. Sha, Analysis of Natural-Convection Phenomena in a 3-Loop PWR during a TMLB' Transient Using the COMMIX Code, NUREG/CR-5070, ANL-87-54, January 1988.

11. W. T. Sha and V. L. Shah, Natural Convection Phenomena in a Prototypic PWR During a Postulated Degraded Core Accident, EPRI TR-103574, January 1994.

12. D. L. Knudson and C. A. Dobbe, Assessment of the Potential for High Pressure Melt Ejection Resulting from a Surry Station Blackout Transient, NUREG/CR-5949, EGG-2689, November 1993.

13. D. L. Knudson, P. D. Bayless, C. A. Dobbe, and F. Odar, "Assessment of the Potential for HPME During a Station Blackout in the Surry and Zion PWRs," Twenty-First Water Reactor Safety Meeting, Bethesda, MD, October 1993. 


\section{Appendix A}

\section{Natural Circulation Parameter Importance Evaluation}





\section{Appendix A}

\section{Natural Circulation Parameter Importance Evaluation}

\section{A-1. INTRODUCTION}

Early failure of a pressurized water reactor (PWR) containment has been identified as a significant contributor to risk for some severe accident sequences. At issue is whether the reactor coolant system (RCS) depressurizes before or after the corium melts through the lower head of the pressure vessel. If a melt-through occurs while the RCS pressure is above approximately $1.38 \mathrm{MPa}$ (200 psia), the ejected corium may be expelled rapidly in a finely dispersed state, resulting in direct containment heating (DCH). If, however, the RCS pressure is reduced prior to lower head melt-through, the effects of DCH can be mitigated and early overpressure failure of the containment can be averted for certain severe accident sequences.

Both experimental results and detailed analyses indicate that natural circulation processes within the reactor vessel, the hot leg, and the steam generators can result in the transfer of significant amounts of energy from the core to the ex-vessel structures during the latter stages of some severe accidents. This energy transfer may cause the hot leg, pressurizer surge line, or steam generator tubing to become very hot and incur a creep rupture failure prior to vessel lower head failure. If a failure occurs in these regions, the reactor coolant system (RCS) may depressurize to a pressure that is low enough to mitigate the effects of DCH. The flow rates and duration of this natural circulation are therefore important in assessing whether an ex-vessel structure or the vessel lower head fails first.

The objective of this work is twofold, namely to (a) identify the parameters that influence natural circulation behavior, and (b) rank their importance for influencing pressure boundary failure. Separate parameter lists are developed for the reactor vessel, the lower head, and the hot leg piping. Westinghouse, Combustion Engineering
(CE), and Babcock \& Wilcox (B\&W) reactor designs are all considered. Both activities utilize the input of several experts in specialized fields. The ranking process is achieved via the "Analytical Hierarchy Process" (AHP). A-1,A-2 This procedure involves a series of pair-wise rankings of the identified parameters followed by an automated statistical analysis of the rankings. The product is a numerical quantification of relative importance of each parameter for various phases of the accident. Consequently, subsequent analyses can be performed more expeditiously by considering the most influential factors on a priority basis.

Section A-2 provides a description of the AHP. A listing and brief discussion of the controlling parameters for each of the RCS regions is contained in Section A-3. A discussion of the rankings of the parameters is presented in Section A-4 and the report conclusions are in Section A-5. Section A-6 contains the references.

\section{A-2. ANALYTICAL HIERARCHY PROCESS}

\section{A-2.1 Background}

An importance ranking of parameters that affect the outcome of a physical process for which there is no precise analytical description is often both subjective and complex. Nevertheless, it is generally recognized that for even the most arcane problems, much information may exist in the form of limited test results or individual findings from analytical studies. The question may then arise of how to bring together and organize the contributing information to best state the present understanding of the problem. AHP was developed to assist in resolving information organization for decisionmaking in complex problems. It is the tool of choice for this report. G. E. Wilson, of Lockheed Idaho who has studied this 
procedure extensively, has provided the following discussion of the methodology. ${ }^{A-3}$

\section{A-2.2 The Analytical Hierarchy Process}

As decisions become more and more complex, decision makers are faced with the challenge of sorting through many variables to arrive at a sound decision. The Analytic Hierarchy Process is a tool, developed by T. L. Saaty, A-1,A-2 that provides a systematic, logical approach for reducing complex issues into manageable pieces. The decision maker can then sort through the variables and determine to what degree a particular variable should influence the final decision. The power of the AHP as a management tool comes from the fact that it reduces the problem to many pair-wise decisions. Only two items need be compared against one another, a much simpler task than comparing an item to all the others simultaneously. By comparing appropriate pairs in a priority matrix, each item will have been compared with every other item. Matrix algebra can then operate on this priority matrix to rank the items according to their importance toward achieving the goal.

As the name suggests, the AHP contains hierarchies or levels. Each level contains items that will be ranked relative to an item in the level above it. By starting at the bottom level, the most fundamental level, the decision maker can rank items with respect to a more general item contained in the next higher level. As the decision maker proceeds through the levels, the items become more general until, finally, the most general item-the goal-is reached. Thus, the decision maker proceeds as if building a pyramid. At the bottom he makes many fundamental decisions. As he proceeds toward the top he makes fewer and fewer decisions but they are more general. Finally the AHP manipulates the decision maker's pair-wise decisions to determine how important each of the most fundamental items is with respect to the most general one, the goal.
Items in each level are ranked with a tool called a priority matrix. Each entry into a priority matrix compares the relative importance of two items-a pair-wise decision. Each level will contain one or more priority matrices that are filled with pairwise decisions. In the process of building the priority matrices, the decision maker may inadvertently enter decisions that contradict one another. A measurement for the amount of contradiction in a priority matrix is included in the AHP as a consistency index, which is discussed further in Section A-2.5.

\section{A-2.3 Levels}

One can have as many levels as needed, but the first level always contains the goal to be achieved. The last level contains the items to be prioritized with respect to their effect on achieving the goal. All the levels in between help the decision maker relate the most fundamental items on the bottom level to the goal on the top level. Each level contains items that relate to the more general items in the level above it. The more complex the problem is, the more levels it is likely to have. For the present case, only two levels are required.

\section{A-2.4 Priority Matrices}

Priority matrices are key elements in the AHP. It is the priority matrices in which the decisionmaker enters his pair-wise rankings. Also, the AHP uses the priority matrices to determine the ranking of items on each level, and the overall hierarchy (i.e., the items on the last level with respect to the top level). A given set of priority matrices bridges the levels. Each level below level 1 will have a set of matrices (level 1 contains no matrix). One matrix will rank items in the current level with respect to an item in the level above it. Thus, each level will have as many matrices as there are items in the level above it.

To construct a priority matrix, the decisionmaker begins by listing the items in the current level along the left of, and at the top of, an empty matrix. He enters " 1 's" on the diagonal (row a, column a equals 1 ; row $b$, column $b$ equals 1 ; etc.). These unit 1 cells indicate that each item is 
as important as itself. Now, the decision maker is ready to enter pair-wise rankings in the upper right half of the matrix (or, one can enter pairwise rankings in the lower left half realizing that the two halves of the matrix are reciprocals). Each entry into the priority matrix is a pair-wise ranking (i.e., a judgment of how important one item is with respect to the other). Matrix solution schemes within the program then determine the absolute ranking of the items within the composite of all items. Only the top right corner of the matrix need be filled in because the lower left portion of the matrix is the inverse of the top right portion (i.e., row a, column $d$ is the inverse of row d, column a). Once the priority matrices are completed, the work for the decision maker is finished. Now the AHP software can operate on the matrices to determine the absolute priorities.

\section{A-2.5 Consistency}

It is possible for two decisions to inadvertently contradict one another in a priority matrix. For example, the decision maker might say that item $A$ is more important than item $B$, and item $B$ is more important than item $C$, but item $C$ is more important than item $\mathrm{A}$. There is a measurement for the amount of contradiction in a matrix called the inconsistency index. Inconsistency indexes from each priority matrix in the hierarchy can be used to determine an overall hierarchy inconsistency. Generally, if the inconsistency index for a matrix is less than 0.1 , the inconsistency is probably not significant.

The pair-wise ranking scales used as input to the AHP tend to influence the inconsistency. A coarse scale will tend to increase the inconsistency relative to a fine scale; however, the scale selection also depends on other factors. The most coarse scale ( 1 to 3 ) is the easiest to use in the pair-wise ranking. That is, it is easy to decide that two parameters are of equal importance (1), or that one is somewhat more important (2) or significantly more important (3). It is more difficult to rank using a scale of 1 to 9 . Experience indicates that what is usually done is to establish 1 as equally important, 5 as somewhat more important, 9 as significantly more important, and then use the in-between numbers to resolve differences in the opinions of the personnel performing the ranking. Based on considerable experience the normal recommendation is to use a scale of 1 to 5 . This scale usually provides the best compromise relative to ease of use and influence on the inconsistency of the resulting product.

It should be noted that the preceding discussion applies only to the pair-wise ranking scales which are input to the AHP software. The relative ranking performed by the AHP software is output in a scale which is normalized to the total (i.e., zero to one). This scale is further converted to a relative scale of 1 to 9 by assigning 1 to the lowest normalized value, 9 to the highest normalized value, and then linearly interpolating the remaining normalized values. It has been found the 1 to 9 relative scale is generally more convenient in reviewing the relative importance of the items at each hierarchical level.

\section{A-3. SELECTION OF PARAMETERS}

This section identifies and describes the parameters that are important during hot leg natural circulation or vessel lower head failure. Since failure of the hot legs or lower head may be influenced by a large number of parameters, it was necessary to categorize the parameters. The approach taken was to first identify features of the RCS or the accident that would influence the effect of natural circulation on the outcome of the accident and then to determine how these features could be categorized to allow identification of a common set of applicable parameters. The following features were used to establish the categories:

- Design of the RCS-Energy transfer during natural circulation can be influenced by the structural configuration of the vessel internals, the hot legs, and the steam generator. Differences in the design of the vessel, hot legs, and steam generators were considered for each of the three reactor vendors: Westinghouse, CE, and $B \& W$. 
- Regions of the RCS-Different parameters may influence the energy transfer and failure mechanisms for the in-vessel and exvessel regions. The vessel and hot leg regions were considered separately because the natural circulation phenomena in these regions are not the same. In addition, the lower head was considered as a separate region because many of the parameters that influence its failure will be unique when compared to the vessel and hot legs.

- How far the accident has progressed-The temperature of the core material and its geometry influence the amount of energy that will be transferred by natural circulation. Four distinct core damage phases were identified in which different parameters will influence the natural circulation behavior. These phases are:

Phase I-This is the temperature range in which control rod melting begins and fuel rod ballooning occurs, from the fluid saturation temperature up to $1,500 \mathrm{~K}$.

Phase II-This is the thermal interval in which most of the zirconium oxidation occurs and some metallic eutectics melt and relocate. The control rods are totally melted at these temperatures, from 1,500 to $2,100 \mathrm{~K}$.

Phase III-Core metallic structures melt and relocate, from 2,100 to $2,500 \mathrm{~K}$.

Phase IV-Ceramics and ceramic eutectics melt and relocate in this temperature range, from $2,500 \mathrm{~K}$ on up.

Since there are three designs, three regions, and four phases, a total of 36 categories is possible. However, by examining similarities in the designs and regions and by assessing the effects of the different phases during the ranking process, it is possible to define the following four categories that can be used to identify appropriate parameters:
1. Vessel Natural Circulation Parameters-All Reactor Types

2. Vessel Lower Head Parameters-All Reactor Types

3. Hot Leg Piping Parameters-Westinghouse and CE Reactors

\section{Hot Leg Piping Parameters-B\&W Reactors.}

Top events were developed for each of these four categories. Parameter lists were then developed by first collecting all the parameters that might remotely affect a given "top event." Table A-1 contains a complete list of the parameters. This unabridged list of natural circulation parameters is a composite set provided by personnel at the Idaho National Engineering Laboratory with expertise in reactor safety analysis and by a group of personnel assembled at the Nuclear Regulatory Commission Nicholson Lane Facility with expertise in natural convection and severe accident analyses.

There are some overlaps in the extent of the parameters among the entries. For instance, "Loss of core geometry" and "Core debris bed formation" are obviously not independent. The extensive list was then reduced to those parameters that were judged to have a significant impact on the top event. These lists are presented in the remainder of this section.

\section{A-3.1 Vessel Natural Circulation Parameters-All Reactor Types}

The top event for Vessel Natural Circulation is the transfer of energy from the reactor core to the hot leg-vessel interface. This is important because it directly affects creep rupture failure in the hot leg. Parameters judged to significantly affect this energy transport are listed below:

1. Core Convective Heat Transfer-This is the measure of energy transfer from the core material to the surrounding coolant. The 
Table A-1. Unabridged parameter list.

Table A-1. Unabidged parameter list.

\begin{tabular}{ccc}
\multicolumn{3}{c}{ Areas primarily affected } \\
\hline Vessel & Vessel & Hot leg \\
natural & lower & natural \\
circulation & head & circulation \\
\hline
\end{tabular}

1. Mixing in the steam generator inlet plenum

2. Hydrogen generation

3. Noncondensible gas transport

4. Loss of core geometry

5. Core debris bed formation

6. Corium relocation

7. Flow losses in the core

8. Flow losses in the upper plenum

9. Hot leg turbulence

10. Pressure distribution in the hot leg

11. Hot leg circumferential heat transfer

12. System water level

13. System pressure

14. Core convective heat transfer

15. Core radiative heat transfer

16. Upper plenum convective heat transfer

17. Upper plenum radiative heat transfer

18. Core bypass flow

19. Fission product release/transport

20. Fission product deposition/removal

21. Core radial peaking factor

22. Core axial peaking factor

23. Coolant flashing

24. Material properties; weldments, cracks, etc.

25. Fuel-coolant interactions

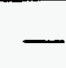

\section{$\mathbf{X}$}

$\mathrm{X}$

$\mathrm{x}$

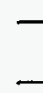

26. PORV operation

27. Water injection

28. Pressurizer drainage

29. Steam generator secondary side conditions

30. Letdown flow

31. Noncondensible gas behavior

32. Fuel decay heat
$\mathrm{X}$

$\mathrm{x}$

$\mathrm{x}$

$\mathrm{x}$

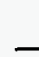

- $\mathrm{x}$

$x$

$\mathrm{x}$ $\mathrm{X}$
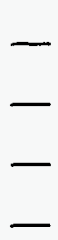

X

X

$\mathrm{X}$

$\mathbf{X}$

X

$\mathrm{X}$

X

X

$\mathrm{X}$

$\mathrm{X}$

X

$X$

X

$\mathbf{X}$

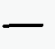

X

X

$\mathrm{X}$

$\mathrm{X}$

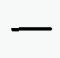

$\mathrm{X}$

$\mathrm{X}$

$\mathrm{X}$
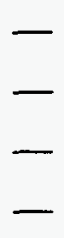

$\mathrm{X}$

$\mathrm{X}$

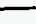

$\begin{array}{ll}- & - \\ - & \mathrm{x} \\ \mathrm{x} & \mathrm{x} \\ \mathrm{x} & - \\ - & \mathrm{x} \\ - & \mathrm{x} \\ - & \mathrm{x} \\ - & \mathrm{x} \\ - & \mathrm{x} \\ - & -\end{array}$

$x$


Table A-1. (continued).

\begin{tabular}{ccc}
\multicolumn{3}{c}{ Areas primarily affected } \\
\hline Vessel & Vessel & Hot leg \\
natural & lower & natural \\
circulation & head & circulation \\
\hline
\end{tabular}

33. Hot leg countercurrent flow

\begin{tabular}{|c|c|c|}
\hline- & - & $x$ \\
\hline - & - & $\mathrm{x}$ \\
\hline- & - & $x$ \\
\hline- & - & $\mathrm{x}$ \\
\hline$x$ & - & $\mathrm{x}$ \\
\hline - & $x$ & - \\
\hline- & - & $\mathrm{x}$ \\
\hline $\mathrm{x}$ & - & $\mathrm{x}$ \\
\hline $\mathrm{x}$ & - & $\mathrm{x}$ \\
\hline$x$ & $\mathrm{x}$ & - \\
\hline $\mathrm{x}$ & $\mathrm{x}$ & - \\
\hline 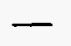 & $\mathrm{x}$ & - \\
\hline$x$ & $\mathrm{x}$ & - \\
\hline- & $\mathrm{x}$ & - \\
\hline$x$ & $x$ & - \\
\hline- & - & $x$ \\
\hline- & - & $x$ \\
\hline$x$ & - & - \\
\hline- & - & $\mathrm{x}$ \\
\hline$x$ & $x$ & - \\
\hline- & $x$ & - \\
\hline
\end{tabular}

34. Vertical hot leg natural circulation cells

35. Steam condensation/heat transfer

36. Steam generator blockage

37. Multicomponent gas heat transfer coefficients

38. Average vessel/penetration temperature

39. Water and corium dead weight

40. Vapor-to-vapor heat transfer

41. Vapor-to-structure heat transfer

42. Corium power distribution

43. Corium power generation

44. Corium sensible energy

45. Corium heat transfer to coolant

46. Corium heat transfer to lower head

47. Vessel-to-containment heat transfer

48. Hot leg-to-containment heat transfer

49. Pressure distribution in the hot leg

50. Flow losses in the upper plenum

51. Temperature gradient in the hot leg piping

52. Metal/ceramic interactions

53. Coolant-to-structure heat transfer

importance of this parameter varies with the fluid conditions and flow rates, core temperature, core geometry, metal-water reactions, etc. Note that these factors may vary during the accident so that in the subsequent rankings, its importance must be evaluated in context with the RCS region and accident phase that characterize the case under consideration.

2. Core Power Distribution-This is the distribution of energy within the core region. This parameter includes the effects of decay power, peaking factors, metal-water reactions, and fuel redistribution as appropriate.

3. Vessel Water Level-The water level affects the fluid quality and heat removal from the core, and if the water is being vaporized it can affect the cladding oxidation rates. It is reasonable to expect the water level to drop as boiloff occurs during the accident and, consequently, its potential effects will vary with the accident phase, providing more cooling initially.

4. Loss of Core Geometry-Primarily refers to the core flow resistance and area available 
for heat transfer. In the latter accident phases it is also related to the migration of corium to the lower plenum.

5. Core Radiative Heat Transfer-This parameter includes rod-to-rod, rod-to-fluid, and rod-to-structure thermal radiation. Although minimal, nuclear radiation heating in the surrounding structure can be treated as an energy source in the structural material.

6. Fission Product Behavior-The behavior of fission products including release, transport, deposition, removal, and heat generation in both gaseous and aerosol forms is considered. Much of the noble gas inventory could be entrained in steam discharged through the PORV, and other components, such as CsI, are water soluble. Some of the particulate matter could reach the hot legs. Deposition or settling of fission products on these structures would accelerate heating.

7. Upper Plenum Convective Heat TransferThe convective heat transfer between the fluid and structure in the upper plenum causes cooling of the effluent from the core, which serves to drive the natural circulation flow. Variations in the flow patterns may be locally influenced by unique geometrical configurations. For example, flow patterns around and through the B\&W upper plenum flow cylinder, reported by Lillington and Lyons, ${ }^{\mathrm{A}-4}$ exhibit a more protracted path than would be expected for either the Westinghouse or $C E$ vessel designs.

8. Upper Plenum Radiative Heat TransferVapor-to-structure and structure-tostructure thermal radiation is a significant mode of heat transfer at temperatures above about 1,400 K; hence, it becomes more important later in the accident and competes with convection as an energy dissipation process.

9. Noncondensible Gases-The noncondensible gases comprise hydrogen, from the metal-water reaction; helium, from the fuel rod manufacturing process; and fission product gases such as krypton, xenon, and argon. The relative quantities of helium, krypton, xenon and argon will be small compared to the quantity of hydrogen generated as the accident progresses. Some analysts have proposed that after the core temperature reaches approximately $1,800 \mathrm{~K}$, sufficient hydrogen may be generated to cause hydrogen to stratify in the vessel. Recent calculations, however, cast doubt upon this being a serious consideration because there are no cool condensing surfaces in the vessel to concentrate the hydrogen, and natural circulation mixing in the upper plenum tends to break up the stratification. Other, more probable effects include modification of the heat transfer coefficient for vapor-to-structure heat transfer.

10. Hot Leg Water Injection/Pressurizer Drainage-Early in the accident, water entering the vessel through the hot leg as a result of injection or pressurizer drainage is not expected to have a major effect. Later in the accident, however, water entering the vessel may enhance the metal-water reaction and steam production. Some subcooling of the resident inventory may occur as well as a change in the water level. The effect on the hot leg-vessel interface mechanics becomes more important as the accident progresses.

11. System Pressure-Pressure will affect fluid properties, which may influence the natural circulation flows and heat transfer.

\section{A-3.2 Vessel Lower Head Parameters-All Reactor Types}

The top event for the vessel lower head is the breach of the pressure boundary of the lower head caused by either an instrument tube penetration failure or global vessel failure. Parameters judged to significantly affect this top event are: 
1. Corium Power Generation Level-The total power generated in the corium because of subcritical fission, decay heat, and metalwater reactions.

2. Corium Power Distribution-The energy generated in relocated mass and the position in the lower plenum where it resides are both time dependent. For example, during Phase III, the corium that transfers to a specific region in the lower plenum would be expected to have a high ratio of metal mass to ceramic mass. Moreover, during Phase IV, debris with lower ratios of metal to ceramic mass may relocate to a different location in the lower plenum. Note that the potential for ceramic-rich debris to enter the lower head penetrations and cause them to fail was considered.

3. Corium Sensible Energy-The stored energy associated with the product of mass, specific heat, and temperature at the time of relocation. Note again that the potential for ceramic-rich debris to fail lower head penetrations was considered where appropriate.

4. Corium Heat Transfer to Coolant-The heat stored and generated in the corium will end up in the coolant, the reactor structures, or remain in the corium. Depending upon the phase of the accident and variations of the melt/water interactions during corium relocation, the heat transferred to the coolant can vary a great deal and have important consequences on the course and outcome of the accident.

5. Corium Heat Transfer to Lower Head-All heat transfer to the vessel lower head through contact with molten or solidified corium is included. This parameter is similar to "corium heat transfer to the coolant" except that the heat transfer is to the vessel structure. Factors influencing corium-vessel heat transfer include corium porosity, corium composition and vessel surface roughness.
6. System Pressure-System pressure is primarily significant because of its direct contribution to vessel stresses. However, it may also have secondary influences on other thermal-hydraulic phenomena as noted earlier.

7. Coolant-to-Structure Heat Transfer-This parameter accounts for the heat transfer along the vessel wall from locations where water and corium are in close proximity and are coincidentally cooling and heating the wall over small distances. This heat transfer is generally from near the bottom of the vessel, which is heated by relocated corium, up toward the vessel cylinder, where water lying on top of the relocated debris is removing energy.

8. Vessel Lower Head-to-Containment Heat Transfer-The radial heat transfer from the vessel lower head to the air or water in the containment that is adjacent to the vessel exterior. The area surrounding the vessel may be dry or it may contain water that has accumulated as a result of containment sprays or other systems that can flood the reactor vessel cavity. This heat transfer parameter directly affects the energy removed from the lower head and has the potential to provide sufficient cooling to maintain lower head temperatures below the material failure temperature.

9. Water and Corium Dead Weight-These factors directly contribute to the vessel stresses in the lower head. In general, however, stresses caused by dead loads are small (i.e., less than $20 \%$ of the stress caused by $1 \mathrm{MPa}$ pressure). By comparison, the operating pressure of a PWR is about $15 \mathrm{MPa}$.

\section{A-3.3 Hot Leg Piping Parameters- Westinghouse and CE Reactors}

The top event for the RCS piping is creep rupture failure of the hot leg, surge line, or steam generator tubes. For ease of discussion these three 
components are lumped together and referred to simply as "hot leg." Parameters judged to significantly affect this top event are given below:

1. Hot Leg Countercurrent Flow-Flow in the hot leg transports energy from the vessel to the hot leg including the steam generator structures. Tests have shown that a countercurrent flow pattern is typical for plants with an inverted U-tube steam generator design such as those built by Westinghouse and $C E$. A vigorous flow pattern suggests that the vessel is transferring a significant amount of heat and is evidence of a large temperature gradient between the top (hotter) region of the hot leg and the bottom (cooler) region of the hot leg. If the surge line enters the top of the hot leg, it can be assumed to have drained and natural circulation cells in the vertical section would cause it to be a candidate failure location. Small natural circulation cells may transport energy into the vertical section of the surge line. Because of the surge line's thinner walls, many analysts predict that it will fail before the hot leg if the PORV is cycling. The steam generator tubes are generally predicted to fail last.

2. Steam Generator Inlet Plenum MixingThe principal effect of vigorous mixing in the steam generator inlet plenum is to reduce the temperature of the vapor entering the steam generator tubes. Reduced heat transfer to the steam generator tubes may decrease the flow rate into the hot leg and thereby slow the heatup of the structure.

3. Hot Leg Circumferential Temperature Gradient-A circumferential temperature gradient would be set up in the pipe wall as a result of the temperature difference in the fluid flowing along the top and bottom of the hot leg. This temperature gradient has two effects. First, the upper region of the pipe is more prone to incur a creep rupture failure because it is at a higher temperature. Second, the temperature differential between the top and bottom of the pipe may induce warpage, which contributes to the stress field.

4. Noncondensible Gases-This parameter includes the effects of noncondensible gases on the natural circulation flow in the hot legs. The largest quantity of noncondensibles for the severe accidents was considered to be hydrogen. Although noble gases are released as fission products, their quantities are relatively small compared to hydrogen. In addition, most are too heavy to effectively participate in blockage of flow into the steam generators. However, a mixture of steam and hydrogen could fill the hot leg and steam generator tubes. If water flow is reestablished to the steam generator secondary side and primary side condensation occurs, the resulting concentration of hydrogen at the high points in the steam generator or hot leg piping may inhibit flow into the steam generator. An additional effect of hydrogen would be to slightly enhance the vapor-to-structure heat transfer in the absence of condensation. In any event, hydrogen-related effects would not be very significant until after core temperatures reach approximately $1,800 \mathrm{~K}$ (i.e., after Phase I).

5. Vapor-to-Vapor Heat Transfer-This heat transfer process occurs between the countercurrent flows in the hot leg pipe. At lower temperatures, the primary process is convective mixing at the shear interface of adjacent flow streams. At higher temperatures radiation becomes relatively more important. High rates of energy transfer between the streams will reduce the temperature differential, which reduces the flow rates and exchange of energy with the structure.

6. Vapor-to-Structure Heat Transfer-Heat transfer from the vapor to the hot leg structure during hot leg natural circulation directly affects the hot leg temperatures. These temperatures, in conjunction with the system pressure, determine the timing and location of the failure of the hot leg. 
7. Hot Leg Water Injection/Pressurizer Drainage-Since water injection/drainage poses the potential for local quenching, this is potentially an important parameter, becoming more important as the accident progresses. One concern, however, is the variability of injection/drainage locations because of individual plant designs. Only one hot leg would be affected by drainage of the pressurizer and hot leg injection is not a general occurrence for most plants. Consequently, the quenching process may leave at least one hot leg largely unaffected. On the other hand, where quenching occurs, the creep rupture process may be arrested.

8. Fission Products-If fission products are transported to the hot legs and pressurizer line in large quantities, they would add to the existing heat load and promote hot leg failure. However, there are several factors that would tend to reduce the effect of this heating. First, the initial fission product gas releases, which might be expected in Phase II, do not contain large quantities of highly energetic nuclides. Most of the fission product gas would be discharged to the containment if the pressure relief valves are cycling. Second, the in-vessel natural circulation velocities are low, which results in the suspension of only small particles (i.e., particles estimated to be 10 microns or less). The larger particulates would likely remain in the vessel or be deposited on the upper vessel structure. Finally, when fuel melting occurs and particulate material is released, some of the constituents, for example CsI, could be affected if there is any remaining water inventory.

9. Material Properties-Material properties, as used here, refers to uncertainties in structural strength under accident loading conditions. Overall, this was not regarded to be a major uncertainty but this assumption needs some qualification. Specifically, there are two classes of uncertainty: those which derive from lack of data; such as the lack of multiaxial-loading creep failure data, and uncertainties associated with unit-to-unit manufacturing variations, such as the grain structure of weldments.

10. Steam Generator Secondary Side Conditions-If the secondary side temperature falls below the saturation temperature of the primary side, steam condensation is likely to occur. At core temperatures below about $1,800 \mathrm{~K}$, little hydrogen is likely to be present and the hot leg response would be simple, continuous steam migration from the vessel to the steam generator. Although the flow through the hot leg would be substantial under these conditions, the temperatures would be moderate. At higher temperatures, evolved hydrogen would be entrained with the steam and likely cause a steam generator blockage. This phenomenon was addressed in item 4, Noncondensible Gases.

11. Reactor Coolant System Pressure-The system pressure directly affects the pressure boundary stresses. It also changes the value of the density-dependent thermodynamic parameters, which could affect flow velocities and energy exchange rates.

12. Power Operated Relief Valve (PORV) Operation-The PORV opens and closes at preset pressure levels and operates automatically to keep the system pressure within specified limits. (At pressures below the lower setpoint the PORV remains closed.) If during an accident the system pressure rises sufficiently to cause the PORV to open, a strong forced convection flow exhausts hot gases though a portion of the hot leg, pressurizer surge line, pressurizer tank, and the PORV. Calculations indicate that this strong flow of hot gases overcomes natural circulation flow patterns and dramatically increases the surge line and hot leg temperatures. If the configuration of the pressurizer surge line is such that it has drained, temperature increases from successive PORV operation cycles would tend to accrue monotonically. Surge lines in many 
Westinghouse and some $\mathrm{CE}$ plants have this design.

\section{A-3.4 Hot Leg Piping Parameters-B\&W Reactors}

The top event for the hot leg piping is creep rupture failure of the hot leg, surge line, or steam generator tubes. For simplicity, these three components are often lumped together and referred to simply as "hot leg." Parameters judged to significantly affect this top event are given below:

1. Hot Leg Countercurrent Flow/TurbulenceThis flow occurs in the horizontal section of the hot leg and is functionally similar to Item 1 of Section A-3.3. However, the oncethrough design of $\mathrm{B} \& \mathrm{~W}$ steam generators will not support the more vigorous natural circulation flow patterns of Westinghouse and $C E$ inverted $U$-tube steam generator designs. Instead, experiments indicate that a single countercurrent natural circulation flow cell will be established in the horizontal portion of the hot legs. This cell would circulate with a relatively low velocity and a small top-to-bottom temperature difference.

2. Hot Leg Flow Cells/Vertical SectionExperiments indicate that the flow pattern in the vertical section of the hot leg consists of a series of counter rotating cells. This flow pattern would be a relatively inefficient means for transferring heat away from the horizontal section of the hot leg and, hence, from the vessel. Consequently, the hottest portion of the hot leg should lie just outside the vessel nozzle. This flow pattern is expected to be largely unaffected by either the accident phase or the presence of noncondensible gases.

3. Noncondensible Gases-This parameter should have essentially the same effect as described in Item 4, Section A-3.3 except that the $B \& W$ reactor designs inherently inhibit vessel-to-steam generator communication during natural circulation so hydrogen blockage is not expected to be a significant phenomenon.

4. Vapor-to-Vapor Heat Transfer-Same as in Item 5, Section A-3.3.

5. Vapor-to-Structure Heat Transfer--Same as in Item 6, Section A-3.3.

6. Water Injection/Pressurizer DrainageSince at least some B\&W pressurizer lines have a U-tube "manometer" shape, they will not drain completely. Hence, during the accident, system pressure variations may cause the water to slosh back and forth and some may enter the hot leg. Otherwise, the situation is similar to that described in Item 7, Section A-3.3.

7. Fission Products-Same as in Item 8, Section A-3.3.

8. Material Properties-Same as in Item 9, Section A-3.3.

9. Steam Generator Secondary Side-Similar to Item 10, Section A-3.3 except that the hydrogen blockage region forms at the top of the hot leg (i.e., at the highest point of the "candy cane").

10. Reactor Coolant System Pressure-Same as in Item 11, Section A-3.3.

11. Power Operated Relief Valve OperationThis is similar to Item 12, Section A-3.3 with the exception noted in Item 6 , above. Specifically, the "manometer-shaped" pressurizer lines in $\mathrm{B} \& \mathrm{~W}$ plants cannot be relied upon to clear free of liquid water. Hence PORV operation in a B \&W reactor may enhance hot leg failure but its effect on the surge line failure is less certain. Small system pressure changes may induce water sloshing in the surge line and thereby cool it and inhibit its failure. 


\section{A-4. PARAMETER EVALUATIONS AND STATISTICAL RANKINGS}

In this section the various parameters are ranked in a pair-wise fashion in their respective lists and then processed through the Analytical Hierarchy Process. The raw values are presented to show the basis for the subsequent statistical ranking of their overall importance as computed by the AHP.

\section{A-4.1 Ranking Procedures}

Because the initial phase of an AHP effort is unavoidably subjective, it cannot be shown that any given pair-wise rank is "absolutely correct." To enhance overall accuracy, therefore, an attempt was made to be both explicit in the definition of each ranking basis and consistent in the related evaluation process. This led to the adoption of the procedures given below:

1. The top event was clearly defined for each ranking matrix. The top events are defined prior to the parameter lists presented in Section A-3.

2. When parameters were ranked for either the hot-leg or the vessel, the hot leg-vessel interface was always treated as a boundary of the region being evaluated. That is, parameters indicative of conditions existing beyond the hot leg-vessel boundary were considered only to the extent of their effect at the boundary.

3. In evaluating the relative importance of the parameter sets, each parameter was assumed to be operative during the accident. However, it is recognized that some parameters may not be present in all accident sequences and the subsequent importance ranking of the parameters would not be appropriate for every case. For example, "water injection" was found to be a consistently high ranking parameter. But, if water was not injected during a particular accident being considered, it would obviously be unimportant in that instance. The utility of the ranked parameters, therefore, requires some knowledge of the specific accident being addressed.

\section{A-4.2 Results of Parameter Rankings}

In the parameter ranking matrices and corresponding statistical evaluations given below, it may be noticed that some reactor types and/or accident phases are ranked together. Rankings were combined only when distinctions of relative parameter importance because of geometry and/or core damage regimes were judged to be insignificant. For example, the vessel lower heads in both Westinghouse and $\mathrm{B} \& \mathrm{~W}$ reactors have nozzle penetrations, whereas $C E$ reactors usually do not. Since the presence of nozzle penetrations affected the rankings, the groups were separated accordingly. Similarly, the presence of an upper plenum flow cylinder in $\mathrm{B} \& W$ reactors was the basis for ranking them separately from the Westinghouse and $\mathrm{CE}$ reactors when considering in-vessel natural circulation.

Also, note that prior to ranking the parameters, the original unabridged list (Table A-1) contained in excess of 50 parameters. Therefore, it may be assumed that all of the parameters in the reduced lists may be at least somewhat important for specific accidents. The AHP software program, however, force-ranks each parameter set over the range of 1 (least important) to 9 (most important) so that some low-number rankings necessarily occur for the reduced lists. Finally, the AHP software program is set up to calculate four-digit values in the output ranking table although the input matrices have only single-digit entries. This is a nuance of the software program and is not intended to exaggerate the accuracy.

Rankings in the following twelve categories were performed and are reported in Tables A-2 through A-13:

1. Vessel natural circulation for Westinghouse and CE-Phase I (Table A-2)

2. Vessel natural circulation for Westinghouse and $\mathrm{CE}$-Phase II (Table A-3) 
Table A-2. Vessel natural circulation for Westinghouse and CE-Phase I.

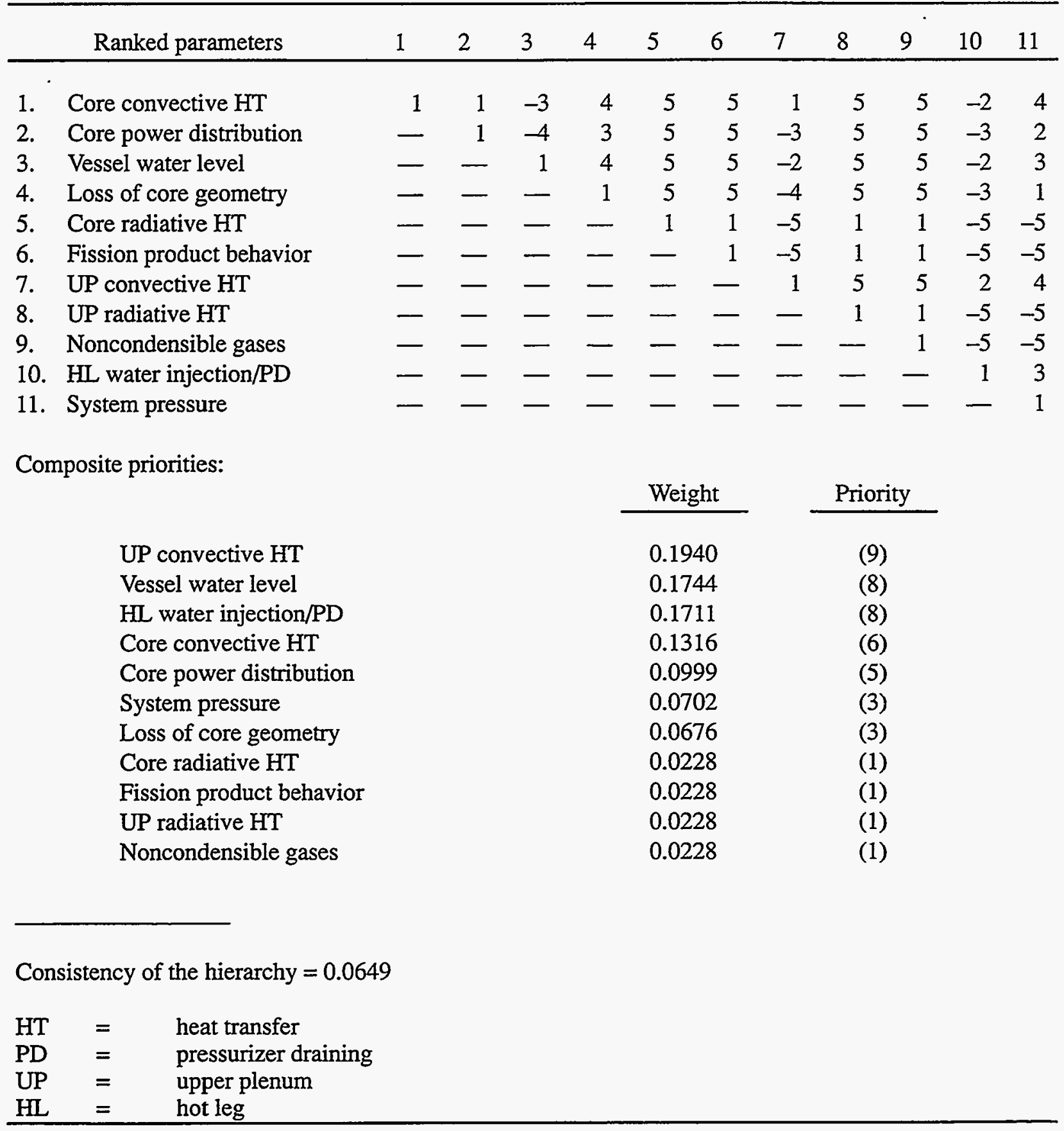

3. Vessel natural circulation for Westinghouse and CE-Phases III \& IV (Table A-4)

4. Vessel natural circulation for $B \& W-P h a s e$ I (Table A-5)
5. Vessel natural circulation for $B \& W-P h a s e$ II (Table A-6)

6. Vessel natural circulation for B\&WPhases III \& IV (Table A-7) 
Appendix A

Table A-3. Vessel natural circulation for Westinghouse and CE-Phase II.

\begin{tabular}{|c|c|c|c|c|c|c|c|c|c|c|c|}
\hline Ranked parameters & 1 & 2 & 3 & 4 & 5 & 6 & 7 & 8 & 9 & 10 & 11 \\
\hline Core convective HT & 1 & 1 & -4 & 4 & 3 & 4 & 1 & 4 & 4 & -2 & 4 \\
\hline Core power distribution & 一 & 1 & -4 & 3 & 1 & 4 & -3 & 4 & 4 & -3 & 2 \\
\hline Vessel water level & 一 & - & 1 & 4 & 3 & 4 & -2 & 4 & 3 & -2 & 3 \\
\hline Loss of core geometry & - & - & - & 1 & -2 & 4 & -4 & 4 & 2 & -3 & 1 \\
\hline Core radiative HT & - & - & - & - & 1 & 4 & -3 & 4 & 4 & -3 & -2 \\
\hline Fission product behavior & - & - & - & 一 & 一 & 1 & -4 & 1 & -2 & -4 & -3 \\
\hline UP convective HT & - & - & - & - & 一 & - & 1 & 4 & 4 & -2 & 4 \\
\hline UP radiative $\mathrm{HT}$ & - & - & - & - & - & - & - & 1 & -2 & -4 & -4 \\
\hline 9. Noncondensible gases & - & - & - & - & 一 & - & - & - & 1 & -4 & -4 \\
\hline 10. HL water injection/PD & 一 & - & - & - & - & - & - & - & - & 1 & 3 \\
\hline 11. System pressure & - & - & - & - & - & - & - & - & 一 & - & 1 \\
\hline
\end{tabular}

Composite priorities:

$\mathrm{HL}$ water injection/PD

$\underline{\text { Weight }} \underline{\text { Priority }}$

Vessel water level

0.1858

(9)

UP convective HT

0.1729

Core convective HT

0.1639

Core power distribution

0.1246

Core radiative HT

0.0866

System pressure

0.0687

Loss of core geometry

0.0652

Noncondensible gases

0.0511

(3)

Fission product behavior

0.0320

(2)

UP radiative $\mathrm{HT}$

0.0248

(1)

0.0244

Consistency of the hierarchy $=0.0731$
$\mathrm{HT}=$ heat transfer
$\mathrm{PD}=\quad$ pressurizer draining
$\mathrm{UP}=$ upper plenum
$\mathrm{HL}=$ hot leg

7. Lower head failure for Westinghouse and B\&W-Phase III (Table A-8)

8. Lower head failure for Westinghouse and B\&W-Phase IV (Table A-9)

9. Lower head failure for CE-Phase III (Table A-10)
10. Lower head failure for CE-Phase IV (Table A-11)

11. Hot leg natural circulation for Westinghouse and CE-All Phases (Table A-12)

12. Hot leg natural circulation for $B \& W-A l l$ Phases (Table A-13). 
Table A-4. Vessel natural circulation for Westinghouse and CE-Phases III and IV.

\begin{tabular}{|c|c|c|c|c|c|c|c|c|c|c|c|c|}
\hline & Ranked parameters & 1 & 2 & 3 & 4 & 5 & 6 & 7 & 8 & 9 & 10 & 11 \\
\hline 1. & Core convective HT & 1 & 1 & -3 & -2 & 1 & 2 & -2 & 3 & 5 & -3 & 4 \\
\hline 2. & Core power distribution & - & 1 & -4 & -2 & -2 & 3 & -3 & 4 & 5 & -4 & 3 \\
\hline 3. & Vessel water level & - & - & 1 & 3 & 4 & 5 & 2 & 4 & 5 & 1 & 4 \\
\hline 4. & Loss of core geometry & - & - & - & 1 & 3 & 4 & 2 & 4 & 5 & -4 & 4 \\
\hline 5. & Core radiative HT & - & - & - & - & 1 & 3 & -2 & 3 & 5 & -4 & 3 \\
\hline 6. & Fission product behavior & 一 & - & - & 一 & 一 & 1 & -3 & 2 & 2 & -5 & 3 \\
\hline 7. & UP convective HT & - & - & - & - & - & - & 1 & 4 & 4 & -3 & 4 \\
\hline 8. & UP radiative HT & - & - & - & - & - & - & - & 1 & 2 & -4 & 2 \\
\hline 9. & Noncondensible gases & - & - & - & - & - & - & - & - & 1 & -4 & -3 \\
\hline 10. & HL water injection/PD & - & - & - & - & - & - & - & - & - & 1 & 3 \\
\hline & System pressure & - & - & - & - & - & - & - & - & - & - & 1 \\
\hline
\end{tabular}

Composite priorities:

HL water injection/PD

Vessel water level

Loss of core geometry

UP convective HT

Core radiative HT

Core convective HT

Core power distribution

Fission product behavior

UP radiative $\mathrm{HT}$

System pressure

Noncondensible gases

$\begin{array}{lll}\text { Weight } & & \text { Priority } \\ 0.2155 & & (9) \\ 0.2001 & & (8) \\ 0.1265 & & (5) \\ 0.1106 & & (5) \\ 0.0765 & & (3) \\ 0.0745 & & (3) \\ 0.0703 & & (3) \\ 0.0402 & & (2) \\ 0.0326 & & (1) \\ 0.0314 & & (1) \\ 0.0217 & & (1)\end{array}$

Consistency of the hierarchy $=0.0637$

$\begin{array}{ll}\mathrm{HT}= & \text { heat transfer } \\ \mathrm{PD}= & \text { pressurizer draining } \\ \mathrm{UP}= & \text { upper plenum } \\ \mathrm{HL}= & \text { hot leg }\end{array}$

The AHP rankings were initially performed by a group that have expertise in severe accident behavior, severe accident analysis, and reactor safety analysis. These rankings were then reviewed by additional personnel with expertise in severe accident code development and modeling. The following personnel were used in the ranking process for the listed categories:
- Personnel that participated in rankings for vessel natural circulation for all plants and all phases (Categories 1, 2, 3, 4, 5, 6 on the above list):

C. A. Dobbe

D. J. Hanson

L. D. Schlenker 
Table A-5. Vessel natural circulation for B\&W-Phase I.

\begin{tabular}{|c|c|c|c|c|c|c|c|c|c|c|c|}
\hline Ranked parameters & 1 & 2 & 3 & 4 & 5 & 6 & 7 & 8 & 9 & 10 & 11 \\
\hline Core convective $\mathrm{HT}$ & 1 & 1 & -3 & 4 & 5 & 5 & 1 & 5 & 5 & -2 & \\
\hline Core power distribution & 一 & 1 & -4 & 3 & 5 & 5 & -4 & 5 & 5 & -3 & \\
\hline Vessel water level & - & - & 1 & 4 & 5 & 5 & -2 & 5 & 5 & -2 & \\
\hline Loss of core geometry & - & - & - & 1 & 5 & 5 & -5 & 5 & 5 & -3 & \\
\hline Core radiative $\mathrm{HT}$ & - & - & - & - & 1 & 1 & -5 & 1 & 1 & -5 & -5 \\
\hline Fission product behavior. & - & - & - & - & - & 1 & -5 & 1 & 1 & -5 & -5 \\
\hline UP convective HT & - & - & - & - & - & - & 1 & 5 & 5 & 2 & \\
\hline 8. UP radiative HT & - & - & - & - & 一 & - & - & 1 & 1 & -5 & -5 \\
\hline 9. Noncondensible gases & - & - & - & - & - & - & - & - & 1 & -5 & - \\
\hline 10. HL water injection/PD & - & - & - & - & - & - & - & - & - & 1 & \\
\hline 11. System pressure & 一 & - & - & - & - & - & - & - & - & - & \\
\hline
\end{tabular}

Composite priorities:

UP convective HT

$\underline{\text { Weight }} \underline{\text { Priority }}$

Vessel water level

0.2099

(9)

$\mathrm{HL}$ water injection/PD

0.1709

(7)

Core convective HT

0.1678

(7)

Core power distribution

0.1301

0.0967

(6)

System pressure

0.0683

Loss of core geometry

0.0658

Core radiative $\mathrm{HT}$

0.0226

UP radiative $\mathrm{HT}$

0.0226

Noncondensible gases

0.0226

Fission product behavior

0.0226

Consistency of the hierarchy $=0.0693$

$\mathrm{HT}=$ heat transfer

$\mathrm{PD}=$ pressurizer draining

$\mathrm{UP}=$ upper plenum

$\mathrm{HL}=$ hot leg

- Personnel that participated in rankings for lower head failure for all plants and all phases (Categories 7, 8, 9, 10 on the above list):

S. A. Chavez

C. A. Dobbe

D. H. Hanson

J. L. Rempe

L. D. Schlenker 
Table A-6. Vessel natural circulation for B\&W-Phase II.

\begin{tabular}{|c|c|c|c|c|c|c|c|c|c|c|c|}
\hline Ranked parameters & 1 & 2 & 3 & 4 & 5 & 6 & 7 & 8 & 9 & 10 & 11 \\
\hline Core convective HT & 1 & 1 & -4 & 4 & 3 & 4 & 1 & 4 & 4 & -2 & 4 \\
\hline Core power distribution & - & 1 & -4 & 3 & 1 & 4 & -4 & 4 & 4 & -3 & 2 \\
\hline Vessel water level & - & - & 1 & 4 & 3 & 4 & -2 & 4 & 3 & -2 & 3 \\
\hline Loss of core geometry & - & 一 & 一 & 1 & -2 & 4 & -5 & 4 & 2 & -3 & 1 \\
\hline Core radiative HT & - & - & - & - & 1 & 4 & -4 & 4 & 4 & -3 & -2 \\
\hline Fission product behavior & - & - & - & - & - & 1 & -5 & 1 & -2 & -4 & -3 \\
\hline UP convective HT & - & - & - & - & - & - & 1 & 5 & 4 & -2 & 5 \\
\hline UP radiative $\mathrm{HT}$ & - & - & - & - & - & - & - & 1 & -2 & -4 & -4 \\
\hline 9. Noncondensible gases & - & - & - & - & - & - & - & - & 1 & -4 & -4 \\
\hline 10. HL water injection/PD & - & - & - & 一 & 一 & 一 & 一 & - & - & 1 & 3 \\
\hline 11. System pressure & - & - & - & - & 一 & - & - & 一 & 一 & 一 & 1 \\
\hline
\end{tabular}

Composite priorities:

UP convective HT

$\mathrm{HL}$ water injection/PD

Vessel water level

Core convective HT

Core power distribution

Core radiative $\mathrm{HT}$

System pressure

Loss of core geometry

Noncondensible gases

Fission product behavior

UP radiative HT
Weight $\quad$ Priority
0.1857
0.1841
0.1682
0.1224
0.0832
0.0658
0.0627
0.0491
0.0315
0.0238
0.0234

(9)

(1)

Consistency of the hierarchy $=0.0756$
$\mathrm{HT}=$ heat transfer
$\mathrm{PD}=$ pressurizer draining
$\mathrm{UP}=$ upper plenum
$\mathrm{HL}=$ hot leg

- Personnel that participated in rankings for hot leg natural circulation for all plants and all phases (Categories 11 and 12 on the above list):
C. A. Dobbe
C. M. Allison
D. J. Hanson
L. J. Siefken.

L. D. Schlenker

- The following personnel were used to review the initial rankings: 
Appendix A

Table A-7. Vessel natural circulation for B\&W-Phases III and IV.

\begin{tabular}{|c|c|c|c|c|c|c|c|c|c|c|c|}
\hline Ranked parameters & 1 & 2 & 3 & 4 & 5 & 6 & 7 & 8 & 9 & 10 & 11 \\
\hline Core convective HT & 1 & 1 & -3 & -2 & 1 & 2 & -3 & 3 & 5 & -3 & 4 \\
\hline Core power distribution & - & 1 & -4 & -2 & -2 & 3 & -4 & 4 & 5 & -4 & 0 \\
\hline Vessel water level & - & - & 1 & 3 & 4 & 5 & 1 & 4 & 5 & 1 & 4 \\
\hline Loss of core geometry & - & - & - & 1 & 3 & 4 & 1 & 4 & 5 & -4 & A \\
\hline Core radiative $\mathrm{HT}$ & - & - & - & - & 1 & 3 & -3 & 3 & 5 & -4 & 3 \\
\hline Fission product behavior & - & - & - & - & - & 1 & -4 & 2 & 2 & -5 & 3 \\
\hline UP convective HT & - & - & 一 & 一 & - & - & 1 & 4 & 4 & -3 & 5 \\
\hline UP radiative $\mathrm{HT}$ & - & - & - & - & - & - & - & 1 & 2 & -4 & 2 \\
\hline Noncondensible gases & - & - & - & - & - & - & - & - & 1 & -4 & -3 \\
\hline 10. HL water injection/PD & 一 & - & - & 一 & 一 & - & 一 & 一 & 一 & 1 & 3 \\
\hline 11. System pressure & - & - & - & - & - & - & - & - & 一 & - & 1 \\
\hline
\end{tabular}

Composite priorities:

$\mathrm{HL}$ water injection/PD

Vessel water level

UP convective HT

Loss of core geometry

Core radiative $\mathrm{HT}$

Core convective HT

Core power distribution

Fission product behavior

UP radiative $\mathrm{HT}$

System pressure

Noncondensible gases
Weight $\quad$ Priority

0.2155

0.1859

0.1459

0.1161

0.0735

0.0716

0.0681

0.0389

0.0323

0.0305

0.0217
(9)

(1)

Consistency of the hierarchy $=0.0670$
$\mathrm{HT}=$ heat transfer
$\mathrm{PD}=$ pressurizer draining
$\mathrm{UP}=$ upper plenum
$\mathrm{HL}=$ hot leg

\section{A-5. CONCLUSIONS}

The parameters that have a major influence on natural circulation behavior in Westinghouse, $\mathrm{CE}$, and $B \& W$ PWRs following a severe accident have been identified and ranked. These evaluations were made by analysts who have experience in severe accident behavior and subsequently processed via a statistical program to provide the final rankings.

The parameters ranked for all twelve categories in Tables A-2 through A-13 were selected as the most important from a much longer list of parameters. Consequently, the lowest ranked 
Table A-8. Lower head failure for Westinghouse and B\&W-Phase III.

\begin{tabular}{lllllllllll}
\hline & $\quad$ Ranked parameters & 1 & 2 & 3 & 4 & 5 & 6 & 7 & 8 & 9 \\
\hline 1. & Corium power generation & 1 & 1 & -3 & -3 & -5 & -3 & 1 & -2 & 2 \\
2. & Corium power distribution & - & 1 & -4 & -4 & -5 & -4 & 2 & -2 & 2 \\
3. $\quad$ Corium thermal inertia & & - & - & 1 & 1 & -2 & 2 & 4 & -2 & 3 \\
4. $\quad$ Corium HT to coolant & - & - & - & - & 1 & -3 & 2 & 4 & -2 & 4 \\
5. $\quad$ Corium HT to lower head & - & - & - & - & - & 1 & 3 & 5 & 2 & 5 \\
6. & System pressure & - & - & - & - & - & 1 & 4 & -3 & 3 \\
7. $\quad$ Coolant-structure HT & - & - & - & - & - & - & 1 & -4 & 1 \\
8. $\quad$ Lower head HT to containment & - & - & - & - & - & - & - & - & 1 & 3 \\
9. $\quad$ Water-corium dead weight & & - & - & - & - & - & - & - & - & 1
\end{tabular}

Composite priorities:

Corium HT to lower head

Lower head HT to containment

Corium thermal inertia

Corium HT to coolant

System pressure

Corium power distribution

Corium power generation

Water-corium dead weight

Coolant-structure HT
Weight $\quad \underline{\text { Priority }}$

0.2649

(9)

0.1738

0.1401

0.1393

0.1063

0.0513

0.0508

0.0372

0.0362

Consistency of the hierarchy $=0.0401$

$\mathrm{HT}=$ heat transfer

parameters should not necessarily be considered to be unimportant for the selected top events. The rankings simply indicate an order of importance.

Results from parameter rankings for vessel natural circulation for Westinghouse and CE plants indicated that the effects of water addition to the hot leg and water levels in the core were consistently ranked high in influencing the conditions at the hot leg-vessel interface for all accident phases. The upper plenum heat transfer was also generally highly ranked for all phases while the core convective heat transfer was highly ranked only for Phases I and II. The loss of core geometry was ranked relatively low for accident Phases I and II but was ranked much higher for Phases III and IV because core relocation will change the heat transfer areas and flow resistance in the core region. The effects of fission products and noncondensible gases are consistently ranked low although they both become somewhat more important during Phases III and IV. 
Appendix A

Table A-9. Lower head failure for Westinghouse and B\&W-Phase IV.

\begin{tabular}{|c|c|c|c|c|c|c|c|c|c|c|}
\hline & . Ranked parameters & 1 & 2 & 3 & 4 & 5 & 6 & 7 & 8 & 9 \\
\hline 1. & Corium power generation & 1 & -3 & 1 & 1 & -2 & 2 & 5 & -2 & 5 \\
\hline 2. & Corium power distribution & - & 1 & 1 & 2 & -3 & 3 & 5 & 2 & 5 \\
\hline 3. & Corium thermal inertia & - & - & 1 & 1 & -3 & 3 & 4 & -2 & 3 \\
\hline 4. & Corium HT to coolant & - & - & - & 1 & -2 & 1 & 3 & -4 & 3 \\
\hline 5. & Corium HT to lower head & - & - & - & - & 1 & 3 & 5 & 1 & 5 \\
\hline 6. & System pressure & - & - & - & - & - & 1 & 3 & -4 & 4 \\
\hline 7. & Coolant-structure HT & - & - & - & - & - & - & 1 & -5 & -3 \\
\hline 8. & Lower head HT to containment & - & - & - & - & - & - & - & 1 & 5 \\
\hline 9. & Water-corium dead weight & - & - & - & - & - & - & - & - & 1 \\
\hline
\end{tabular}

Composite priorities:

Corium HT to lower head

$\underline{\text { Weight }} \underline{\text { Priority }}$

$\begin{array}{ll}\text { Lower head HT to containment } & 0.1871 \\ \text { Corium power distribution } & 0.1762 \\ \text { Corium thermal inertia } & 0.1076 \\ \text { Corium power generation } & 0.1022 \\ \text { Corium HT to coolant } & 0.0812 \\ \text { System pressure } & 0.0651 \\ \text { Water-corium dead weight } & 0.0341 \\ \text { Coolant-structure HT } & 0.0260\end{array}$

(1)

Consistency of the hierarchy $=0.0540$

$\mathrm{HT}=$ heat transfer

The rankings for vessel natural circulation for $\mathrm{B} \& \mathrm{~W}$ were similar to those for the Westinghouse and $C E$ plants with one exception. The upper plenum convective heat transfer was ranked slightly higher for the latter phases of the accident in the $B \& W$ plant design because the upper plenum geometry is more complex in these plants. This complex geometry would somewhat delay the transport of hot gases from the core region to the hot leg-vessel interface.

Results from the parameter rankings for lower head failure for Westinghouse and B\&W plants indicated that the parameters influencing heat transfer into and out of the lower head wall (corium heat transfer to lower head and vessel lower head-to-containment heat transfer) were ranked highest in both Phases III and IV. The parameters ranked below these two were somewhat different for the two phases reflecting that the material relocating during Phase $\mathrm{III}$ is primarily metallic, whereas the material relocating during Phase IV is primarily ceramic (fuel). The effects of the dead weight and the coolant to structure heat transfer were both ranked as having a relatively low influence on lower head failure for Phases III and IV.

The parameter rankings for lower head failure for $C E$ plants were only slightly different than the 
Table A-10. Lower head failure for CE-Phase III.

\begin{tabular}{|c|c|c|c|c|c|c|c|c|c|c|}
\hline & Ranked parameters & 1 & 2 & 3 & 4 & 5 & 6 & 7 & 8 & 9 \\
\hline 1. & Corium power generation & 1 & 1 & -3 & -3 & -4 & -3 & 1 & -3 & 2 \\
\hline 2. & Corium power distribution & 一 & 1 & -4 & -4 & -5 & -4 & 2 & -3 & 2 \\
\hline 3. & Corium sensible energy & - & - & 1 & 1 & -2 & 2 & 4 & -3 & 3 \\
\hline 4. & Corium HT to coolant & - & - & - & 1 & -2 & 2 & 4 & -3 & 4 \\
\hline 5. & Corium HT to lower head & - & 一 & - & - & 1 & 2 & 5 & 1 & 5 \\
\hline 6. & System pressure & 一 & - & 一 & - & 一 & 1 & 4 & -2 & 3 \\
\hline 7. & Coolant-structure HT & 一 & - & - & - & 一 & - & 1 & -4 & 1 \\
\hline 8. & Lower head HT to containment & 一 & - & - & - & 一 & - & - & 1 & 5 \\
\hline 9. & Water-corium dead weight & - & - & - & - & 一 & - & 一 & - & 1 \\
\hline
\end{tabular}

Composite priorities:

$\begin{array}{llll} & \text { Weight } & & \text { Priority } \\ \text { Lower head HT to containment } & & & \\ \text { Corium HT to lower head } & 0.2252 & & (9) \\ \text { Corium HT to coolant } & 0.2152 & & (9) \\ \text { Corium sensible energy } & 0.1402 & (5) \\ \text { System pressure } & 0.1365 & (5) \\ \text { Corium power generation } & 0.1136 & (4) \\ \text { Corium power distribution } & 0.0494 & (2) \\ \text { Coolant-structure HT } & 0.0487 & (2) \\ \text { Water-corium dead weight } & 0.0365 & (1)\end{array}$

Consistency of the hierarchy $=0.0326$

$\mathrm{HT}=$ heat transfer

rankings for Westinghouse and $\mathrm{B} \& \mathrm{~W}$ plants. The differences in ranking were because there are no instrument penetrations in the lower head of a $\mathrm{CE}$ plant, which would decrease the importance of parameters that affect this failure mechanism.

The parameter rankings for hot leg natural circulation for Westinghouse and $\mathrm{CE}$-all phases indicated that parameters that represent external influences on the natural circulation phenomena (e.g., hot leg water injection/pressurizer drainage, PORV operation, and steam generator secondary side conditions) were ranked as having the high- est influence on creep rupture failure of the hot leg. Parameters representing the hot leg phenomena, such as heat transfer and flow parameters, were ranked as being intermediate in importance, and the material properties and effects of fission products were ranked as having a lower importance. The rankings for the hot leg behavior in $\mathrm{B} \& W$ plants were similar to the Westinghouse and $C E$ plants although the order of the parameters representing the hot leg phenomena was slightly different because of differences in the geometry of the piping. 
Appendix A

Table A-11. Lower head failure for CE-Phase IV.

\begin{tabular}{|c|c|c|c|c|c|c|c|c|c|}
\hline Ranked parameters & 1 & 2 & 3 & 4 & 5 & 6 & 7 & 8 & 9 \\
\hline 1. Corium power generation & 1 & -3 & 2 & 1 & -2 & 2 & 5 & -3 & 5 \\
\hline Corium power distribution & 一 & 1 & 2 & 2 & -3 & 3 & 5 & -2 & 5 \\
\hline Corium thermal inertia & - & - & 1 & -2 & -4 & -2 & 2 & -3 & 1 \\
\hline Corium HT to coolant & - & - & - & 1 & -2 & 1 & 3 & -4 & 3 \\
\hline Corium HT to lower head & - & - & - & - & 1 & 3 & 5 & 1 & 5 \\
\hline System pressure & - & - & - & - & - & 1 & 3 & -2 & 4 \\
\hline 7. Coolant-structure HT & 一 & - & - & - & - & - & 1 & -5 & -3 \\
\hline 8. Lower head HT to containment & - & - & - & - & 一 & - & - & 1 & 4 \\
\hline 9. Water-corium dead weight & - & - & - & - & - & - & - & - & 1 \\
\hline
\end{tabular}

Composite priorities:

Corium HT to lower head Lower head HT to containment

Weight $\underline{\text { Priority }}$

Corium power distribution

0.2216

(9)

Corium power generation

0.2160

(9)

Corium HT to coolant

0.1615

(7)

0.1094

(4)

System pressure

0.0873

Corium thermal inertia

0.0847

Water-corium dead weight

0.0520

Coolant-structure HT

0.0396

0.0279

Consistency of the hierarchy $=0.0469$

$\mathrm{HT}=$ heat transfer 
Table A-12. Hot leg natural circulation for Westinghouse and CE-all phases.

\begin{tabular}{llllllllllllll} 
& Ranked parameters & 1 & 2 & 3 & 4 & 5 & 6 & 7 & 8 & 9 & 10 & 11 & 12 \\
\hline 1. & HL CC flow & 1 & -2 & 2 & 4 & 2 & -4 & -5 & 5 & 4 & -4 & -2 & -5 \\
2. & SG plenum mixing & - & 1 & 2 & 4 & 2 & -3 & -5 & 5 & 4 & -4 & -3 & -5 \\
3. & HL circumferential gradient & - & - & 1 & 3 & 2 & -4 & -5 & 4 & 4 & -5 & -4 & -5 \\
4. & Noncondensible gases & - & - & - & 1 & -3 & -5 & -5 & 2 & 3 & -5 & -5 & -5 \\
5. & Vapor-to-vapor HT & - & - & - & - & 1 & -3 & -5 & 4 & 4 & -5 & -5 & -5 \\
6. & Vapor-to-structure HT & - & - & - & - & - & 1 & -3 & 5 & 4 & -2 & -2 & -3 \\
7. & HL water injection/PD & - & - & - & - & - & - & 1 & 5 & 4 & 1 & 2 & 2 \\
8. & Fission products & - & - & - & - & - & - & - & 1 & 1 & -5 & -5 & -5 \\
9. & Material properties & - & - & - & - & - & - & - & - & 1 & -5 & -5 & -5 \\
10. & SG secondary side & - & - & - & - & - & - & - & - & - & 1 & 1 & -2 \\
11. & RCS pressure & - & - & - & - & - & - & - & - & - & - & 1 & -2 \\
12. & PORV operation & - & - & - & - & - & - & - & - & - & - & - & 1
\end{tabular}

Composite priorities:

$\begin{array}{lll}\text { HL water injection/PD } & 0.1909 & (9) \\ \text { PORV operation } & 0.1824 & (9) \\ \text { Steam generator secondary side } & 0.1460 & (7) \\ \text { Reactor coolant system pressure } & 0.1228 & (6) \\ \text { Vapor-to-structure HT } & 0.1011 & (5) \\ \text { Steam generator inlet plenum mixing } & 0.0595 & (3) \\ \text { HL countercurrent flow } & 0.0540 & (3) \\ \text { HL circumferential temperature gradient } & 0.0426 & (2) \\ \text { Vapor-to-vapor HT } & 0.0382 & (2) \\ \text { Noncondensible gases } & 0.0246 & (1) \\ \text { Material properties } & 0.0196 & (1) \\ \text { Fission product behavior } & 0.0183 & (1)\end{array}$

Consistency of the hierarchy $=0.0713$
$\mathrm{CC}=$ countercurrent
$\mathrm{HL}=$ hot leg
$\mathrm{HT}=$ heat transfer
$S G=$ steam generator
$\mathrm{PD}=$ pressurizer draining
$\mathrm{RCS}=\quad$ reactor coolant system 
Appendix A

Table A-13. Hot leg natural circulation for B\&W-all phases.

\begin{tabular}{|c|c|c|c|c|c|c|c|c|c|c|c|}
\hline Ranked parameters & 1 & 2 & 3 & 4 & 5 & 6 & 7 & 8 & 9 & 10 & 11 \\
\hline HL CC flow/turbulence & 1 & 4 & 4 & 2 & -4 & -5 & 5 & 3 & -4 & -2 & -5 \\
\hline HL cells, vertical & - & 1 & 2 & 1 & -5 & -5 & 3 & 1 & -5 & -4 & -5 \\
\hline Noncondensible gases & - & - & 1 & -3 & -5 & -5 & 2 & 2 & -5 & -4 & -5 \\
\hline Vapor-to-vapor HT & - & - & - & 1 & -4 & -5 & 3 & 2 & -5 & -4 & -5 \\
\hline Vapor-to-structure HT & - & - & - & - & 1 & -3 & 5 & 4 & -3 & 1 & -2 \\
\hline $\mathrm{HL}$ water injection/PD & - & 一 & - & - & - & 1 & 5 & 4 & 3 & 2 & -3 \\
\hline Fission product behavior & - & - & - & - & - & - & 1 & -2 & -5 & -5 & -5 \\
\hline Material properties & - & $\dot{-}$ & - & - & - & - & - & 1 & -5 & -5 & -5 \\
\hline SG secondary side & - & 一 & - & - & - & - & - & - & 1 & -2 & -3 \\
\hline 10. RCS pressure & - & - & - & - & - & - & - & - & - & 1 & -2 \\
\hline 11. PORV operation & - & - & - & - & - & - & - & - & $\longrightarrow$ & - & 1 \\
\hline
\end{tabular}

Composite priorities:

$\begin{array}{ll}\text { PORV operation } & 0.2261 \\ \text { HL water injection/PD } & 0.1895 \\ \text { Steam generator secondary side } & 0.1379 \\ \text { Reactor coolant system pressure } & 0.1225 \\ \text { Vapor-to-structure HT } & 0.1141 \\ \text { HL countercurrent flow/turbulence } & 0.0638 \\ \text { Vapor-to-vapor HT } & 0.0389 \\ \text { HL cells, vertical piping } & 0.0326 \\ \text { Noncondensible gases } & 0.0274 \\ \text { Material properties } & 0.0271 \\ \text { Fission product behavior } & 0.0200\end{array}$

$\underline{\text { Weight }} \underline{\text { Priority }}$

$0.2261 \quad(9)$

$0.1895 \quad(8)$

$0.1379 \quad(6)$

$0.1225 \quad$ (5)

0.1141

$0.0638 \quad(3)$

0.0389

$0.0326 \quad$ (1)

(1)

(1)

(1)

Consistency of the hierarchy $=0.0718$
$\mathrm{CC}=$ countercurrent
$\mathrm{HL}=$ hot leg
$\mathrm{HT}=$ heat transfer
$\mathrm{SG}=$ steam generator
$\mathrm{PD}=$ pressurizer draining
$\mathrm{RCS}=$ reactor coolant system 


\section{A-6. REFERENCES}

A-1. L. Saaty, Decision Making for Leaders, Pittsburgh, PA: University of Pittsburgh, 1988.

A-2. L. Saaty, Decision Making, The Analytic Hierarchy Process, Pittsburgh, PA: University of Pittsburgh, 1988.
A-3. G. E. Wilson, C. D. Wadsworth, and B. G. Miller, Component and Phenomena Based Ranking of Modeling Requirements for the NP-MHTGR Analysis Code Verification and Validation, Appendix F (Final Draft), EGGNPR-9704, EG\&G Idaho, Inc., June 1991.

A-4. J. N. Lillington and A. N. Lyons, "Detailed Flow Analysis for the Three Mile Island Unit 2 Reactor Accident," Nuclear Energy, 29, No. 4, August 1990, pp. 235-241. 


\section{Appendix B}

\section{Scaling Review of the Westinghouse Test Apparatus and Natural Circulation Experiments}





\section{Appendix B}

\section{Scaling Review of the Westinghouse Test Apparatus and Natural Circulation Experiments}

\section{SUMMARY}

This report reviews the methodology used to scale a Westinghouse four-loop plant to an experimental facility that is designed to provide data on natural circulation behavior. The purpose is to determine which tests provide the best representation of behavior in the full-scale plant. In assessing the scaling of the model, the effects of radiative heat transfer (neglected in a previous scaling analysis) have been included because the full-scale plant would reach higher pressures and temperatures than those encountered in the model. Moreover, a detailed scaling assessment of the Westinghouse high-pressure $\mathrm{SF}_{6}$ tests (not performed in an earlier analysis) has been included in this report. The approach has been to use an order-of-magnitude comparison of coefficients in the conservation equations. Areas of primary interest are the hot legs, the steam generators, the core region, and certain boundary conditions that may affect transient tests. Following is a brief summary of the findings.

1. Hot Leg Results-Thermal conditions in the hot leg countercurrent flow are not well simulated in either the water tests or the low-pressure $\mathrm{SF}_{6}$ tests. Higher heat transfer will occur between the two fluid streams in the full-scale plant because of radiative heat transfer. This tends to reduce the average temperature and density differences between the two streams, and hence the driving force for the countercurrent flow in the hot leg. Consequently, extrapolation of the model data to conditions in the full-scale plant may result in overprediction of the mass flow rate through the hot leg. At high Reynolds numbers (typical of the high $\mathrm{SF}_{6}$ tests), however, heat transfer from convection overwhelms radiation and the tests appear to be properly scaled even when the effects of radiative heat transfer are included.

2. U-Tube Steam Generator Results-Conversion from buoyant (potential) energy to kinetic energy in the model steam generator is a factor of 36 higher than that in the fullscale steam generator because of geometrical differences and the absence of radiative heat transfer in the model. Nonetheless, if the scaled steam generator is considered to be a boundary condition for the hot leg, the overall scaling is fairly good.

3. Core Results-Friction factors in the model core are a factor of two to three lower than those in the full-scale core for both vertical and horizontal directions. As a consequence, the natural circulation flow rate through the actual core will be lower than that predicted from the behavior of the model. The dominant flow resistance to natural circulation occurs in the vertical core segments. Consequently, distortion of the radial flow resistance will have a lesser effect on the model performance.

The combined radiation/convection term in the fluid energy equation is about two orders of magnitude higher in the core region of the full-scale plant than in the model because of the effects of radiative heat transfer. Therefore, the heating rate of the fluid in the actual core may be faster than the rate indicated by the Westinghouse data.

The ratio of the heated perimeter to the nonheated perimeter is a factor of 14 higher in the full-scale plant than in the model. As a result of this difference and the distortion in the radiation/convection coefficient, the scaled temperature in the heated region of the actual core may be lower than that of the model for the same heat source. 
4. Boundary Condition Results-The boundary conditions for the high-pressure $\mathrm{SF}_{6}$ tests are similar to those in the water and low-pressure $\mathrm{SF}_{6}$ tests. The thermal inertia of the upper plenum internals is about two orders of magnitude high, while that of the upper plenum core barrel is about one order of magnitude high in the model. This will cause these components to heat up more slowly compared to other components in a transient test. The difference in the thermal inertia of the upper plenum core barrel, however, is not critical because of the rela- tively small magnitude of its heat sink compared to the total heat dissipation.

Thermal inertia of the full-scale steam generator is well represented by that of the model steam generators.

5. Code Assessment Using The Westinghouse Data-The high-pressure $\mathrm{SF}_{6}$ tests provide the closest representation of natural circulation behavior in the full-scale plant. These tests are adequate for code assessment with the exception of the effects of radiative heat transfer in the core region. 


\section{NOMENCLATURE}

\section{Roman}

\begin{tabular}{|c|c|}
\hline A & area, $\mathrm{m}^{2}$ \\
\hline$c_{f}$ & friction coefficient \\
\hline $\mathrm{C}_{\mathrm{p}}$ & specific heat, J/(kg.K) \\
\hline $\mathrm{D}$ & diameter, $\mathrm{m}$ \\
\hline Ek & Eckert number \\
\hline $\mathrm{Eu}$ & Euler number \\
\hline $\mathrm{f}$ & friction factor \\
\hline $\mathrm{g}$ & gravitational acceleration, $\mathrm{m} / \mathrm{s}^{2}$ \\
\hline $\mathrm{Gr}$ & Grashof number \\
\hline $\mathrm{k}$ & thermal conductivity, $\mathrm{W} / \mathrm{m}-\mathrm{K}$ \\
\hline $\mathrm{K}$ & $\begin{array}{l}\text { loss coefficient due to } \\
\text { expansion/contraction }\end{array}$ \\
\hline $\mathrm{L}$ & length, $m$ \\
\hline $\mathrm{m}$ & mass flow rate, $\mathrm{kg} / \mathrm{s}$ \\
\hline $\mathbf{N}$ & number of tubes in steam generator \\
\hline $\mathrm{Nu}$ & Nusselt number \\
\hline $\mathrm{p}$ & perimeter, m \\
\hline $\mathbf{P}$ & pressure, $\mathrm{N} / \mathrm{m}^{2}$ \\
\hline $\operatorname{Pr}$ & Prandtl number \\
\hline Q & heat generation/removal rate, $\mathrm{W}$ \\
\hline $\mathrm{R}$ & Richardson number \\
\hline $\mathrm{Ra}$ & Rayleigh number \\
\hline $\operatorname{Re}$ & Reynolds number \\
\hline St & Stanton number \\
\hline $\mathrm{t}$ & time, $s$ \\
\hline $\mathrm{T}$ & temperature, $\mathrm{K}$ \\
\hline $\mathrm{u}$ & velocity in $\mathrm{x}$ direction, $\mathrm{m} / \mathrm{s}$ \\
\hline $\mathrm{v}$ & velocity in y direction, $\mathrm{m} / \mathrm{s}$ \\
\hline
\end{tabular}

$\mathrm{x}$ axial distance, $\mathrm{m}$

$\mathrm{y}$

Greek

$\beta \quad$ coefficient of thermal expansion, $\mathrm{K}^{-1}$

$\varepsilon \quad$ porosity

$\theta$ temperature difference, $\mathrm{K}$

H Planck mean absorption coefficient, $\mathrm{m}^{-1}$

$\lambda \quad$ eigenvalues

$\rho$ density, $\mathrm{kg} / \mathrm{m}^{3}$

$\sigma \quad$ Stefan-Boltzmann constant, $\mathrm{W} / \mathrm{m}^{2}-\mathrm{K}^{4}$

\section{Subscript}

c cross sectional

f fluid

h hydraulic

$\mathrm{H}$ heated

HL hot leg

$\mathrm{i}$ inlet or interfacial

$\mathrm{NH}$ non-heated

o outlet

S solid

SG steam generator

t total

v volumetric

w wall or wetted

$\mathrm{x} \quad$ vertical direction

y horizontal (radial) direction

\section{Superscript}

$*, * * \quad$ dimensionless quantities 


\section{B-1. INTRODUCTION}

During certain reactor accidents, natural circulation is a mechanism by which energy can be transferred from the core to other parts of the system such as the upper plenum, hot leg and steam generator. The magnitude and regional distribution of the natural circulation phenomenon and its heat transfer efficiency are of fundamental importance in assessing subsequent failure modes as shown in Reference B-1.

Recently, Westinghouse performed a series of tests with a $1 / 7$-scale mockup of a four-loop Westinghouse plant. ${ }^{\mathrm{B}-2, \mathrm{~B}-3}$ Experiments were carried out with water or $\mathrm{SF}_{6}$ as the working fluid at pressures and temperatures that were relatively low compared to those in the full-scale plant. Wassel et al. ${ }^{\mathrm{B}-4}$ conducted an independent scaling analysis for the Westinghouse experiments. Their analysis, however, did not examine possible distortions due to radiative heat transfer as pointed out by Ostrach ${ }^{B-5}$ and Viskanta. ${ }^{\text {B- }}$ Radiation becomes particularly important when one attempts to extrapolate the Westinghouse results to the thermal-hydraulic conditions in the fullscale plant, which is at a much higher temperature and pressure. Moreover, Wassel et al. ${ }^{\mathrm{B}-4}$ only considered scaling for the low-pressure tests because the high-pressure test results ${ }^{\mathrm{B}-3}$ were unavailable at the time.

To bridge this gap, an order-of-magnitude analysis is provided in this appendix to determine the relative importance of terms in the conservation equations governing the flow and heat transfer in selected components of the system. The objective is to determine which tests provide the best representation of behaviors in the full-scale plant. This analysis will help assess whether or not the distortion caused by radiative heat transfer is indeed a concern in the scaling. Also included in the appendix is a general scaling analysis that compares the magnitude of dominant terms in the full-scale plant to the Westinghouse model. Both low- and high-pressure tests by Westinghouse are included in the analysis. The primary areas examined in this report are
1. Countercurrent flow in the hot leg

2. Flow and heat transfer in the steam generators

3. Flow and heat transfer in the core

4. Boundary conditions such as thermal inertia of the heat sinks.

Scaling in these areas is discussed in Sections B-2 through B-5 of this appendix.

\section{B-2. COUNTERCURRENT FLOW IN THE HOT LEG}

An analysis of the hydrodynamics of countercurrent flow in the hot leg is presented in the FPI report. ${ }^{\mathrm{B}-4}$ Distortion from heat transfer, however, was not examined there. Heat transfer between the hot and cold streams of fluid tends to decrease the temperature and density difference, which is the main driving force of the flow. This is most relevant in the full-scale plant since the model does not have significant radiative heat transfer. Therefore, even though the FPI results appear to agree with the Westinghouse data, appropriate scaling between the full-scale plant and the experimental model still cannot be assured.

\section{B-2.1 Analysis}

If the wall-to-fluid and interfacial heat transfer coefficients are assumed to be the same, ${ }^{a}$ the energy equation for the two streams of fluid can be written

$$
\begin{aligned}
& \left(\dot{m} C_{p}\right)_{1} \frac{d T_{1}}{d x}=h p_{1}\left(T_{w}-T_{1}\right)+h p_{i}\left(T_{2}-T_{1}\right) \\
& \left(\dot{m} C_{p}\right)_{2} \frac{d T_{2}}{d x}=h p_{2}\left(T_{w}-T_{2}\right)+h p_{i}\left(T_{1}-T_{2}\right),
\end{aligned}
$$

where p's are the wetted perimeters and the subscripts 1,2 and i refer to the hot stream, cold

a. This is approximately true if mixing between the two streams is negligible and the velocities of the two streams are similar. 
stream and the interface, respectively. If it is also assumed that the hot leg cross-sectional flow area is roughly divided in half for each stream of fluid, ${ }^{b}$ the perimeters can be given by

$$
p_{1}=p_{2}=p=\pi D / 2 ; p_{i}=D \text {. }
$$

Unless condensation in the steam generator is taking place at very high rates, the steady-state flow rates of the two streams should be fairly similar, that is,

$$
\left(\dot{m} C_{p}\right)_{1}=-\left(\dot{m} C_{p}\right)_{2}=C
$$

The energy equations then may be rewritten as

$$
\begin{aligned}
& C \frac{d T_{1}}{d x}=h p\left(T_{w}-T_{1}\right)+h p_{i}\left(T_{2}-T_{1}\right) \\
& -C \frac{d T_{2}}{d x}=h p\left(T_{w}-T_{2}\right)+h p_{i}\left(T_{1}-T_{2}\right) .
\end{aligned}
$$

By defining the following temperature differences $^{c}$

$\theta_{1}=T_{1}-T_{w} ; \dot{\theta}_{2}=T_{2}-T_{w} ;$

$\theta=\left(\theta_{1}-\theta_{2}\right) ; \phi=\left(\theta_{1}+\theta_{2}\right)$,

adding and subtracting the two equations in Eq. (B-4) yield

$$
\begin{aligned}
& \frac{d \theta}{d x^{*}}=-\frac{h p L}{C} \phi=-\lambda_{1} \phi ; \\
& \frac{d \phi}{d x^{*}}=-\frac{h\left(p+2 p_{i}\right) L}{C} \theta=-\lambda_{2} \theta ; \\
& x^{*}=x / L,
\end{aligned}
$$

b. The FPI report ${ }^{\mathrm{B}-4}$ indicated that this condition is approximately true except for a very small region near the entrance and exit. It is also supported by observations in the Westinghouse experiments. ${ }^{\mathrm{B}-2, \mathrm{~B}-3}$

c. The pipe wall temperature $T_{w}$ is assumed to be the same for both halves of the hot leg. where the axial length has been normalized by the total length of the hot leg. Combining the two energy equations in Eq. (B-6) yields

$$
\frac{d^{2} \theta}{d x^{*^{2}}}=\lambda^{2} \theta ; \frac{d^{2} \phi}{d x^{*^{2}}}=\lambda^{2} \phi ; \lambda^{2}=\lambda_{1} \lambda_{2}
$$

If one employs the values of p's given in Eq. (B-2), the relationship between the eigenvalues can be approximated as

$$
\lambda^{2}=\lambda_{1} \lambda_{2} ; \lambda=\frac{3}{2} \lambda_{1}=\frac{2}{3} \lambda_{2} \quad .
$$

The solutions of Eq. (B-7) then can be given by

$$
\begin{aligned}
& \theta=A \cosh \left(\lambda x^{*}\right)+B \sinh \left(\lambda x^{*}\right) \\
& -\phi=\frac{3}{2} B \cosh \left(\lambda x^{*}\right)+\frac{3}{2} A \sinh \left(\lambda x^{*}\right),
\end{aligned}
$$

where $\mathrm{A}$ and $\mathrm{B}$ are two integration constants that must be determined later. Integrating $\mathrm{Eq}$. (B-9) yields the following average temperature difference

$$
\bar{\theta}=[A \sinh \lambda+B(\cosh \lambda-1)] / \lambda .
$$

At this point the coefficients $A$ and $B$ must be evaluated based on the inlet temperatures of the two streams. By examining the solutions in Eq. (B-9) and using the definitions in Eq. (B-5), it can be shown that

$$
\begin{aligned}
\theta_{1}= & \frac{1}{2}\left(A-\frac{3}{2} B\right) \cosh \left(\lambda x^{*}\right) \\
& +\frac{1}{2}\left(B-\frac{3}{2} A\right) \sinh \left(\lambda x^{*}\right) ; \\
\theta_{2}= & -\frac{1}{2}\left(A+\frac{3}{2} B\right) \cosh \left(\lambda x^{*}\right) \\
& -\frac{1}{2}\left(B+\frac{3}{2} A\right) \sinh \left(\lambda x^{*}\right) .
\end{aligned}
$$

Then, applying the inlet temperatures at $\mathrm{x}^{*}=0$ and $\mathrm{x}^{*}=1$ yields 


$$
\begin{aligned}
\left\{\begin{array}{l}
A \\
B
\end{array}\right\}= & \frac{4}{12 \cosh \lambda+13 \sinh \lambda} \\
\cdot & {\left[\begin{array}{rr}
2 \sinh \lambda+3 \cosh \lambda & -3 \\
-2 \cosh \lambda-3 \sinh \lambda & -2
\end{array}\right] } \\
& \left\{\begin{array}{l}
\theta_{i, 1} \\
\theta_{i, 2}
\end{array}\right\} .
\end{aligned}
$$

Substituting these coefficients into Eq. (B-10) results in

$$
\begin{aligned}
& \frac{\bar{T}_{1}-\bar{T}_{2}}{T_{i, 1}-T_{i, 2}} \\
& =\frac{4(2 \cosh \lambda+3 \sinh \lambda-2)}{\lambda(12 \cosh \lambda+13 \sinh \lambda)} .
\end{aligned}
$$

The above result is surprisingly compact. Simply stated, it means the average temperature difference (hence density difference) of the two streams is proportional to the difference in the inlet temperatures. At small $\lambda$ 's, the ratio in Eq. (B-13) approaches unity; at larger values of $\lambda$ it approaches zero. The next task is to obtain an estimate of these eigenvalues for both the full-scale plant and the Westinghouse model. The magnitude of $\lambda$ can be obtained from Eqs. (B-6) and (B-7) as

$\lambda=\frac{3}{2} \frac{h p L}{C}=6 \frac{L}{D} \frac{h\left(\pi D^{2} / 8\right)}{C}$.

The last fraction in the right-hand side of Eq. (B-14) contains the Stanton number such that Eq. (B-14) may be rewritten as

$\lambda=6 \frac{L}{D} S t$

Using the Reynolds analogy given by Petukhov ${ }^{\mathrm{B}-7}$ for turbulent duct flows, the Stanton number can be written as

$$
\begin{aligned}
& S t=\frac{c_{f} / 2}{1.07+12.7\left(\mathrm{Pr}_{e}^{2 / 3}-1\right) \sqrt{c_{f} / 2}} \\
& \frac{c_{f}}{2}=\frac{3.86 \times 10^{-2}}{\log _{10}^{2}(6.9 / \mathrm{Re})}
\end{aligned}
$$

However, Eq. (B-16) is only valid for Prandtl numbers between 0.7 and 1,000 . For lower Prandtl numbers $(\operatorname{Pr}<0.1)$ the following correlation is suggested by Sleicher and Rouse ${ }^{B-8}$

$$
\begin{aligned}
S t= & \left(6.3+0.0167 \operatorname{Re}^{0.85} \operatorname{Pr}_{e}^{0.93}\right) / \\
& \operatorname{Re} \operatorname{Pr}_{e} .
\end{aligned}
$$

The L/D ratio in the full-scale plant has been preserved in the Westinghouse model. Therefore, if similitude prevails in the hot leg, the Reynolds number must be assumed to be the same for both so that friction is properly scaled. In this work, a value $L / D=6^{\text {d }}$ will be used while the Reynolds number will be varied parametrically. Furthermore, care must be taken to include the effect of radiative heat transfer in Eqs. (B-16) and (B-17). Assuming that the gas is optically thick as suggested by Ostrach, ${ }^{\mathrm{B}-5}$ the effective Prandtl number can be given in terms of the conductionradiation parameter in Sparrow and $\mathrm{Cess}^{\mathrm{B}-9}$ as

$$
N=\frac{k \varkappa}{4 \sigma T^{3}} ; \operatorname{Pr}_{e}=\operatorname{Pr} /\left(1+\frac{4}{3 N}\right)
$$

For the Westinghouse tests, the fluid temperatures are quite low and radiation is relatively unimportant. As a consequence, the effective Prandtl number is essentially the molecular Prandtl number ( 0.8 for $\mathrm{SF}_{6}$ and 4.6 for water) in these tests. The temperature in the full-scale plant, however, is much higher. For steam at 160 bar and $1,000 \mathrm{~K}$, the effective Prandtl number is about a factor of 14 lower than the molecular Prandtl number, (i.e., $\mathrm{Pr}_{e}=0.07$ ). Table $\mathrm{B}-1$ shows the temperature difference ratio calculated by using Eqs. (B-13) and (B-15 through B-17). In the range of turbulent flow, the entrance length region is small enough to be ignored. However, the entrance length in laminar flow normally exceeds the $\mathrm{L} / \mathrm{D}$ ratio under consideration here. Hence, the correlation by Sieder and Tate ${ }^{B-10}$ will

d. Calculated from the dimensions found in References B-2 and B-3 to be between 6 and 7; a value of 6 is used here. 
Table B-1. Average temperature difference in the hot leg.

\begin{tabular}{cccc}
\hline & \multicolumn{3}{c}{$\Delta \overline{\mathrm{T}} / \Delta \mathrm{T}_{\mathrm{i}}$} \\
\cline { 2 - 4 } $\operatorname{Re}$ & $\begin{array}{c}\text { Full-scale } \\
\text { plant }\end{array}$ & $\underline{\mathrm{W} \mathrm{SF}_{6}}$ & $\underline{\mathrm{W} \text { water }}$ \\
\hline $10^{3}$ & 0.37 & 0.75 & 0.91 \\
$10^{4}$ & 0.71 & 0.90 & 0.96 \\
$10^{5}$ & 0.89 & 0.94 & 0.97 \\
$10^{6}$ & 0.93 & 0.96 & 0.98 \\
\hline & & & \\
$\mathrm{W}=$ & Westinghouse. & \\
\hline
\end{tabular}

be used in the laminar flow region to account for this effect

$$
\begin{aligned}
\overline{N u}= & 1.86\left(\frac{L / D}{\operatorname{RePr}}\right)^{-1 / 3} ; 0.5 \leq \operatorname{Pr} \leq 17,000 ; \\
& \left(\frac{\mathrm{L} / \mathrm{D}}{\operatorname{RePr}}\right) \leq \frac{1}{8} .
\end{aligned}
$$

The effective Prandtl number for the full-scale plant, however, is low enough such that the entrance length can be ignored and a value $\mathrm{Nu}=3.66$ will be used. From Table B- 1 it can be concluded that, as far as the hot leg countercurrent flow is concerned, some distortion can occur when results from Westinghouse tests are extrapolated to conditions in the full-scale plant. It is anticipated that the mass flow rates in the fullscale plant will be smaller than the values scaled up from the Westinghouse data, simply because the density difference is less than that projected by the data. The level of distortion from radiative heat transfer between the two streams, however, depends on the Reynolds number. At lower Reynolds numbers, radiation is a more dominant mode of heat transfer and the distortion is more prominent as shown in Table B-1. As the Reynolds number increases, the effect of radiation becomes less important, since convection is the dominant mode of heat transfer at high flow velocities. Consequently, the discrepancy in $\Delta \bar{T} / \Delta \mathrm{T}_{\mathrm{i}}$ between the full-scale plant and the experiment should diminish at higher Reynolds numbers as shown in Table B-1. The Reynolds number in the Westinghouse experiments is on the order of $10^{3}$ for water tests and low-pressure $\mathrm{SF}_{6}$ tests, and $10^{5}$ for the high-pressure $\mathrm{SF}_{6}$ tests. The Reynolds number in the high-pressure $\mathrm{SF}_{6}$ tests is sufficiently high so that radiation heat transfer should not result in significant distortions in the scaling.

\section{B-2.2 Comparison With Applicable Westinghouse Data}

Bearing in mind the relationship between the Reynolds number and the level of distortion from radiation as discussed earlier, a closer examination of the Westinghouse tests can now be made. Comparisons of Reynolds number and temperature difference ratio are provided in Tables B-2 through B-4. Because of a lack of documented flow rates in the hot leg, the flow rates were calculated using the following correlation, which was provided in the Westinghouse reports ${ }^{\mathrm{B}-2, \mathrm{~B}-3}$

$\dot{m}=0.1153 \bar{\varrho}\left(g \beta D^{5} \Delta T\right)^{1 / 2}$.

Also, the experimental data were not given in sufficient details to justify an integration of the fluid temperatures from the inlet to the exit. Therefore, the ratio $\Delta \bar{T} / \Delta T_{i}$ for the experiments has been approximated by

$\frac{\Delta \bar{T}}{\Delta T_{i}}=\frac{\frac{1}{2}\left(T_{i, 1}+T_{o, 1}\right)-\frac{1}{2}\left(T_{i, 2}+T_{o, 2}\right)}{T_{i, 1}-T_{i, 2}}$.

The experimental observations shown in Tables B-2 through B-4 appear to be in fairly good agreement with expected values shown in Table B-1. As far as countercurrent flow in the hot leg is concerned, the results obtained with water and low-pressure $\mathrm{SF}_{6}$ may have been incorrectly scaled because the Reynolds number is too small. However, tests conducted with highpressure $\mathrm{SF}_{6}$ have sufficiently high Reynolds numbers such that the scaling should be valid for the hot leg. 
Appendix B

Table B-2. Westinghouse water data.

\begin{tabular}{ccccccc}
\hline Test & $\begin{array}{c}\mathrm{T}_{\mathrm{i}, 1} \\
\left({ }^{\circ} \mathrm{C}\right)\end{array}$ & $\begin{array}{c}\mathrm{T}_{\mathrm{o}, 1} \\
\left({ }^{\circ} \mathrm{C}\right)\end{array}$ & $\begin{array}{c}\mathrm{T}_{\mathrm{i}, 2} \\
\left({ }^{\circ} \mathrm{C}\right)\end{array}$ & $\begin{array}{c}\mathrm{T}_{\mathrm{o}, 2} \\
\left({ }^{\circ} \mathrm{C}\right)\end{array}$ & $\operatorname{Re}$ & $\Delta \overline{\mathrm{T}} / \Delta \mathrm{T}_{\mathrm{i}}$ \\
\hline 5 & 34.6 & 34.4 & 10.8 & 12.4 & 2,390 & 0.96 \\
6 & 41.2 & 41.1 & 22.6 & 24.3 & 3,110 & 0.95 \\
7 & 43.0 & 42.9 & 20.3 & 21.1 & 3,380 & 0.98 \\
8 & 43.5 & 43.3 & 20.8 & 22.4 & 3,460 & 0.96 \\
9 & 36.5 & 35.3 & 17.9 & 19.4 & 2,550 & 0.93 \\
10 & 31.9 & 26.5 & 13.7 & 14.7 & 1,950 & 0.82 \\
\hline
\end{tabular}

Table B-3. Westinghouse low-pressure $\mathrm{SF}_{6}$ data.

\begin{tabular}{ccccccc}
\hline Test & $\begin{array}{c}\mathrm{T}_{\mathrm{i}, 1} \\
\left({ }^{\circ} \mathrm{C}\right)\end{array}$ & $\begin{array}{c}\mathrm{T}_{\mathrm{o}, 1} \\
\left({ }^{\circ} \mathrm{C}\right)\end{array}$ & $\begin{array}{c}\mathrm{T}_{\mathrm{i}, 2} \\
\left({ }^{\circ} \mathrm{C}\right)\end{array}$ & $\begin{array}{c}\mathrm{T}_{\mathrm{o}, 2} \\
\left({ }^{\circ} \mathrm{C}\right)\end{array}$ & $\operatorname{Re}$ & $\Delta \overline{\mathrm{T}} / \Delta \mathrm{T}_{\mathrm{i}}$ \\
\hline 13 & 53.1 & 43.2 & 17.8 & 22.5 & 3,880 & 0.79 \\
14 & 52.6 & 43.1 & 20.2 & 24.0 & 3,700 & 0.79 \\
15 & 54.8 & 45.0 & 22.4 & 25.7 & 3,640 & 0.80 \\
16 & 56.4 & 45.7 & 23.0 & 26.4 & 3,670 & 0.79 \\
17 & 43.8 & 36.6 & 25.6 & 26.9 & 2,810 & 0.77 \\
18 & 44.5 & 37.7 & 26.5 & 26.5 & 2,980 & 0.77 \\
\hline
\end{tabular}

Table B-4. Westinghouse high-pressure $\mathrm{SF}_{6}$ data.

\begin{tabular}{|c|c|c|c|c|c|c|}
\hline Test & $\begin{array}{c}\mathrm{T}_{\mathrm{i}, 1} \\
\left({ }^{\circ} \mathrm{C}\right)\end{array}$ & $\begin{array}{l}\mathrm{T}_{\mathrm{o}, 1} \\
\left({ }^{\circ} \mathrm{C}\right)\end{array}$ & $\begin{array}{l}\dot{\mathrm{T}}_{\mathrm{i}, 2} \\
\left({ }^{\circ} \mathrm{C}\right)\end{array}$ & $\begin{array}{l}\mathrm{T}_{\mathrm{o}, 2} \\
\left({ }^{\circ} \mathrm{C}\right)\end{array}$ & $\operatorname{Re}$ & $\Delta \overline{\mathrm{T}} / \Delta \mathrm{T}_{\mathrm{i}}$ \\
\hline$S-3$ & 107.4 & 100.4 & 58.6 & 59.2 & 49,700 & 0.92 \\
\hline$S-4$ & 138.5 & 129.3 & 66.0 & 67.2 & 55,400 & 0.93 \\
\hline$S-5$ & 142.6 & 134.3 & 68.6 & 70.0 & 52,200 & 0.93 \\
\hline S-6 & 138.5 & 129.7 & 64.6 & 65.9 & 61,700 & 0.93 \\
\hline S-7 & 116.7 & 110.7 & 60.8 & 62.2 & 76,100 & 0.93 \\
\hline S-8 & 117.8 & 113.8 & 70.4 & 71.2 & 85,300 & 0.95 \\
\hline S-9 & 146.6 & 138.6 & 66.9 & 68.2 & 76,700 & 0.94 \\
\hline$S-10$ & 119.5 & 114.1 & 59.5 & 60.3 & 106,400 & 0.95 \\
\hline S-11 & 135.8 & 130.4 & 81.5 & 82.0 & 100,900 & 0.95 \\
\hline HL-3 & 81.5 & 77.6 & 49.7 & 50.5 & 66,400 & 0.93 \\
\hline
\end{tabular}




\section{B-3. FLOW IN THE STEAM GENERATOR TUBE BUNDLE}

Natural convection in the steam generator is driven by density differences caused by cooling in the U-tubes. To examine the scaling of the flow, the energy and momentum equations must be considered simultaneously. In the following analysis, subscript 1 will be used to denote the tubes carrying the hot fluid from the inlet plenum to the outlet plenum and subscript 2 will be used to denote the tubes carrying the return flow.

\section{B-3.1 Momentum Equation}

The pressure drop through a pipe of length $L$ is given by

$$
\begin{aligned}
\Delta P= & \int_{L} \varrho g_{u} d x-\frac{1}{\varrho_{o}}\left(\frac{\dot{m}}{A}\right)^{2} \\
& \left(\frac{4 c_{f}}{2} \frac{L}{D}+\frac{K}{2}-\frac{\Delta \varrho}{\varrho_{o}}\right),
\end{aligned}
$$

where $c_{f}$ is the friction coefficient, $K$ is the total loss because of entrance and exit at the plena and $\mathrm{g}_{\mathrm{u}}$ is the gravitational component in the direction of the flow. The acceleration/deceleration term $\Delta \mathrm{Q} / \mathrm{Q}_{0}$ is about 0.04 for the high-pressure $\mathrm{SF}_{6}$ data and about 0.2 for the full-scale plant. In comparison, the frictional term is on the order of 6 for the high-pressure $\mathrm{SF}_{6}$ data and 14 for the full-scale plant. As a consequence, the acceleration/ deceleration term is negligible compared to friction and may be eliminated from the above equation

$$
\begin{gathered}
\Delta P=\int_{L} \varrho g_{u} d x-\frac{1}{\varrho_{o}}\left(\frac{\dot{m}}{A}\right)^{2} \\
\left(\frac{4 c_{f}}{2} \frac{L}{D}+\frac{K}{2}\right)
\end{gathered}
$$

By summing the above equation for both legs of the steam generator, one obtains

$$
\begin{aligned}
O= & \int_{1} \varrho g_{u} d x+\int_{2} \varrho g_{u} d x \\
& -\frac{1}{\varrho_{o}}\left(\frac{\dot{m}_{t}}{A_{t}}\right)^{2}\left[\frac{1}{\phi_{1}^{2}}\left(\frac{4 c_{f}}{2} \frac{L}{D}+\frac{K}{2}\right)_{1}\right. \\
& \left.+\frac{1}{\phi_{2}^{2}}\left(\frac{4 c_{f}}{2} \frac{L}{D}+\frac{K}{2}\right)_{2}\right],
\end{aligned}
$$

where the subscript $t$ refers to the total mass flow rate and cross section while $\phi$ 's are fractions of the total area occupied by the hot flow and the cold flow, respectively. From the high-pressure $\mathrm{SF}_{6}$ data, ${ }^{\mathrm{B}-3}$ the hot flow occupies about $30 \%$ of the total number of tubes in the steady state tests. The transient tests, ${ }^{\mathrm{B}-3}$ however, indicate that the total area is split about evenly between the hot flow and the cold flow. It should be noted that an even split results in minimum resistance and maximum flow rates through the steam generators.

\section{B-3.2 Energy Balance}

The energy equation for flow inside a pipe can be written as

$$
\begin{aligned}
\dot{m} C_{p} \frac{d T_{f}}{d x} & =-\frac{T_{f}-T_{w}}{R} ; \frac{d T_{f}}{T_{f}-T_{w}} \\
& =-\frac{L}{R \dot{m} C_{p}} d x^{*},
\end{aligned}
$$

where the axial distance has been normalized using the tube length $\mathrm{L}$. The thermal resistance $\mathrm{R}$ may include both the resistance of the tube wall and the resistance from convection within the tube. However, the tube wall thermal resistance is negligible compared to the convective resistance. As such, it will be ignored and the above equation may be rewritten as

$$
\begin{aligned}
\frac{d T_{f}}{T_{f}-T_{w}} & =-\lambda d x^{*} \quad ; \quad \lambda=\frac{\pi h D L}{\dot{m} C_{p}} \\
& =4 \frac{L}{D} S t
\end{aligned}
$$

It should be pointed out that the effect of radiation will be included in the above equation, since the Stanton number is calculated using the modified Prandtl number discussed in Section B-2, 
Eq. (B-18). If the wall temperature is assumed to be constant, the solution becomes

$$
T_{f}-T_{w}=\left(T_{i}-T_{w}\right) \mathrm{e}^{-\lambda x^{*}}
$$

where $T_{i}$ is the fluid temperature at the inlet. The above solution must be used to obtain the integrals in Eq. (B-24). If the density variation is assumed to be small, these integrals can be written as

$$
\begin{aligned}
\int_{L} \varrho g_{u} d x= & L \varrho_{o} \\
& \int_{L} g_{u}\left[1-\beta\left(T_{f}-\bar{T}\right)\right] d x^{*}
\end{aligned}
$$

Each U-tube in the steam generator now can be divided into two sections, each of length $L / 2$. The first section involves a rise of the hot fluid associated with a value $-\mathrm{g}$ for $\mathrm{g}_{\mathrm{u}}$, while the second section involves a fall of the cooler fluid, and a value of $+\mathrm{g}$ for $\mathrm{g}_{\mathrm{u}}$. As a consequence

$$
\begin{aligned}
\int_{L} g_{u} d x= & 0 \Rightarrow \int_{L} \varrho g_{u} d x \\
= & -L \beta \varrho_{o} \\
& \int_{L} g_{u}\left(T_{f}-T_{w}\right) d x^{*} .
\end{aligned}
$$

Evaluating the above integral results in

$$
\begin{aligned}
\int_{1+2} \varrho g_{u} d x= & L g \beta \varrho_{o} \\
& {\left[\left(T_{i, 1}-T_{w}\right) \frac{\left(1-e^{-\lambda_{1} / 2}\right)^{2}}{\lambda_{1}}\right.} \\
& \left.+\left(T_{i, 2}-T_{w}\right) \frac{\left(1-e^{-\lambda_{2} / 2}\right)^{2}}{\lambda_{2}}\right] .
\end{aligned}
$$

Since the eigenvalues are quite large, the temperature of the fluid returning to the inlet plenum should become very close to the wall temperature of the tubes. Consequently, the above equation can be approximated as

$$
\begin{aligned}
\int_{1+2} \varrho g_{u} d x= & L g \beta \varrho_{o}\left(T_{i}-T_{e}\right) \\
& \left\{\frac{\left(1-e^{-\lambda_{1} / 2}\right)^{2}}{\lambda_{1}}\right. \\
& \left.+\frac{e^{-\lambda_{1}\left(1-e^{-\lambda_{2} / 2}\right)^{2}}}{\lambda_{2}}\right\} \\
= & L g\left(\varrho_{e}-\varrho_{i}\right) \\
& \left\{\frac{\left(1-e^{-\lambda_{1} / 2}\right)^{2}}{\lambda_{1}}\right. \\
& \left.+\frac{e^{-\lambda_{1}\left(1-e^{-\lambda_{2} / 2}\right)^{2}}}{\lambda_{2}}\right\},
\end{aligned}
$$

where $\mathrm{L}$ is the average length of a U-tube while the subscripts $i$ and e refer to the inlet and exit conditions at the steam generator.

\section{B-3.3 Scaling of the Steam Generator}

The Richardson number is defined as a ratio between the potential energy caused by buoyancy and the resulting kinetic energy of the flow

$$
R=\frac{G r}{\operatorname{Re}^{2}}=\frac{L g \varrho_{o}\left(\varrho_{e}-\varrho_{i}\right)}{\left(\dot{m}_{t} / A_{t}\right)^{2}}
$$

Substituting Eq. (B-31) into Eq. (B-24) then yields

$$
R=\frac{\frac{1}{\phi_{1}^{2}}\left(\frac{4 c_{f}}{2} \frac{L}{D}+\frac{K}{2}\right)_{1}+\frac{1}{\phi_{2}^{2}}\left(\frac{4 c_{f}}{2} \frac{L}{D}+\frac{K}{2}\right)_{2}}{\frac{\left(1-e^{-\lambda_{1} / 2}\right)^{2}}{\lambda_{1}}+\frac{e^{-\lambda_{1}\left(1-e^{-\lambda_{2} / 2}\right)^{2}}}{\lambda_{2}}} .
$$

To predict the mass flow rate through the steam generators from the above equation, $\phi$ must be known a priori. Lacking this information, one may assume that the flow area is split evenly to produce the maximum flow rate through the steam generator. Equation (B-32) then becomes

$$
\begin{gathered}
R=\frac{4 \lambda\left(4 c_{f} \frac{L}{D}+K\right)}{\left(1+e^{-\lambda}\right)\left(1-e^{-\lambda / 2}\right)^{2}} \\
\lambda=4 \frac{L}{D} S t
\end{gathered}
$$


Assessment of the steam generator's scalability is difficult because of the differences in geometry between the model and the full-scale generators (for example, the number of U-tubes present). In light of this, the intended function of the steam generator will be examined. In general, the steam generator serves as a heat sink for natural convection through the loop. As such it provides one of the boundary conditions for the flow through the hot leg. High-pressure $\mathrm{SF}_{6}$ tests indicated that the total mass flow rate through the steam generator is about twice the mass flow rate through the hot leg because of mixing in the inlet plenum of the steam generator. Assuming that mixing in the inlet plenum is similar, this ratio of mass flow rates must also hold for the full-scale plant. Then the Reynolds number in the steam generator may be related to the Reynolds number through the hot leg by

$\operatorname{Re}_{S G}=2 \frac{D_{H L}}{N \cdot D_{S G}} \operatorname{Re}_{H L}$

Taking $10^{5}$ as a typical Reynolds number in the hot leg, Reynolds numbers in the full-scale and model steam generators become 2,200 and 12,000 , respectively. The flow thus is borderline laminar in the full-scale generator and turbulent in the model steam generator. Even though this may be sufficient to disqualify similarity in the steam generator model, the data will still be useful if the Richardson number in Eq. (B-34) turns out to be similar for the model and the full-scale steam generators. With the Reynolds numbers shown above, the Richardson number can be calculated to be 260 for the model and 9,360 for the full-scale steam generator. These represent a factor of 36 between the full-scale and the model generators indicating that conversion from buoyant energy to kinetic energy is more efficient in the experimental facility than in the plant. As a consequence, similarity between the model and the full-scale steam generators is not preserved. Nonetheless, similarity between the U-tube sections of the two generators is not the main objective in the Westinghouse tests. As mentioned earlier, the steam generator tube bundle serves as a boundary condition for the hot leg. As such, the appropriate concern should be the relationship between the driving buoyant force $\left(\mathrm{Gr}_{\mathrm{HL}}\right)$ and the resulting kinetic energy in the hot leg $\left(\operatorname{Re}^{2} \mathrm{HL}\right)$. In this context, the steam generator can be considered a black box whose input is the buoyant force and whose output is the resulting Reynolds number in the hot leg. As such, the parameter pertinent to the scalability of the Westinghouse experiments should be the Richardson number for the hot leg, $\mathrm{R}_{\mathrm{HL}}=\mathrm{Gr}_{\mathrm{HL}} / \mathrm{Re}^{2} \mathrm{HL}$, which may be obtained by substituting Eq. (B-35) into Eq. (B-32). Using values obtained earlier for the steam generators, the Richardson number for the hot leg is found to be 2.66E-04 for the model and $3.09 \mathrm{E}-04$ for the full-scale generator. This represents a difference of $16 \%$ between the model and the full-scale generators and a difference of $8 \%$ in the hot leg Reynolds number for the same Grashof number. It can thus be concluded that the scaling of the 216-tube steam generator as a boundary condition for the hot leg is fairly good even if similarity between the U-tube section of the model and the full-scale steam generators is not preserved.

\section{B-4. FLOW IN THE CORE}

The scaling in the core is based on an analysis similar to that by Wassel et al. ${ }^{\mathrm{B}-4}$ However, the characteristic quantities will be modified slightly to render the results more tractable. Moreover, radiative heat transfer in the full-scale plant will be incorporated in the scaling of the energy equations through the use of the modified Prandtl number, defined by Eq. (B-18). The scaling should be applicable to both sets of Westinghouse data (high-pressure and low-pressure). Following the FPI scaling rationale, ${ }^{\mathrm{B}-4}$ the characteristic velocity and temperature difference are given by

$\varrho_{o} C_{p o} U_{o} \Delta T_{o}=Q_{v} L_{o} ;$
$\varrho_{o} \beta \Delta T_{o} g L_{o}=f_{t}^{*} \varrho_{o} U_{o}^{2} / 2$,

where the modified friction factor $f^{*}{ }_{t}$ includes form drag caused by flow contraction and expansion

$f_{t}^{*}=\Sigma\left[K / \varepsilon^{2}+f\left(L / D_{h}\right) / \varepsilon^{2}\right]$. 
It should be pointed out that the characteristic velocity $U_{0}$ represents the superficial velocity through the core (i.e., it is calculated based on the total cross-sectional area of the flow). As such the friction factor $\mathrm{f}^{*}$ must be modified as shown in Eq. (B-37) to account for changes in area because of the presence of the solid in the core. Solving Eq. (B-36) yields

$$
\begin{aligned}
& U_{o}=\left(\frac{2 \beta g Q_{v} L_{o}^{2}}{\varrho_{o} C_{p o} f_{t}^{*}}\right)^{1 / 3} ; \\
& \Delta T_{o}=\left(\frac{f_{t}^{*} Q_{v}^{2} L_{o}}{2 \beta g\left(\varrho_{o} C_{p o}\right)^{2}}\right)^{1 / 3} .
\end{aligned}
$$

The reference pressure drop then can be defined as

$$
\Delta P_{o}=\varrho_{o} \beta \Delta T_{o g} L_{o}
$$

Velocity, pressure, temperature, axial length and time then can be scaled as

$$
\begin{aligned}
& u^{*}=\frac{u}{U_{o}} ; v^{*}=\frac{v}{U_{o}} ; P^{*}=\frac{P+\varrho_{o} g x}{\Delta P_{o}} ; \\
& \theta^{*}=\frac{T-T_{o}}{\Delta T_{o}} ; x^{*}=\frac{x}{L_{o}} ; t^{*}=\frac{t U_{o}}{\varepsilon L_{o}},
\end{aligned}
$$

where $u$ and $v$ are the superficial velocities in the $x$ and $y$ directions, and $\varepsilon$ is the porosity in the core.

\section{B-4.1 Momentum Equation}

Nondimensionalization of the momentum equation for all segments of the flow can now be made with the reference quantities shown above.

B-4.1.1 Vertical Segments. Using the Boussinesq approximation, the momentum equation in the vertical segments can be nondimensionalized as

$$
\begin{aligned}
\frac{\partial u^{*}}{\partial t^{*}}+u^{*} \frac{\partial u^{*}}{\partial x^{*}}= & -\operatorname{Eu}_{0} \frac{\partial P^{*}}{\partial x^{*}} \\
& +\mathrm{R}_{0} \theta^{*}-\frac{1}{2} f_{x}^{*}\left|u^{*}\right| u^{*},
\end{aligned}
$$

where the Euler number $\mathrm{Eu}_{0}$ and Richardson number $R_{0}$ are given by

$E u_{o}=\frac{\Delta P_{o}}{\varrho_{o} U_{o}^{2} / \varepsilon^{2}} ; R_{o}=\frac{G r_{o}}{\operatorname{Re}_{o}^{2} / \varepsilon^{2}} \quad$.

Substituting the reference pressure and temperature drop into $(B-40)$ yields

$E u_{o}=\frac{1}{2} \varepsilon^{2} f_{t}^{*} ; R_{o}=\frac{1}{2} \varepsilon^{2} f_{t}^{*}$

The momentum equation for the vertical segment of the flow then becomes

$$
\begin{aligned}
\frac{\partial u^{*}}{\partial t^{*}}+u^{*} \frac{\partial u^{*}}{\partial x^{*}}= & \frac{1}{2} \varepsilon^{2} f_{t}^{*}\left(-\frac{\partial P^{*}}{\partial x^{*}}+\theta^{*}\right) \\
& -\frac{1}{2} f_{x}^{*}\left|u^{*}\right| u^{*}
\end{aligned}
$$

The above equation implies that the momentum equation in the vertical segment is satisfactorily scaled only if the modified friction factors $\varepsilon^{2} \mathrm{f}^{*}$, and $f_{x}^{*}$ are the same for both the model and the full-scale cores. It should also be pointed out that the modified friction factor $\mathrm{f}^{*} \mathrm{x}$ must include the losses from expansion and contraction. Moreover, unlike $\mathrm{f}_{\mathrm{t}}^{*}, \mathrm{f}_{\mathrm{x}}^{*}$ is based on the absolute velocity of the flow instead of the superficial velocity.

B-4.1.2 Horizontal Segment. The dimensionless momentum equation for the horizontal segment of the flow can be written in a similar manner

$$
\begin{aligned}
\frac{\partial v^{*}}{\partial t^{*}}+v^{*} \frac{\partial v^{*}}{\partial y^{*}}= & -\frac{1}{2} \varepsilon^{2} f_{t}^{*} \frac{\partial P^{*}}{\partial y^{*}} \\
& -\frac{1}{2} f_{y}^{*}\left|v^{*}\right| v^{*},
\end{aligned}
$$

where the friction factor $f^{*} y$ in the horizontal direction again includes both frictional and form drags from contraction and expansion. This equation implies that the horizontal momentum equation is satisfactorily scaled if the friction factors $\varepsilon^{2} \mathrm{f}^{*}{ }_{\mathrm{t}}$ and $\mathrm{f}^{*} \mathrm{y}$ are similar for the full-scale and the model cores.

B-4.1.3 Scaling. As mentioned earlier, the momentum equation in the vertical segments is satisfactorily scaled only if both $\varepsilon^{2} \mathrm{f}^{*}{ }_{\mathrm{t}}$ and $\mathrm{f}_{\mathrm{x}}{ }_{\mathrm{x}}$ are 
similar for the model and the full-scale cores. Likewise, the momentum equation in the horizontal segment is satisfactorily scaled only if both $\varepsilon^{2} \mathrm{f}^{*}{ }_{t}$ and $\mathrm{f}^{*}{ }_{\mathrm{y}}$ are similar. Westinghouse ${ }^{\mathrm{B}-2, \mathrm{~B}-3}$ has tabulated their results on friction factors in the experiments for a Reynolds number of 5.0E+05 based on the bare rod bundle diameter. However, their values are different from $f^{*}{ }_{x}$ and $f^{*}{ }_{y}$ by a factor of $\varepsilon^{2}$ since their values are based on the superficial velocities in the core. The friction factors $\mathrm{f}^{*}{ }_{\mathrm{x}}$ and $\mathrm{f}^{*}{ }_{\mathrm{y}}$ deduced from the values published by Westinghouse are shown in Table B-5. These results indicate that the modified friction factors in the model are roughly a factor of 2 to 3 lower than those in the full-scale core. As a consequence, the natural circulation flow rate in the full-scale core will be lower than that expected in an extrapolation from the Westinghouse data. It should also be mentioned that the axial flow resistance is the dominant factor in the momentum equation as shown in Table B-5. As such, distortion in the radial flow resistance will have a lesser effect on the overall similarity between the Westinghouse model and the full-scale plant compared to a difference in the axial flow resistance.

\section{B-4.2 Fluid Energy Equation}

The energy balance for the fluid can be written in dimensionless form as

$$
\begin{aligned}
\frac{D \theta^{*}}{D t^{*}}= & E u_{o} E k_{o} \frac{D P^{*}}{D t^{*}}+S t \frac{A_{w}}{A_{f}} \\
& {\left[\left(\theta_{s, H}^{*}-\theta^{*}\right) \frac{p_{H}}{p_{t}}+\left(\theta_{s, N H}^{*}-\theta^{*}\right) \frac{p_{N H}}{p_{t}}\right], }
\end{aligned}
$$

where the subscripts $\mathrm{t}, \mathrm{H}$, and $\mathrm{NH}$ refer to the total, heated, and nonheated perimeters respectively; $A_{f}$ is the flow cross-section; $A_{w}$ is the total wetted area over the whole length; $\mathrm{D} / \mathrm{Dt}^{*}$ is the total derivative; $\mathrm{Ek}_{\mathrm{o}}$ is the Eckert number; and $S t$ is the Stanton number. Radiative heat transfer in the full-scale plant can be included in the above equation through the use of the previously defined modified Prandtl numberEq. (B-18) - in the calculation of the Stanton number.
The product $E u_{0} E k_{0}$ is roughly $10^{-5}$, while the product $S t A_{w} / A_{f}$ is between 0.2 and 100 . As such, the first term can be dropped from the above equation to yield

$$
\begin{aligned}
\frac{D \theta^{*}}{D t^{*}}= & S t \frac{A_{w}}{A_{f}}\left[\left(\theta_{s, H}^{*}-\theta^{*}\right) \frac{p_{H}}{p_{t}}\right. \\
& \left.+\left(\theta_{s, N H}^{*}-\theta^{*}\right) \frac{p_{N H}}{p_{t}}\right] .
\end{aligned}
$$

Similarity between the model and the full-scale cores thus requires that the product $S t \mathrm{~A}_{\mathrm{w}} / \mathrm{A}_{\mathrm{f}}$ and perimeter ratios be the same for both.

- These dimensionless coefficients are shown in Table B-6 for both the model and the full-scale reactors. Results indicate that heat transfer is more efficient in the full-scale plant than in the model since the product $S t \mathrm{~A}_{\mathrm{w}} / \mathrm{A}_{\mathrm{f}}$ for the full-scale plant is about 2 orders of magnitude higher than that for the model. Part of this difference is because of the inclusion of radiative heat transfer in the calculation of St as mentioned earlier. Under transient conditions, this difference leads to faster heating of the fluid in the full-scale plant compared to that in the model. Moreover, the ratio of heated perimeter to nonheated perimeter has not been properly scaled between the model and the full-scale plant. The higher ratio $\mathrm{pH}_{\mathrm{H}} / \mathrm{p}_{\mathrm{t}}$ in the full-scale core will result in a lower scaled temperature in the heated part there.

\section{B-4.3 Solid Energy Equation}

The energy equation for the solid must include both nonheated and heated regions. Therefore, it will be broken up into two equations-one for each region. The subscripts $\mathrm{H}$ and $\mathrm{NH}$ will again be used to denote the heated and nonheated regions, respectively.

B-4.3.1 Heated Solid Region. The energy equation for the heated region can be written as

$$
\begin{aligned}
\frac{\partial \theta_{s, H}^{*}}{\partial t^{*}}= & Q^{*}-S t^{*}\left(\theta_{s, H}^{*}-\theta^{*}\right) \\
& +k^{*} \frac{\partial^{2} \theta_{s, H}^{*}}{\partial x^{* 2}},
\end{aligned}
$$


Table B-5. Modified friction factors.

\begin{tabular}{cccc}
$f^{*}{ }_{x, \text { model }}$ & $f^{*}{ }_{x, \text { full-scale }}$ & $f^{*}{ }_{\text {,model }}$ & $f^{*}$,full-scale \\
\hline 7.6 & 18.8 & 1.9 & 3.7
\end{tabular}

Table B-6. Similarity in the fluid energy equation.

\begin{tabular}{ccl} 
Dimensionless group & Full-scale & Model \\
\hline $\mathrm{pH}_{\mathrm{H}} / \mathrm{p}_{\mathrm{t}}$ & 0.82 & 0.24 \\
$\mathrm{PNH} / \mathrm{p}_{\mathrm{t}}$ & 0.18 & 0.76 \\
$\mathrm{St}\left(\mathrm{A}_{\mathrm{w}} / \mathrm{A}_{\mathrm{f}}\right)$ & 90 & $0.19^{\mathrm{a}} / 0.48^{\mathrm{b}}$
\end{tabular}

\section{a. Water test. \\ b. Both sets of $\mathrm{SF}_{6}$ tests.}

where the heat source number $Q^{*}$, the combined radiation/convection term $\mathrm{St}^{*}$, and the axial conduction term $\mathrm{k}^{*}$ are defined as

$Q^{*}=\frac{Q_{v} A_{f} L_{o}^{2}}{m_{s, H} C_{p s, H} U_{\Delta} \Delta T_{o}} ;$

$S t^{*}=S t \frac{\varrho_{o} C_{p o} A_{w, S, H} L_{o}}{m_{s, H} C_{p s, H}} ;$

$k^{*}=\frac{\Sigma k_{s, H} A_{c, s, H}}{m_{s, H} C_{p s, H} U_{o} / \varepsilon}$.

The heat source number is basically a boundary condition and can be varied at will. Therefore, if similarity is to prevail the other two coefficients must be identical for the full-scale and the model cores. Closer scrutiny, however, reveals that the third coefficient (axial conduction) is about 2 to 6 orders of magnitude smaller than the second coefficient (convection/radiation). This implies that axial conduction in the solid is unimportant compared with convection and radiation. The third term can thus be dropped from the energy equation. This leaves only the second term, which must be matched between the model and the fullscale core. Table B-7 shows a comparison of the combined radiation/convection coefficient in the heated region. It should be pointed out that radiative heat transfer is included in this coefficient through the use of the modified Prandtl number in calculating the Stanton number. This term can be seen to be 9 to 3,300 times larger in the full-scale core. As such, heat transfer in the full-scale core is again much more efficient compared to the model. Eq. (B-47) shows that, as a result, the scaled rate of temperature rise in the heated part of the full-scale core may be lower than that of the model core, especially for the low-pressure $\mathrm{SF}_{6}$ tests.

B-4.3.2. Nonheated Solid Region. The energy equation for the nonheated solid region is very similar to that for the heated solid. However, there is no source term and one may write

$$
\frac{\partial \theta_{s, N H}^{*}}{\partial t^{*}}=-S t^{* *}\left(\theta_{s, N H}^{*}-\theta^{*}\right)+k^{* *} \frac{\partial^{2} \theta_{s N H}^{*}}{\partial x^{* 2}} .
$$

Again, the axial conduction term is very small compared to the combined radiation/convection term and can thus be discarded from the above equation.

A comparison of the combined radiation/ convection term for the model and the full-scale core is shown in Table B-8. Again, results show that heat transfer in the full-scale core is much more efficient than that in the model because of radiative heat transfer. The difference between the model and the full-scale core, however, is 
Table B-7. Similarity in the heated solid energy equation.

\begin{tabular}{lcccc}
\hline & Full-scale & $\underline{\text { W water test }}$ & $\underline{\text { W LP SF }}$ test & W HP SF 6 test \\
\hline $\mathrm{St}^{*}$. & 2.9 & 0.31 & $8.8 \mathrm{E}-04$ & $1.7 \mathrm{E}-02$ \\
\hline$\underline{\mathrm{W}}=$ & & & \\
\hline
\end{tabular}

Table B-8. Similarity in the nonheated solid energy equation.

\begin{tabular}{lcccc}
\hline & Full-scale & $\underline{\text { W Water test }}$ & $\underline{\text { W LP SF }}$ test & $\underline{\text { W HP SF }}$ test \\
\hline $\mathrm{St}^{* *}$ & 4.5 & 2.2 & $6.3 \mathrm{E}-03$ & $1.2 \mathrm{E}-01$ \\
\hline$\underline{\mathrm{W}}=$ & & & \\
\hline
\end{tabular}

about a factor of 2 to 720 , which is somewhat less severe than that observed in the heated solid region.

\section{B-5. BOUNDARY CONDITIONS}

Boundary conditions for the Westinghouse experiments involve the heat sinks in the upper plenum, the core barrel and the steam generator. A comparison of these terms for the water tests and low-pressure $\mathrm{SF}_{6}$ tests has been carried out in the FPI report, ${ }^{\mathrm{B}-4}$ where the heat sinks are nondimensionalized by

$$
Q^{*}=Q / Q_{v} L_{o}^{3}
$$

Table B-9 shows the relative magnitude of each heat sink compared to the heat generation rate in the core. Only the values for the full-scale plant are taken from the FPI report. ${ }^{B-4}$ The other values are calculated from the experimental data provided by Westinghouse. ${ }^{\mathrm{B}-2, \mathrm{~B}-3}$ The values calculated here for the water tests and low-pressure $\mathrm{SF}_{6}$ tests are very similar to those presented in the FPI report.

Results shown in Table B-9 indicate that the heat sink in the steam generator is well represented by the model. The heat sinks in the core barrel and the upper plenum, however, are much higher in the experimental model. This will result in atypically large predicted natural circulation flows if the test results are extrapolated to the fullscale plant. The heat sink of the core barrel, however, is small relative to that of the upper plenum. As such, a difference in this heat sink is not critical to the scalability of the experiments.

\section{B-6. CONCLUSIONS}

At low Reynolds numbers, radiative heat transfer is dominant in the full-scale plant. Consequently, the driving force for countercurrent flow in the hot leg (i.e., density and temperature differences) of the full-scale plant is not well simulated by the water and low-pressure $\mathrm{SF}_{6}$ tests, where no radiative heat transfer is present. As a result, extrapolation of experimental results to the fullscale plant will result in overprediction of the mass flow rate through the hot leg.

At high Reynolds numbers (typical of the Westinghouse high-pressure $\mathrm{SF}_{6}$ tests), convection is dominant in the hot leg and the countercurrent flow is properly scaled even when radiative heat transfer is included.

Conversion from buoyant energy to kinetic energy in the 216-tube model steam generator is a 
Appendix B

Table B-9. Scaling of boundary conditions.

\begin{tabular}{|c|c|c|c|c|}
\hline$Q^{*}$ & Full-scale & $\underline{\text { W Water test }}$ & $\underline{W} \mathrm{LP} \mathrm{SF}_{6}$ test & $\underline{\mathrm{W}} \mathrm{HP} \mathrm{SF}_{6}$ test \\
\hline Upper plenum & 1.6-3.3E-03 & 1.1-1.7E-01 & 2.6-3.0E-01 & $1.2-2.1 \mathrm{E}-01$ \\
\hline Steam generator & $9.8 \mathrm{E}-03$ & 2.8-7.3E-02 & $0.68-1.2 \mathrm{E}-02$ & $3.2-6.0 \mathrm{E}-02$ \\
\hline Core barrel & $0.24-2.1 \mathrm{E}-03$ & $3.6-5.9 \mathrm{E}-02$ & 7.9-9.3E-02 & $3.4-7.9 \mathrm{E}-02$ \\
\hline
\end{tabular}

factor of 36 higher than that in the full-scale U-tube steam generator tube bundle. This is because of:

- Geometrical differences that arise from scaling compromises necessary in fabricating the model steam generator such as the number and diameter of the U-tubes.

- Higher radiative heat transfer in the fullscale generator resulting in smaller temperature-induced buoyancy.

In spite of these differences, it is found that scaling of the steam generator as a boundary condition for the hot leg is fairly good since a similar mass flow through the hot leg $\left(\mathrm{Re}_{\mathrm{HL}}\right)$ is produced by a similar driving force $\left(\mathrm{G}_{\mathrm{HL}}\right)$.

The friction factors in the model core design are a factor of 2 to 3 lower than those in the actual core. As a consequence, the natural circulation flow rate through the full-scale core will be lower than that expected in an extrapolation from the Westinghouse data. Moreover, the dominant friction factor is that in the vertical segment of the flow. As such, distortion in the radial flow resistance will have a lesser effect on the overall similarity between the full-scale core and the Westinghouse model compared to a difference in axial resistance.

The work done by pressure force and the axial conduction terms in the energy equation of the core are very small compared to the combined radiation/convection term. As such, differences in the dimensionless coefficients associated with these terms present very little if any distortion to the scaling.

In the core region, the scaled radiative/ convective heat transfer from the heated solid to the fluid is about 2 orders of magnitude higher in the full-scale plant than in the model because of the effects of radiative heat transfer. Therefore, the actual heating of the fluid in the full-scale core may be faster than that indicated by the Westinghouse data. Accordingly, the scaled rate of temperature rise in the full-scale core compared to that in the model core may be lower for the heated solid and higher for the nonheated solid.

The ratio of heated perimeter over nonheated perimeter is a factor of 14 higher in the actual core than in the model. As a result, the scaled temperature in the heated region of the actual core may be lower than that of the model for the same heat source number.

The thermal inertia of the upper plenum internals is about 2 orders of magnitude higher in the model than in the full-scale plant. This may result in overprediction of the natural convection flow rate if the test results are extrapolated to the fullscale plant.

The thermal inertia of the upper plenum core barrel is about 1 order of magnitude higher in the model than in the full-scale plant. However, this difference is not critical since the core barrel represents only a small part of the total heat dissipated in the core.

The thermal inertia of the actual steam generators is well represented by that of the model steam generators. 
The high-pressure $\mathrm{SF}_{6}$ tests provide the closest representation of natural circulation behavior in the full-scale plant. These tests are adequate for code assessment with the exception of the effects of radiative heat transfer in the core region.

\section{B-7. REFERENCES}

B-1. P. D. Bayless, Analyses of Natural Circulation During a Surry Station Blackout Using SCDAP/RELAP5, NUREG/CR-5214, 1988.

B-2. W. A. Stewart et al., Experiments on Natural Circulation in a Pressurized Water Reactor Model for Degraded Core Accidents, Final Report, EPRI Project No. RP2177-5, 1990.

B-3. W. A. Stewart et al., Experiments on Natural Circulation in a Pressurized Water Reactor Model With High-Pressure SF6, Draft EPRI Report, 1990.

B-4. A. T. Wassel et al., Modeling of Natural Circulation in Reactor Coolant System, FPI R88-05-04, 1988.

B-5. S. Ostrach, "COMMIX Code ReviewLDS-3-90," R. J. Dallman letter to L. M.
Shotkin, RJD-38-90, Transmittal of COMMIX Code Review, Enclosure 5, September 27, 1990.

B-6. R. Viskanta, "Review of COMMIX Computer Code," R. J. Dallman letter to L. M. Shotkin, RJD-38-90, Transmittal of COMMIX Code Review, Enclosure 7, September 27, 1990.

B-7. B. S. Petukhov, "Heat Transfer and Friction in Turbulent Pipe Flow With Variable Physical Properties," Advances in Heat Transfer, 6, J. P. Harnett and T. F. Irvine, Jr. (eds.), New York: Academic Press, 1970.

B-8. C. A. Sleicher and M. W. Rouse, "A Convenient Correlation for Heat Transfer to Constant and Variable Property Fluids in Turbulent Pipe Flow," International Journal of Heat \& Mass Transfer, 18, 1975.

B-9. E. M. Sparrow and R. D. Cess, Radiation Heat Transfer, Brooks/Cole, Belmont, California, 1970.

B-10. E. N. Sieder and C. E. Tate, "Heat Transfer and Pressure Drop of Liquids in Tubes." Industrial and Engineering Chemistry, 28, 1963. 


\section{Appendix C \\ Reevaluation of Scaling Considerations for the Westinghouse 1/7-Scale PWR Experiments}




\section{Appendix C}

\section{Reevaluation of Scaling Considerations for the Westinghouse 1/7-Scale PWR Experiments \\ NOMENCLATURE}

\begin{tabular}{|c|c|c|c|c|c|}
\hline$A_{f}$ & $=$ & flow cross sectional area, $\mathrm{m}^{2}$ & $\mathrm{Nu}_{\mathrm{c}}$ & $=$ & convective Nusselt number \\
\hline$A_{w}$ & $=$ & wetted surface area, $\mathrm{m}^{2}$ & $\mathrm{Nu}_{\mathrm{R}}$ & $=$ & radiative Nusselt number \\
\hline $\mathrm{B}_{\mathrm{v}}$ & $=$ & spectral black body radiosity & $\mathrm{Nu}_{\mathrm{T}}$ & $=$ & total Nusselt number \\
\hline & $=$ & $\frac{2 \pi h c^{2} v^{3}}{\exp (h c v / k T)-1}$ & $q_{c}^{\prime \prime}$ & $=$ & convective heat flux, $\mathrm{W} / \mathrm{m}^{2}$ \\
\hline & & {$[W$} & $q_{R}^{\prime \prime}$ & $=$ & radiative heat flux, $\mathrm{W} / \mathrm{m}^{2}$ \\
\hline & & {$\left[\overline{m^{2}} \mathrm{~cm}^{-1}\right]$} & $\mathrm{Pr}_{\mathrm{e}}$ & $=$ & effective Prandtl number \\
\hline c & $=$ & speed of light, $\mathrm{m} / \mathrm{s}$ & $\mathrm{R}$ & $=$ & pipe radius, $\mathrm{m}$ \\
\hline $\mathrm{C}_{\mathrm{f}}$ & $=$ & skin friction coefficient & $\mathrm{R}_{\mathrm{t}}$ & $=$ & turbulent Reynolds number \\
\hline $\mathrm{C}_{\mathrm{p}}$ & $=$ & specific heat, $\mathrm{J} /(\mathrm{kg} \cdot \mathrm{K})$ & $\operatorname{Re}_{\mathrm{D}}$ & $=$ & pipe Reynolds number \\
\hline $\mathrm{D}$ & $=$ & pipe diameter, $m$ & $\mathrm{Ri}$ & $=$ & Richardson number \\
\hline g & $=$ & gravitational constant, $\mathrm{m} / \mathrm{s}^{2}$ & St & $=$ & Stanton number \\
\hline h & $=$ & Planck's constant, J s & $\mathrm{St}^{*}$ & $=$ & $\begin{array}{l}\text { transient heat conduction parame- } \\
\text { ter, heated structures, Eq. (C-10) }\end{array}$ \\
\hline$k_{\text {eff }}$ & $=$ & $\begin{array}{l}\text { Boltzmann constant, J/K } \\
\text { effective thermal conductivity, } \\
\mathrm{W} / \mathrm{m} \mathrm{K}\end{array}$ & $\mathrm{St}^{* *}$ & $=$ & $\begin{array}{l}\text { transient heat conduction parame- } \\
\text { ter, unheated structures, Eq. (C-11) }\end{array}$ \\
\hline $\mathrm{k}_{\mathrm{m}}$ & $=$ & $\begin{array}{l}\text { gas molecular thermal conductiv- } \\
\text { ity, W/m K }\end{array}$ & $\begin{array}{l}\mathrm{T} \\
\mathrm{T}_{\mathrm{w}}\end{array}$ & $\begin{array}{l}= \\
=\end{array}$ & $\begin{array}{l}\text { temperature, } \mathrm{K} \\
\text { wall temperature, } \mathrm{K}\end{array}$ \\
\hline $\mathrm{L}_{\mathrm{o}}$ & $=$ & $\begin{array}{l}\text { characteristic height of core region, } \\
\text { m }\end{array}$ & $\mathrm{T}_{\mathrm{b}}$ & $=$ & fluid bulk temperature, $K$ \\
\hline $\mathrm{m}_{\mathrm{s}, \mathrm{h}}$ & $=$ & mass of heated solid, $\mathrm{kg}$ & & $=$ & inlet temperature of hot fluid, $\mathrm{K}$ \\
\hline$N$ & $=$ & conduction-radiation parameter & $\mathrm{T}_{\mathrm{i}, 2}$ & $=$ & inlet temperature of cold fluid, $\mathrm{K}$ \\
\hline $\mathrm{N}_{\mathrm{mm}}$ & $=$ & $\begin{array}{l}\text { radiation to molecular conductance } \\
\text { ratio }\end{array}$ & $\begin{array}{l}\bar{T}_{1} \\
\bar{T}_{2}\end{array}$ & $\begin{array}{l}= \\
=\end{array}$ & $\begin{array}{l}\text { mean temperature of hot fluid, } \mathrm{K} \\
\text { mean temperature of cold fluid, } \mathrm{K}\end{array}$ \\
\hline
\end{tabular}


Appendix C

Greek

$\alpha_{i}=$ integrated band intensity,

$$
\left[\frac{\mathrm{cm}^{-1}}{\mathrm{~kg} / \mathrm{m}^{2}}\right] \text {. }
$$

$\beta=$ volumetric thermal expansion coefficient, $\mathrm{K}^{-1}$

$\eta=$ nongrayness factor

$x \quad=\quad$ Planck mean absorption coefficient, $\mathrm{m}^{-1}$
$x_{R}=$ Rosseland mean absorption coefficient, $\mathrm{m}^{-1}$

$\lambda=$ eigenvalue related to Stanton number, Eq. (C-7) and (C-8)

$\rho \quad=\quad$ gas density, $\mathrm{kg} / \mathrm{m}^{3}$

$v \quad=\quad$ wavenumber, $\mathrm{cm}^{-1}$

$\sigma=$ Stefan-Boltzmann constant, $\left[\mathrm{W} / \mathrm{m}^{2} \mathrm{~K}^{4}\right]$

$\tau_{R}=$ optical depth of the tube radius

$\omega_{i}=$ band wing decay width parameter, $\mathrm{cm}^{-1}$ 


\section{C-1. INTRODUCTION}

During certain hypothetical pressurized water reactor (PWR) severe accident scenarios such as a TMLB' sequence (loss of both onsite and offsite power), a high-pressure boiloff of primary fluid can occur and natural circulation flows of highpressure steam can become established in various regions of the reactor coolant system. Heat transfer during this type of hypothetical high-pressure accident transient is characterized by natural circulation of steam upward through the center of the core region and downward through the core outer periphery, distributing decay heat throughout the reactor vessel. In addition, for Westinghouse designs, countercurrent flow of steam through the hot leg allows for convective transport of thermal energy from the core to the steam generator tubes and other primary system components, delaying core heatup and potentially leading to primary system depressurization because of failure of an ex-vessel component such as the surge line. Passive system depressurization through this mechanism would prevent a highpressure failure of the reactor pressure vessel, thereby minimizing the potential for direct containment heating. Analysis of the scenario is complicated by several factors including complex three-dimensional geometry, turbulent natural convection coupled with transient heat conduction in the various solid structures, and radiation heat transfer with a participating gas.

Natural circulation experiments were performed by Westinghouse $\mathrm{C}^{\mathrm{C}}, \mathrm{C}-2$ using a $1 / 7$-scale model of a reactor coolant system. The model included a scaled reactor pressure vessel, two hot legs and two steam generators. While some scaling distortions were present in the model, the experiments did demonstrate the existence and the robustness of the natural circulation flows described above. An independent scaling review of the first phase of the Westinghouse experiments in which water and low-pressure $\mathrm{SF}_{6}$ were used as working fluids was performed by Wassel et al. ${ }^{\mathrm{C}-3}$ This analysis did not consider possible scaling distortions associated with the fact that radiation heat transfer plays a significant role in the full-scale plant accident scenario. The Wassel report also did not consider the results of the second phase of the Westinghouse experiments in which high-pressure $\mathrm{SF}_{6}$ was employed as the working fluid. To address these issues, an additional scaling report was prepared by Vu Tung (Appendix B), in which estimates of radiation heat transfer were included for the full-scale plant and comparisons of scaling parameters were made with all of the Westinghouse tests, including the high-pressure $\mathrm{SF}_{6}$ tests. This scaling report was reviewed by an external committee consisting of Professors R. Viskanta, S. Ostrach, and P. Griffith. The reviewers found the treatment of radiation heat transfer in this report to be inadequate and recommended that a more detailed approach be used. This reevaluation report was prepared with the objective of providing a more adequate treatment of radiation heat transfer and its impact on scaling of the Westinghouse experimental results.

\section{C-2. EFFECTIVE THERMAL CONDUCTIVITY APPROACH}

A scaling review of the Westinghouse $1 / 7$-scale test apparatus was prepared by Vu Tung (Appen$\operatorname{dix} B$ ) to assess the usefulness of the Westinghouse data for modeling events in a full-scale plant and/or for code validation. This review included consideration of radiation heat transfer in the full-scale plant and included comparisons of estimated scaling parameters for the full-scale plant, the low-pressure water and $\mathrm{SF}_{6}$ tests, and the high-pressure $\mathrm{SF}_{6}$ tests. All of the Westinghouse tests were performed at low enough temperatures such that radiation did not play a significant role in the transport processes. In the full-scale plant, however, surface and steam temperatures during the natural circulation portion of the transient may exceed $1,500 \mathrm{~K}^{\mathrm{C}-4}$ before core relocation. Consequently, radiation contributes significantly to energy transport to and from the steam which, for a high-pressure accident sequence, behaves as a participating gas. An effective thermal conductivity approach was used by Tung in conjunction with convective heat transfer correlations in order to estimate the effect of combined convection plus radiation during the 
natural circulation portion of a high-pressure severe accident scenario. This approach was based on the assumption that the high-pressure steam behaves as an optically thick gas which means that radiation heat transfer in the gas is analogous to molecular diffusion. In his scaling report, Tung used an effective thermal conductivity ratio, $\mathrm{k}_{\text {eff }} / \mathrm{k}$ equal to 14 for steam at $1,000 \mathrm{~K}$ and 160 bar. This ratio is defined in Reference $\mathrm{C}-5$ by

$$
\frac{k_{e f f}}{K_{m}}=1+\frac{4}{3 N},
$$

where the conduction-radiation parameter, $\mathrm{N}$, is given by

$$
N=\frac{k_{m} \varkappa}{4 \sigma T^{3}} .
$$

As a first step in reevaluating Tung's scaling report, $\mathrm{k}_{\mathrm{eff}} / \mathrm{k}_{\mathrm{m}}$ was calculated as a function of gas temperature using Eq. (C-1) and (C-2). Data for $x$ for $\mathrm{H}_{2} \mathrm{O}$ at 1 atmosphere were taken from Reference $\mathrm{C}-5$ and multiplied by $\mathrm{p} / \mathrm{p}_{\mathrm{atm}}$ ( $x$ is proportional to gas pressure). Thermal conductivity of steam at 160 bar was obtained from Reference C-6. Results are presented in Figure C-1.

The effective thermal conductivity is obviously a strong function of temperature. At $1,000 \mathrm{~K}$, a value of 4.1 was obtained for $\mathrm{k}_{\text {eff }} / \mathrm{k}_{\mathrm{m}}$ instead of 14. Apparently, a value of 14 was obtained by Tung from Reference C-7 and used throughout his analysis. A value of $k_{\text {eff }} / k_{m}$ equal to 14 is approximately correct for a temperature of $1,000^{\circ} \mathrm{C}$, not $1,000 \mathrm{~K}$. In any case, based on the recommendations of the external review committee (Professors Viskanta, Ostrach, and Griffith), a more rigorous approach to estimating radiation heat transfer effects with participating gas radiation will be employed in this appendix.

\section{C-3. COMBINED TURBULENT CONVECTION PLUS RADIATION METHODOLOGY}

To provide a more detailed treatment of radiation heat transfer within the scope of this task, calculations were performed, based on the analysis of Wassel and Edwards, ${ }^{C-8}$ of combined convection and gas radiation in a laminar or turbulent pipe flow. Their results allow for the estimation of convective and radiative contributions to total heat transfer with a participating gas. The procedure requires computation of three parameters: the turbulent Reynolds number, $R_{t}$; the radiationto-conduction conductance ratio, $\mathrm{N}_{\mathrm{rm}}$; and the optical depth of the tube radius, $t_{R}$. These parameters are defined as

$$
R_{t}=\operatorname{Re}_{D} \sqrt{C_{f} / 8} ;
$$

$N_{r m}=\sum_{i=1}^{k} \omega_{i} \frac{d B_{v_{i}}}{d T}\left(\frac{k_{m}}{R}\right)^{-1}$

$\tau_{R, i}=\frac{\alpha_{i}}{\omega_{i}} \varrho R$

With values of these parameters determined, convective and radiative Nusselt numbers can be determined from Table 1 in Reference C-8. These Nusselt numbers are defined as

$$
\begin{aligned}
& N u_{c}=\frac{q_{c}^{\prime \prime} D}{\left(T_{w}-T_{b}\right) k_{m}} ; \\
& N u_{R}=\frac{q_{R}^{\prime \prime} D}{\left(T_{w}-T_{b}\right) k_{m}} .
\end{aligned}
$$

The radiative Nusselt numbers tabulated in Table 1 of Reference C-8 were obtained for the case of a black wall and consequently represent an upper bound. For nonblack gray walls, an estimate of the radiative contribution can be obtained by direct scaling with emissivity. ${ }^{\mathrm{C}-8}$

\section{C-4. FLOW IN THE HOT LEG}

Values of $\tau_{R}$ were calculated for steam in the hot leg at 160 bar and $1,000 \mathrm{~K}$ using reference 


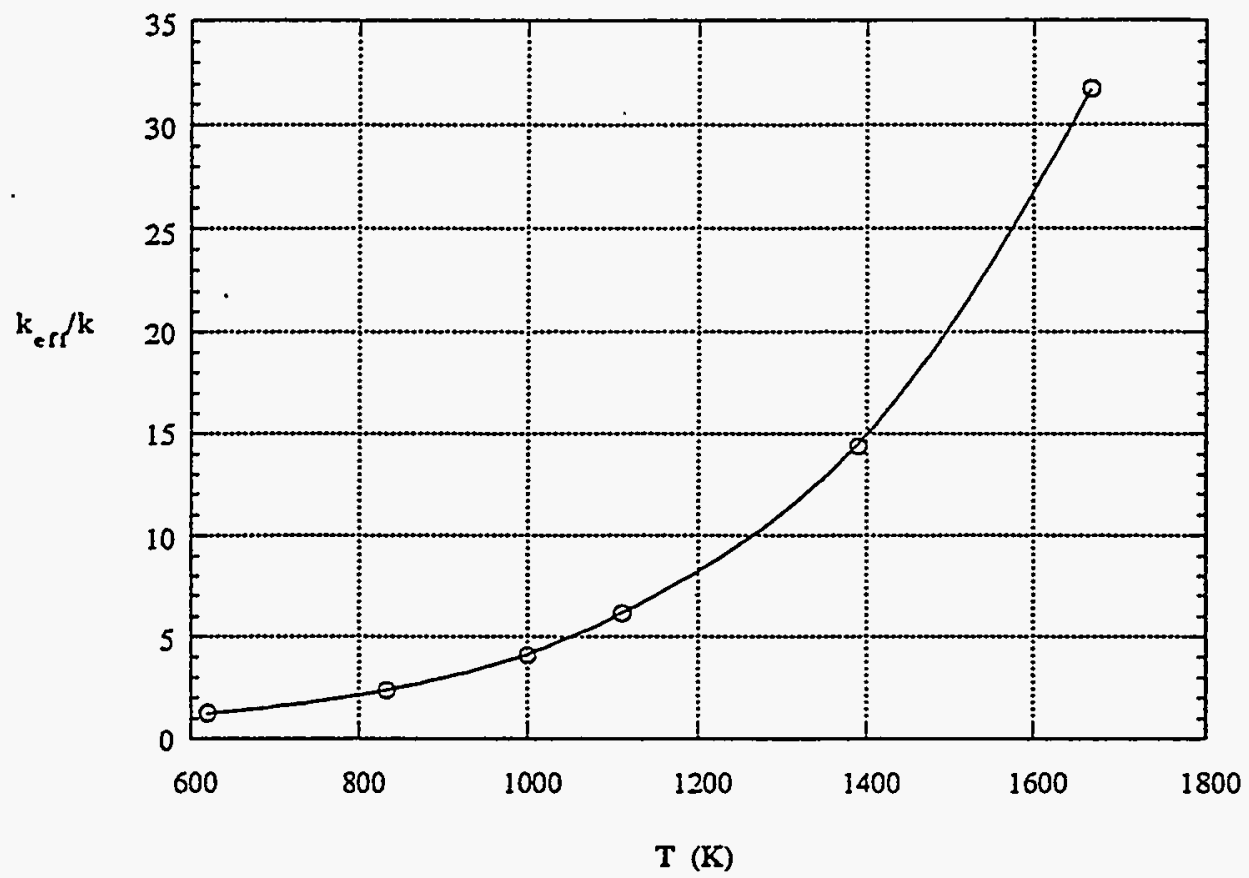

Figure C-1. Effective thermal conductivity dependence on gas temperature.

Table C-1. Wavelength band radiation properties for steam at 160 bar and $1,000 \mathrm{~K}$.

\begin{tabular}{rccr}
\hline$v_{\varkappa}, \mathrm{cm}^{-1}$ & $\omega_{x,} \mathrm{~cm}^{-1}$ & $\mathrm{~dB} / \mathrm{dT}, \mathrm{W} / \mathrm{m}^{2} \mathrm{~cm}^{-1} \mathrm{~K}$ & $\tau_{\mathrm{R}}$ \\
\hline 500 & 109.4 & $1.982 \mathrm{E}-03$ & 2,512 \\
1,600 & 225.1 & $1.387 \mathrm{E}-02$ & 2,530 \\
3,760 & 283.3 & $1.545 \mathrm{E}-02$ & 1,258 \\
5,350 & 172.3 & $6.374 \mathrm{E}-03$ & 272 \\
7,250 & 155.0 & $1.395 \mathrm{E}-03$ & 192 \\
\hline
\end{tabular}

values of $\omega_{i}, \tau_{R, i}$, and $v_{x}$ provided in Reference $\mathrm{C}-9$ at $1,000 \mathrm{~K}$ and assuming a hot leg pipe radius of $35.56 \mathrm{~cm}$. Results of these calculations are summarized in Table $C-1$. Hot leg values of $\tau_{R}$ are large, reflecting the optically thick highpressure steam environment. In fact, the Nusselt number table provided in Reference C- 8 includes values of $\tau_{R}$ only up to 200 . However, the authors point out that logarithmic extrapolation is appropriate for determining the radiation Nusselt number dependence on $\tau_{R}$. Applying Eq. (C-4), using $35.6 \mathrm{~cm}$ (14 in.) as a typical full-scale hot leg radius, a value of $\mathrm{N}_{\mathrm{m}}$ equal to 29.5 was also obtained. Linear interpolation/extrapolation is quite accurate for determining the $\mathrm{Nu}_{R}$ dependence on $\mathrm{N}_{\mathrm{rm}}$. Heat transfer results are tabulated directly in Reference C- 8 for a value of $\mathrm{N}_{\mathrm{mm}}$ equal to 30 , however, so interpolation was not needed.

Convective Nusselt numbers are not independent of the radiation parameters since radiation and convection are coupled. A power-law fit was made to the convective Nusselt numbers to determine the dependence of $\mathrm{Nu}_{C}$ on $\tau_{R}$. Linear interpolation was used for determining the dependence of $\mathrm{Nu}_{\mathrm{C}}$ on $\mathrm{N}_{\mathrm{rm}}$. Prototypical Reynolds numbers for 
flow in the hot leg are on the order of $10^{5} . \mathrm{C}-2 \mathrm{Com}$ bined convection/radiation heat transfer results were tabulated in Reference C- 8 for a Reynolds number, $\operatorname{Re}_{\mathrm{D}}$, of 80,650 . This tabulation, extended to higher values of $\tau_{R}$ using logarithmic extrapolation, is presented in Table C-2. For a value of $\mathrm{N}_{\mathrm{mm}}$ equal to 30 , radiation Nusselt numbers significantly exceed convective Nusselt numbers in all cases. For multiple $\tau_{R}$ band-absorbing/emitting gases such as $\mathrm{H}_{2} \mathrm{O}$, estimation of an "effective" value for $\tau_{R}$, including contributions from all relevant wavelength bands, is not simple. However, for the case of steam at $1,000 \mathrm{~K}$ and $160 \mathrm{bar}$, this value will be in the 2,500-6,000 range, as seen from Table C-1. Consequently, an estimated total Nusselt number of 440 is reasonable for these conditions. This total Nusselt number is the sum of the convective and radiative Nusselt numbers and is based on the molecular thermal conductivity.

In the scaling report of Vu Tung (Appendix B), an effective thermal conductivity approach was used to estimate total heat transfer from the lowPrandtl-number Sleicher-Rouse correlation

$$
N u=6.3+0.0167 \operatorname{Re}_{D}^{0.85} \operatorname{Pr}_{e}^{0.93} \cdot(\mathrm{C}-7)
$$

For a Reynolds number of 80,650 and an effective Prandtl number of 0.07 , this correlation predicts a Nusselt number of 27.2 based on effective thermal conductivity. Since the effective thermal conductivity used by Tung is a factor of 14 higher than the molecular conductivity, the Nusselt number should be multiplied by 14 for comparison to the total Nusselt number predicted from Table C-2. On this basis, Tung's approach yielded a Nusselt number based on molecular conductivity of 381 compared to 440 predicted from Table C-2. So, the combined convection plus radiation analysis of Reference C-5 yields a prediction for wall heat flux in the hot leg that is only about $15 \%$ higher than the effective thermal conductivity approach used by Tung in Appendix B. A nondimensional characteristic average fluid temperature difference ratio for the hot leg was defined in Appendix B as

$$
\frac{\Delta \bar{T}}{\Delta T_{i}}=\frac{\bar{T}_{1}-\bar{T}_{2}}{T_{i, 1}-T_{i, 2}},
$$

where the subscripts 1,2 , and $i$ refer to hot stream, cold stream, and inlet, respectively. Using a heat exchanger-type analysis, this average temperature difference ratio was shown in Appendix B to be predicted by

$$
\frac{\Delta \bar{T}}{\Delta T_{i}}=\frac{4(\cosh \lambda+3 \sinh \lambda-2)}{\lambda(12 \cosh \lambda+13 \sinh \lambda)},
$$

where the eigenvalue, $\lambda$, is given by

$$
\lambda=6 \frac{L}{D} S t .
$$

The average temperature difference ratio in the hot leg for a Reynolds number of 80,650 calculated on the basis of the new higher Nusselt number is 0.87 compared to 0.88 predicted by Tung's analysis. Consequently, the conclusion drawn in Appen$\operatorname{dix} \mathrm{B}$ that no significant scaling distortion was present in the hot leg for the high-pressure $\mathrm{SF}_{6}$ Westinghouse $1 / 7$-scale tests, which were characterized by large hot leg Reynolds numbers, would still hold.

\section{C-5. FLOW IN THE STEAM GENERATOR TUBES}

Heat transfer in the full-scale plant steam generator tubes was also estimated in Appendix B using an effective thermal conductivity approach. Based on a reasonable flow Reynolds number in the hot leg of $10^{5}$, the Reynolds number for flow in the prototypical steam generator tubes is 2,200 , which indicates borderline laminar flow. The case of fully developed laminar flow with participating gas radiation is also addressed by Wassel and Edwards ${ }^{\mathrm{C}-8}$ for the uniform heat flux boundary condition. New values of $\mathrm{N}_{\mathrm{rm}}$ and $\tau_{R}$ were calculated for the conditions in the steam generator tubes at $1,000 \mathrm{~K}$. Both quantities are directly proportional to the tube characteristic dimension, $R$, which is $0.98 \mathrm{~cm}$ for the steam generator tubes. Consequently, both work out to be much smaller than their corresponding hot leg values. A value of 0.815 was obtained for $N_{\mathrm{rm}}$ and a value of $\tau_{R}$ in the $100-200$ range. Both of these values were well 
Table C-2. Nusselt numbers for combined convection and radiation heat transfer in a turbulent pipe flow; $\operatorname{Re}_{\mathrm{D}}=80,650$.

\begin{tabular}{|c|c|c|c|c|c|c|c|c|}
\hline \multirow{3}{*}{$\mathrm{N}_{\mathrm{rm}}=10$} & & $\tau_{R}=10$ & 50 & 100 & 200 & $\begin{array}{l}1,000 \\
\text { (Est.) }\end{array}$ & $\begin{array}{l}2,000 \\
\text { (Est.) }\end{array}$ & $\begin{array}{l}5,000 \\
\text { (Est.) }\end{array}$ \\
\hline & $\mathrm{Nu}_{\mathrm{C}}$ & 149.67 & 146.43 & 145.34 & 144.61 & 142.40 & 141.45 & 140.21 \\
\hline & $\mathrm{Nu}_{\mathrm{R}}$ & 59.60 & 76.30 & 80.84 & 83.91 & 99.12 & 104.89 & 112.52 \\
\hline \multirow{4}{*}{$\mathrm{N}_{\mathrm{mm}}=30$} & $\mathrm{Nu}_{\mathrm{T}}$ & 209.28 & 222.73 & 226.17 & 228.52 & 241.52 & 246.34 & 252.73 \\
\hline & $\mathrm{Nu}_{C}$ & 146.44 & 138.84 & 136.52 & 135.13 & 129.94 & 127.86 & 125.15 \\
\hline & $\mathrm{Nu}_{\mathrm{R}}$ & 177.02 & 222.41 & 233.88 & 241.38 & 282.25 & 297.56 & 317.79 \\
\hline & $\mathrm{Nu}_{\mathrm{T}}$ & 323.46 & 361.25 & 370.40 & 376.51 & 412.19 & 425.41 & 442.94 \\
\hline
\end{tabular}

within the range of Table 2 provided in Reference C-8. A portion of this table has been reproduced as Table $\mathrm{C}-3$ below along with estimated values for $\mathrm{N}_{\mathrm{rm}}=0.815$ based on linear interpolation.

Heat transfer from radiation in the steam generator tubes is therefore enhanced by approximately a factor of 2 , whereas the effective thermal conductivity approach with $\mathrm{k}_{\text {eff }} / \mathrm{k}_{\mathrm{m}}=14$ predict a factor of 14 enhancement for laminar flow. Using this new approximation for combined radiation/convection heat transfer, a value of 1,650 for the steam generator Richardson number is obtained, compared to the value of 9,360 reported in Appendix B. In the Westinghouse model steam generator tubes, with negligible radiation, a value of 260 is obtained for the steam generator Richardson number, still too low by a factor of 6.3. However, as pointed out in Appendix B, the primary purpose of the model steam generator is to provide an appropriate boundary condition for the hot leg. Therefore, the Richardson number for the hot leg is a more important system scaling parameter. Relating the Richardson number for the steam generator tubes to the Richardson number for the hot leg using
$\frac{R i_{H L}}{R i_{S G}}=4\left(\frac{D_{H L}}{L_{S G}}\right)^{3}\left(\frac{D_{H L}}{N D_{S G}}\right)^{2}$

and substituting 1,650 for RisG results in a hot leg Richardson number of $5.44 \times 10^{-5}$, which is lower than the hot leg Richardson number predicted by Tung by a factor of 5.65 and lower than the Westinghouse model hot leg Richardson number of $2.66 \times 10^{-4}$ by a factor of 4.9 . The conclusion drawn in Appendix $B$ that the model steam generator serves as a reasonable boundary condition for the hot leg is therefore weakened.

\section{C-6. NUMERICAL ANALYSIS OF HEAT TRANSFER IN THE STEAM GENERATOR TUBES}

Heat transfer rates in the steam generator tubes were also estimated using the finite-element computational fluid dynamics code FIDAP. ${ }^{\mathrm{C}-10}$ Version 7.0 of this code allows estimation of combined convection and radiation heat transfer with participating media for the case of optically thick fluids. For this case, the so-called P-1 approximation may be invoked. In FIDAP, the 
Table C-3. Nusselt number for combined convection and radiation heat transfer in a laminar pipe flow, uniform heat flux boundary condition.

\begin{tabular}{llcc}
\hline \multirow{4}{*}{$N_{\mathrm{mm}}$} & & \multicolumn{1}{c}{$\tau_{R}=$} & \multicolumn{1}{c}{$\tau_{R}=$} \\
\cline { 3 - 4 } 0 & & 100 & 200 \\
\cline { 3 - 4 } 0.815 & $\mathrm{Nu}_{\mathrm{c}}$ & 4.474 & 4.474 \\
& $\mathrm{Nu}^{\mathrm{R}}$ & 0.374 & 0.378 \\
& $\mathrm{Nu}^{\mathrm{T}}$ & 4.848 & 4.852 \\
& & & \\
& $\mathrm{Nu}^{\mathrm{c}}$ & 5.133 & 5.127 \\
& $\mathrm{Nu}^{\mathrm{R}}$ & 3.189 & 3.198 \\
& $\mathrm{Nu}^{\mathrm{T}}$ & 8.292 & 8.325 \\
& & & \\
& $\mathrm{Nu}^{\mathrm{c}}$ & 5.303 & 5.295 \\
& $\mathrm{Nu}^{\mathrm{R}}$ & 3.877 & 3.926 \\
& $\mathrm{Nu}^{\mathrm{T}}$ & 9.18 & 9.221 \\
\hline
\end{tabular}

P-1 method has been implemented to solve graygas problems or to solve nongray participating media problems with radiation properties expressed as a band function of wavelength. Both methods were used for the present analysis.

For the gray-gas analysis, a single additional coupled field equation, the irradiance equation, must be solved. The gray-gas analysis can be modified to account for nongrayness, without resorting to the multiple-band approach, by including a "nongrayness factor,"

$$
\eta=\sqrt{\varkappa / \varkappa_{R}} \text {, }
$$

where $x$ is the Planck mean absorption coefficient and $x_{R}$ is the Rosseland mean absorption coefficient. Values for these quantities for highpressure steam were obtained from Reference $\mathrm{C}-11$.

For the nongray analysis, the spectrum can be divided into bands, with each band assumed to exhibit gray-gas behavior, but with properties varying from band-to-band. An additional coupled irradiance equation must be solved for each band. For the high-pressure steam problem, the spectrum was divided into five active bands, centered on wavelengths of $20,6.3,2.7,1.9$, and $1.4 \mu \mathrm{m}$. The gas was assumed to be transparent outside of these bands with wall-to-wall radiation occurring in the transparent bands. Extension coefficients were specified for each active band, based on reference optical depth data provided in Reference C-9. Details of the governing equations and numerical procedures for the radiation problem with participating media are provided in Reference C-10.

For the purposes of the present problem, an axisymmetric finite element model of a steam generator tube was created that included eight nine-noded elements in the radial direction and 250 elements in the axial direction. To achieve fully developed conditions, calculations were performed for an axial length, L/D of 200. As a check on the numerical procedure, a laminar convection problem was solved initially without radiation for a uniform heat flux thermal boundary condition along the tube wall. The exact analytical solution for the fully developed Nusselt number for this case is 4.36 . The numerical results with $L / D$ of 200 produced a Nusselt number of 4.40 , about $1 \%$ high.

Results of the numerical calculations, with radiation included, indicated an even more modest augmentation of heat transfer in the steam generator tubes than was predicted by the analysis discussed in the previous section. For fully developed flow and heat transfer in the steam generator tubes, a total Nusselt number of 5.95, accounting for convection plus radiation, was predicted for the modified gray-gas analysis, and a total Nusselt number of 5.26 was predicted for the multiple-band gray-gas analysis. These results should be compared to the value of 8.3 listed in Table C-1. Consequently, the conclusion that heat transfer in the steam generator tubes was significantly overpredicted by the effective thermal conductivity approach used by Tung is still valid. Steam generator and hot leg Richardson numbers based on a total Nusselt number of 5.95 are 1,180 and $3.9 \times 10^{-5}$, respectively. This new hot leg Richardson number is lower than the estimated Westinghouse model hot leg Richardson number of $2.66 \times 10^{-4}$ by a factor of 6.8 . Again 
the argument that the model steam generator may provide a reasonable boundary condition for the hot leg is weakened.

\section{C-7. FLOW IN THE CORE}

\section{C-7.1 Momentum Equation}

Scaling in the core was analyzed by Tung (Appendix B) using a procedure developed by Wassel et al. C-3 Nondimensionalization of the fluid momentum equation leads to the conclusion that axial and radial friction factors, which are shown to be related to the Euler and Richardson numbers, must be equal in the model and prototype for valid similitude. Estimates of these quantities at a representative core flow Reynolds number were provided by Westinghouse ${ }^{\mathrm{C}-1}$ and a comparison was made in Appendix B. The comparison showed that modified friction factors in the model core were a factor of 2-3 too low, indicating that natural circulation flow rates in the full-scale core would be smaller than predicted from direct extrapolation of the Westinghouse test data. No consideration of heat transfer was required in analyzing the momentum equation since the comparison was made at a specified Reynolds number.

\section{C-7.2 Fluid Energy Equation}

Inspection of the nondimensional core energy equation reveals that a similitude requirement for the model core is that the quantity St $\left(\mathrm{A}_{\mathrm{w}} / \mathrm{A}_{\mathrm{f}}\right)$ be preserved. Using geometrical and Reynolds number information supplied by Westinghouse, ${ }^{C-1}$ Tung estimated values of this quantity for a Westinghouse test heating rod assembly and for a pro- totypical fuel bundle. Values of 0.48 and 90 , respectively, were obtained. The value of 90 was based on a Stanton number estimate derived from the effective thermal conductivity approach. Using the method outlined in Reference C-8 to account for radiation, a value of 11 was obtained for St $\left(A_{w} / A_{f}\right)$, which is significantly lower than the previous estimate from Tung, but still about a factor of 23 higher than values for the Westinghouse $\mathrm{SF}_{6}$ tests. Consequently, the conclusion that heat transfer is significantly more efficient in the full-scale plant than in the model still holds. Values for $S t\left(A_{w} / A_{f}\right)$ in the core are summarized in Table C-4.

\section{C-7.3 Solid Energy Equation-Heated Solid Region}

Natural convection in the core and in other regions is coupled with transient heat conduction in the solid structures. Inspection of the energy equation (Appendix B) for heated structures reveals that the primary similitude parameter governing transient heat conduction in the solids is

$S t *=S t \frac{\varrho_{o} C_{p o} A_{w, s, H} L_{o}}{m_{s, H} C_{p s, H}}$

where the subscript o refers to reference gas properties and s, $\mathrm{H}$ refers to the heated solid properties. A summary of $\mathrm{St}^{*}$ values is presented in Table C-5. Using the effective thermal conductivity approach, a value of 2.9 was estimated for $\mathrm{St}^{*}$ in the full-scale plant. In the Westinghouse model, without significant radiation, a value of $1.7 \times 10^{-2}$ was estimated for the high-pressure

Table C-4. Summary of St $\left(A_{w} / A_{f}\right)$ values.

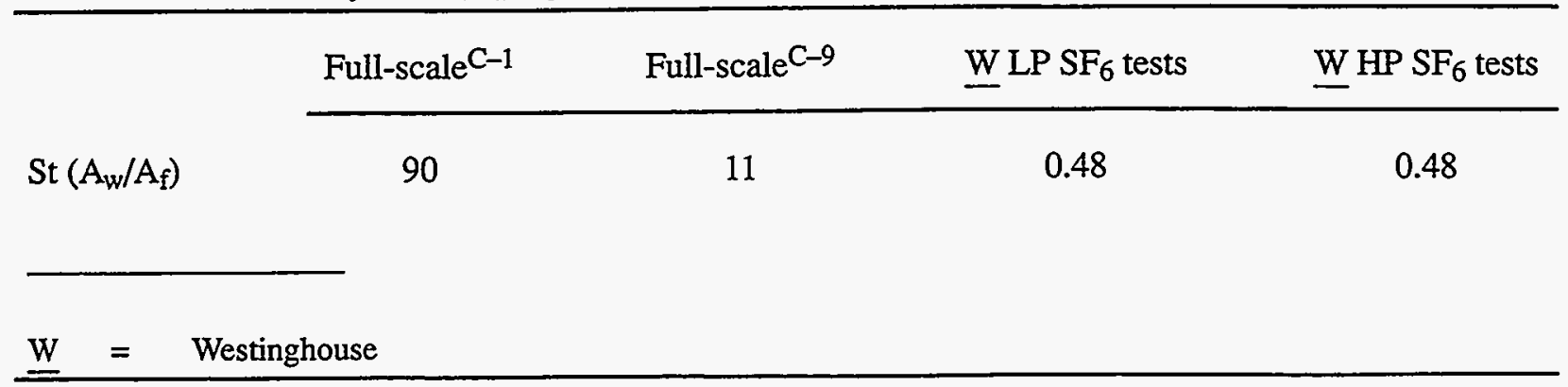


Table C-5. Summary of $\mathrm{St}^{*}$ values.

\begin{tabular}{ccccc} 
& Full-scale $^{\mathrm{C}-1}$ & Full-scale $^{\mathrm{C}-9}$ & W LP SF $_{6}$ tests & W HP SF 6 tests \\
\cline { 2 - 4 } $\mathrm{St}^{*}$ & 2.9 & 0.37 & $8.8 \times 10^{-4}$ & $1.7 \times 10^{-2}$ \\
\hline
\end{tabular}

$\mathrm{SF}_{6}$ tests. Using the method of Reference C- 8 to estimate combined convection and radiation, a value of 0.37 was obtained from the full-scale plant. This value is still about a factor of 20 larger than the estimated value for the Westinghouse high-pressure tests. Consequently, the conclusion that scaled hot-zone solid structure heatup rates will be lower in the full-scale plant than in $1 / 7$-scale model is still valid, but the distortion is not as great as indicated by Tung.

\section{C-7.4 Solid Energy Equation-Nonheated Solid Region}

For the nonheated solid regions, convection heat transfer occurs from the fluid to the solid, increasing the temperature of the nonheated solid structures via transient heat conduction, thereby distributing decay heat throughout the primary system. The primary similitude parameter governing this process was defined in Appendix B as

$$
S t^{* *}=S t \frac{\varrho_{0} C_{p o} A_{w, s, N H} L_{o}}{m_{s, N H} C_{p, s, N H}} \text {, }
$$

where the denominator now represents the thermal mass of the nonheated solid structures. A summary of values for $\mathrm{St}^{* *}$ is presented in Table C-6.

The new prototypical value of $\mathrm{St}^{* *}$ shown in column 2 of Table C-6 is much closer to the value estimated for the high-pressure $\mathrm{SF}_{6}$ tests. Concerns about this scaling aspect of the Westinghouse experiments are therefore minimal in comparison to other distortions.

\section{C-8. BOUNDARY CONDITIONS}

A discussion of the boundary conditions imposed on the Westinghouse experiments was also provided in Appendix B. The actively imposed boundary conditions included the heat input and the heat sinks. Active heat sinks were included in the experiment design to allow for steady-state tests to be performed. ${ }^{C-2}$ These heat sinks were located in the model upper plenum, upper head, and steam generator regions. Upper plenum cooling was accomplished via the model control rod guide tubes and upper plenum wall. The upper head was cooled via cooling tube extensions and manifolds for the upper plenum guide tubes. The model steam generators were cooled by water circulating on their shell sides. During transient tests, coolant was removed from all cooling circuits and the experiments were performed with only passive cooling of the fluid through transient conduction in the model structures. The analysis of the magnitude of the nondimensional heat sinks provided in Appendix B indicated that the steam generator heat sinks were approximately properly scaled, but that the upper plenum heat sink was too large, resulting in enhanced natural circulation flows in the model core compared to the prototype.

\section{C-9. STEADY-STATE FLOW APPROXIMATION}

Much of the analysis outlined above and in Appendix B assumes steady-state flow and heat transfer. In the actual full-scale severe accident scenario, these processes are transient and coupled. Usage of a quasi-steady approximation and corresponding heat transfer analyses is justified if the characteristic timescale for transient heat conduction in the solid structure is longer than the characteristic timescale for flow establishment. Estimation of the characteristic heat conduction timescale is straightforward, but estimation for the flow establishment timescale is 
Table C-6. Summary of $\mathrm{St}^{* *}$ values.

\begin{tabular}{ccccc}
\hline & Full-scale $^{C-1}$ & Full-scale $^{C-9}$ & W LP SF $_{6}$ tests & W HP SF \\
\cline { 2 - 5 } $\mathrm{St}^{* * *}$ & 4.5 & 0.56 & $6.3 \times 10^{-3}$ & 0.12 \\
\hline
\end{tabular}

difficult for a complex system undergoing natural circulation flow and would have to be estimated differently in different regions of the system.

Both transient and steady-state tests were performed by Westinghouse in their $1 / 7$-scale facility. Therefore, for the purposes of comparison to the Westinghouse steady-state experimental results, a steady-state analysis is not only reasonable, but necessary. Also, observations cited in the high-pressure report ${ }^{\mathrm{C}-2}$ indicated that flow establishment was rapid and that temperature and flow distributions were very similar for the transient and steady-state tests. Based on these observations, a quasi-steady approximation is reasonable for analysis of the transient processes.

\section{C-10.REYNOLDS ANALOGY}

One of the concerns expressed by the reviewers of the scaling report of Tung (Appendix B) was that some heat transfer estimates for buoyancydriven flows were obtained using correlations developed for forced flows. This concern is valid in regions where the fluid flow and heat transfer are intimately coupled, but this approach should be adequate in regions that are somewhat removed from the primary heat sources and sinks, such as the hot leg and the steam generator tubes. In fact, Wassel et al. ${ }^{\mathrm{C}-3}$ discuss the distinction between natural convection phenomena and natural circulation and point out that a free stream velocity can be identified in natural circulation flows. An appropriate reference driving pressure difference can be defined for natural circulation flows as $\Delta \mathrm{P}=\rho g \beta \Delta \mathrm{TL}$, where $\mathrm{L}$ is the height of the heated section. Reynolds number appears as similitude parameter in their scaling methodology for natural circulation flows. Therefore, in some situations, such as the steam generator tubes, a fully developed pipe flow that strongly resembles a standard fully developed forced flow will become established. Estimation of heat transfer using forced flow correlations in this case should be reasonably accurate.

Combined radiation and convection heat transfer was estimated in this report using the method of Reference C-8, which was also developed for forced flow situations. It would be difficult to identify a similar methodology for turbulent natural convection heat transfer with a participating gas in the literature.

\section{C-11. CONCLUSIONS}

The primary objective of this scaling reevaluation was to provide a more detailed treatment of combined radiation plus convection heat transfer in the high-pressure, high-temperature environment existing in the full-scale plant during a TMLB' sequence. From these heat transfer results, magnitudes of governing nondimensional scaling parameters were estimated for prototypical conditions in the core, hot leg, and steam generator regions of the primary coolant system. These estimates were compared to corresponding values for the Westinghouse experiments, primarily focusing on the high-pressure $\mathrm{SF}_{6}$ conditions. Comparison with results of the previous scaling study of Tung (Appendix B) were also made. A summary of conclusions organized by region follows.

\section{C-11.1 Hot Leg}

Using the method for estimating combined convection plus radiation heat transfer outlined in this appendix, total wall heat transfer in the fullscale hot leg was predicted to be about $15 \%$ higher than the previous estimate reported by Tung (Appendix B). The average nondimensional temperature difference ratio in the hot leg for a Reynolds number of 80,650 , calculated on the basis of this higher Nusselt number, is 0.87 , 
compared to 0.88 predicted by Tung's analysis. Consequently, the conclusion drawn in Appendix $B$ that no significant scaling distortion was present in the hot leg of the high-pressure $\mathrm{SF}_{6}$ Westinghouse $1 / 7$-scale tests, which were characterized by large hot leg Reynolds numbers, would still hold.

\section{C-11.2 Steam Generator}

Using the method of Wassel and Edwards, ${ }^{C-8}$ heat transfer enhancement caused by radiation in the full-scale steam generator tubes was predicted to be equal to approximately a factor of 2 , whereas the effective thermal conductivity approach (Appendix B) with $k_{\text {eff }} / k=14$ predicts a factor of 14 enhancement for laminar flow. The resulting prototypical steam generator Richardson number is a factor of 6.3 higher than for the Westinghouse model, but this distortion is not as great as was reported by Tung. If the model steam generator is viewed as a device whose primary purpose is to provide a reasonable boundary condition for the hot leg, however, the hot leg Richardson number is the more important scaling parameter. The parameter, obtained via direct scaling from the steam generator Richardson number, was found to be about a factor of 5 lower for the full-scale plant than for the Westinghouse model, indicating a larger hot leg scaling distortion than was reported in Appendix B and a more vigorous natural circulation hot leg flow in the model.

A numerical analysis was also performed for flow and heat transfer in the steam generator tubes with participating media radiation using the finite-element computational fluid dynamics code FIDAP. Results of this analysis also indicated that the effective thermal conductivity approach used by Tung significantly overpredicts heat transfer rates in the steam generator tubes. A prototypical steam generator Richardson number of 1,180 was predicted, which is a factor of 4.5 higher than the estimated model steam generator Richardson number. An estimate of the prototypical hot leg Richardson number equal to $3.9 \times 10^{-5}$ was obtained, which is a factor of 6.8 lower than the estimated model hot leg Richardson number.
Again the argument that the model steam generator may provide a reasonable boundary condition for the hot leg is weakened.

\section{C-11.3 Core-Momentum Equation}

Consideration of natural circulation flow in the core region at a representative Reynolds number led to the conclusion (unchanged from Appen$\operatorname{dix} B$ ) that modified friction factors in the model core were a factor of 2-3 too low and that natural circulation flow rates in the full-scale core would be smaller than predicted from direct extrapolation of the Westinghouse test data.

\section{C-11.4 Core-Fluid Energy Equation}

The primary scaling parameter governing heat transfer in the core, $S t\left(A_{w} / A_{f}\right)$, was predicted to be a factor of 23 higher in the full-scale plant than in the Westinghouse $\mathrm{SF}_{6}$ tests. This distortion is smaller than the factor of 188 reported by Tung, but still is indicative of a significant scaling distortion characterized by much more efficient heat transfer in the full-scale core compared to the model.

\section{C-11.5 Core-Solid Structure Energy Equation}

Examination of the governing equation for transient heat conduction in the heated core structures led to the conclusion that scaled hot-zone solid structure heatup rates will be lower in the full-scale plant than in 1/7-scale model. Similar examination of the nondimensional parameter governing transient heat conduction in the unheated core structures indicated reasonable similitude for this aspect of core scaling.

\section{C-11.6 Boundary Conditions}

The analysis of the magnitude of the nondimensional heat sinks provided in Appendix B did not require modification. It indicated that the stream generator heat sinks were approximately 
properly scaled, but that the upper plenum heat sink was too large, resulting in enhanced natural circulation flows in the model core compared to the prototype.

\section{C-11.7 Steady-State Flow Approximation}

Observations cited in the Westinghouse highpressure report ${ }^{\mathrm{C}-2}$ indicated that flow establishment was rapid and that temperature and flow distributions were very similar for the transient and steady-state tests. Based on these observations, a quasi-steady approximation is reasonable for analysis of the transient processes.

\section{C-11.8 Reynolds Analogy}

In regions that are somewhat removed from the primary heat sources and sinks, such as the hot leg and the steam generator tubes, estimation of heat transfer using forced flow correlations should be reasonably accurate.

\section{C-12 REFERENCES}

C-1. W. A. Stewart, A. T. Pieczynski, and V. Srinivas, Experiments on Natural Circulation in a Pressurized Water Reactor Model for Degraded Core Accidents, EPRI Project No. RP2177-5 Final Report, 1990.

C-2. W. A. Stewart, A. T. Pieczynski, V. Srinivas, Experiments on Natural Circulation in a Pressurized Water Reactor Model with High-Pressure $S F_{6}$, Draft EPRI Report, 1990.

C-3. A. T. Wassel et al., Modeling of Natural Circulation in Reactor Coolant Systems,
Fluid Physics Int., Report FPI R88-05-04, 1988.

C-4. P. D. Bayless, Analyses of Natural Circulation During a Surry Station Blackout Using SCDAP/RELAP5, NUREG/ CR-5214, October, 1988.

C-5. E. M. Sparrow and R. D. Cess, Radiation Heat Transfer, New York: McGraw-Hill, 1978.

C-6. J. H. Keenan et al., Steam Tables, New York: John Wiley and Sons, 1969.

C-7. S. Ostrach, "Commix Code ReviewLDS-3-90," R. J. Dallman letter to L. M. Shotkin, RJD-38-90, Transmittal of COMMIX Code Review, Enclosure 7, September 27, 1990.

C-8. A. T. Wassel and D. K. Edwards, "Molecular Gas Radiation in a Laminar or Turbulent Pipe Flow," Journal of Heat Transfer, 98, 1976, pp. 101-107.

C-9. A. Balakishnan and D. K. Edwards, "Molecular Gas Radiation in the Thermal Entrance Region of a Duct," Journal of Heat Transfer, 101, 1979, pp. 489-495.

C-10. M.S. Englemann, FIDAP 7.0 Theory Manual, Evanston, IL: Fluid Dynamics International.

C-11. M. M. Abu-Romia and C. L. Tien, "Appropriate Mean Absorption Coefficients for Infrared Radiation of Gases," Journal of Heat Transfer, 89, no. 4, 1967, pp. 321-327. 


\section{Appendix D}

RELAP5 Analysis of Natural Circulation Flow in the Westinghouse High-Pressure $\mathrm{SF}_{6}$ Experiments 



\section{Appendix D}

\section{RELAP5 Analysis of Natural Circulation Flow in the Westinghouse High-Pressure $\mathrm{SF}_{6}$ Experiments}

\section{D-1. INTRODUCTION}

This appendix describes an analytical model of the Westinghouse high-pressure, steady-state experiments on natural circulation in a $1 / 7$-scale pressurized water reactor (PWR) model. ${ }^{\mathrm{D}-1, \mathrm{D}-2}$ Using the RELAP5/MOD3 computer code, ${ }^{\mathrm{D}-3}$ calculations were performed and the results were compared with the experimental data. This natural circulation model was developed in support of the Nuclear Regulatory Commission's program to study natural circulation in PWRs during severe accidents.

This appendix is organized as follows. Section $\mathrm{D}-1$ provides the objectives of this study and describes the modeled experiments. Section D-2 discusses the procedure used in deriving experimental flow rates and parameters using simple energy balances and the measured temperature and heat removal data. Section D-3 describes the RELAP5/MOD3 model of the experimental apparatus and boundary and initial conditions. Section D-4 presents the RELAP5/MOD3 simulations and compares the results with experimental data. Section D-5 gives conclusions and describes areas of future work.

The objective of this study is to evaluate the capability of RELAP5/MOD3 to calculate the natural circulation flow behavior observed during the Westinghouse experiments. RELAP5/MOD3 is a one-dimensional, thermal-hydraulics code used in severe accident analyses of nuclear systems. The code uses best-estimate integral calculations to model the thermal-hydraulic response.

The procedure used in this study is as follows. Two Westinghouse steady state experiments were selected for modeling. A RELAP5/MOD3 model of the 1/7-scale PWR experimental apparatus was constructed, which consists of three distinct components: the reactor pressure vessel (RPV) (core and upper plenum), two hot legs (modeled as four pipes to simulate hot leg countercurrent flow), and two steam generators. Experimental boundary and initial conditions were defined and specified as model inputs. Also, property data for $\mathrm{SF}_{6}$ vapor was obtained and added to the code to simulate the fluid used in the experiments. In adding this property data, code modifications were necessary to account for the nonideal gas behavior of $\mathrm{SF}_{6}$ at the pressures and temperatures encountered in the experiments. Finally, using the RELAP5/MOD3 model, the two experiments were simulated and the results compared with the experimental data. The experimental data consisted of $\mathrm{SF}_{6}$ vapor temperatures in the RPV, hot legs, and steam generators. Experimental flow rates for the core, hot legs, and steam generator tube bundle were estimated using simple energy balances and the vapor temperature data.

Of the Westinghouse steady-state and transient experiments described in Reference D-2, two steady-state experiments were chosen for simulation using RELAP5/MOD3. The steady-state experiments were chosen because they provided the necessary data to benchmark the RELAP5 input model. Modeling the transient experiments would require additional effort to develop RELAP5 input models for most of the experimental apparatus heat structures. Therefore, only selected steady-state experiments were modeled. However, in the future, modeling the transient experiments would be useful in evaluating how well the input model predicts the transient aspects of the natural circulation flow.

Of the two series of steady-state experiments, the first series was better suited for modeling because the experimental results and boundary conditions presented for this series are the most extensive. The experimental data reported includes the fluid temperatures in the reactor vessel, hot legs, and the left steam generator tube 
bundle. Also, the experimental thermal boundary conditions were adequately defined and included the heat removed by the upper internals (guide tubes and upper head), the upper plenum wall, and steam generators; the cooling water flow rates; and inlet and outlet temperatures for the cooling water supplied to the heat removal structures. The reported experimental data for these tests is sufficient to obtain the necessary boundary conditions for modeling the tests with RELAP5/MOD3.

Of the 14 steady-state tests in the first series of experiments, Tests S-6 and S-7 were chosen for modeling with RELAP5/MOD3. These two tests were selected because they had representative system conditions (steam generator cooling, no hot leg heating), and the core heating was very closely balanced with the heat removal. For many of the experiments, the core heating was not in balance with the heat removal because of experimental difficulties in maintaining the cooling water at a constant inlet temperature for the duration of the test. Tests S-6 and S-7 both had core powers of $20.5 \mathrm{~kW}$, but different system pressures of 1.655 and $2.172 \mathrm{MPa}$ (240 and $315 \mathrm{psia}$ ), respectively.

\section{D-2. WESTINGHOUSE EXPERIMENTAL RESULTS}

The experimental data provided for Tests S-6 and S-7 includes the vapor temperatures within the reactor vessel, upper and lower plenum, upper head, hot legs, and left steam generator tube bundle (see Reference D-2). Additionally, the system pressure, the core heating power, the heat removal cooling water inlet and outlet temperatures, and the cooling water mass flow rates were measured and reported. The heat removed by the upper internals and steam generators was calculated as the product of the cooling water temperature change, mass flow rate, and specific heat.

In the experiments, the $\mathrm{SF}_{6}$ mass flow rates and velocities were not measured. Instead, flow parameters were estimated in the Westinghouse report using the experimental core power, heat removal rates, and vapor temperatures. For the various series of experiments performed, the experimental flow parameters were derived for different areas of interest which included: natural circulation flow in the core and upper internals, countercurrent flow in the hot legs, and flow through the steam generators. For the first series of steady-state experiments, including Tests S-6 and $S-7$, the derived experimental flow parameters were reported only for the flow in the core and upper plenum. However, the raw data was available to derive flow parameters for the hot legs and steam generators. Therefore, as part of this study, using the analytical models, methodology, and experimental data presented in the Westinghouse report (see Reference D-2), the hot leg and steam generator flow parameters were derived for Tests S-7 and S-6. The Westinghouse derivation of the flow parameters for the core, hot legs, and steam generator is summarized below. Also, the experimental results reported by Westinghouse and those calculated as part of this study are presented. These experimental results are compared with RELAP5 predictions later in this appendix.

\section{D-2.1 Derived Flow Parameters in the Core and Upper Plenum}

Using the temperature data, heat inputs and outputs, and simple analytical models, the Westinghouse report derived flow parameters to describe the natural circulation flow in the core (see Reference D-2). These flow parameters included:

- Average inlet and outlet vapor temperatures in the core

- Average core flow velocity

- $\quad$ Effective core Reynolds number $(\mathrm{Re})$

- $\quad$ Richardson number (1/C).

The average core flow velocity, $\overline{\mathrm{V}}$, was defined by relating the core power, $\mathrm{q}$, to the change in 
energy of fluid flowing through the core with a cross-sectional area, $A_{f}$

$$
q=\bar{\varrho} A_{f} V \bar{C}_{p}\left(T_{h}-T_{c)}\right.
$$

where

$$
\begin{array}{lll}
q & = & \text { core power, } \mathrm{W} \\
\bar{\rho} & = & \text { average density, } \mathrm{kg} / \mathrm{m}^{3} \\
A_{f} \quad= & \begin{array}{l}
\text { minimum area for axial flow in } \\
\text { half of the model fuel assem- } \\
\text { blies, } 1.778 \times 10^{-2} \mathrm{~m}^{2}
\end{array} \\
\bar{C}_{p} \quad=\quad \text { average heat capacity, } \mathrm{J} /(\mathrm{kg} \cdot \mathrm{K}) \\
T_{h}=\quad \begin{array}{l}
\text { averaged core outlet tempera- } \\
\text { ture, } \mathrm{K}
\end{array} \\
T_{c}=\quad \begin{array}{l}
\text { averaged core inlet temperature, } \\
\quad
\end{array}
\end{array}
$$

$T_{h}$ was found as the average value of the temperatures at the top of the core that were much hotter than those of the cooled flow near the baffle wall. $T_{c}$ was found as the average of the fluid temperatures in the outside perimeter of the bottom of the upper plenum prior to heating by the core or mixing with the hot flow exiting the core. The flow area $A_{f}$ was consistently chosen as the minimum area for vertical flow in half of the model fuel assemblies. Thus, $\overline{\mathrm{V}}$ was equivalent to the average velocity of the cooled inlet flow and the heated outlet flow and was calculated by solving Eq. (D-1) for $\overline{\mathrm{V}}$.

The core Reynolds number was defined using $\bar{V}$, the average density, the hydraulic diameter of a single fuel assembly minimum area, $\mathrm{D}_{\mathrm{e}}$, and the average dynamic viscosity

$$
\operatorname{Re}_{D .}=\frac{\bar{\varrho} V D_{e}}{\bar{\mu}},
$$

where

$$
\begin{aligned}
D_{e}= & \text { hydraulic diameter correspond- } \\
& \text { ing to one fuel assembly mini- } \\
& \text { mum area, } 4.445 \times 10^{-3} \mathrm{~m}
\end{aligned}
$$

$\bar{\mu} \quad=\quad$ average dynamic viscosity, $\mathrm{Pa} \cdot \mathrm{s}$.

The Richardson number, $1 / \mathrm{C}$, is a measure of the loss coefficient for flow through the core. It was defined by setting the buoyant pressure head proportional to the number of dynamic head loss for the flow through the core. The proportionality constant is defined as $1 / \mathrm{C}$ and calculated as

$1 / C=\frac{g\left(\varrho_{c}-\varrho_{h}\right) D_{e}}{\varrho^{2}}$,

where $\mathrm{g}$ is the gravitational constant.

Table D-1 presents the derived flow parameters for the core and upper plenum.

\section{D-2.2 Derived Flow Parameters in the Hot Legs}

For Tests S-7 and S-6, the derived hot leg flow parameters were not reported in the Westinghouse report (see Reference D-2). However, for the third series of experiments, which focused on the flow conditions in the hot legs and steam generator, flow parameters in the hot leg were derived from the experimental data. Therefore, using the methodology outlined in the Westinghouse report, hot leg flow parameters were derived from the experimental data for Tests S-7 and S-6. The derived flow parameters included

- Mass flow rate in each stream of the hot leg

- Average temperature in each stream of the hot leg

- $\quad$ Reynolds number $(\mathrm{Re})$

- The maximum loss coefficient, $C_{\max }^{\prime}$.

The definitions of these flow parameters follow.

The experimental mass flow rate in the hot leg, $\dot{m}_{h l}$, was found by equating the change in energy of fluid flowing through the hot leg with the heat rejected by the steam generator

$$
\dot{m}_{h l}=\frac{q_{S G}}{\bar{C}_{p}\left(T_{h}-T_{c}\right)},
$$


Table D-1. Core natural circulation flow parameters for Tests S-6 and S-7 (obtained from Reference D-2).

\begin{tabular}{cc}
\multicolumn{3}{c}{ Test number } \\
\hline S-6 & $S-7$ \\
\hline
\end{tabular}

Flow parameters

Pressure (MPa)

Core power $(\mathrm{kW})$

Upper plenum cooling (kW)

$\mathrm{T}_{\mathrm{h}}\left({ }^{\circ} \mathrm{C}\right)$

$\mathrm{T}_{\mathrm{c}}\left({ }^{\circ} \mathrm{C}\right)$

$\mathrm{T}_{\mathrm{h}}-\mathrm{T}_{\mathrm{c}}\left({ }^{\circ} \mathrm{C}\right)$

$\bar{\rho}\left(\mathrm{kg} / \mathrm{m}^{3}\right)$

$\rho_{c}-\rho_{h}\left(\mathrm{~kg} / \mathrm{m}^{3}\right)$

$\overline{\mathrm{C}}_{\mathrm{p}}(\mathrm{J} / \mathrm{kg} \cdot \mathrm{K})$

$\bar{\mu}\left(\mathrm{Pa} \cdot \mathrm{s} \times 10^{5}\right)$

$\overline{\mathrm{V}}(\mathrm{m} / \mathrm{s})$

$\operatorname{Re}_{\mathrm{De}}$

$1 / \mathrm{C}$

where qSG $_{\text {is }}$ the measured heat rejected by the steam generator, and $T_{h}$ and $T_{c}$ are the average vapor outlet and inlet temperatures in the hot leg at the steam generator junction, respectively. The hot outlet temperature in the hot leg was obtained from the single upper hot leg exit thermocouple reading. At the same time $T_{h}$ was found, the cooled inlet temperature was obtained as an average of the lower two hot leg thermocouple readings.

The Reynolds number for the hot leg flow was calculated using an effective diameter, $D_{\mathrm{e}}$. This effective diameter was chosen as the hydraulic diameter at the point that the sloping interface of the countercurrent flows passes through the centerline of the pipe. Assuming the countercurrent flows are symmetric, this location was near the middle. The effective diameter, $D_{e}$, at this location was defined as

$D_{e}=\frac{4 \cdot A_{c}}{P_{w}}$
1.655

20.48

15.4

206.2

92.3

162.7

113.9

90.1

75.35

72.6

25.05

102.1

845.2

2.13

836.8

0.159

0.186

2,510

4,100

0.573

$$
=\frac{4 \cdot\left(\pi D^{2} / 8\right)}{(\pi D / 2+D)}=0.611 D,
$$

where

$A_{c} \quad$ cross-sectional area of half the pipe

$P_{w} \quad$ wetted perimeter including the interface between the hot and cold streams

$D \quad$ inside pipe diameter, 4.026 in. $(0.1023 \mathrm{~m})$.

The hot leg characteristic Reynolds number is then

$$
\begin{aligned}
\operatorname{Re}_{D e} & =\frac{\bar{V} D_{e}}{\bar{\mu} / \bar{\varrho}}=\frac{\dot{m}_{h l} D_{e}}{\left(\pi D^{2} / 8\right) \bar{\mu}} \\
& =\frac{15.22 \cdot \dot{m}_{h l}}{\bar{\mu}} \frac{(\mathrm{kg} / \mathrm{s})}{(P a \cdot s)} .
\end{aligned}
$$

The maximum loss coefficient, $C^{\prime}{ }_{\max }$, is defined by setting the buoyant pressure head proportional to the dynamic head loss for the flow 
through the hot leg. The buoyant pressure head is equal to $H / 2 \cdot\left(\rho_{c-} \rho_{h}\right)$, where $H$ is the vertical distance that the countercurrent interface plane changes from the reactor end to the steam generator end. The head loss from the shearing friction at the interface and on the pipe wall is proportional to the kinetic energy of each stream with an outlet velocity of $V_{0}$ at the outlet area $A_{0}$. The proportionality constant is defined as $C^{\prime}$. Equating the buoyant pressure head to the head loss results in:

$$
\begin{aligned}
\frac{H}{2}\left(\varrho_{c}-\varrho_{h}\right) & =C^{\prime} \cdot \frac{\bar{\varrho} V_{o}^{2}}{2 g} \\
& =C^{\prime} \cdot \frac{\dot{m}^{2}}{2 g \bar{\varrho} A_{o}^{2}} .
\end{aligned}
$$

After multiplying both sides by the pipe diameter raised to the fifth power and rearranging one obtains:

$$
\left(\frac{H A_{o}}{C^{\prime} D^{5}}\right)^{1 / 2}=\frac{\dot{m}_{h l}}{\left[g \varrho\left(\varrho_{c}-\varrho_{h}\right) D^{5}\right]^{1 / 2}}
$$

The term on the right-hand side of Eq. (D-8) is a correlating parameter for the hot leg flow and is in terms of known quantities on the left-hand side. From experimental observations, the geometrical factor $\left(\mathrm{HA}_{\mathrm{o}}{ }^{2} / \mathrm{D}^{5}\right)$ was a maximum and thus the mass flow rate was a maximum. The reported optimum value of $\left(\mathrm{HA}_{\mathrm{o}}{ }^{2} / \mathrm{D}^{5}\right)$ was 0.0182 (see Reference D-2). The maximum value of $C^{\prime}$ is found as

$$
\begin{aligned}
C_{\max }^{\prime} & =\frac{\left(\frac{H A_{o}{ }^{2}}{D^{5}}\right)_{o p t i m u m}}{\left(\frac{H A_{o}^{2}}{C^{\prime} D^{5}}\right)} \\
& =\frac{0.0182}{\frac{\dot{m}_{h l}^{2}}{\left[g \bar{\varrho}\left(\varrho_{c}-\varrho_{h}\right) D^{5}\right]}} .
\end{aligned}
$$

Table D-2 lists the temperatures, densities, heat

\begin{tabular}{|c|c|c|c|c|}
\hline \multirow[b]{3}{*}{ Hot leg } & \multicolumn{4}{|c|}{ Test number } \\
\hline & \multicolumn{2}{|c|}{ S-6 } & \multicolumn{2}{|c|}{ S-7 } \\
\hline & Left & Right & Left & Right \\
\hline \multicolumn{5}{|l|}{ Flow parameters } \\
\hline $\mathrm{T}_{\mathrm{c}, \text { in }}\left({ }^{\circ} \mathrm{C}\right)$ & 65.5 & 63.4 & 60.8 & 60.3 \\
\hline $\mathrm{T}_{\mathrm{h}, \text { out }}-\mathrm{T}_{\mathrm{c}, \text { in }}\left({ }^{\circ} \mathrm{C}\right)$ & 64.2 & 71.5 & 49.9 & 54.6 \\
\hline$\rho_{\mathrm{h}}\left(\mathrm{kg} / \mathrm{m}^{3}\right)$ & 77.1 & 75.8 & 110.4 & 108.6 \\
\hline$\rho_{c}\left(\mathrm{~kg} / \mathrm{m}^{3}\right)$ & 98.9 & 99.6 & 140.8 & 141.0 \\
\hline$\rho_{c}-\rho_{h}\left(k g / m^{3}\right)$ & 21.8 & 23.8 & 30.4 & 32.4 \\
\hline $\mathrm{q}_{\mathrm{sg}}(\mathrm{kW})$ & 2.43 & 2.67 & 2.95 & 3.26 \\
\hline$\dot{\mathrm{m}}_{\mathrm{hl}}(\mathrm{kg} / \mathrm{s})$ & 0.0467 & 0.0461 & 0.071 & 0.072 \\
\hline$\left(\mathrm{HA}_{\mathrm{o}} / \mathrm{C}^{\prime} \mathrm{D}^{5}\right)^{1 / 2}$ & 0.1025 & 0.0972 & 0.1111 & 0.1090 \\
\hline$C_{\text {max }}^{\prime}$ & 1.73 & 1.93 & 1.47 & 1.53 \\
\hline $\mathrm{Re}_{\mathrm{De}}$ & 36,700 & 36,300 & 56,100 & 56,700 \\
\hline
\end{tabular}
fluxes, mass flows, the correlating parameter $\left(\mathrm{HA}_{\mathrm{o}}{ }^{2} / \mathrm{C}^{\prime} \mathrm{D}^{5}\right)$, the maximum value of $\mathrm{C}^{\prime}$, and the hot leg Reynolds number for Tests S-6 and S-7.

Table D-2. Hot leg countercurrent flow parameters for Tests S-6 and S-7. 


\section{D-2.3 Derived Flow Parameters in the Steam Generators}

For Tests S-7 and S-6, the derived steam generator flow parameters were not reported in the Westinghouse report (see Reference D-2). However, for the third series of experiments, which focused on the flow conditions in the hot legs and steam generator, steam generator flow parameters were derived from the experimental data. Therefore, using the methodology outlined in the Westinghouse report, steam generator flow parameters were derived from the experimental data for Tests S-7 and S-6. The derived flow parameters included

- Left steam generator tube bundle mass flow rate

- $\quad$ Average inlet and outlet temperatures

- Number of tube bundles carrying hot and cold flow

- Average temperature in the inlet plenum mixing volume

- Fraction of flow entering the inlet plenum that mixes with the flow exiting the tube bundle.

The definitions of these flow parameters follow. Flow parameters were only calculated for the left steam generator because vapor temperatures were not recorded in the right steam generator inlet plenum.

The left steam generator tube bundle mass flow rate, $\dot{m}_{t}$, was derived by equating the change in energy of fluid flowing through the steam generator with the heat rejected by the steam generator

$\dot{m}_{t}=\frac{q_{S G}}{\bar{C}_{p}\left(T_{h t}-T_{c t}\right)}$

where $q_{S G}$ is the measured heat rejected by the steam generator, and $T_{h t}$ and $T_{c t}$ are the average fluid temperature entering and leaving the tube bundle in the inlet plenum, respectively. As was done in the Westinghouse report, fluid temperatures in the tubes on the inlet plenum side were sorted to find those that had hot fluid entering the bundle and those that had cooled flow returning. For Tests S-6 and S-7, there were 51 functioning thermocouples and 216 steam generator tubes. The total number of hot tubes was estimated as the number of hot thermocouples times 216 and divided by 51 . The number of cold tubes was then simply 216 minus the number of hot tubes. The average fluid temperatures entering and leaving the tube bundle, $\mathrm{T}_{\mathrm{ht}}$ and $\mathrm{T}_{\mathrm{ct}}$, were calculated as the average temperature of the identified hot and cold thermocouple readings, respectively.

The average temperature in the inlet plenum, $\mathrm{T}_{\mathrm{m}}$, was derived using the Westinghouse analytical mixing model and experimental data (see Reference D-2). The mixing model results in the following expression for $T_{m}$

$T_{m}=\frac{T_{h}+\left(\dot{m}_{t} / \dot{m}_{h l}\right) T_{c t}}{I+\left(\dot{m}_{t} / \dot{m}_{h l}\right)}$

where

$$
\begin{aligned}
\dot{m}_{h l}= & \text { mass flow rate through the hot } \\
& \operatorname{leg}(\mathrm{kg} / \mathrm{s}) .
\end{aligned}
$$

The mixing model was also used to estimate the mixing fractions, $f_{1}$ and $f_{2}$, which quantify the fraction of flow entering the inlet plenum from the hot leg and from the tube bundle, respectively. The flow mixing results in a lower inlet temperature to the tube bundle and raises the temperature of vapor returning to the hot leg. For symmetrical mixing, $f_{1}=f_{2}=f$ and the mixing fraction is defined as

$f=1-\left(\dot{m}_{t} / \dot{m}_{h l}\right) \frac{\left(T_{h t}-T_{m}\right)}{\left(T_{h}-T_{m}\right)}$

Table D-3 lists the steam generator flow parameters for Tests S-6 and S-7. 
Table D-3. Steam generator flow parameters for Tests S-6 and S-7.

\begin{tabular}{|c|c|c|c|c|}
\hline \multirow[b]{3}{*}{ Steam generator } & \multicolumn{4}{|c|}{ Test number } \\
\hline & \multicolumn{2}{|c|}{$S-6$} & \multicolumn{2}{|c|}{$S-7$} \\
\hline & Left & Right & Left & Right \\
\hline \multicolumn{5}{|l|}{ Flow parameters } \\
\hline $\mathrm{q}_{\mathrm{sg}}(\mathrm{kW})$ & 2.43 & 2.67 & 2.95 & 3.26 \\
\hline Number of hot tubes & 64 & NA & 72 & NA \\
\hline Number of cold tubes & 152 & NA & 144 & NA \\
\hline$\dot{\mathrm{m}}_{\mathrm{t}}(\mathrm{kg} / \mathrm{s})$ & 0.0919 & NA & 0.147 & NA \\
\hline$\dot{\mathrm{m}}_{\mathrm{hl}}(\mathrm{kg} / \mathrm{s})$ & 0.0467 & 0.0461 & 0.071 & 0.072 \\
\hline$\dot{\mathrm{m}}_{\mathrm{t}} / \dot{\mathrm{m}}_{\mathrm{hl}}$ & 1.97 & NA & 2.06 & NA \\
\hline $\mathrm{f}$ & 0.85 & NA & 0.89 & NA \\
\hline $\mathrm{T}_{\mathrm{ht}}\left({ }^{\circ} \mathrm{C}\right)$ & 77.5 & NA & 69.5 & NA \\
\hline $\mathrm{T}_{\mathrm{ct}}\left({ }^{\circ} \mathrm{C}\right)$ & 44.5 & NA & 45.9 & NA \\
\hline 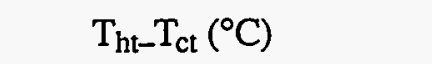 & 33.0 & NA & 23.6 & $\mathrm{NA}$ \\
\hline $\mathrm{T}_{\mathrm{m}}\left({ }^{\circ} \mathrm{C}\right)$ & 73.2 & NA & 67.1 & NA \\
\hline
\end{tabular}

\section{D-3. RELAP5/MOD3 MODEL DESCRIPTION}

The RELAP5/MOD3 model of the Westinghouse experimental apparatus included all of the major components necessary to perform the steady-state analyses. The reactor vessel, two hot legs, and two steam generators were modeled. Also, thermodynamic and thermal hydraulic properties of $\mathrm{SF}_{6}$ vapor were obtained. All information was obtained from References D-1 and D-2.

\section{D-3.1 Reactor Pressure Vessel}

The reactor vessel model was developed analogous to that of the Surry vessel model developed by Bayless. ${ }^{\mathrm{D}-4}$ The core and upper plenum were divided into three radial regions. The core regions were selected so that similarly powered fuel assemblies were grouped together. The upper plenum regions were extensions of the core regions. However, the outer channel of the upper plenum was wider than the outer channel of the core because of the core barrel extension in the upper plenum region. The three channels were connected at each elevation by crossflow junctions, thereby approximating a two-dimensional model of the core and upper plenum. The three-channel model nodalization is shown in Figure D-1.

Vessel heat structures modeled include the reactor vessel walls, the fuel assemblies, the top nozzle assembly, the upper core plate, the upper plenum structures, and the upper head walls and internal structures. Figures D-2 and D-3 show the cross sections of the three-channel core and upper plenum models, respectively. Also provided in 


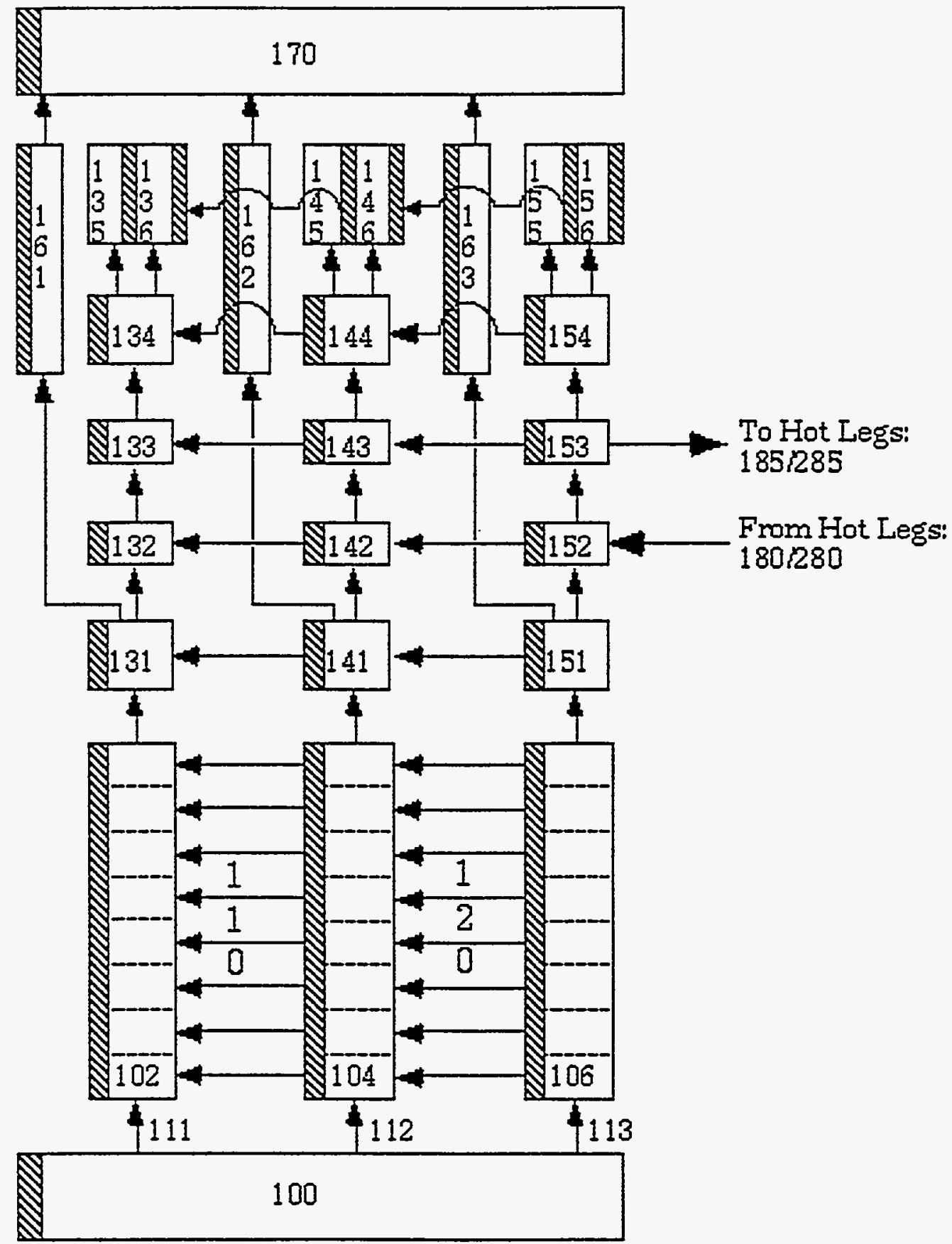

Figure D-1. RELAP5/MOD3 nodalization of the reactor vessel for in-vessel natural circulation.

Figure D-2 is the number of fuel assemblies in each core region, along with their relative powers. The upper plenum's internal structure locations within the defined channels are shown in Figure D-3. These internal structures include the control rod guide tubes, communication tubes, and support columns.
The upper head was modeled with a branch volume and communicated with the lowest volumes in the upper plenum via the modeled communication tube flow paths. The lower plenum was modeled as a pipe divided into two axial volumes. This axial nodalization enabled simulation of stratified vapor in the lower plenum. The lower 


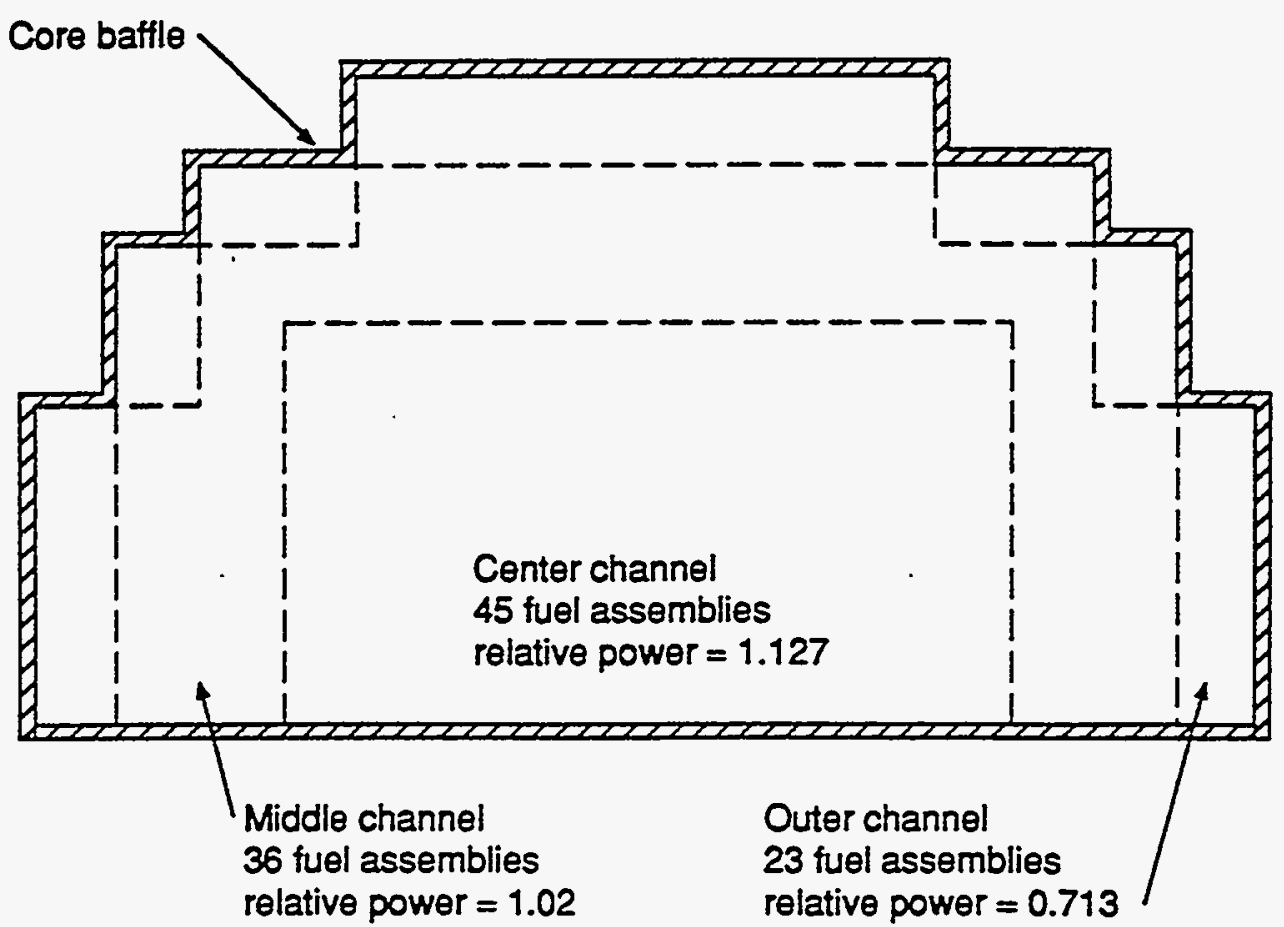

Figure D-2. Cross section of the three-channel core region.

plenum's upper volume communicated with each of the three core channels via three single junctions. Another junction connected the lower plenum's lower volume to a time-dependent volume. The time-dependent volume was used to specify the system pressure.

In the Westinghouse experiments, the reactor fuel was simulated with 104 0.5-in.-diameter sheathed rods, heated over a 21 -in. length with internal electric resistance elements. The electric core heaters were grouped into 10 sections, which were parallel connected. Each heater section was energized and controlled separately to match the radial decay heat density variation through the core. Five radial power groups established a radial distribution of $114 \%$ of average at the center, $112 \%$ in the center-middle, $102 \%$ in the middle-outer, $80 \%$ at the outer boundary, and $55 \%$ in the corners of the core barrel baffle assembly. The axial power distribution was uniform for all of the heater elements. For the calculational model, the experimental radial power distribution was regrouped into three radial power bands to correspond with the model's three core channels. The model's center channel combined the experimental center and center-middle sections with an average power distribution of $113 \%$ of the average power. The model's middle channel consisted of the experimental middleouter section with a power distribution of $102 \%$ of average. The model's outer channel combined the experimental outer boundary and corner sections with an average power of $71 \%$ of the average power.

The active heater length was divided into eight equal axial nodes, numbered 1 to 8 from the bottom to top, corresponding to the nodalization of the fluid volumes in the core. This nodalization was based upon the Westinghouse experimental fuel assemblies, which had eight interconnected cells separated by grid spacers along its length. The grid spacers had openings that behaved as orifices. The modeled flow area of the openings was based upon the experimental apparatus geometry. The axial form loss coefficients of the grid spacers were specified as 0.947 based upon a reference Reynolds number of 5,460 for flow through the grid spacer (see Reference D-1, 


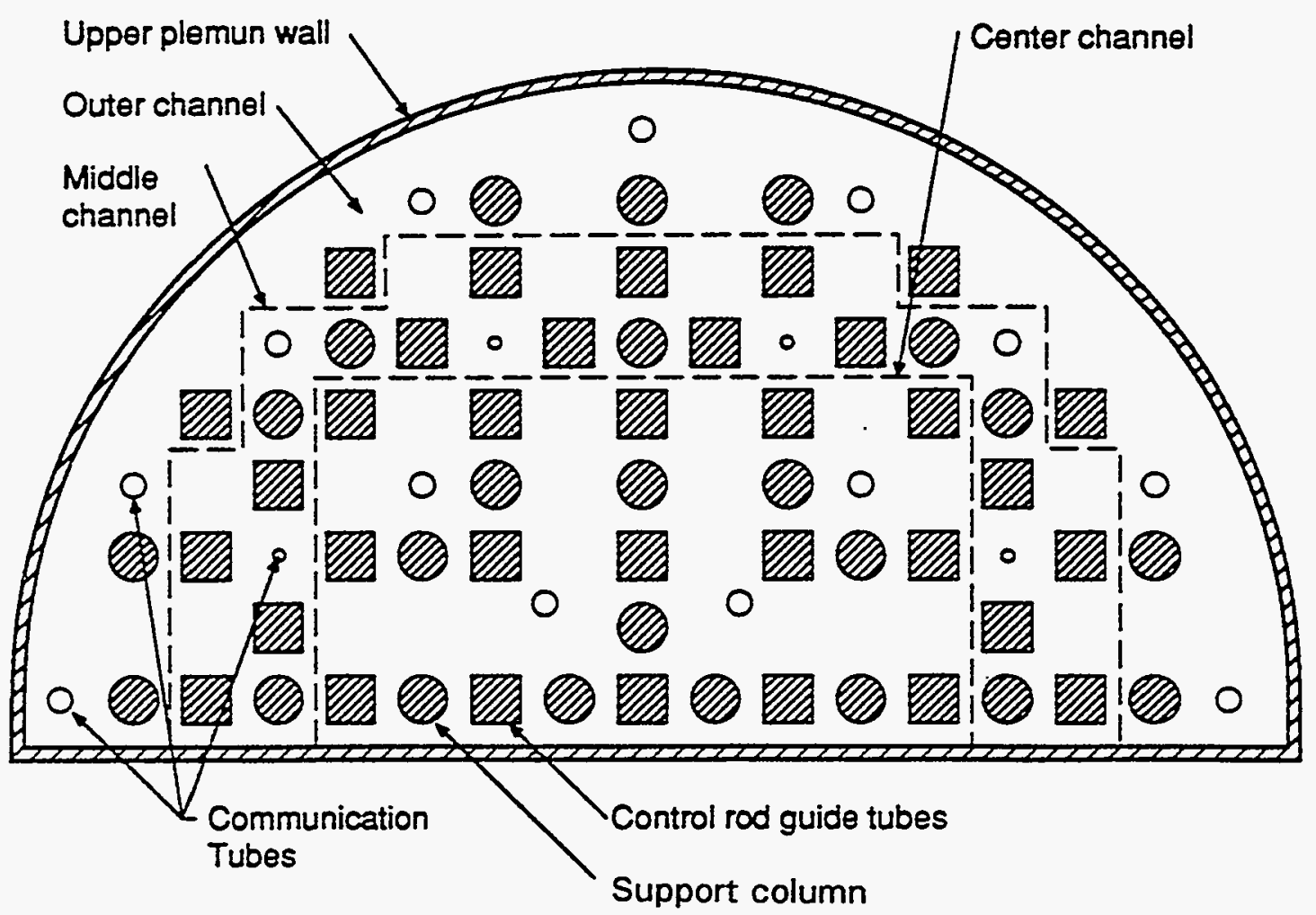

Figure D-3. Cross section of the three-channel upper plenum region and internal structures.

page $A-10$ ). The surface loss coefficients were calculated by the code and ranged in value from 0.1 to 0.55 , depending upon the flow conditions.

Radial flow in the core was modeled using crossflow junctions to connect the three core channels. The crossflow geometry was based upon the experimental apparatus. For lateral flow traveling from the core periphery towards the core center, the flow loss coefficients at the core channel junctions were specified as 1.881 . This radial loss coefficient was based upon the total loss coefficient for radial flow through one fuel assembly and a reference Reynolds number of 5,780 for flow through the crossflow slots (see Reference D-1, page A-11). For lateral flow traveling from the center of the core towards the periphery of the core, the loss coefficients were increased by a factor of 10 to 18.81 . While one would not expect different loss coefficients for the different directions, it was found that increasing the center-to-periphery loss coefficient by a factor of 10 yielded better results.
In the experimental apparatus, the top nozzle assembly and the upper core plate separate the top of the fuel assemblies from the upper plenum. In the RELAP5/MOD3 model, the top nozzle assembly and upper core plate were not modeled explicitly, but were simplified to a multiple junction connecting the three core channels with the upper plenum volumes above each core channel. To model the flow losses through the top nozzle assembly and upper core plate, the junction overall loss coefficients were evaluated by use of the electrical resistance network method. ${ }^{D-5}$ That is, the pressure losses for the top nozzle assembly and the upper core plate were calculated separately as if the other did not exist and the pressure loss coefficients added. The separate loss coefficients of the top nozzle assembly and upper core plate were calculated for flow through an orifice plate of prescribed geometry. Since the flow loss coefficients are dependent upon the Reynolds numbers for flow through the plates and vice versa, determining the loss coefficients was an iterative process. First, an assumed flow 
Reynolds number for each component was used to calculate the loss coefficients. The loss coefficients were then input to the RELAP5 input model. A transient calculation was run until the flow conditions reached steady state, and the assumed Reynolds numbers were compared with the latest calculated values. If the Reynolds numbers were not comparable, then new loss coefficients were calculated based upon the latest calculated Reynolds numbers. The process was repeated until the Reynolds numbers and loss coefficients converged.

Using this iterative process, the flow Reynolds numbers and loss coefficients were obtained for the three junctions of the core channels with the upper plenum volumes in the RELAP5 input model. The RELAP5 input model for Westinghouse steady-state Test S-7 was used in determining the loss coefficients. Table D-4 presents the flow Reynolds numbers and loss coefficients obtained. In the center channel, the flow is upward out of the core with Reynolds numbers of approximately 4,500 and 28,000 through the top nozzle assembly and upper core plate, respectively. In the middle channel, the flow is down- ward into the core with Reynolds numbers of approximately 3,100 and 19,300 . In the outer channel, the flow is also downward with Reynolds numbers of 4,400 and 28,300 . The top nozzle assembly and upper core plate combined loss coefficients for the center, middle, and outer channels are $12.7,9.8$, and 10.0 , respectively.

For Test $\mathrm{S}-6$, these same flow loss coefficients were used. The resulting Reynolds numbers and corresponding loss coefficients are presented in Table D-5. While the resulting Reynolds numbers are somewhat different than those calculated in Test S-7, the overall loss coefficients were not significantly different from those obtained for Test S-7. Therefore, further iteration of the loss coefficients for Test S- 6 was not necessary and the reported calculation was performed with loss coefficients for the center, middle, and outer channels of $12.7,9.8$, and 10.0 , respectively.

The specific geometry for the junction between the lower plenum and the fuel assemblies was not provided in the apparatus description presented in References D-1 and D-2. However, based upon personal communications with William Stewart

Table D-4. Reynolds numbers and loss coefficients for the top nozzle assembly and upper core plate for Test S-7.

Flow channel

\begin{tabular}{lll}
\multicolumn{1}{c}{ Center } & \multicolumn{1}{c}{ Middle } & \multicolumn{1}{c}{ Outer } \\
\hline Exiting core & Entering core & Entering core \\
& & \\
4,500 & 3,100 & 4,400 \\
28,000 & 19,200 & 28,300 \\
& & \\
4.52 & 4.50 & 4.52 \\
8.14 & 5.29 & 5.44 \\
12.7 & 9.8 & 10.0
\end{tabular}

a. Obtained from RELAP5 calculation of the natural circulation flow.

b. Obtained for flow through an orifice plate of prescribed geometry. 
Table D-5. Reynolds numbers and loss coefficients for the top nozzle assembly and upper core plate for Test S-6.

\begin{tabular}{|c|c|c|c|}
\hline & \multicolumn{3}{|c|}{ Flow channel } \\
\hline & Center & Middle & Outer \\
\hline Flow direction ${ }^{\mathrm{a}}$ & Exiting core & Entering core & Entering core \\
\hline \multicolumn{4}{|l|}{ Reynolds number ${ }^{\mathrm{a}}$} \\
\hline Top nozzle assembly & 3,300 & 2,300 & 3,300 \\
\hline Upper core plate & 20,600 & 14,200 & 21,500 \\
\hline \multicolumn{4}{|l|}{ Flow loss coefficient ${ }^{b}$} \\
\hline Top nozzle assembly & 4.50 & 4.49 & 4.50 \\
\hline Upper core plate & 7.97 & 5.09 & 5.34 \\
\hline Total loss coefficient & 12.5 & 9.6 & 9.8 \\
\hline \multicolumn{4}{|c|}{ a. Obtained from RELAP5 calculation of the natural circulation flow. } \\
\hline \multicolumn{4}{|c|}{ b. Obtained for flow through an orifice plate of prescribed geometry. } \\
\hline
\end{tabular}

of Westinghouse, some circulation of coolant into the lower plenum occurred, but was not measured. Thermocouple data reveal that the vapor temperatures in the middle of the lower plenum were lower than that recorded at the bottom of the core channels. This temperature data suggests that the vapor was thermally stratified in the lower plenum. Therefore, for lack of better information, the junction loss coefficients for the three junctions connecting the core channels and the lower plenum were specified as 0.947 . This value is the same as that specified for the core channel grid spacers (see Reference D-1, page A-10). These lower plenum junctions allow vapor from the core channels to circulate through the upper volume of the lower plenum, while the bulk of the lower plenum vapor remains undisturbed and cooler in the lower volume.

The upper plenum channels were divided into five axial nodes. Located within these volumes were the upper plenum internal structures. These included the control rod guide tubes, support columns, and communication tubes. Additionally, the upper plenum wall structure enclosed these internal structures. The radial distribution of these structures is shown on the upper plenum cross section in Figure D-3. A schematic view of the upper plenum internal structure and nodalization is presented in Figure D-4. The two hot legs communicated with the outer channel. During steadystate experiments, cooling water flowed through tubing attached to the outside surface along the cylindrical portion of the upper plenum wall. This cooling was modeled by specifying a surface heat flux on the upper plenum wall outside surface. The surface heat flux was determined by dividing the heat removed through the wall by the surface area and was specified as input. The axial and crossflow form loss coefficients for flow between adjoining upper plenum volumes were not known and assumed values of 1.0 were used for all volume junctions.

In the experimental apparatus, the 34 control rod guide tubes extended from the upper support plate to the upper core plate. Over the upper 15.2 in., the guide tubes were modeled as 1-in.-square stainless steel tubes with 0.083-in. wall thickness and closed off at both ends. The lower 5.66 in. above the upper core plate were 


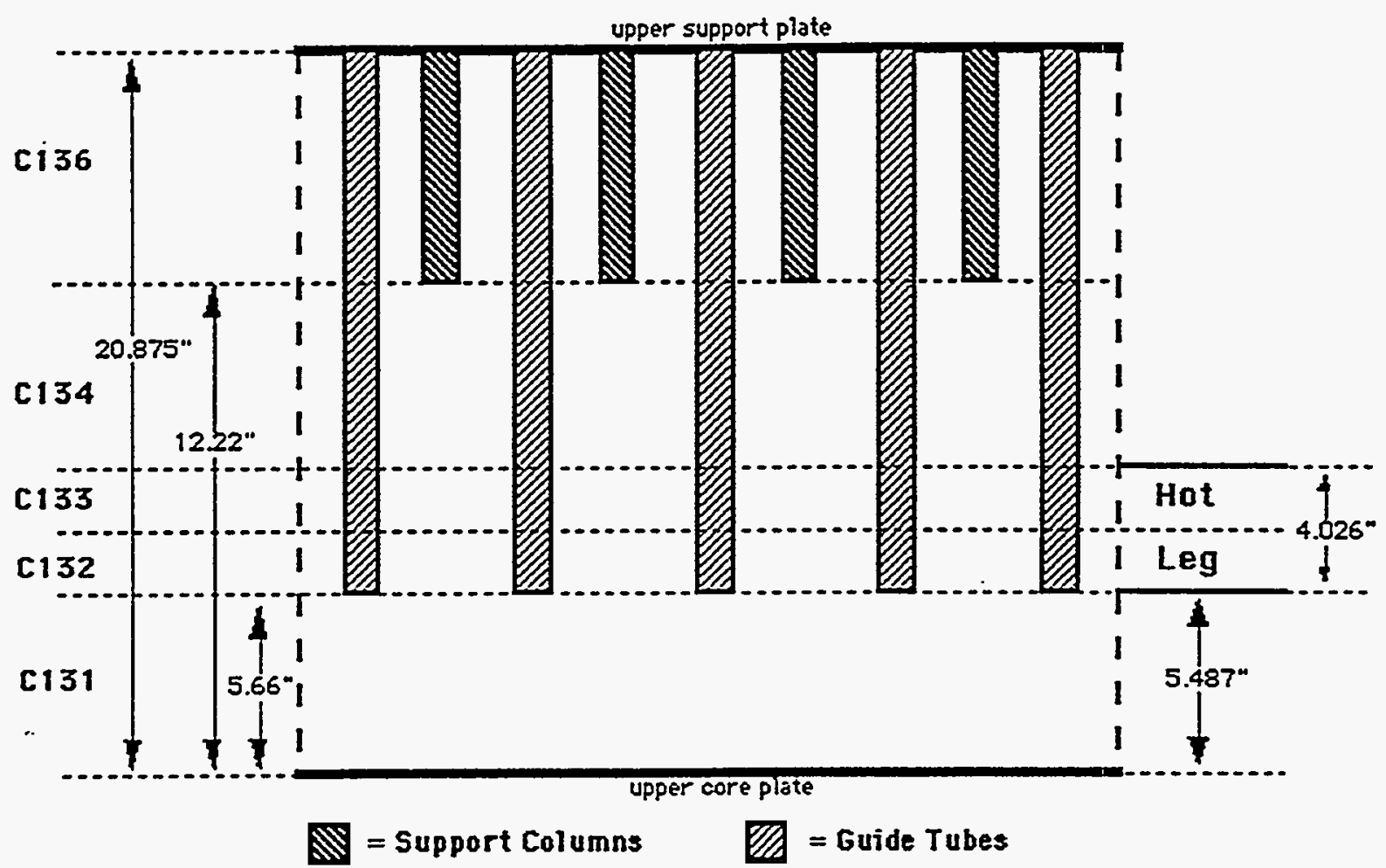

Figure D-4. Schematic view of the upper plenum internal heat structure geometry and nodalization.

open to permit transverse flow. For the steadystate experiments, cooling water recirculated through tubing attached to the inside of the closed off portion of the guide tubes. This cooling water entered the guide tubes through a manifold system located in the upper head. As modeled, these 34 cooled guide tubes were lumped together into three heat structures. These three heat structures were distributed one to each upper plenum radial channel. These heat structures extended from the upper support plate to the upper core plate. The upper head manifold system was modeled simply as a heat structure located in the upper head volume. The heat removed by these structures was modeled by specifying a surface heat flux on the inside surface of the guide tube structure and on the manifold system structure. As was done in modeling the upper plenum wall cooling, the surface heat flux was determined by dividing the heat removed through the guide tube cooling system by the sum total of the guide tube and manifold surface areas.

In the experimental apparatus, 24 support columns extended from the upper support plate to the upper core plate. Over the upper 8.66 in., the support columns were 1.062-in.-diameter tubes with 0.069 -in. wall thickness, open at the lower end, but closed off on the top. The lower 12.2 in. of the tubes above the upper core plate had large openings in the tube sides to permit transverse flow. As modeled, these 24 support columns were lumped together into three hydrodynamic volumes and associated heat structures. These three modeled columns were distributed one to each upper plenum radial channel. The columns' hydrodynamic volume extended 8.66 in. from the upper support plate and were open only at the lower end forming a cul-de-sac. The support column heat structures extended from the upper support plate to the upper core plate. Friction losses were not calculated for these components and the entrance form losses were specified as 1.0.

In the experimental apparatus, 17 communication tubes were used to provide flow paths between the upper plenum and the upper head. (In a reactor, this flow path is provided by the clearances in the control rod guide tubes.) Thirteen of the communication tubes were 0.5 -in.-diameter 
tubes with 0.049 -in. wall thickness. The remaining four were 0.25 -in.-diameter tubes with 0.035-in. wall thickness. As modeled, these 17 tubes were lumped together into three hydrodynamic volumes and associated heat structures. These three modeled tubes were distributed one to each upper plenum radial channel. The tubes extended from the upper support plate to 5.66 in. above the upper core plate and were open at both ends to provide communication between the upper head and the lower volume of the upper plenum. The communication tubes' friction and form loss coefficients were calculated by the code for the given flow conditions and specified geometry.

\section{D-3.2 Hot Legs}

Both of the hot leg pipes were modeled. The hot leg models were identical and included both the fluid volume and the metal structures. The piping was assumed to be adiabatic on the outer surface. In order to model the countercurrent flow in the hot legs, the hot leg was divided into top and bottom flow paths. Figure D-5 shows the nodalization of one hot leg for countercurrent flow calculations. Previous split hot leg input models divided the total flow area of the hot leg pipe into two equal halves (see Reference D-4). However, during the Westinghouse experiments, it was observed that the interface of the countercurrent flow was sloped, rising from the reactor vessel to the steam generator. Under steady-state conditions, the hot flow occupied approximately $72 \%$ of the hot leg volume at the reactor vessel connection; the returning cooled flow occupied the remaining $28 \%$. At the steam generator end of the hot leg, the volume of the hot flow entering the steam generator was reduced to $28 \%$ of the hot leg volume and the returning cooled flow occupied the remaining $72 \%$. The reduction in the

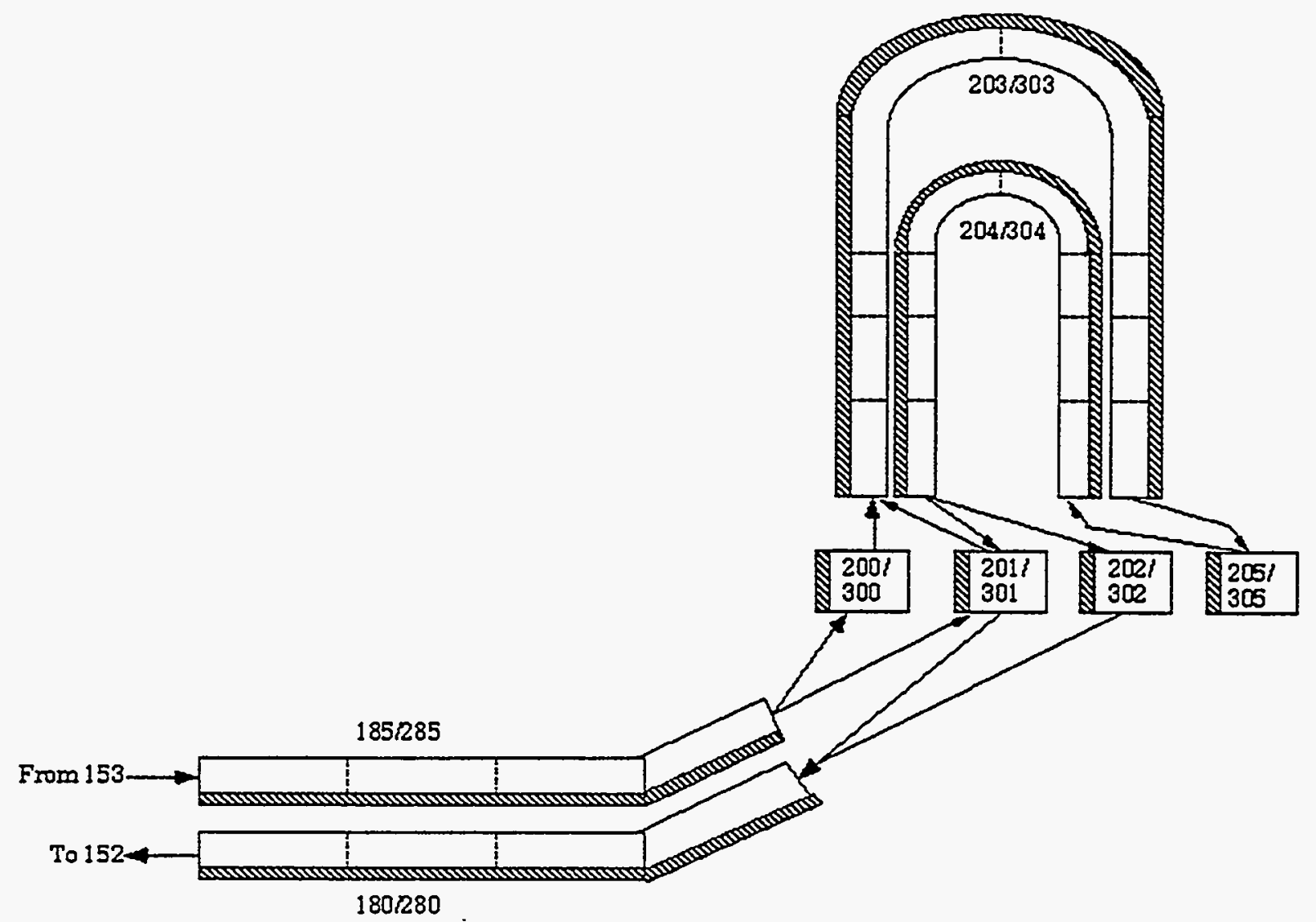

Figure D-5. RELAP5/MOD3 nodalization of the hot leg and steam generator for hot leg natural circulation. 
flow cross-sectional area along the length of the hot leg was approximated by dividing the hot leg into a series of four subvolumes with discreet flow areas that decreased in the direction of flow. This interface nodalization for one hot leg is shown in Figure D-6. The fractional flow areas for the four subvolumes are $0.68,0.57,0.42$, and 0.31 for the hot fluid traveling from the reactor vessel to the steam generator. For the cooled returning flow, the fractional flow areas are reversed with 0.68 and 0.31 at the steam generator and reactor vessel ends, respectively.

The form loss coefficients at the hot leg subvolume junctions were specified as zero. The shear loss at the countercurrent flow interface was approximated by assuming the interface acted as a very rough surface with a wall roughness of $9 \mathrm{~mm}$. The surface roughness of the pipe wall was specified as $5 \times 10^{-5} \mathrm{~m}$. An equivalent wall roughness for each hot leg volume was then defined as a surface area weighted average of the interface roughness and the pipe wall roughness.

The hot leg junction with the reactor vessel was modeled such that the flow leaves the reactor vessel and enters the top path of the hot leg at the midpoint of Volume 153. The return flow from the bottom path of the hot leg enters the reactor vessel at the midpoint of Volume 152, as shown in Figure D-1. The pressurizer surge line on the right hot leg was not modeled because the safety valve venting was not operated during the steady-state experiments.

\section{D-3.3 Steam Generators}

The steam generator model included the tubes, the tube sheet, the inlet channel head and flange, and the shell-side cooling water system. The left and right steam generators were modeled identically except for the cooling water inlet conditions. The metal masses associated with the steam generator walls and internals were modeled, with the outer surface of the steam generators assumed to be adiabatic. The steam generator inlet plenum was divided into three volumes. A mixing volume in the middle connected to the flows entering and leaving both the hot leg and the steam generator tubes. The volumes on either side of the mixing volume passed hot and cold vapor directly to the steam generator and hot legs, respectively, without mixing with the other fluid in the inlet plenum. The amount of flow entering and leaving the mixing volume was adjusted by changing the junction loss coefficients and flow areas of the inlet plenum volumes. Simultaneously, the ratio of steam generator flow to the hot leg flow was also adjusted. This ratio and the fraction of hot leg flow entering the inlet plenum mixing volume, $\mathrm{f}_{2}$, were derived from the Westinghouse experimental data. For these experiments, the fraction of cooled steam generator flow entering the mixing volume, $f_{1}$, was assumed to be equal to $f_{2}$. For the RELAP5/MOD3 calculations, the junction loss coefficients and flow areas for the inlet plenum volumes were adjusted until the mass flow ratio and mixing fractions, $f_{1}$ and $f_{2}$, matched the correlated experimental data for Test S-7. For Test $\mathrm{S}-7$, the mass flow ratio and mixing fractions were found to be 2.06 and 0.89 , respectively. Once the experimental junction parameters were

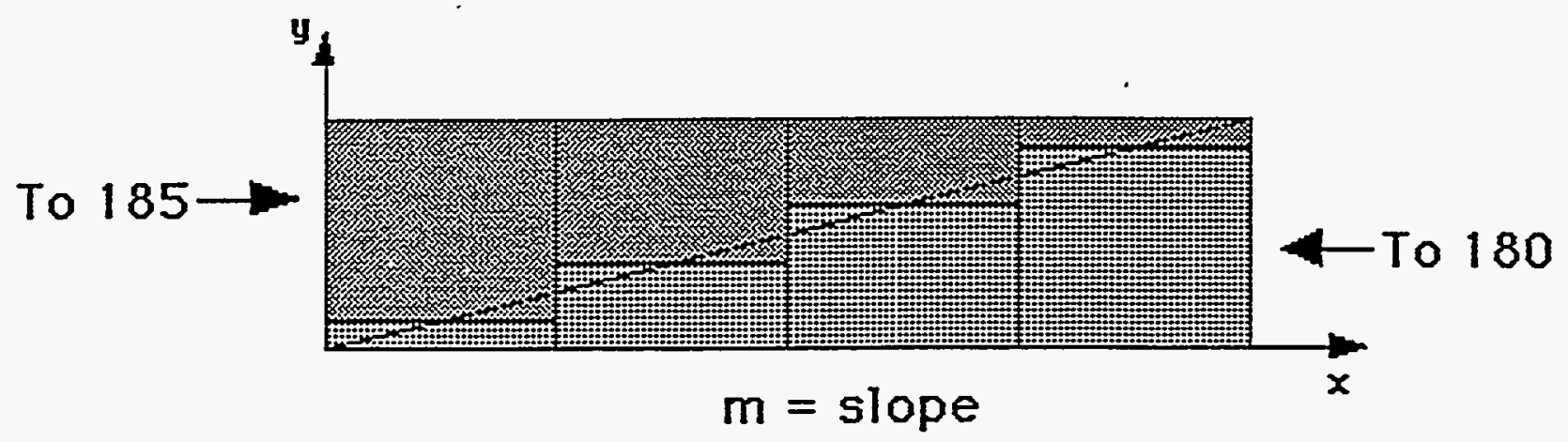

Figure D-6. Hot leg hot/cold interface and slope. 
matched for Test $S-7$, the same junction areas and loss coefficients were then used for Test S- 6 calculations.

Two sets of steam generator tubes connected the inlet and outlet plena. The number of tubes representing hot and cold flow tubes was derived from the Westinghouse experimental temperature data. For Test S-7, the number of hot and cold tubes were estimated as 72 and 144, respectively. For Test $S-6$, the number of hot and cold tubes were estimated as 64 and 152, respectively. For the code calculations, the number of hot and cold tubes was chosen as 72 and 144, respectively. This number of hot and cold tubes was used for both the S-7 and S- 6 calculations.

The shell side of the steam generator was modeled as a large pipe with a specified cooling water inlet flow rate and temperature. The steam generator cooling water inlet parameters were obtained from the Westinghouse experiments.

\section{D-3.4 $\quad \mathrm{SF}_{6}$ Vapor Properties}

For the modeled high-pressure Westinghouse experiments, the system conditions were such that the $\mathrm{SF}_{6}$ vapor properties deviated a considerable amount from ideal gas property relations. For example, at the system pressure of $2.172 \mathrm{MPa}$ (315 psia), a temperature of $45^{\circ} \mathrm{C}$, and using the ideal gas law of $\mathrm{Pv}=\mathrm{RT}$, the density of $\mathrm{SF}_{6}$ is underpredicted by $23 \%$. Similarly, at this same pressure and temperature, the coefficient of thermal expansion, $\beta$, is underpredicted by $58 \%$ when using the ideal gas relation of $1 / \mathrm{T}$. Because of these and other property value inaccuracies, approximate nonideal gas property models for $\mathrm{SF}_{6}$ vapor were developed and implemented in the RELAP5/MOD3 code calculations. Approximate gas property models were developed for the specific volume, $v$, the coefficient of thermal expansion, $\beta$, isothermal compressibility, $x$, and heat capacity at constant pressure, $\mathrm{C}_{\mathrm{p}}$. These property models were obtained using a fivecoefficient Martin-Hou type equation of state and thermodynamic relations. ${ }^{\mathrm{D}-6}$

\section{D-4. MODEL ANALYSES}

Two analytical simulations were performed for the Westinghouse steady-state experiments on natural circulation in a pressurized water reactor model using the RELAP5/MOD3 computer code. Tests S-6 and S-7 were modeled. These tests were steady-state experiments with $\mathrm{SF}_{6}$ at system pressures of 1.655 and $2.172 \mathrm{MPa}$ (240 and $315 \mathrm{psia}$ ), respectively. Both tests had core heating of $20.5 \mathrm{~kW}$. Section D-4.1 provides a brief description of the calculation procedure. Section $D-4.2$ presents the results for the two analytical simulations and compares the results with the Westinghouse experimental data. These results are organized and presented for the reactor vessel, hot legs, and steam generators separately. Coupling between the various components is discussed as appropriate. Section D-4.3 describes some of the uncertainties and limitations of the analyses.

\section{D-4.1 Procedure}

In performing the calculations, Test $\mathrm{S}-7$ was modeled first. The analysis consisted of specifying the experimental boundary and initial conditions, after which a series of code calculations was made. For each calculation, the form loss coefficients in the steam generator inlet plenums were adjusted until the mixing fractions and the ratio of steam generator to hot leg mass flow rates matched the experimental values of 0.89 and 2.06 , respectively. Once these parameters were matched satisfactorily, the calculations were repeated for Test S- 6 using the same loss coefficients, but with the Test S- 6 experimental boundary and initial conditions. Both calculations were run for $10,000 \mathrm{~s}$ of problem time. This problem time assured steady-state results. The minimum and maximum time steps were specified as $1.0 \times 10^{-7}$ and $0.1 \mathrm{~s}$, respectively.

\section{D-4.2 Results and Comparisons}

Analytical results were obtained and are presented for the core and upper plenum, the two hot legs, and the two steam generators. These results include the $\mathrm{SF}_{6}$ vapor temperatures, the 
mass flow rates, the heat added and removed, and flow parameters derived in the Westinghouse experiments. The results are grouped and presented for each modeled system: the core and upper plenum, the hot legs, and the steam generators.

\section{D-4.2.1 Natural Circulation Flow in the} Core and Upper PIenum. The available experimental data for the core and upper plenum consisted of vapor temperatures, core power, upper plenum cooling rates, and system pressure. Vapor flow rates and velocities were not measured in the experiments. Nevertheless, an averaged temperature distribution in the core and upper plenum was derived from the recorded experimental vapor temperatures and simple energy balances. The derivation of these experimêntal core and upper plenum flow parameters was presented in Section D-2.1.

Figures D-7 and D-8 present the experimental average temperature distributions for Tests $\mathrm{S}-7$ and $S-6$, respectively. The averaged temperatures were obtained by locating the position of each thermocouple relative to the RELAP5/MOD3 defined volumes. Then, an arithmetic average of the thermocouple readings assigned to each volume was calculated. RELAP5 volumes that did not have a corresponding thermocouple were left blank in the distribution diagram. The experimental range of temperatures for each volume is not depicted in these figures, but is reported later in comparison plots of the RELAP5-calculated temperatures.

The measured right and left hot leg temperatures were averaged and the result is also shown in Figures D-7 and D-8. The upper temperature represents the average temperature for the hot flow in the top of the hot leg and the lower temperature is the average temperature for the cooled flow in the bottom of the hot leg. In the experiments, the vapor temperatures in each stream changed along the length of the hot leg because of heat transfer and mixing of the two countercurrent streams. The average temperatures shown in these diagrams were obtained from thermocouples located at the hot leg/reactor vessel junction.
Recorded temperatures at the steam generator end of the hot leg are not depicted in these figures, but are presented later with the hot leg and steam generator results.

In the discussion that follows, the calculated vapor temperatures in the core and upper plenum are presented and compared with the experimental data. Next, the vapor mass flow rate and velocity distributions are discussed. Experimental flow rates for the core and upper plenum are not available so no comparisons with the calculated results are made. Finally, the code-calculated flow parameters are presented and compared with the derived experimental values.

Vapor Temperature Distribution. Figures D-9 and D-10 present the calculated vapor temperatures for the core and upper plenum control volumes for Tests S-7 and S-6, respectively. Figures D-11 and D-12 compare the experimental temperature data with the RELAP5-calculated values for Tests S-7 and S-6, respectively. In these latter two figures, the experimental data includes the average temperature and data variation associated with each average value. This data is presented separately for the center, middle, and outer channels of the vessel model.

The temperature distribution reflects the recirculating flow in the core and upper plenum. In the core there is a radial temperature distribution with higher temperatures in the center and lower temperatures at the periphery. The axial temperature distribution also outlines this recirculating flow. At the core periphery, the vapor temperature increases as the flow travels down through the core. In the center channel, the vapor heatup continues and drives the flow up through the core. In the middle channel, the axial temperature distribution is somewhat more complicated because of the recirculating flow in the core. The maximum temperature is seen about half way up the channel with cooler temperatures above and below this location. This is due to a combination of two phenomena. First, high temperatures occur half way up the channel because flow that stagnated in the recirculating pattern is heated to higher temperatures. Secondly, lower 


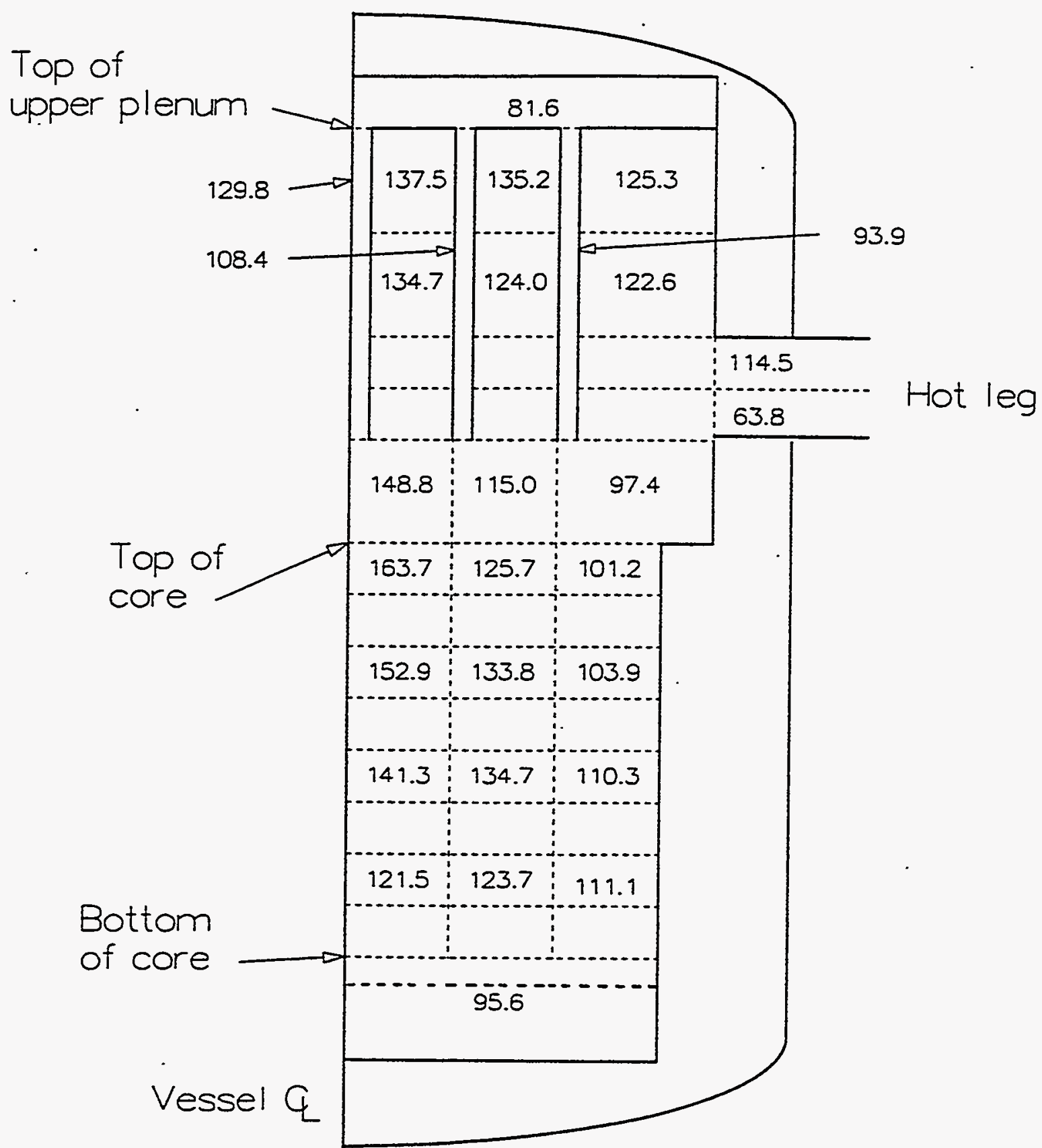

Figure D-7. Experimental $\mathrm{SF}_{6}$ vapor temperatures $\left({ }^{\circ} \mathrm{C}\right)$ in the core and upper plenum for Test S-7.

temperatures occur at the top of the core because of cooler vapor in the upper plenum flowing into the core.

In the upper plenum, the radial temperature distribution is similar to that in the core with hotter vapor rising in the center channel and cooler fluid descending at the plenum periphery. The axial temperature trend in the upper plenum is reversed to that in the core. As the vapor rises in the center channel, the temperature decreases as energy is transferred to the cooled guide tube structures. The vapor temperature continues to decrease as it turns across the top of the upper plenum and descends down the periphery of the plenum. In the outer channel, the descending vapor continues to cool as it transfers energy to the guide tube structures and the cooled upper plenum wall. 


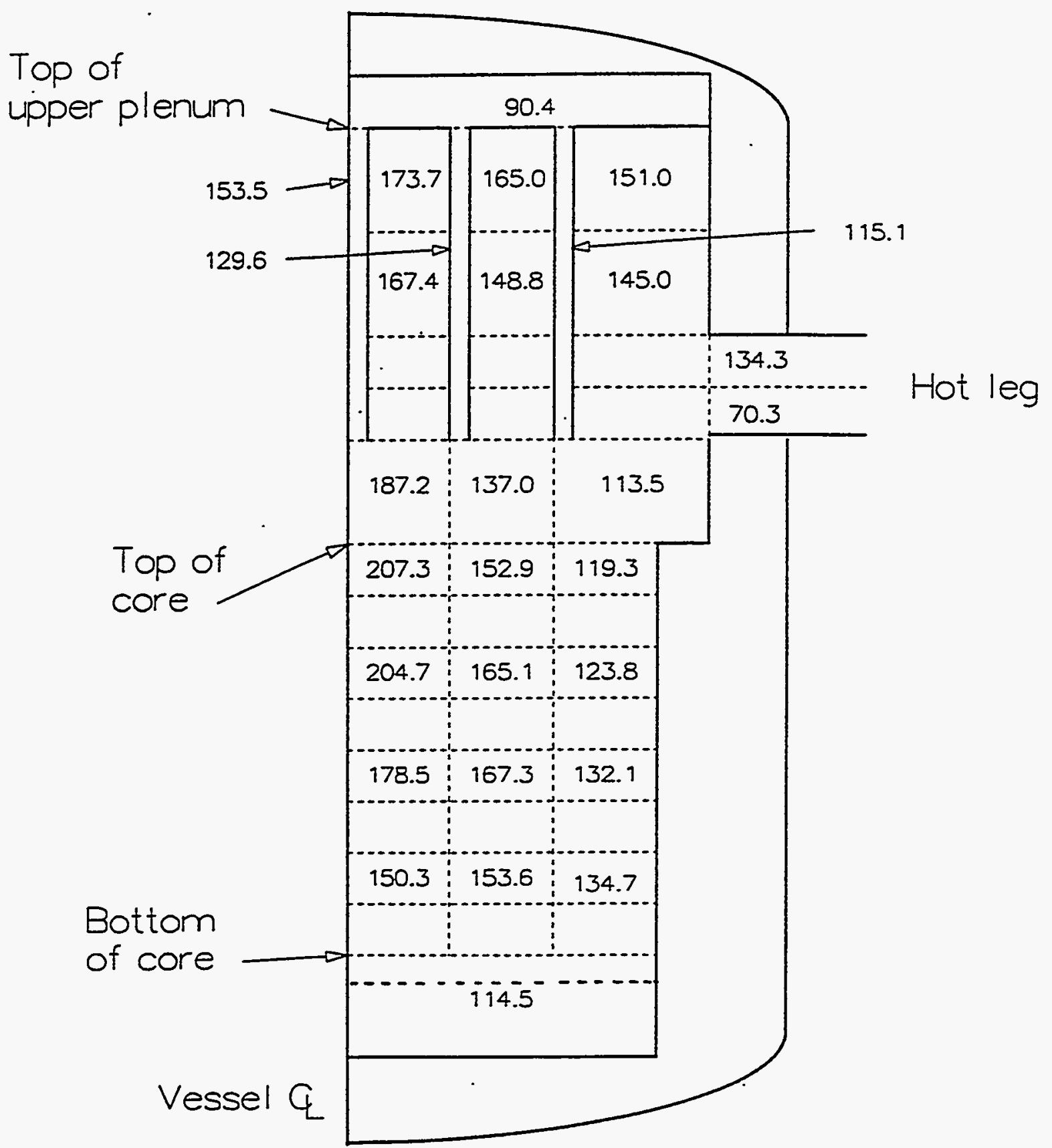

Figure D-8. Experimental $\mathrm{SF}_{6}$ vapor temperatures $\left({ }^{\circ} \mathrm{C}\right)$ in the core and upper plenum for Test S-6.

A comparison of the calculated temperature distribution with the experimental average temperatures reveals that the model matches up well in the core and upper plenum regions, overpredicts the lower plenum temperature, underpredicts in the upper head, and yields mixed results in the communication tubes. For both tests, the coolant temperature rise through the outer core channel is slightly overpredicted and underpredicted in the center core channel. For example, in the Test S-7 experiment, the vapor temperature increased approximately $10^{\circ} \mathrm{C}$ as the coolant traveled down the outside core channel and increased approximately $42^{\circ} \mathrm{C}$ as it traveled upwards in the center channel. The calculated temperature increase in the outer and center channels was 
Appendix D

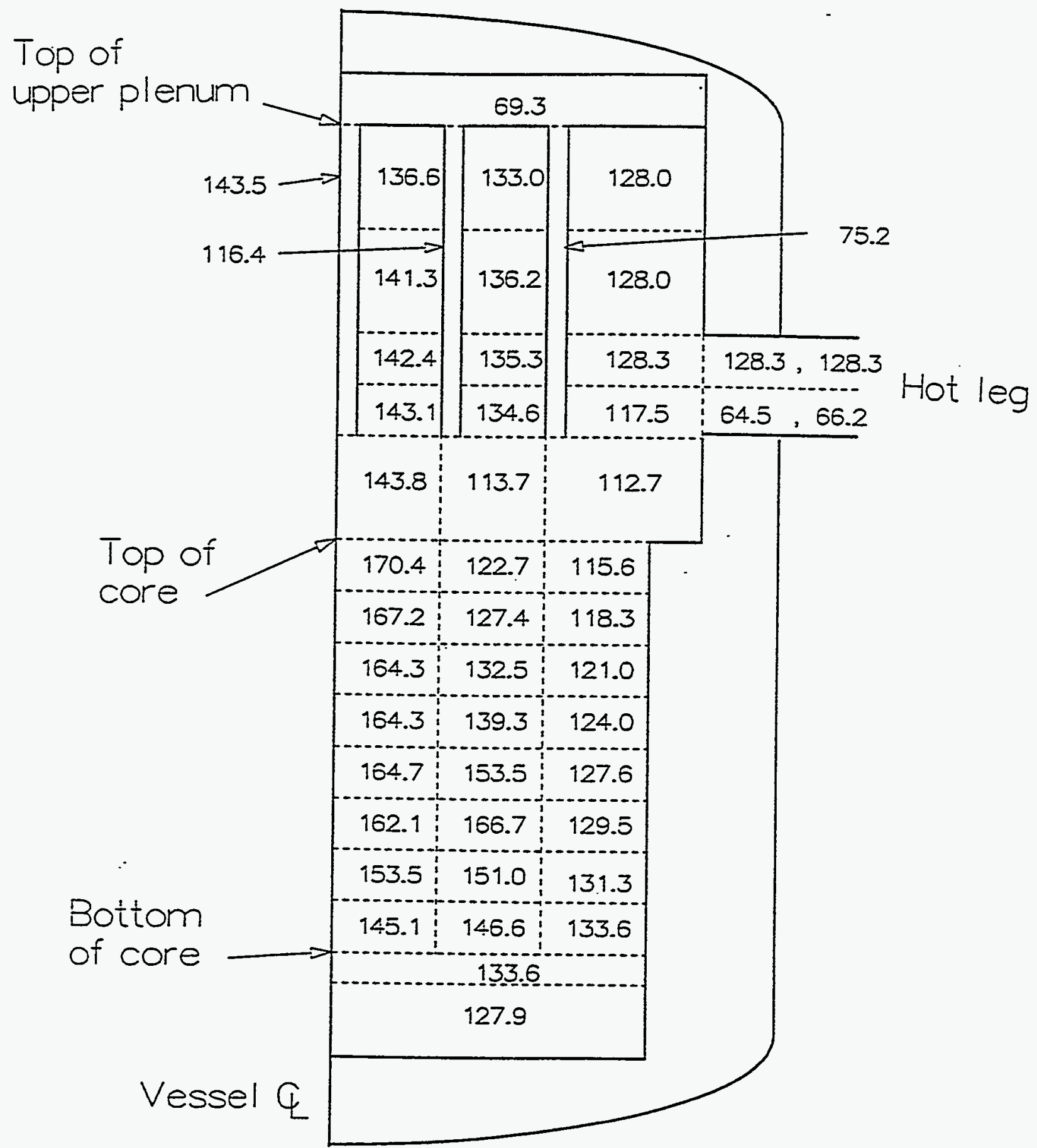

Figure D-9. Calculated $\mathrm{SF}_{6}$ vapor temperatures $\left({ }^{\circ} \mathrm{C}\right)$ in the core and upper plenum for Test $\mathrm{S}-7$. 
Appendix D

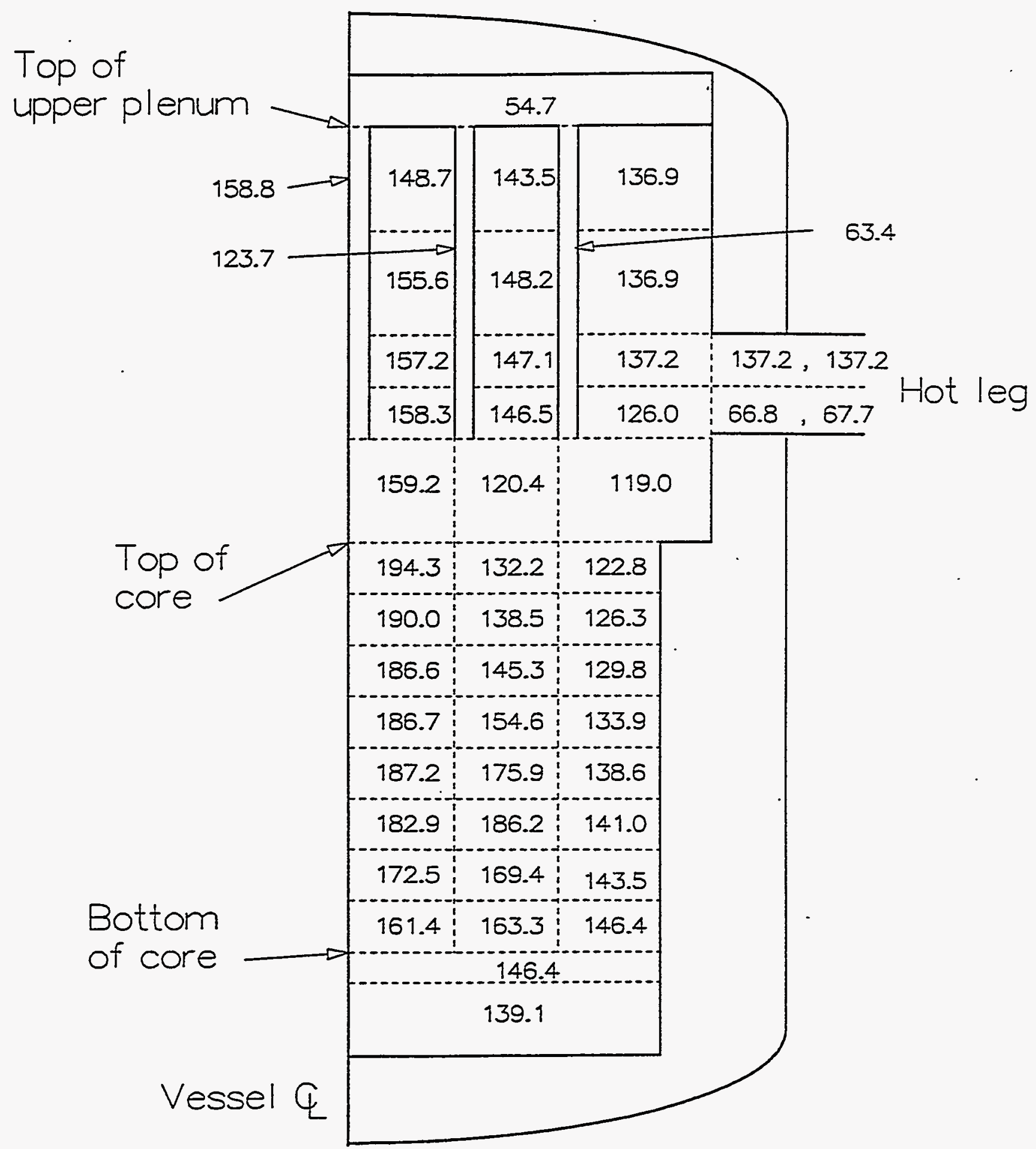

Figure D-10. Calculated $\mathrm{SF}_{6}$ vapor temperatures $\left({ }^{\circ} \mathrm{C}\right)$ in the core and upper plenum for Test S-6. 
Appendix D
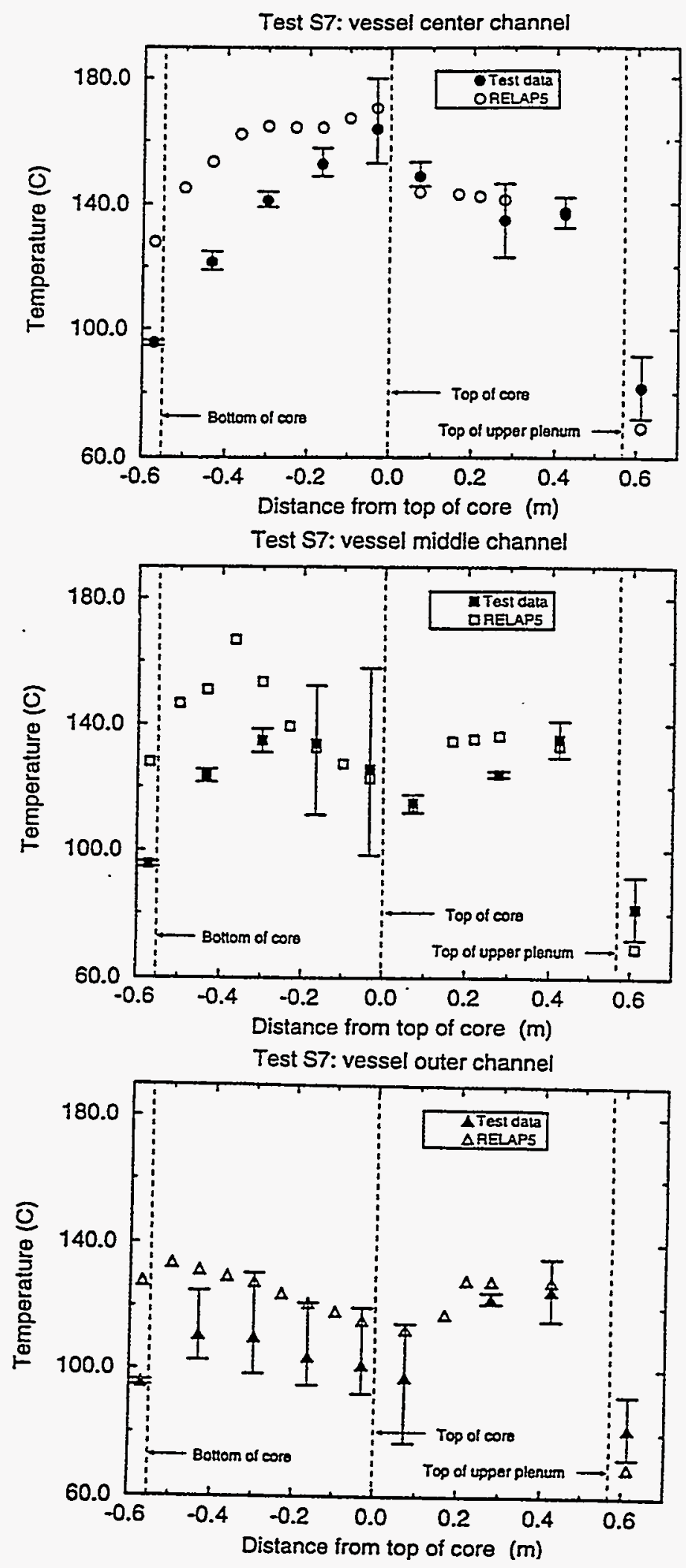

Figure D-11. Comparison of experimental and calculated $\mathrm{SF}_{6}$ vapor temperatures in the core and upper plenum for Test S-7. 

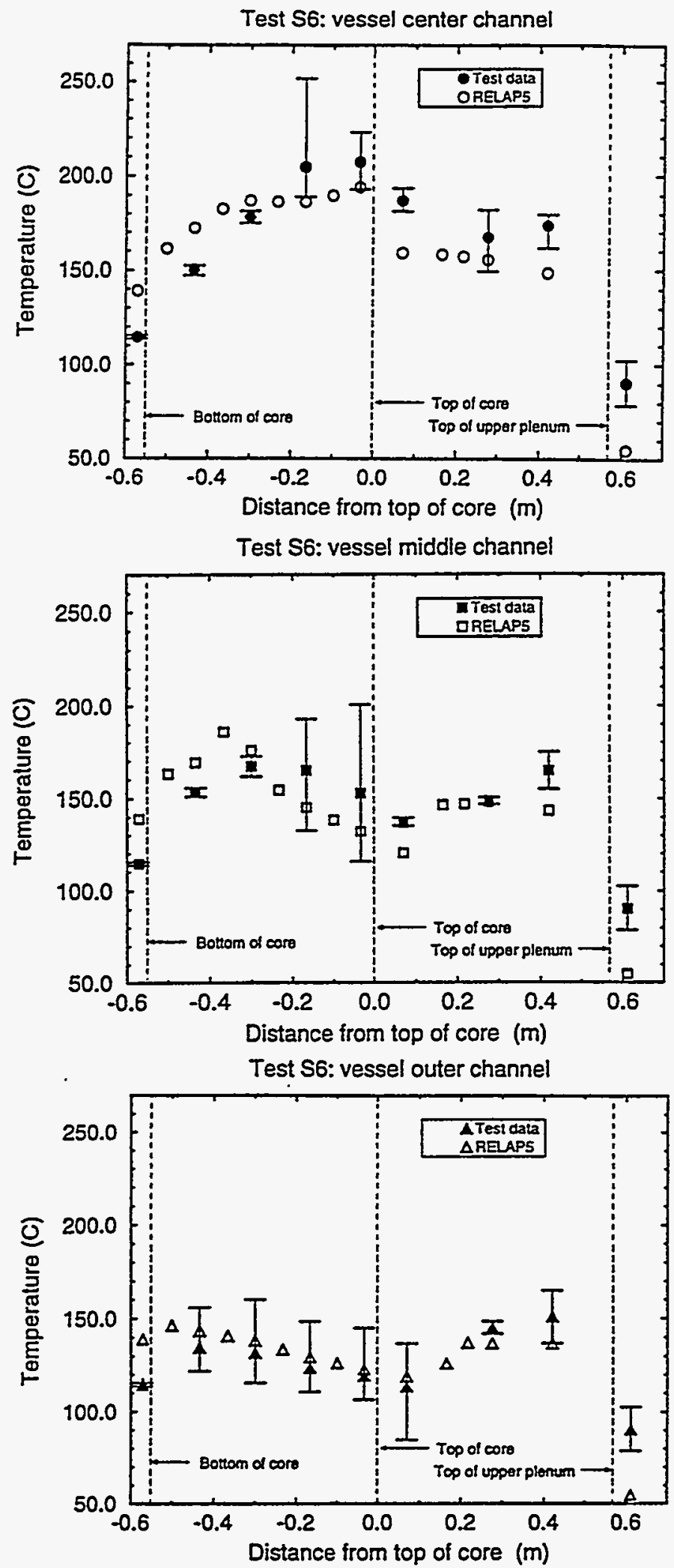

Figure D-12. Comparison of experimental and calculated $\mathrm{SF}_{6}$ vapor temperatures in the core and upper plenum for Test S-6. 
approximately 16 and $17^{\circ} \mathrm{C}$, respectively (as based upon the temperatures in the first and seventh RELAP5 volumes). For Test S-6, the experimental data indicated that the coolant temperature increased 15 and $57^{\circ} \mathrm{C}$ in the outer and center channels, respectively. The calculated temperature increase was 21 and $22^{\circ} \mathrm{C}$ in the outer and center channels, respectively.

In the middle channel, the axial temperature distribution is more complicated because of the complex flows there. The experiment results indicate the middle channel temperature peaks about $0.3 \mathrm{~m}$ below the top of the core. The calculated results peak a little lower at approximately $0.38 \mathrm{~m}$ from the core top. Above this location, the experimental and calculated values compare well. Below this location, the calculated results overpredict the experimental values. However, overall, the middle channel results compare favorably with the experimental trends.

Discrepancies in the vapor heating as it travels through the core could be due to using a fixed flow loss coefficient for the grid spacer junctions that does not account for variations in the flow Reynolds number. Also, the crossflow modeling of the radial core flow may not be appropriate in the lower regions of the core where the radial flow increases and the axial flow diminishes. The first of these issues could be addressed by modifying RELAP5 to allow flow loss coefficients as a function of Reynolds numbers. The second issue can only be addressed by modeling the experiments in three dimensions. Currently, this is not possible with RELAP5.

The maximum temperature is found at the top of the core in the center channel. For Tests S-7 and S-6, the maximum temperatures calculated were 170.4 and $194.3^{\circ} \mathrm{C}$, respectively. The experimental maximum average temperatures were also seen at this location and were 163.7 and $207.3^{\circ} \mathrm{C}$ for Tests S-7 and S-6, respectively. These calculated temperatures are about $7^{\circ} \mathrm{C}$ higher and $13^{\circ} \mathrm{C}$ lower than the experiment average values, but are within the range of experimental values for both tests.
The minimum temperature is found in the upper head, where the vapor is cooled by the cooling water manifold located there. The calculated vapor temperatures in the upper head for Tests S-7 and S-6 were 69.3 and $54.7^{\circ} \mathrm{C}$, respectively. In the experiments, the average vapor temperatures in the upper head were 81.6 and $90.4^{\circ} \mathrm{C}$, respectively. The calculated temperatures are about 12 and $36^{\circ} \mathrm{C}$ lower than the experiment average values.

In the upper plenum, the lowest vapor temperature is found at the bottom of the outer channel where the cooled flow returning from the hot leg is mixed with the flow descending from the upper plenum and cool vapor returning from the upper head via the communication tubes. The calculated minimum upper plenum temperatures were 112.7 and $119.0^{\circ} \mathrm{C}$ for Tests $\mathrm{S}-7$ and S-6, respectively. Experimentally, the minimum upper plenum temperatures were also observed in this region with average values of 97.4 and $113.5^{\circ} \mathrm{C}$, respectively. The calculated temperatures are about 15 and $5^{\circ} \mathrm{C}$ higher than the experiment average values, but are with in the range of experimental values for both tests.

For both tests, the upper head vapor temperature is underpredicted, most likely because of an overestimation of the heat removed by the cooling water manifold. The vapor flow exiting the upper head and returning to the upper plenum via the outer channel communication tubes is also underestimated because of the underestimated upper head vapor temperatures. The heat removed by the cooling water manifold was not reported explicitly in the experimental results, but was included in the total heat removed via the upper plenum guide tube cooling. Therefore, the heat removed by the manifold was estimated by specifying a surface heat flux. The surface heat flux was estimated by dividing the total heat removed through the guide tubes by the total surface area of the guide tubes and manifold combined. This simplification assumed that the heat flux removed by the manifold and guide tubes was equal. However, the results indicate that this assumption is most likely incorrect. A better comparison of the upper head results could be obtained by adjusting the specified heat flux. In 
any case, the vapor circulation through the upper head accounts for less than $5 \%$ of the heat removed from the core and does not significantly affect the overall problem.

Flow Pattern Distributions. The calculated average $\mathrm{SF}_{6}$ vapor mass flow rate and velocity vectors in the core and upper plenum for Test S-7 are presented in Figures D-13 and D-14, respectively. The vapor flow diagrams for Test S-6 are presented in Figures D-15 and D-16. Comparison with experimental data was not possible because no mass flow rates or velocities were measured in the experiments.

For both tests, the core and upper plenum vector diagrams show two dominant recirculation flows and a third smaller recirculating flow between the upper plenum and the upper head via the communication tubes. Additionally, a fraction of the vapor in the upper plenum recirculates through the two hot leg/steam generator loops before returning to the upper plenum. This hot leg flow will be discussed in the next section. A qualitative discussion of the core and upper plenum flows is provided below.

The primary pattern in the core and upper plenum is of hot flow rising from the core center channel to the upper plenum, where it loses energy to the cooler structures, turns back toward the outer channel of the plenum, and then descends back into the core through the outer channel. Within this primary circulation pattern, a secondary circulating flow occurs in the upper plenum, just above the upper core plate, where flow from the outer channel of the plenum travels across the top of the core to the center channel. In the center channel, this flow is mixed with hot vapor rising from the core and flows upward before returning to the outer channel. For both tests, the recirculating mass flow rate in the upper plenum is approximately 1.7 times that in the core. For Test S-7, the recirculating mass flow rates in the upper plenum and core regions are approximately 0.78 and $0.45 \mathrm{~kg} / \mathrm{s}$, respectively. By comparison, the mass flow rate recirculating through the upper head is only $0.06 \mathrm{~kg} / \mathrm{s}$ and that through each hot leg loop is $0.065 \mathrm{~kg} / \mathrm{s}$, on aver- age. For Test S-6, the mass flow rates in the upper plenum and core are smaller at 0.60 and $0.34 \mathrm{~kg} / \mathrm{s}$, respectively. The mass flow rate recirculating through the upper head is $0.05 \mathrm{~kg} / \mathrm{s}$ and that through each hot leg loop is $0.045 \mathrm{~kg} / \mathrm{s}$, on average. The flow pattern in the core and upper plenum is well established within the first $100 \mathrm{~s}$ of the transient calculation and remains nearly constant thereafter.

The velocity vector diagrams show a flow pattern similar to that of the mass flow rate diagrams. In the core, the maximum velocity occurs in the top of the center channel and is approximately 0.31 and $0.34 \mathrm{~m} / \mathrm{s}$ for Tests S-7 and S-6, respectively. In the upper plenum, the maximum velocity occurs in the center channel and is 0.26 and $0.28 \mathrm{~m} / \mathrm{s}$ for Tests S-7 and S-6, respectively. The velocity in the communication tubes is much higher than in other regions of the upper plenum because of the relatively small cross-sectional flow area of the tubes. For Tests S-7 and S-6, the velocities in the center channel communication tubes are 1.3 and $1.5 \mathrm{~m} / \mathrm{s}$, respectively.

Flow Parameter Comparison. Derived flow parameters in the core and upper plenum are presented and compared with the experimental results in Tables D-6 and D-7 for Tests S-7 and $S-6$, respectively. The core and upper plenum flow parameters presented include the system pressure, the core power, and the upper plenum cooling. $T_{h}$ in these tables represents the temperature at the top of the core, which is much hotter than that of cooler flow near the core periphery. The predicted value was obtained as the vapor temperature at the top of the core center channel. $T_{c}$ is the average of cooled flow temperatures in the bottom wall area of the upper plenum before heating by the core or core mixing can occur. The predicted value was obtained as the vapor temperature in Volume 151 in the upper plenum. The average core velocity is equivalent to a superficial velocity through the core and was calculated using Eq. (D-1) with code-calculated input. Similarly, the Reynolds and Richardson numbers were calculated using Eqs. (D-2) and (D-3) except with code-calculated input. Average property values were calculated 
Appendix D

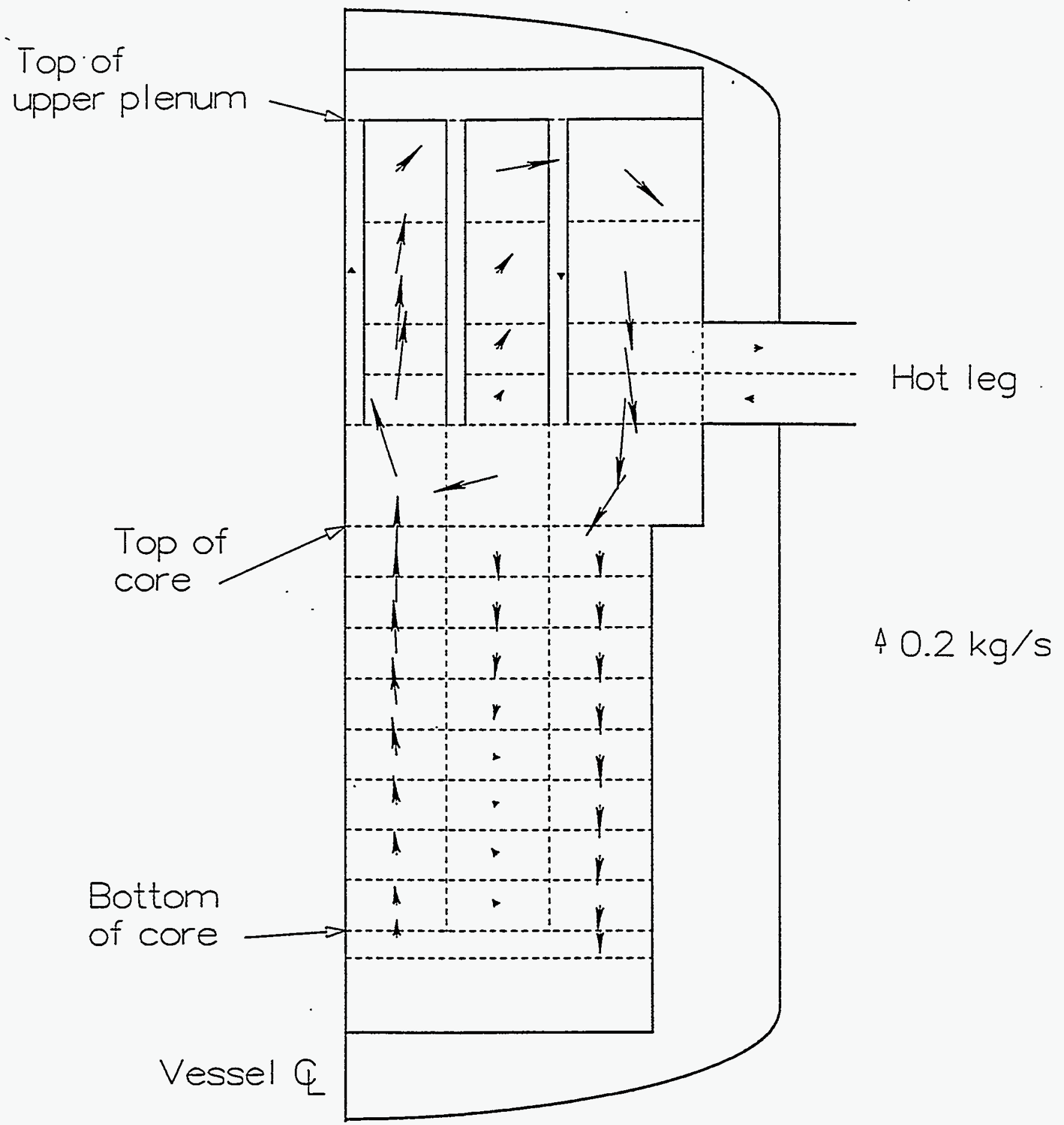

Figure D-13. Calculated $\mathrm{SF}_{6}$ vapor mass flow rate vectors in the core and upper plenum for Test S-7. 


\section{Appendix D}

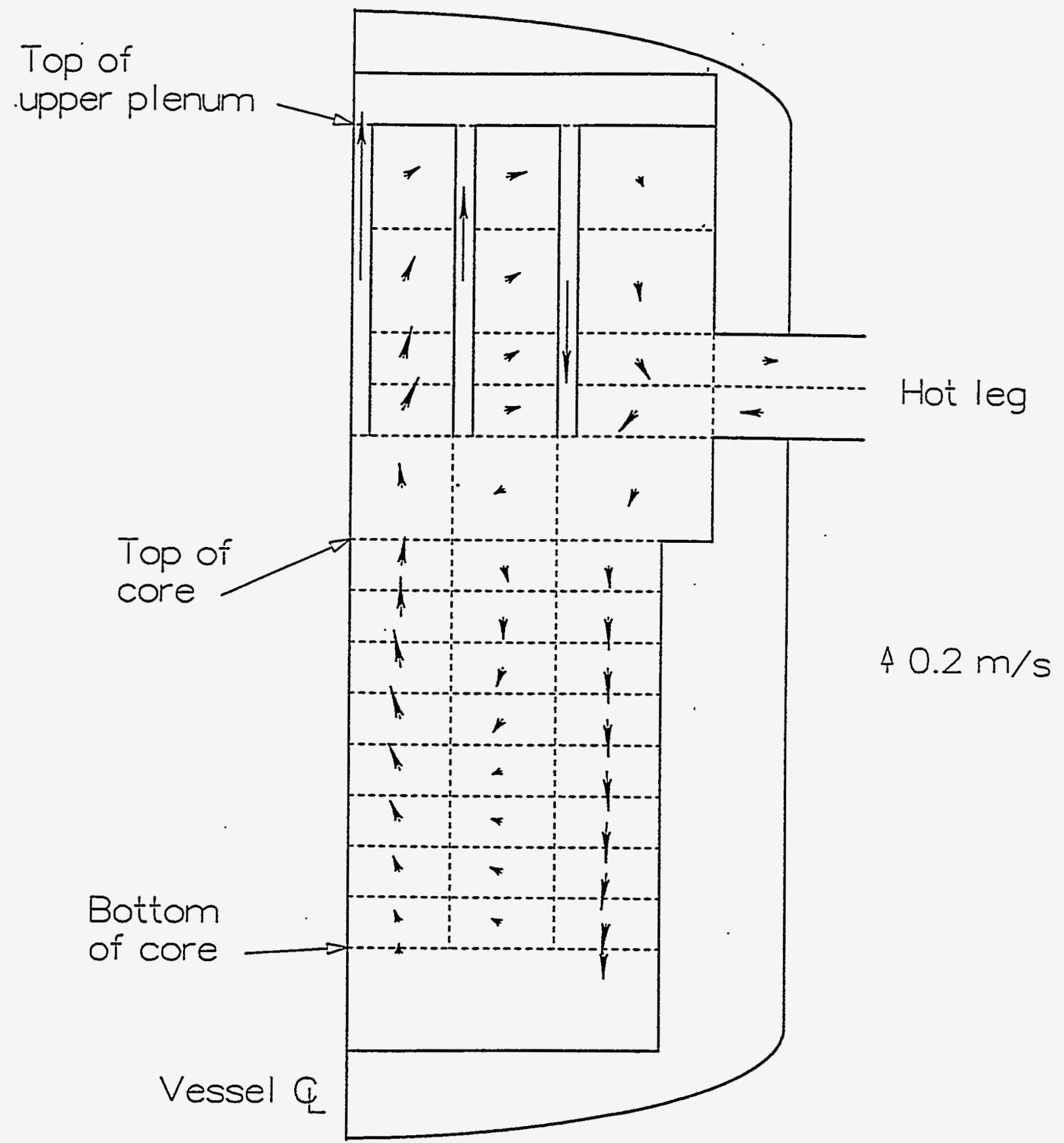

Figure D-14. Calculated $\mathrm{SF}_{6}$ vapor velocity vectors in the core and upper plenum for Test S-7. 


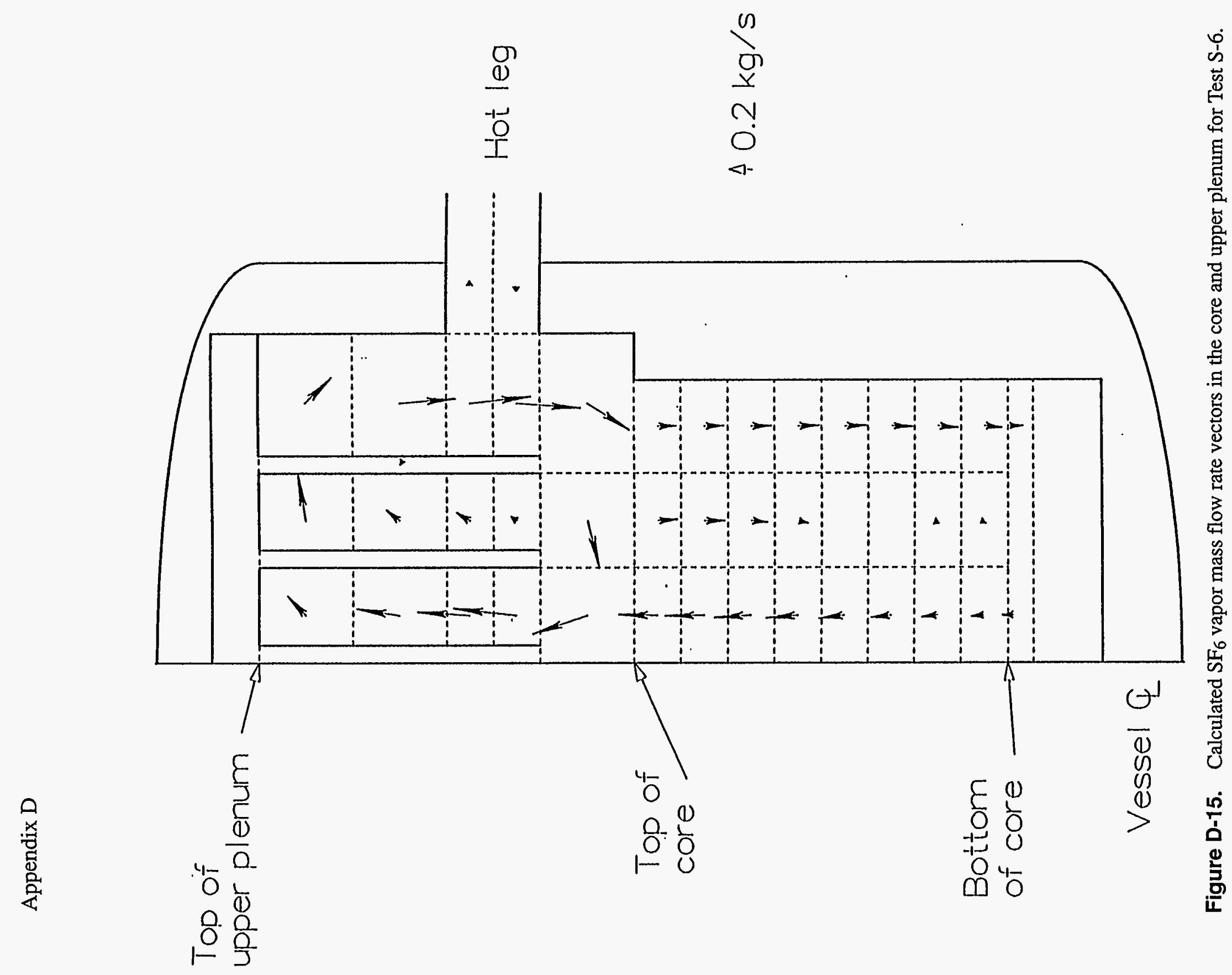


Top of upper plenum
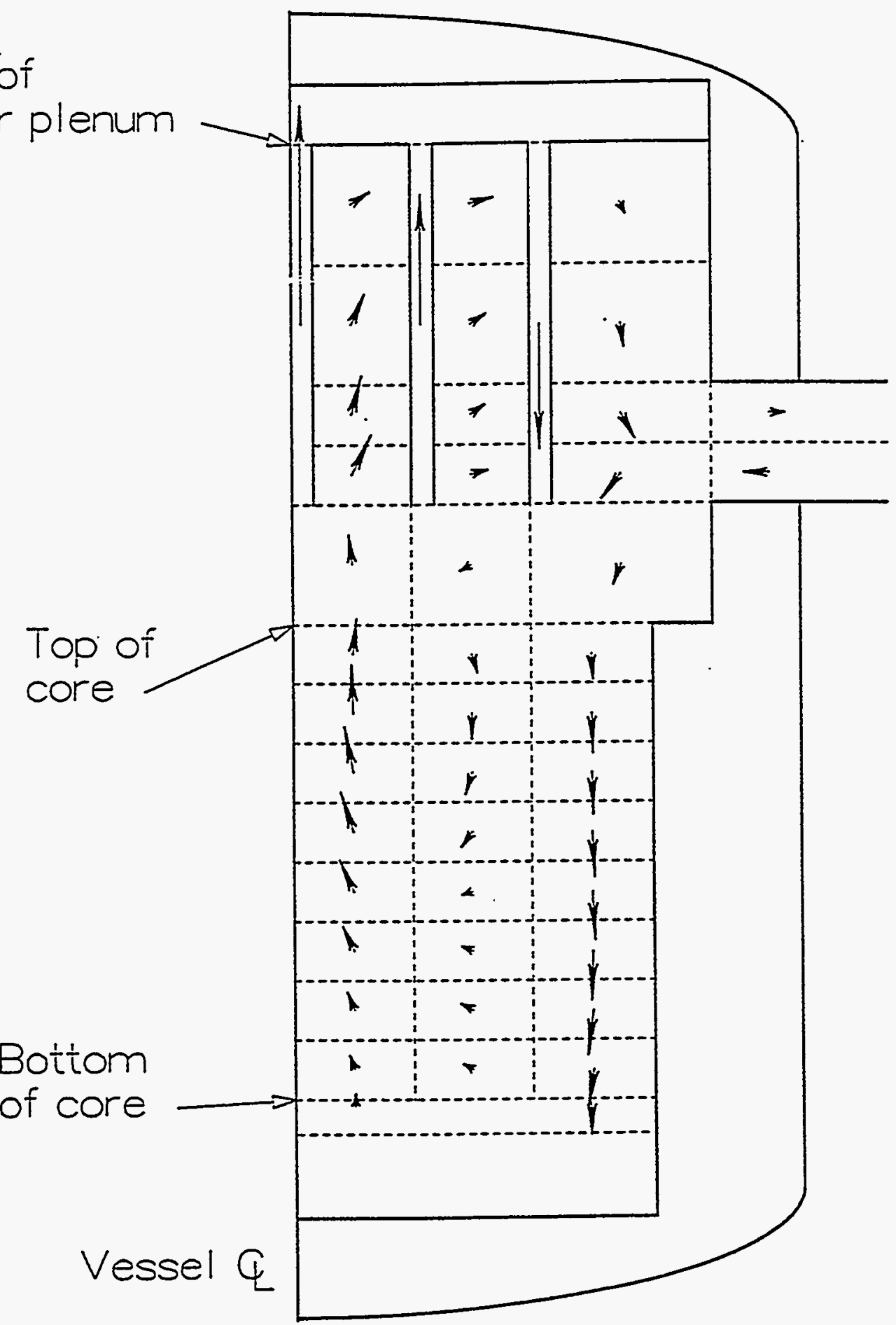

$\Delta 0.2 \mathrm{~m} / \mathrm{s}$

Figure D-16. Calculated $\mathrm{SF}_{6}$ vapor velocity vectors in the core and upper plenum for Test S-6. 
Appendix D

Table D-6. Experimental and RELAP5-calculated core natural circulation flow parameters for Test S-7.

Pressure (MPa)

Core power $(\mathrm{kW})$

Upper plenum cooling $(\mathrm{kW})$

$\mathrm{T}_{\mathrm{h}}\left({ }^{\circ} \mathrm{C}\right)$

$\mathrm{T}_{\mathrm{c}}\left({ }^{\circ} \mathrm{C}\right)$

$\mathrm{T}_{\mathrm{h}}-\mathrm{T}_{\mathrm{c}},\left({ }^{\circ} \mathrm{C}\right)$

$\bar{\rho}\left(\mathrm{kg} / \mathrm{m}^{3}\right)$

$\rho_{\mathrm{c}}-\rho_{\mathrm{h}}\left(\mathrm{kg} / \mathrm{m}^{3}\right)$

$\overline{\mathrm{C}}_{\mathrm{p}}(\mathrm{J} / \mathrm{kg} \cdot \mathrm{K})$

$\bar{\mu}\left(\mathrm{Pa} \cdot \mathrm{s} \times 10^{5}\right)$

$\overline{\mathrm{V}}(\mathrm{m} / \mathrm{s})$

$\mathrm{Re}_{\mathrm{De}}$

1/C

Experiment

2.172

20.49

13.95

162.7

90.1

72.6

102.1

25.24

836.8

2.05

0.186
4,100
0.312
Prediction $^{\mathrm{a}}$

2.172

20.46

13.96

170.4

112.7

57.7

100.9

18.96

848.9

2.16

0.233

4,840

0.151
Percent error

0.0

$-0.1$

0.1

4.7

25.1

$-20.5$

$-1.2$

$-24.9$

1.4

5.4

25.3

18.0

$-51.6$

a. Predictions at $10,000 \mathrm{~s}$ problem time.

Table D-7. Experimental and RELAP5-calculated core natural circulation flow parameters for Test S-6.

\begin{tabular}{lccr}
\hline & Experiment & Prediction & Percent error \\
\cline { 2 - 4 } & 1.655 & 1.655 & 0.0 \\
Pressure $(\mathrm{MPa})$ & 20.48 & 20.45 & -0.1 \\
Core power $(\mathrm{kW})$ & 15.40 & 15.44 & 0.3 \\
Upper plenum cooling $(\mathrm{kW})$ & & & -5.8 \\
& 206.2 & 194.3 & 28.9 \\
$\mathrm{~T}_{\mathrm{h}}\left({ }^{\circ} \mathrm{C}\right)$ & 92.3 & 119.0 & -33.9 \\
$\mathrm{~T}_{\mathrm{c}}\left({ }^{\circ} \mathrm{C}\right)$ & 113.9 & 75.3 & \\
$\mathrm{~T}_{\mathrm{h}}-\mathrm{T}_{\mathrm{c}},\left({ }^{\circ} \mathrm{C}\right)$ & & & -4.0 \\
& 75.35 & 72.3 & -38.1 \\
$\bar{\rho}\left(\mathrm{kg} / \mathrm{m}^{3}\right)$ & 25.05 & 15.5 & 0.4 \\
$\rho_{\mathrm{c}}-\rho_{\mathrm{h}}\left(\mathrm{kg} / \mathrm{m}^{3}\right)$ & 845.2 & 848.3 & 3.8 \\
$\overline{\mathrm{C}} \mathrm{p}(\mathrm{J} / \mathrm{kg} \cdot \mathrm{K})$ & 2.13 & 2.21 & 56.6 \\
$\bar{\mu}\left(\mathrm{Pa} \cdot \mathrm{s} \times 10^{5}\right)$ & & & 44.6 \\
$\bar{V}(\mathrm{~m} / \mathrm{s})$ & 0.159 & 0.249 & -73.6 \\
$\operatorname{Re}{ }_{\mathrm{De}}$ & 2,500 & 3,630 & \\
$1 / \mathrm{C}$ & 0.573 & 0.151 & \\
\hline a. Predictions at 10,000 s problem time. & & & \\
\hline
\end{tabular}


as the arithmetic average of the property values in the two control volumes described above.

Comparison of the experimental and predicted values reveals large deviations for some of the derived flow parameters. The derived temperature $\mathrm{T}_{\mathrm{h}}$ compares well with only 4.7 and $5.8 \%$ deviation. However, $\mathrm{T}_{\mathrm{c}}$ does not compare as well. For both tests, $T_{c}$ is overpredicted by about $25 \%$. Also, this overprediction of $\mathrm{T}_{\mathrm{c}}$ results in an underprediction of the calculated temperature difference, $T_{h}-T_{c}$. The superficial velocity, $\overline{\mathrm{V}}$, is inversely related to the temperature difference and is thus overpredicted. Likewise, the Reynolds number, which is proportional to the velocity, is overpredicted and the Richardson number is underpredicted because of a combination of disparities in the density difference and superficial velocity.

All of these derived flow parameters are based upon the averaged temperature difference, $T_{h}-T_{c}$. The experimental values were obtained as the average of selected thermocouple readings whose locations did not necessarily correspond with the control volume locations used in evaluating the predicted values of $T_{h}$ and $T_{c}$. Therefore, the experimental and predicted values are not completely equivalent quantities. A better comparison would be to calculate the experimental values of $T_{h}$ and $T_{c}$ using the averaged temperatures of thermocouples located in the same control volumes used in the predictions. Using the experimental average temperatures presented in Figures D-7 and D-8, $T_{h}$ and $T_{c}$ were recalculated for Tests S-7 and S-6, respectively. The results are presented in Tables D-8 and D-9, for the two tests, respectively. In general, these revised experimental temperatures compare better with the calculated values presented in Tables D-6 and D-7.

Additionally, some of the deviations may be the result of three-dimensional effects that cannot be modeled adequately with the current

Table D-8. Derived average core outlet and inlet temperatures, $T_{h}$ and $T_{c}$, using averaged temperatures obtained from Figure D-7 and Figure D-9 for Test S-7.

\begin{tabular}{lcrr}
\hline & Experiment $^{\mathrm{a}}$ & Prediction $^{\mathrm{b}}$ & Percent error \\
\cline { 2 - 4 } $\mathrm{T}_{\mathrm{h}}\left({ }^{\circ} \mathrm{C}\right)$ & 163.7 & 170.4 & 4.1 \\
$\mathrm{~T}_{\mathrm{c}}\left({ }^{\circ} \mathrm{C}\right)$ & 97.4 & 112.7 & 15.7 \\
$\mathrm{~T}_{\mathrm{h}}-\mathrm{Tc}\left({ }^{\circ} \mathrm{C}\right)$ & 66.3 & 57.7 & -13.0 \\
& & & \\
a. Values obtained from Figure D-7. & & \\
b. Predictions at 10,000 s problem time, obtained from Figure D-9. & \\
\hline
\end{tabular}

Table D-9. Derived average core outlet and inlet temperatures, $T_{h}$ and $T_{c}$, using averaged temperatures obtained from Figure D-8 and Figure D-10 for Test S-6.

\begin{tabular}{lcrr}
\hline & Experiment $^{\mathrm{a}}$ & Prediction $^{\mathrm{b}}$ & Percent error \\
\cline { 2 - 4 } $\mathrm{T}_{\mathrm{h}}\left({ }^{\circ} \mathrm{C}\right)$ & 207.3 & 194.3 & -6.3 \\
$\mathrm{~T}_{\mathrm{c}}\left({ }^{\circ} \mathrm{C}\right)$ & 113.5 & 119.0 & 4.8 \\
$\mathrm{~T}_{\mathrm{h}}-\mathrm{Tc}\left({ }^{\circ} \mathrm{C}\right)$ & 93.8 & 75.3 & -19.7 \\
& & & \\
a. Values obtained from Figure D-8. & & \\
b. Predictions at 10,000 s problem time, obtained from Figure D-10. & \\
\hline
\end{tabular}


one-dimensional RELAP5/MOD3 models. If three-dimensional effects are significant, increased nodalization and improved geometry models will be of no benefit. Rather, threedimensional flow models would have to be devised. While such upgrades may be desired to reduce uncertainties in the core and upper plenum results, uncertainties in system modeling or calculated behavior in the core and upper plenum have only a small effect on the hot leg and steam generator results. A discussion of the hot leg results follows.

\section{D-4.2.2 Countercurrent Hot Leg Flow.}

Derived flow parameters in the hot legs are presented and compared with the experimental results in Tables D-10 and D-11 for Tests S-7 and S-6, respectively. The hot leg results include the vapor temperatures and mass flow rates. Derived flow parameters include the parameter $\left(\mathrm{HA}_{\mathrm{o}} / \mathrm{C}^{\prime} \mathrm{D}^{5}\right)^{1 / 2}$; the flow Reynolds number in the hot leg, $\mathrm{Re}_{\mathrm{De}}$; and the correlated maximum loss coefficient, $C^{\prime}$ max. The methodology used in determining the experimental results was discussed in Section D-2.2. As noted there, the experimental hot leg vapor temperatures, $T_{h, o u t}$ and $T_{c, i n}$, were obtained from the hot leg control volumes at the steam generator end of the hot leg. As noted previously, in the experiments the vapor temperatures in each stream changed along the length of the hot leg because of heat transfer and mixing of the two countercurrent streams. However, this heat transfer and mixing is not modeled in the RELAP5 two-pipe countercurrent hot leg model. Therefore, under steady-state conditions, the calculated vapor temperatures in each stream remain constant along the length of the hot leg. The calculated flow parameters $\mathrm{C}_{\max }^{\prime},\left(\mathrm{HA}_{\mathrm{o}} / \mathrm{C}^{\prime} \mathrm{D}^{5}\right)^{1 / 2}$, and $R e_{D e}$ for the hot leg were obtained using the same methodology and equations used to obtain the experimental result presented in Section D-2.2, except with code-calculated inputs.

For Test S-7, the calculated hot vapor temperatures in the two hot legs are overpredicted, on average, by approximately $14 \%$. The returning cold vapor temperatures are also overpredicted but to a lesser degree. The average error for the cold temperature is approximately $8 \%$. The vapor temperature difference across the hot legs is overpredicted, on average, by about $21 \%$ of the

Table D-10. Experimental and RELAP5-calculated hot leg natural circulation flow parameters for Test S-7.

\begin{tabular}{|c|c|c|c|c|c|c|}
\hline \multirow[b]{2}{*}{ Hot leg } & \multicolumn{2}{|c|}{ Experiment } & \multicolumn{2}{|c|}{ Prediction $^{\mathrm{a}}$} & \multicolumn{2}{|c|}{ Percent error } \\
\hline & Left & Right & Left & Right & Left & Right \\
\hline \multicolumn{7}{|l|}{ Flow parameters } \\
\hline $\mathrm{T}_{\mathrm{h}, \text { out }}\left({ }^{\circ} \mathrm{C}\right)$ & 110.7 & 114.9 & 128.3 & 128.3 & 15.9 & 11.7 \\
\hline $\mathrm{T}_{\mathrm{c}, \text { in }}\left({ }^{\circ} \mathrm{C}\right)$ & 60.8 & 60.3 & 66.2 & 64.5 & 8.9 & 7.0 \\
\hline $\mathrm{T}_{\mathrm{h}, \text { out }}-\mathrm{T}_{\mathrm{c}, \text { in }}\left({ }^{\circ} \mathrm{C}\right)$ & 49.9 & 54.6 & 62.1 & 63.8 & 24.4 & 16.8 \\
\hline$\rho_{\mathrm{h}}\left(\mathrm{kg} / \mathrm{m}^{3}\right)$ & 110.4 & 108.6 & 104.3 & 104.3 & -5.5 & -4.0 \\
\hline$\rho_{c}\left(\mathrm{~kg} / \mathrm{m}^{3}\right)$ & 140.8 & 141.0 & 136.2 & 137.5 & -3.3 & -2.5 \\
\hline$\rho_{c}-\rho_{h}\left(\mathrm{~kg} / \mathrm{m}^{3}\right)$ & 30.4 & 32.4 & 31.9 & 33.2 & 4.9 & 2.5 \\
\hline $\mathrm{q}_{\mathrm{sg}}(\mathrm{kW})$ & 2.95 & 3.26 & 3.16 & 3.33 & 7.1 & 2.1 \\
\hline$\dot{\mathrm{m}}_{\mathrm{hl}}(\mathrm{kg} / \mathrm{s})$ & 0.071 & 0.072 & 0.0631 & 0.0647 & -11.1 & -10.1 \\
\hline$\left(\mathrm{HA}_{\alpha} / \mathrm{C}^{\prime} \mathrm{D}^{5}\right)^{1 / 2}$ & 0.1111 & 0.1090 & 0.0989 & 0.0992 & -11.0 & -9.0 \\
\hline$C_{\max }^{\prime}$ & 1.47 & 1.53 & 1.86 & 1.85 & 26.5 & 20.9 \\
\hline $\operatorname{Re}_{D e}$ & 56,100 & 56,700 & 48,300 & 49,600 & -13.9 & -12.5 \\
\hline
\end{tabular}

a. Predictions at 10,000 s problem time. 
Table D-11. Experimental and RELAP5-calculated hot leg natural circulation flow parameters for Test S-6.

\begin{tabular}{|c|c|c|c|c|c|c|}
\hline \multirow[b]{2}{*}{ Hot leg } & \multicolumn{2}{|c|}{ Experiment } & \multicolumn{2}{|c|}{ Prediction $^{a}$} & \multicolumn{2}{|c|}{ Percent error } \\
\hline & Left & Right & Left & Right & Left & Right \\
\hline \multicolumn{7}{|l|}{ Flow parameters } \\
\hline $\mathrm{T}_{\mathrm{h}, \text { out }}\left({ }^{\circ} \mathrm{C}\right)$ & 129.7 & 134.9 & 137.2 & 137.2 & 5.8 & 1.7 \\
\hline $\mathrm{T}_{\mathrm{c}, \text { in }}\left({ }^{\circ} \mathrm{C}\right)$ & 65.5 & 63.4 & 67.7 & 66.8 & 3.4 & 5.4 \\
\hline $\begin{array}{l}\mathrm{T}_{\mathrm{h}, \text { out }}-\mathrm{T}_{\mathrm{c}, \text { in }} \\
\left({ }^{\circ} \mathrm{C}\right)\end{array}$ & 64.2 & 71.5 & 69.5 & 70.4 & 8.3 & -1.5 \\
\hline$\rho_{\mathrm{h}}\left(\mathrm{kg} / \mathrm{m}^{3}\right)$ & 77.1 & 75.8 & 75.5 & 75.5 & -2.1 & -0.4 \\
\hline$\rho_{c}\left(\mathrm{~kg} / \mathrm{m}^{3}\right)$ & 98.9 & 99.6 & 97.6 & 98.0 & -1.3 & -1.6 \\
\hline$\rho_{c}-\rho_{h}\left(\mathrm{~kg} / \mathrm{m}^{3}\right)$ & 21.8 & 23.8 & 22.1 & 22.5 & 1.4 & -5.5 \\
\hline $\mathrm{q}_{\mathrm{sg}}(\mathrm{kW})$ & 2.43 & 2.67 & 2.49 & 2.55 & 2.5 & -4.5 \\
\hline$\dot{\mathrm{m}}_{\mathrm{hl}}(\mathrm{kg} / \mathrm{s})$ & 0.0467 & 0.0461 & 0.0446 & 0.0451 & -4.5 & -2.2 \\
\hline$\left(\mathrm{HA}_{\mathrm{o}} / \mathrm{C}^{\prime} \mathrm{D}^{5}\right)^{1 / 2}$ & 0.1025 & 0.0972 & 0.0989 & 0.0992 & -3.5 & 2.1 \\
\hline$C_{\max }^{\prime}$ & 1.73 & 1.93 & 1.86 & 1.85 & 7.5 & -4.1 \\
\hline $\operatorname{Re}_{\mathrm{De}}$ & 36,700 & 36,300 & 33,800 & 34,300 & -7.9 & -5.5 \\
\hline
\end{tabular}

a. Predictions at $10,000 \mathrm{~s}$ problem time.

experimental values. The mass flow rates in the hot legs are underpredicted by approximately $11 \%$. The characteristic hot leg Reynolds numbers are underpredicted by about $13 \%$.

Overall, the hot leg results for Test S-6 compare better than for Test S-7. The hot and cold vapor temperatures are overpredicted by less than 4 and 5\%, respectively. The hot leg temperature differences are overpredicted by $4 \%$, on average. The mass flow rates are underpredicted by approximately $4 \%$, on average. Finally the characteristic Reynolds numbers are underpredicted by $7 \%$, on average. It is not known why these results compare better than those of Test $\mathrm{S}-7$.

While most of the hot leg results are predicted to within approximately $10 \%$ of the experimental data, whether this agreement is adequate or not depends upon how sensitive the core condition and reactor coolant system (RCS) failure time and location are to the hot leg flow parameter. Determination of the various system sensitivities is beyond the scope of this study and would be bet- ter suited to examination with a full plant sensitivity study. However, in the course of this study it was observed that the mass flow rates and vapor temperatures in the hot legs are strongly dependent upon the flow parameters of the steam generators, including the heat removed in the steam generator, the inlet plenum mixing fractions, and the ratio of the steam generator mass flow rate to the hot leg flow rate. It was also observed that changes in the core and upper plenum system modeling had only a small effect on the hot leg flow parameters. For example, the temperature of the hot flow entering the top of the hot leg from the upper plenum is dependent upon the vapor temperature and mixing that occurs in the periphery of the upper plenum. However, in developing the system model, changes in the upper plenum modeling had little effect on the hot flow entering the top of the hot leg. If it is desired to reduce the uncertainty in the hot leg modeling, most likely enhanced modeling of the entire RCS would be required. Possible enhancements would include increased nodalization, mechanistic models of the hot leg countercurrent flow that would include 
heat and mass transfer between the two streams, and three-dimensional models of the steam generator inlet plenum.

D-4.2.3 Steam Generator Flow. The calculated flow parameters in the steam generators are presented and compared with the experimental results in Tables D-12 and D-13 for Tests S-7 and S-6, respectively. The experimental results were only obtained for the left steam generator. The calculated results are presented for both steam generators. The reported steam generator parameters include the heat removed in the steam generators, the tube bundle mass flow rate, the vapor temperature at the tube bundle entrance and exit, and the vapor temperature in the inlet plenum mixing volume. Also reported are the ratio of the tube bundle mass flow rate to the hot leg flow rate, and the two inlet plenum mixing fractions, $f_{1}$ and $f_{2}$. In performing the Test S-7 calculations, the loss coefficients and flow areas of the inlet plenum volume junctions were adjusted until these three parameters were satisfactorily matched. These flow areas and loss coefficients were then used in the Test S-6 calculations.

The calculated tube bundle entrance temperature, $\mathrm{T}_{\mathrm{ht}}$, was obtained using the simple energy balance of the steam generator heat removal described by Eq. (D-10). Solving Eq. (D-10) for $\mathrm{T}_{\text {ht }}$ one obtains

$T_{h t}=\frac{q_{s g}}{\dot{m}_{t} \bar{C}_{p}}+T_{c t}$,

where

$$
\begin{aligned}
& \dot{m}_{t}=\text { mass flow rate through the steam } \\
& \text { generator tubes, } \mathrm{kg} / \mathrm{s} \\
& \bar{C}_{p}=\text { average heat capacity, } \mathrm{J} /(\mathrm{kg} \cdot \mathrm{K}) \\
& q_{s g}=\begin{array}{l}
\text { heat removed in the steam } \\
\text { generator, } \mathrm{W}
\end{array} \\
& T_{c t}=\text { vapor temperature exiting the }
\end{aligned}
$$

\begin{tabular}{|c|c|c|c|c|c|c|}
\hline \multirow[b]{2}{*}{ Steam generator } & \multicolumn{2}{|c|}{ Experiment } & \multicolumn{2}{|c|}{ Prediction } & \multicolumn{2}{|c|}{ Percent error } \\
\hline & Left & Right & Left & Right & Left & Right \\
\hline \multicolumn{7}{|l|}{ Flow parameters } \\
\hline $\mathrm{q}_{s g}(\mathrm{~kW})$ & 2.95 & 3.26 & 3.16 & 3.33 & 7.1 & 2.1 \\
\hline Number of hot tubes & 72 & NA & $72^{\mathrm{a}}$ & $72^{\mathrm{a}}$ & - & - \\
\hline Number of cold tubes & 144 & NA & $144^{a}$ & $144^{a}$ & - & - \\
\hline$\dot{\mathrm{m}}_{\mathrm{t}}(\mathrm{kg} / \mathrm{s})$ & 0.147 & NA & 0.131 & 0.132 & -10.9 & 一 \\
\hline$\dot{\mathrm{m}}_{\mathrm{hl}}(\mathrm{kg} / \mathrm{s})$ & 0.071 & 0.072 & 0.0631 & 0.0647 & -11.1 & -10.1 \\
\hline$\dot{\mathrm{m}}_{\mathrm{t}} / \dot{\mathrm{m}}_{\mathrm{hl}}$ & 2.06 & NA & $2.08^{b}$ & $2: 05^{b}$ & 1.0 & - \\
\hline$f_{1} f_{2}$ & 0.89 & $\mathrm{NA}$ & $0.89^{b}$ & $0.89^{b}$ & 0.0 & - \\
\hline $\mathrm{T}_{\mathrm{ht}}\left({ }^{\circ} \mathrm{C}\right)$ & 69.5 & NA & 72.9 & 71.4 & 4.9 & - \\
\hline $\mathrm{T}_{\mathrm{Ct}}\left({ }^{\circ} \mathrm{C}\right)$ & 45.9 & NA & 44.8 & 42.3 & -2.4 & - \\
\hline $\mathrm{T}_{\mathrm{ht}}-\mathrm{T}_{\mathrm{ct}}\left({ }^{\circ} \mathrm{C}\right)$ & 23.6 & NA & 28.1 & 29.1 & 19.1 & - \\
\hline $\mathrm{T}_{\mathrm{m}}\left({ }^{\circ} \mathrm{C}\right)$ & 67.1 & NA & 72.2 & 70.9 & 7.6 & - \\
\hline
\end{tabular}

Table D-12. Experimental and RELAP5-calculated steam generator natural circulation flow parameters for Test S-7.

a. Not predicted by code; input to code.

b. Not predicted by code; steam generator inlet plenum loss coefficients and junction areas adjusted to obtain mixing fractions and flow ratio.

$\mathrm{NA}=$ Data was not obtained in the experiments. 
Table D-13. Experimental and RELAP5-calculated steam generator natural circulation flow parameters for Test S-6.

\begin{tabular}{|c|c|c|c|c|c|c|}
\hline \multirow{2}{*}{ Steam generator } & \multicolumn{2}{|c|}{ Experiment } & \multicolumn{2}{|c|}{ Prediction } & \multicolumn{2}{|c|}{ Percent error } \\
\hline & Left & Right & Left & Right & Left & Right \\
\hline \multicolumn{7}{|l|}{ Flow parameters } \\
\hline $\mathrm{q}_{\mathrm{sg}}(\mathrm{kW})$ & 2.43 & 2.67 & 2.49 & 2.55 & 2.5 & -4.5 \\
\hline Number of hot tubes & 64 & $\mathrm{NA}$ & $72^{a}$ & $72^{\mathrm{a}}$ & - & - \\
\hline Number of cold tubes & 152 & NA & $144^{\mathrm{a}}$ & $144^{a}$ & - & - \\
\hline$\dot{\mathrm{m}}_{\mathrm{t}}(\mathrm{kg} / \mathrm{s})$ & 0.0919 & NA & 0.0907 & 0.0891 & -1.3 & - \\
\hline$\dot{\mathrm{m}}_{\mathrm{hl}}(\mathrm{kg} / \mathrm{s})$ & 0.0467 & 0.0461 & 0.0445 & 0.0451 & -4.7 & -2.2 \\
\hline$\dot{\mathrm{m}}_{\mathrm{t}} / \dot{\mathrm{m}}_{\mathrm{hl}}$ & 1.97 & NA & $2.04^{b}$ & $1.98^{\mathrm{b}}$ & 3.6 & - \\
\hline$f_{1} f_{2}$ & 0.85 & NA & $0.89^{\mathrm{b}}$ & $0.89^{\mathrm{b}}$ & 4.7 & - \\
\hline $\mathrm{T}_{\mathrm{ht}}\left({ }^{\circ} \mathrm{C}\right)$ & 77.5 & NA & 76.4 & 75.9 & -1.4 & 一 \\
\hline $\mathrm{T}_{\mathrm{ct}}\left({ }^{\circ} \mathrm{C}\right)$ & 44.5 & NA & 42.8 & 40.9 & -3.8 & - \\
\hline $\mathrm{T}_{\mathrm{ht}}-\mathrm{T}_{\mathrm{ct}}\left({ }^{\circ} \mathrm{C}\right)$ & 33.0 & NA & 33.6 & 35.0 & 1.8 & - \\
\hline $\mathrm{T}_{\mathrm{m}}\left({ }^{\circ} \mathrm{C}\right)$ & 73.2 & NA & 74.5 & 74.0 & 1.8 & - \\
\hline
\end{tabular}

a. Not predicted by code; input to code.

b. Not predicted by code; steam generator inlet plenum loss coefficients and junction areas adjusted to obtain mixing fractions and flow ratio.

$\mathrm{NA}=$ Data was not obtained in the experiments.

and all of the terms on the right-hand side of Eq. (D-13) are known code-calculated values. The inlet plenum mixing volume temperatures, $\mathrm{T}_{\mathrm{m}}$, were obtained as the vapor temperature in Volumes 201 and 301 for the right and left steam generators, respectively.

For Test S-7, the steam generator heat removal rates compare quite well with the experimental results and are overpredicted by less than $5 \%$, on average. The mass flow rate through the steam generator tubes is underestimated by approximately $11 \%$. The tube bundle entrance and exit temperature deviate from the experimental values by approximately 5 and $2.4 \%$, respectively. However, the temperature difference is overpredicted by $19 \%$. The mixing volume temperature, $\mathrm{T}_{\mathrm{m}}$, deviates by less than $8 \%$.

As was seen for the hot leg results, the steam generator results for Test S-6 compare better than those of Test S-7. This is not unexpected since the hot leg and steam generator flows are strongly coupled. The calculated steam generator heat removal for Test S-6 deviates by approximately $1 \%$, on average. The tube bundle mass flow rate is underpredicted by approximately $1 \%$. The tube bundle entrance and exit temperatures are underpredicted by 1.4 and $3.8 \%$, respectively, and the steam generator temperature difference is within $2 \%$ of the experimental value. Finally, the mixing volume temperature is within $2 \%$ of the experimental value.

Why the Test S-6 results compare better than those of Test S-7 remains unclear. However, two explanations are proposed. The first explanation is that compensating errors allow the total tube flow to match the measured data for Test S-6. For Test $\mathrm{S}-7$, the number of hot tubes modeled is equal to the number of observed hot flow tubes (72 tubes), but the predicted flow per tube is lower than that measured by approximately $11 \%$. By modeling more hot tubes for Test S-6 (72 tubes) than were observed ( 64 tubes), the predicted tube flow 
matches the measured data. If the number of hot tubes had been reduced by a factor of $8 / 72$ (i.e., set to the observed number of 64), perhaps the flow would have been reduced by a similar factor (i.e., the flow would have been $11 \%$ lower). However, this explanation assumes that the tube flow is proportional to the number of hot tubes, which is not exactly true. Another explanation is that the $\mathrm{SF}_{6}$ property models are more accurate for the lower pressure Test S-6 calculation than for Test S-7 (1.655 versus $2.172 \mathrm{MPa}$ ). Since the accuracy of the gas property models declines as pressure increases and/or temperature decreases, the calculated Test $S-6$ gas properties are more accurate than those of Test S-7. Additionally, in the steam generators, inaccuracies in the gas property models are amplified because of the relatively low gas temperature.

In any case, most of the steam generator results are predicted to within approximately $10 \%$ of the experimental data. Whether this agreement is adequate or not depends upon how sensitive the core condition and RCS failure time and location are to the steam generator flow parameters. As was discussed for the hot legs, it was observed that the mass flow rates and vapor temperatures in the hot legs are strongly dependent upon the flow parameters of the steam generators, including the heat removed in the steam generator, the inlet plenum mixing fractions, and the ratio of the steam generator mass flow rate to the hot leg flow rate. If it is desired to reduce the uncertainty in the steam generator modeling, most likely enhanced modeling of the steam generator inlet plenum would be required. This would most likely require threedimensional flow models of the steam generator inlet plenum.

\section{D-4.3 Uncertainties and Limitations}

This section describes some of the uncertainties and limitations of the models, code, and experimental data used in the analysis.

Uncertainties in the analysis that have not been addressed include what effect the model nodalization has on the results. For example, increasing the core radial nodalization may improve the comparison of the calculated results with the experimental data. Also, the model is limited in its ability to simulate three-dimensional flows with a simplified two-dimensional approximation. Three-dimensional flows have been experimentally observed to occur in the core, upper plenum, hot legs, and steam generator inlet plena. The hot leg model also does not account for heat and mass transfer between the countercurrent streams. Experimentally, the top hot leg flow stream decreased in temperature as it traveled from the reactor vessel to the steam generator inlet plenum and the bottom flow stream increased in temperature as it returned to the reactor vessel. The temperature change was approximately $5^{\circ} \mathrm{C}$ in both directions. In the current hot leg model, at steady-state conditions, the vapor temperature remains constant as it passes from the reactor to the steam generator and vice versa.

Some of the model flow loss coefficients are also uncertain. These include the flow loss coefficients in the core, upper plenum, steam generator inlet plenum, hot leg, and steam generator tube volumes. While many of these loss coefficients, such as the axial flow losses in the core, can be determined explicitly for a particular flow Reynolds number, in the natural circulation experiments the flow Reynolds numbers vary with core location. Furthermore, for the laminar and transition regime type flows that occurred in the experiments, the loss coefficients are a function of the Reynolds number. However, the flow Reynolds number is not known a priori, so that accurate determination of the various flow loss coefficients would involve a lengthy iterative process. Furthermore, a theoretical basis is not known for the flow loss coefficients of the circulating/mixing flows that occur in the upper plenum and steam generator inlet plenum. Therefore, accurate modeling of these flow losses can only be achieved by benchmarking the model with experimental data.

Uncertainties in the experimental data also exist and have not been estimated. One significant uncertainty in the experimental results is the difficulty in maintaining steady-state conditions for the duration of the experiments. As reported in 
Reference D-2, the heat input and the heat removed were not always in balance during the steady-state experiments. Deviations as large as $25 \%$ are reported. The heat imbalances were due mainly to difficulty in maintaining the cooling water at a steady temperature. The sensitivity of the natural circulation flows to this type of transient energy imbalance is not known.

There is uncertainty in the steam generator inlet plenum mixing model. Specifically, the derived mixing fractions assume perfect.mixing and no heat transfer between the defined flow streams in the inlet plenum. The validity of this simplification and the sensitivity of the inlet plenum mixing are unknown. Also, the experimental derived steam generator and hot leg mass flow rates have unquantified uncertainties. These flow rates are derived from averaged hot leg and steam generator inlet and outlet temperatures. Variations as high as $10 \%$ occur in the experimental temperatures used in calculating the averages.

The experimental data is also limited in that vapor mass flow rates and velocities were not recorded. This limitation prevents a direct comparison of the calculated results with experimental data. Comparisons using the derived flow parameters are also limited, because they are not always equivalent to the code-generated results. For example, the derived average core velocity defined by Eq. (D-1) is a superficial velocity that is not equivalent to the code-calculated volume velocities. Furthermore, the derived velocity is based upon average temperatures that do not correspond directly to the defined control volume temperatures. Increased nodalization of the core and plenum model might eliminate this latter deficiency, but the experiment-derived core velocity would still not be comparable to the control volume velocities.

\section{D-5. CONCLUSIONS AND RECOMMENDATIONS}

A RELAP5/MOD3 model of the Westinghouse natural circulation experiment system has been developed. The model includes the reactor core and upper plenum and two hot leg/steam generator loops. Using the RELAP5/MOD3 computer code, this model was used to calculate the natural circulation flows observed in the steadystate, high-pressure $\mathrm{SF}_{6}$ experiments. Two of the steady-state experiments were modeled and the analytical results were compared with experimental data. The model analyses have demonstrated:

- Predicted $\mathrm{SF}_{6}$ vapor flow rates and temperatures in the hot legs and steam generators compare reasonably well with the experimental data. The code tended to overpredict temperatures 4 and $14 \%$.

- Vapor temperatures in the core and upper plenum compare reasonably well with the experimental data. However, the vapor heating through the core is overpredicted as the vapor flows down the core periphery and is underpredicted for the vapor flowing up through the center of the core. One possible explanation for these disparities is uncertainties in the flow loss coefficients because of variations in the flow Reynolds numbers through the core and upper plenum. Another possible cause is the three-dimensional nature of the flows and the simplifications associated with simulating them with a onedimensional code.

- Vapor recirculation flow patterns in the core are simulated and presented but quantitative experimental data are not available for comparison.

- The vapor flow rates and temperatures in the hot legs are strongly coupled with the steam generator tube flow rates and the steam generator inlet plenum mixing. However, the hot leg and steam generator natural circulation loops are weakly coupled with the core and upper plenum flow conditions. Therefore, uncertainties in system modeling or calculated behavior in the core and upper plenum have only a small effect on the hot leg and steam generator results.

- Vapor flow rates and temperatures in the hot legs and steam generators were observed to be very sensitive to the steam generator inlet 
plenum mixing fractions and to the ratio of steam generator tube mass flow rate to the hot leg mass flow rate.

It is difficult to directly relate the findings of this study to the analysis of a full-scale pressurized water reactor natural circulation model. It would appear that the two-pipe model of the hot leg adequately represents the simple countercurrent flow behavior. The coupling between the steam generator and the hot leg piping appears to be adequate. However, the effect of uncertainties in this coupling on full-scale plant calculations is not well understood. It is recommended that the sensitivity of the full-scale system to the steam generator inlet plenum mixing fractions and the ratio of the steam generator mass flow rate to the hot leg flow rate be investigated.

If there is a desire to reduce uncertainties in the core and upper plenum results, a nodalization study of the current model should be performed. Such a study would reveal the sensitivity of the modeled natural circulation flows to the nodalization scheme. Finally, the current model should be used to predict the Westinghouse transient experiments.

\section{D-6. REFERENCES}

D-1. W. A. Stewart, A. T. Pieczynski, and V. Srinivas, Experiments on Natural Circulation in a Pressurized Water Reactor Model for Degraded Core Accidents, EPRI Project No. RP2177-5, Final Report, 1990.

D-2. W. A. Stewart, A. T. Pieczynski, and V. Srinivas, Experiments on Natural Circulation in a Pressurized Water Reactor Model with High Pressure $\mathrm{SF}_{6}$, Westinghouse Electric Corporation, Draft, 1990.

D-3. K. E. Carlson et al., RELAP5/MOD3 Code Manual, NUREG/CR-5535, EGG-2596, Draft, June 1990.

D-4. P. D. Bayless, Analyses of Natural Circulation During a Surry Station Blackout Using SCDAP/RELAP5, NUREG/CR-5214, EGG-2547, October, 1988.

D-5. Erwin Fried and I. E. Idelchik, Flow Resistance: A Design Guide for Engineers, New York: Hemisphere Publishing Corporation, 1989.

D-6. W. H. Mears, E. Rosenthal, and J. V. Sinka, "Physical Properties and Virial Coefficients of Sulfur Hexafloride," Journal of Physical Chemistry, 73, 7, July 1969, pp. 2254-2261. 


\section{Appendix E \\ Effects of Hydrogen Generation on Severe Accident Natural Circulation}


, 


\section{Appendix E}

\section{Effects of Hydrogen Generation on Severe Accident Natural Circulation}

\section{EXECUTIVE SUMMARY}

During certain pressurized water reactor (PWR) severe accident scenarios, natural circulation can play an important role in determining the failure location and time-to-failure of reactor coolant system (RCS) components. At the time in a PWR transient when fuel cladding temperatures reach about $1,500 \mathrm{~K}$, hydrogen generation from the steam/zirconium reaction becomes significant. Effects of this hydrogen production on natural circulation flow and heat transfer are considered in this appendix. Possible flow disruption because of hydrogen stratification in the reactor vessel and/or hydrogen-induced steam generator blockage are both considered. Long-term hydrogen stratification in the reactor vessel appears to be unlikely because of turbulent mixing associated with high Rayleigh number in-vessel natural convection. Mixing times scales were found to be short (a few minutes), even when a fully stratified starting condition was assumed. This finding was consistent with experimental results obtained by Westinghouse with a 1/7-scale PWR RCS model.

If mixing of steam and hydrogen is rapid and no condensation occurs, analysis of the accident progression can be performed by simply accounting for the properties of the gas mixture as the composition changes. This is essentially what is done by RELAP5 since gas mixtures are treated as homogeneous. Therefore, recognizing the inherent limitations of a one-dimensional representation of a multidimensional phenomenon, RELAP5 should provide reasonable estimates of natural circulation heat transfer effects with a steam/hydrogen mixture. If operator actions take place during an accident such that water is reintroduced on the secondary side of a steam generator, condensation would begin, possibly resulting in a sudden enrichment of the gas mixture hydrogen content in the steam generator tubing. This situation could potentially lead to a serious disruption in the natural circulation flow pattern caused by U-tube flow blockage. 


\section{NOMENCLATURE}

\begin{tabular}{|c|c|c|c|}
\hline$c_{p}$ & $\begin{array}{l}\text { constant pressure specific heat, } \\
\mathrm{J} /(\mathrm{kg} \cdot \mathrm{K})\end{array}$ & $\Delta \mathrm{T}$ & temperature difference, $\mathrm{K}$ \\
\hline$c_{v}$ & constant volume specific heat, J/kg K & $\mathrm{u}_{\mathrm{e}}$ & entrainment velocity, $\mathrm{m} / \mathrm{s}$ \\
\hline g & gravitational acceleration, $\mathrm{m} / \mathrm{s}^{2}$ & $\mathrm{u}^{*}$ & convective velocity [Eq. (4)] \\
\hline $\mathrm{h}$ & heat transfer coefficient, $W / \mathrm{m}^{2} \mathrm{~K}$ & $\mathrm{~V}$ & flow velocity, $\mathrm{m} / \mathrm{s}$ \\
\hline L & characteristic length, $\mathrm{m}$ & $\mathrm{x}$ & mole fraction, dimensionless \\
\hline $\mathrm{M}$ & molecular weight, $\mathrm{kg} / \mathrm{kmol}$ & $\alpha$ & thermal diffusivity, $\mathrm{m}^{2} / \mathrm{s}$ \\
\hline $\mathrm{n}$ & $\begin{array}{l}\text { natural convection exponent, } \\
\text { Eq. (12), dimensionless }\end{array}$ & $\beta$ & $\begin{array}{l}\text { volumetric thermal expansion } \\
\text { coefficient, } \mathrm{K}^{-1}\end{array}$ \\
\hline$q_{b}$ & $\begin{array}{l}\text { heat flux for penetrative mixing, } \\
\mathrm{W} / \mathrm{m}^{2}\end{array}$ & $\delta_{\mathrm{b}}$ & height of mixed layer, $\mathrm{m}$ \\
\hline$q^{\prime \prime}$ & heat flux, W/m $\mathrm{m}^{2}$ & $\phi$ & $\begin{array}{l}\text { gas mixture property parameter, } \\
\text { Eq. (6), dimensionless }\end{array}$ \\
\hline $\mathrm{Ra}$ & $\begin{array}{l}\text { Rayleigh number [defined in Eq. (1)], } \\
\text { dimensionless }\end{array}$ & $\mu$ & $\begin{array}{l}\text { absolute viscosity, } \mathrm{N} \mathrm{s} / \mathrm{m}^{2} \\
\text { kinematic viscosity, } \mathrm{m}^{2} / \mathrm{s}\end{array}$ \\
\hline $\mathrm{Ri}$ & $\begin{array}{l}\text { Richardson number [Eq. (5)], } \\
\text { dimensionless }\end{array}$ & $\rho$ & fluid density, $\mathrm{kg} / \mathrm{m}^{3}$ \\
\hline$t$ & time, $\mathrm{s}$ & $\rho_{b}$ & density within mixed layer, $\mathrm{kg} / \mathrm{m}^{3}$ \\
\hline $\mathrm{T}$ & temperature, $\mathrm{K}$ & $\Delta \rho$ & density difference, $\mathrm{kg} / \mathrm{m}^{3}$ \\
\hline
\end{tabular}




\section{E-1. INTRODUCTION AND BACKGROUND}

During certain postulated severe accident scenarios [e.g., loss of both onsite and offsite ac power and early failure of the steam-driven auxiliary feedwater pump (TMLB' sequence)], a high pressure boiloff of reactor coolant system (RCS) water occurs, causing the core and upper regions of the reactor vessel to be filled with steam. During the later stages, the presence of water in the pump loop seals generally precludes the establishment of full-loop natural circulation through the hot leg, steam generator, cold leg, and core. However, both in-vessel and ex-vessel multidimensional natural circulation flows can still occur. Because of the radial power distribution in the core, fuel temperatures are higher in the center than at the core periphery. Consequently, a natural circulation flow of steam can become established through the core with downflow near the periphery and upflow in the center. In addition, heat sinks in the upper plenum allow for the formation of a vigorous natural circulation flow in the upper portion of the reactor vessel. In Westinghouse and Combustion Engineering plants, hot leg countercurrent flow can also become established due to the presence of heat sinks in the hot leg piping and the steam generator. In this flow loop, hot steam exits the reactor vessel through the top half of the hot leg piping and is returned through the lower half. Some of this fluid enters the steam generator tubes where natural circulation flow may also become established, despite significant fluid mixing in the steam generator inlet plenum. An additional complication occurs at the point in the transient when core temperatures become high enough $(\sim 1,000 \mathrm{~K})$ that the zircaloy cladding begins to chemically react with the steam, producing hydrogen gas and exothermic heating. Generation of hydrogen gas in the RCS has the potential to modify or stop the natural circulation flows because of stratification effects. In addition, the presence of hydrogen affects natural circulation heat transfer rates.

The net result of the natural circulation flows is to transport thermal energy from the reactor core to other structures and to reduce the rate of fuel temperature increase in the core. Ultimately, a passive failure of ex-vessel piping could occur because of creep rupture or even melting, thereby depressurizing the RCS prior to the time of a lower head failure. The possibility of a highpressure ejection of molten core materials and the resultant direct containment heating would therefore be reduced (but the potential for an in-vessel steam explosion may be increased). The specific location of the ex-vessel failure is critical, since initial failure of the steam generator tubes would provide a direct path (through the steam line relief valves) for fission product release outside of containment. The most favorable failure location is therefore the surge line or the hot leg.

A research program has been initiated to evaluate vessel and hot leg natural circulation behavior to aid in predicting the likelihood of passive exvessel RCS failure prior to lower head failure and to identify the most likely failure location. One aspect of this project is to evaluate the effect of hydrogen production on natural circulation flow and heat transfer in the RCS. Concerns have been raised that hydrogen stratification could isolate certain regions from natural circulation flows and thus have a significant impact on the timing and location of RCS failure. This type of flow disruption, if present, cannot be modeled using a onedimensional system code such as RELAP5. Even in the absence of stratification, with a homogeneous mixture of steam and hydrogen circulating in the RCS, natural circulation flow rates and heat transfer will be affected by the presence of hydrogen. This appendix addresses quantification and code modeling of these fully mixed binary gas effects.

The objective of the analysis presented in this appendix is to assess the effects of hydrogen generation on severe accident natural circulation flow and heat transfer rates. This assessment includes an attempt to quantify the likelihood that in-vessel hydrogen stratification will persist for any significant time period during a severe accident transient. Characteristic turbulent mixing times will be estimated and compared to appropriate transient time scales. Enhancement of natural convection heat transfer rates from hydrogen enrichment is considered. Finally, the 
implications of operator-induced sudden condensation in the steam generator after significant hydrogen addition are considered.

\section{E-2. HYDROGEN EFFECTS ON NATURAL CIRCULATION}

\section{E-2.1 Stratification and Mixing}

The possibility for hydrogen stratification in the reactor vessel will be examined first. During hydrogen production via the steam-zirconium oxidation reaction, hot streaks of hydrogen-rich gas will be transported upward by buoyancy forces. A hydrogen-enriched atmosphere could therefore be created (at least temporarily) in the reactor vessel upper plenum. Thermally driven in-vessel natural convection will also be occurring because of buoyant forces associated with temperature differences between the core and reactor vessel internal structures. This natural convection will tend to homogenize the gas mixture inside the vessel by turbulent mixing. The strength of the natural convection flow and associated turbulent mixing is governed by the magnitude of the characteristic Rayleigh number for this enclosure as given by

$R a=\frac{g \beta \Delta T L^{3}}{\nu \alpha}$

Using steam properties at $700^{\circ} \mathrm{C}$ and $15 \mathrm{MPa}$ [fluid conditions characteristic of the early stages of core heatup [(Reference E-1)] and choosing a characteristic temperature difference, $\Delta \mathrm{T}$, of $400 \mathrm{~K}$ [typical value based on results for analysis presented in Reference E-1 and TMI-2 lead screw data [(Reference E-2)] and a characteristic length scale of $3.4 \mathrm{~m}$ (typical reactor vessel diameter), a characteristic Rayleigh number of $1.2 \times 10^{14}$ is predicted. Since transition to turbulence occurs at a Rayleigh number around $10^{9}$, vigorous turbulent natural convection is expected at the predicted vessel characteristic Rayleigh number. Chemical energy release from the exothermic steam/zirconium oxidation reaction would be expected to further augment natural convection and mixing during the very time when hydrogen production is occurring.

The order of magnitude of typical in-vessel flow velocities can be estimated using

$V=\sqrt{g z \Delta T / T}$,

where $\mathrm{z}$ is the fluid acceleration height. The upper plenum height is about $3 \mathrm{~m}$. Assuming that buoyant acceleration is effective over one-third of the upper plenum height, and that $\Delta T / T \sim 0.4$, a velocity of about $2 \mathrm{~m} / \mathrm{s}$ is obtained. Recognizing that there will be significant dissipation of flow kinetic energy associated with fluid impingement on the upper plenum support plate and recirculation, a reasonable average velocity magnitude for the upper plenum flow may be $0.5-1 \mathrm{~m} / \mathrm{s}$, which is consistent with the results of Reference E-1.

A method for estimating turbulent mixing times in initially stratified media is provided in Reference E-3. The fluid is characterized by initial stable solutal stratification and is assumed to be uniformly heated from below, as shown in Figure $\mathrm{E}-1$. In this case, a homogeneous mixed layer whose height increases with time forms above the heated surface. A correlation for entrainment (or mixing front) velocity, which quantifies the growth rate of the mixed layer for such systems, is given by

$\frac{u_{e}}{u_{*}}=0.2 R i^{-1}$,

where

$u *=\left[\frac{g \beta_{T} q_{b} \delta_{b}}{\varrho_{b} C_{v, b}}\right]^{1 / 3}$

and the Richardson number, $\mathrm{Ri}$, is given by

$R i=\frac{g \Delta P \delta_{b}}{\varrho_{o} u_{*}^{2}}$ 


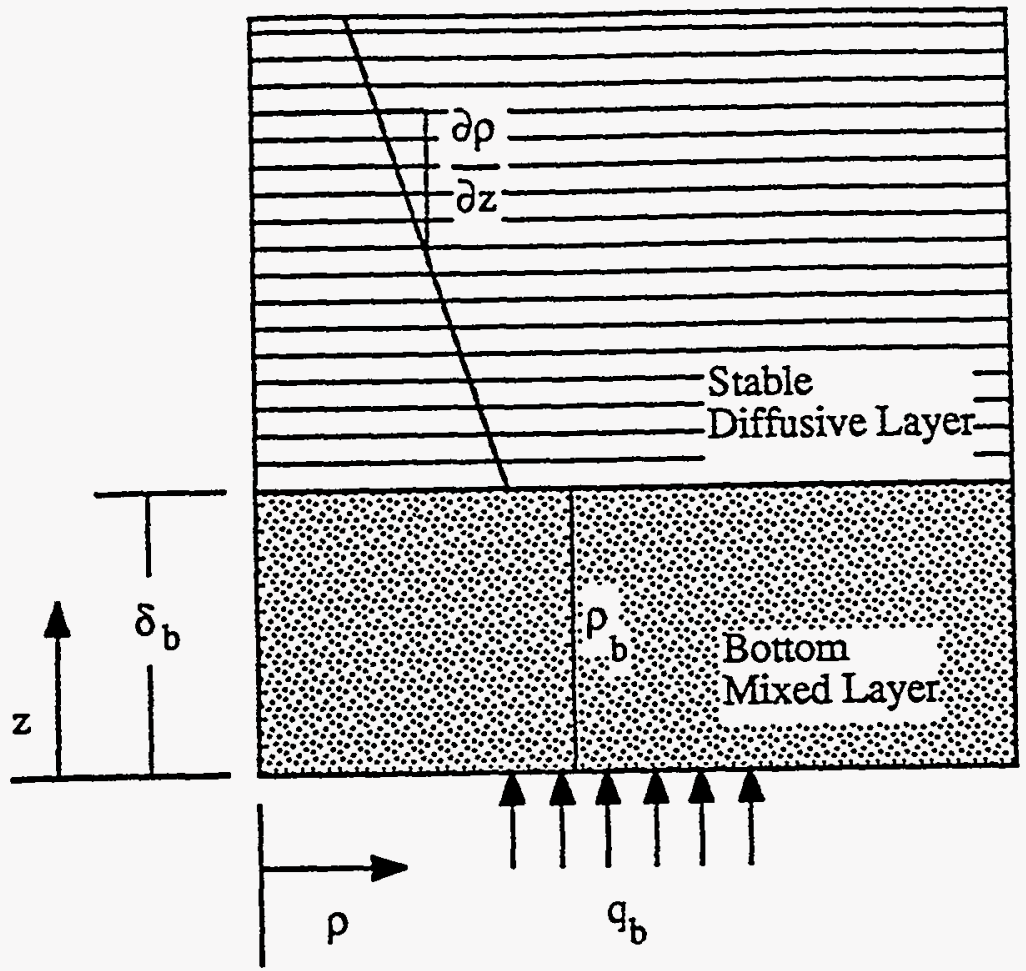

Figure E-1. Schematic of penetrative mixing situation.

The range of applicability for the correlation of Eq. (E-3) is approximately $1<R i<10^{4}$. The density, $\rho_{b}$, is the density of the mixed layer, which changes with time according to

$\varrho_{b}=\frac{1}{\delta_{b}} \int_{0}^{\delta_{b}} \varrho_{i}(z) d z$

in which

$\varrho_{i}(z)=\varrho(z=0)+z\left(\frac{\partial \varrho}{\partial z}\right)_{i}$

The density difference across the interface, $\Delta p$, is therefore given by

$$
\Delta \varrho\left(\delta_{b}\right)=\frac{1}{\delta_{b}} \int_{0}^{\delta_{b}} \varrho_{i}(z) d z-\varrho_{i}\left(z=\delta_{b}\right)
$$

Assuming a linear initial density variation,
$\Delta \varrho=\frac{\delta_{b}}{2}\left(\frac{\partial \varrho}{\partial z}\right)_{i}$.

Now, substituting Eqs. (E-4) and (E-5) into Eq. (E-3) and using Eq. (E-9) for $\Delta p$, the mixing front velocity is given by

$$
u_{e}=\frac{d \delta_{b}}{d t}=\frac{(2)(0.2) \beta_{T, b} q_{b}}{\delta_{b}\left(\frac{\partial \varrho}{\partial z}\right)_{i} c_{\nu, b}}
$$

Integrating to obtain $\delta_{b}$ as a function of time and solving for the mixing time, treating the other mixed layer properties as constant yields

$t_{\text {mix }}=\frac{\delta_{b}^{2}\left(\frac{\partial \varrho}{\partial z}\right)_{i} c_{v, b}}{0.8 \beta_{T, b} q_{b}}$,

which indicates that the mixed layer height increases with the square root of time. In reality, the mixed layer specific heat is also dependent on $\delta_{b}$. Under the assumption of an initial linear density profile, this dependency is relatively weak and was treated by evaluating the gas mixture specific heat for the mixed layer at an 
intermediate hydrogen mole fraction of 0.25 (the maximum hydrogen mole fraction for the mixed layer is 0.5 ).

A mixing time of 99 seconds has been estimated using Eq. (E-11) for the upper plenum of a PWR, again using steam and hydrogen properties at $700^{\circ} \mathrm{C}$ and $15 \mathrm{MPa}$. According to the SCDAP/ RELAP5 simulation (Reference E-1), the time period for significant hydrogen generation lasts about $10 \mathrm{~min}$. Consequently, based on the conservative mixing time estimates provided above, complete hydrogen/steam mixing should occur in a much shorter time period than is required to generate the bulk of the hydrogen. A modeling treatment of the overall transient in which fully mixed conditions are assumed to prevail at each time step is therefore reasonable. This fully mixed model is adopted in SCDAP/RELAP5.

Characteristic convective velocities, $\mathrm{u} *$, within the mixed layer can also be estimated using Eq. (E-4). For the full-scale PWR conditions of $700^{\circ} \mathrm{C}$ and $15 \mathrm{MPa}$, values of 0.73 and $1.2 \mathrm{~m} / \mathrm{s}$ are obtained at mixing heights of 1 and 3 meters, respectively. These values are completely consistent with the order-of-magnitude calculation of Eq. (E-2) and with the results of Reference E-1.

The issue of hydrogen stratification effects on severe accident PWR natural circulation was also addressed during a series of experiments performed at the Westinghouse Research and Development Center (References E-4 and E-5). A 1/7-scale model of a Westinghouse PWR was constructed to observe natural circulation flow patterns and heat transfer. The apparatus was operated under both transient and steady-state conditions using high-pressure $\mathrm{SF}_{6}$ as the working fluid in order to achieve approximate similitude. To examine the effects of possible hydrogen stratification on natural circulation flows and heat transfer, helium was slowly introduced into the model reactor vessel prior to any heating, forming a fully stratified static region in the upper head. This fully stratified starting condition was thought to represent a worst case in terms of stratification effects. Heating was initiated and transient startup of natural circulation flow patterns was observed, primarily by means of thermocouple readings in various locations. No gas sampling was performed during the high-pressure tests. Temperature readings indicated no stratification-induced delay in heating of the top upper plenum fluid. Furthermore, fluid temperature readings recorded at the core exit and at the steam generator end of the hot leg also indicated no stratification-induced heating delays. In fact, no significant stratification effects were observed. The authors conclude that in-vessel fluid mixing is rapid and is dominated by turbulence.

Hydrogen production effects were also simulated in the earlier low-pressure (atmospheric) Westinghouse $1 / 7$-scale experiments using air-helium and $\mathrm{SF}_{6}$-helium (Reference $\mathrm{E}-5$ ). In these low-pressure experiments, measurements included both thermocouple readings and gas sampling, which were carried out at various locations and times to provide a direct indication of the degree of fluid mixing. Helium injection and $\mathrm{SF}_{6}$ withdrawal were carried out differently for the low-pressure tests than for the high-pressure tests. For the low-pressure tests, helium was introduced continuously (and $\mathrm{SF}_{6}$ withdrawn) near the middle of the core for a period of 40 seconds during steady-flow natural circulation. Gas sampling began at the end of the 40 second gas introduction period. Gas concentration measurements for the $\mathrm{SF}_{6}$ tests indicated complete fluid mixing after about 5 minutes in the top of the upper plenum. Gas concentrations in the upper head were observed to acquire their final steady-state fully mixed values virtually instantaneously, however, which is unexpected since the upper head is more isolated from the core than is the upper plenum.

Predictions of mixing times were obtained for the experimental conditions of both the highpressure (Reference E-4) and the low-pressure Westinghouse (Reference E-5) 1/7-scale natural circulation tests using Eq. (E-12). Results of these calculations are summarized in Table E-1, along with the results of a calculation for a full-scale plant at $7 \mathrm{MPa}, 700^{\circ} \mathrm{C}$. 
Table E-1. Summary of mixing time calculation results.

\begin{tabular}{lccc}
\hline & $\begin{array}{c}\mathrm{u} * \\
(\mathrm{~m} / \mathrm{s})\end{array}$ & $\mathrm{Ri}$ & $\begin{array}{c}\mathrm{t}_{\operatorname{mix}} \\
(\mathrm{s})\end{array}$ \\
\hline Full-scale plant, $\mathrm{P}=15 \mathrm{MPa}$ & 1.22 & 16 & 116 \\
Westinghouse $1 / 7$-scale, low-pressure & 0.315 & 39 & 137 \\
Westinghouse $1 / 7$-scale, high-pressure & 0.431 & 21 & 52 \\
Full-scale plant, $\mathrm{P}=7 \mathrm{MPa}$ & 1.51 & 8.8 & 51 \\
\hline
\end{tabular}

The predicted convective velocity, $\mathrm{u} *$, for the Westinghouse low-pressure tests is consistent with results of laser Doppler anemometry measurements obtained in the upper plenum of the 1/7-scale facility (Reference E-5). Richardson numbers of Table E- 1 are all within the range of applicability cited earlier. Mixing time for the Westinghouse low-pressure test is predicted to be 137 seconds, which is lower than the 5-minute value indicated from the gas sampling measurements. Experimental conditions did not correspond exactly to the initially fully stratified condition of the correlation, however, so this level of disagreement is not surprising. Mixing time for the Westinghouse high-pressure experiments was predicted to be 52 seconds, which is about one-twentieth of the overall transient time studied. There were no direct gas sampling measurements obtained during the high-pressure tests, however, so no direct comparison can be made. As mentioned previously, no significant stratification-induced thermal effects were observed during the high-pressure tests.

It should be noted that the predicted mixing times for the $1 / 7$-scale experiments, despite their similarity to the prototypical values, represent a relatively high fraction of the total characteristic transient time for the $1 / 7$-scale model because the time scale for the model is much shorter than for the prototype (Reference E-6). Therefore, for similar predicted mixing times, stratification effects would be expected to be more pronounced in the model.

In fact, some significant stratification-induced effects were noted for the nonprototypical (the primary flow similitude parameter used by
Westinghouse, $g \rho^{2} \beta q^{\prime \prime} L^{2} / c_{p} \mu^{3}$, was more than four orders of magnitude too low with atmospheric $\mathrm{SF}_{6}$ ) Westinghouse low-pressure tests. About 1 minute after the end of helium injection, a temperature inversion was observed in the hot leg with cold light gas overlying warm heavy gas. This situation was because the fluid entering the top of the hot leg from the reactor vessel was helium-enriched. Hot leg temperatures remained steady for about the next 10 minutes, apparently indicating a complete flow stoppage during that period. This flow stoppage may have been caused by blockage of the inverted U-tube steam generator flow by helium-enriched fluid. In any case, clearly the observed stratification effects were much more severe for the low-pressure experiments than for the near-prototypical high-pressure experiments. The severity of the effects was probably due to the longer mixing time (see Table E-1) required for the weaker, less turbulent flow conditions of the low-pressure experiments, allowing transport of a significantly helium-enriched fluid stream to the steam generator tubes where blockage ensued. The method of helium introduction into the experimental apparatus may have also played a role.

The effect of system pressure on mixing time is indicated in the last column in Table E-1. The reduction in predicted mixing time is primarily due to the reduction in density difference between the two gases as the pressure is decreased. The short mixing times of Table E-1 and the results of the high-pressure Westinghouse experiments indicate that hydrogen stratification should not cause any significant disruption of severeaccident natural circulation flows in the reactor vessel. 
Several studies have also been performed on hydrogen stratification and mixing in containment atmospheres (References E-6 through $\mathrm{E}-10)$. The consensus of these studies is that turbulent mixing dominates inside containments as well and that hydrogen stratification will persist for time periods only on the order of tens of minutes (Reference E-6), even with the relatively weak natural convection and much larger volume of a containment compared to a reactor vessel.

Concerns about in-vessel stratification effects on severe accident natural circulation were heightened by observations obtained from metallurgical examination of lead screws from TMI-2 (Reference E-2). These observations revealed that an inverted temperature profile existed (at least in the lead screws) during the accident in the upper region of the reactor vessel, with the lowest temperatures occurring at the top of the vessel. Additional evidence based on oxidation rates indicates that a hydrogen-enriched atmosphere was present in the upper reactor vessel (Reference E-2). Solutal stratification of a relatively low-temperature hydrogen/steam mixture has been suggested as a possible explanation for these observations. Expected TMI- 2 in-vessel mixing times are so short, however, that hydrogen stratification should not have persisted for any significant time period. An analysis of the lead screw temperature response is provided in Appendix G.

\section{E-2.2 Gas Mixture Effects}

If the assumption is made that complete mixing of steam and hydrogen has been achieved in the RCS and that no condensation is occurring, the analysis reduces to one in which the properties of the gas mixture must be used in place of pure steam properties to predict natural circulation (other gas components such as volatile fission products may also be present). Natural convection heat transfer rates for hydrogen/steam are higher than for steam alone. Enhancement is due primarily to the significantly higher thermal conductivity of hydrogen. For a given geometry and temperature difference, the magnitude of the enhancement can be approximated by (Reference E-11)

$$
\bar{h} \sim\left(c_{p} \cdot \varrho^{2} / \mu\right)^{n} \cdot k^{1-n},
$$

where $\mathrm{n}$ is the exponent in the relationship

$\overline{N u} \sim R a^{n}$,

and the properties are evaluated for the gas mixture. Typical values for $n$ are in the range 0.2-0.3. Methods for determination of gas mixture properties are given in Reference E-12. For mixtures of ideal gases, thermodynamic properties (expressed on a molar basis) are simply mole-fraction weighted averages of the constituent properties. Transport properties, on the other hand, are not. In particular, viscosity of gas mixtures is determined from the Sutherland formula

$$
\mu_{g}=\sum_{i=1}^{N} \frac{x_{i} \mu_{i}}{\sum_{j=1}^{N} x_{j} \phi_{i j}}
$$

where

$$
\begin{aligned}
\phi_{i j}= & \frac{1}{\sqrt{8}}\left(1+\frac{M_{i}}{M_{j}}\right)^{-1 / 2} \\
& {\left[1+\left(\frac{\mu_{i}}{\mu_{j}}\right)^{1 / 2}\left(\frac{M_{j}}{M_{i}}\right)^{1 / 4}\right]^{2} . }
\end{aligned}
$$

A similar formula is used for thermal conductivity. As an example of the fully mixed steam /hydrogen effect on natural convection, properties of steam/hydrogen mixtures at $700^{\circ} \mathrm{C}$ and $15 \mathrm{MPa}$ required for use in Eq. (E-12) are plotted in Figure E-2 as a function of hydrogen mole fraction.

In addition, the heat transfer enhancement for natural convection with a steam/hydrogen mixture as predicted by Eq. (E-12) is shown in Figure E-3. It is interesting to note that the maximum heat transfer enhancement occurs with a high mole fraction of hydrogen, but not with pure hydrogen. Equations (E-14) and (E-15) are 


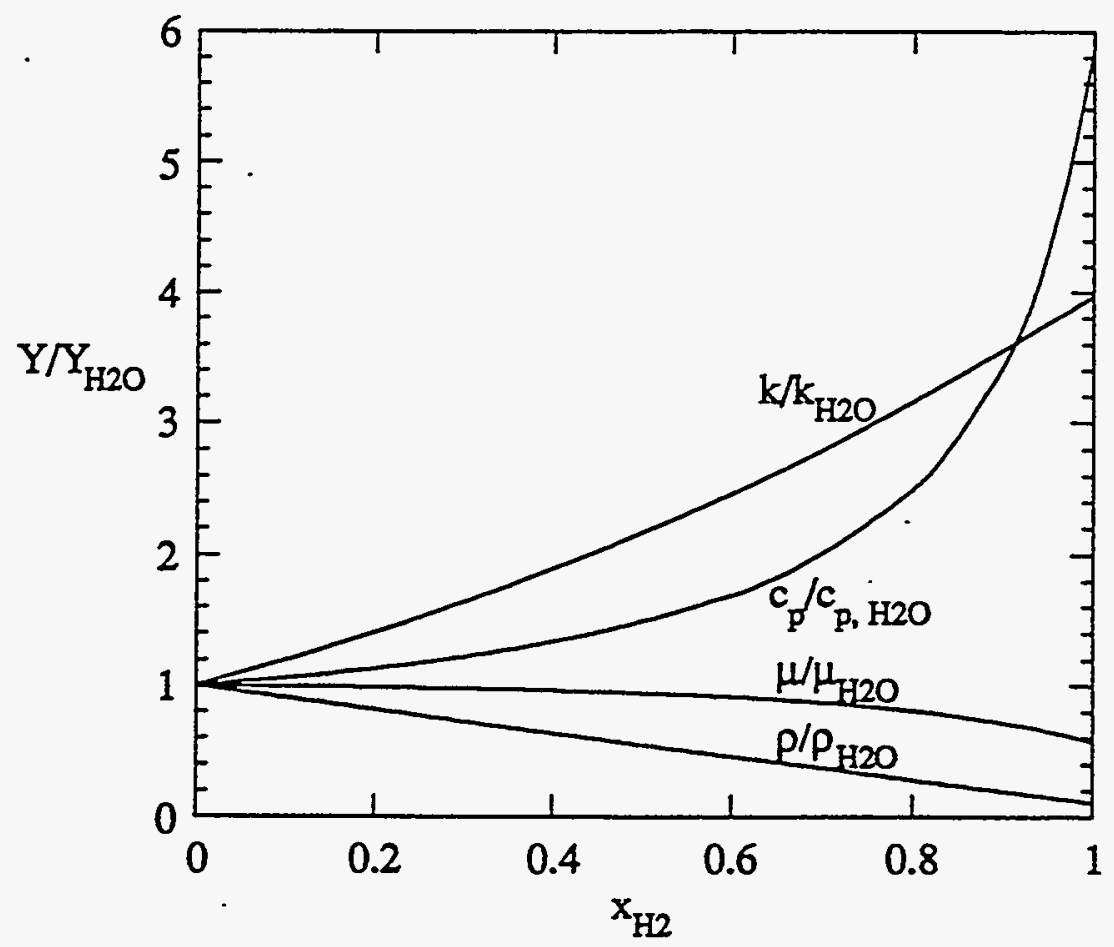

Figure E-2. Gas mixture property variations for increasing hydrogen mole fraction.

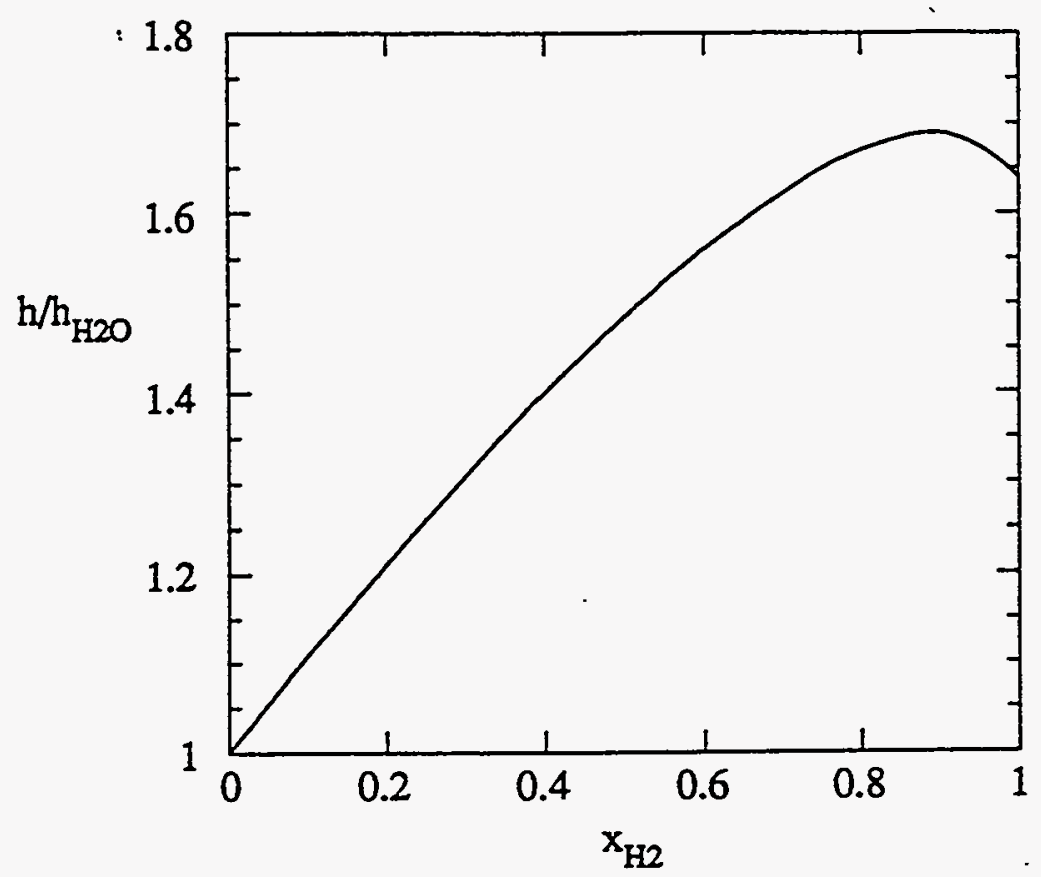

Figure E-3. Natural convection heat transfer enhancement because of increasing hydrogen mole fraction. 
incorporated into RELAP5 (Reference E-13), which treats steam/noncondensible mixtures as being in complete thermal and mechanical equilibrium (i.e., fully mixed) (Reference E-14). Hydrogen properties are also available in the code. Heat addition associated with the exother$\mathrm{mic}$ steam/zirconium oxidation reaction is also modeled. Therefore, recognizing the inherent limitations of a one-dimensional representation of a multidimensional phenomenon, RELAP5, as it was applied in Reference E-1, should provide reasonable estimates of natural circulation heat transfer effects with a steam/hydrogen mixture.

\section{E-2.3 Condensation}

As mentioned previously, condensation in the steam generator would not be expected after boiloff of the secondary side during a TMLB' transient. However, if operator actions take place such that water is reintroduced on the secondary side of a steam generator (as occurred during TMI-2), condensation would begin inside the steam generator tubing. If the fluid inside consists of a steam/hydrogen mixture, sudden enrichment of the hydrogen content will occur. This situation could potentially lead to a serious disruption in the natural circulation flow pattern, especially for the inverted U-tube steam generator design. In particular, U-tube flow blockage could occur as the concentration of light noncondensible hydrogen gas increases inside the tubing. Buoyancy will tend to stabilize the hydrogen in the inverted U-tubes, preventing further natural circulation through the tubes.

An operator-induced transient involving introduction of water to the secondary side of the steam generator could have a significant impact on the time-to-failure of specific RCS components during an accident scenario, especially if hydrogen is present on the primary side at the time of the transient. System response to this type of transient should also be amenable to RELAP5 modeling, possibly requiring inclusion of a steam generator flow blockage model such as the one used in MAAP (Reference E-15). RELAP5 does have the capability to handle condensation in the presence of noncondensibles.

\section{E-3. SUMMARY AND CONCLUSIONS}

Natural circulation can play an important role during certain PWR severe accidents in determining the failure location and time-to-failure of RCS components. At the time in the transient when fuel cladding temperatures reach about $1,500 \mathrm{~K}$, hydrogen generation from the steam/zirconium reaction becomes significant. Effects of this hydrogen production on natural circulation flow and heat transfer have been considered in this report. Long-term hydrogen stratification in the reactor vessel appears to be unlikely because of turbulent mixing associated with high Rayleigh number in-vessel natural convection. Estimated mixing times were found to be short, compared to overall transient time periods, even when a fully stratified starting condition was assumed. This finding was consistent with experimental results obtained at Westinghouse with a $1 / 7$-scale PWR RCS model.

If mixing of steam and hydrogen is assumed to be rapid and no condensation can occur, analysis of the accident progression can be performed by accounting for the properties of the gas mixture as the composition changes. The gas property changes that occur as a result of hydrogen production include (a) increased thermal conductivity and specific heat and (b) decreased viscosity and density. The net effect on natural circulation heat transfer is a significant augmentation. The fully mixed gas model is utilized in RELAP5. Therefore, with its inherent limitations in mind, RELAP5 should provide reasonable estimates of natural circulation effects, system temperatures, failure location, and component time-to-failure with a steam/hydrogen mixture. If operator actions take place during an accident such that water is reintroduced on the secondary side of a steam generator, condensation would begin, possibly resulting in a sudden enrichment of the gas-mixture hydrogen content in the steam generator tubing. This situation could potentially lead to a serious disruption in the natural circulation flow pattern because of 
U-tube flow blockage, possibly delaying or even precluding hot leg or surge line failure.

\section{E-4. REFERENCES}

E-1. P. D. Bayless, Analyses of Natural Circulation During a Surry Station Blackout Using SCDAP/RELAP5, NUREG/ CR-5214, October 1988.

E-2. K.Vinjamuri, D. W. Akers, and R. R. Hobbins, Examination of $H 8$ and $B 8$ Leadscrews from Three Mile Island Unit 2 (TMI-2), GEND-INF-052, 1985.

E-3. T. L. Bergman, F. P. Incropera, and R. Viskanta, "Correlation of Mixed Layer Growth in a Double-Diffusive, SaltStratified System Heated from Below," Journal of Heat Transfer, 108, 1986, pp. 206-211.

E-4. W. A. Stewart, A. T. Pieczynski, and V. Srinivas, Experiments on Natural Circulation in a Pressurized Water Reactor Model with High Pressure SF6, preliminary draft, 1990.

E-5. W. A. Stewart, A. T. Pieczynski, and V. Srinivas, Experiments on Natural Circulation in a Pressurized Water Reactor Model for Degraded Core Accidents, EPRI Project No. RP2177-5, Final Report, 1988.

E-6. A. L. Camp et al., Light Water Reactor Hydrogen Manual, NUREG/CR-2726, Sandia National Laboratory, 1983.

E-7. G. Langer et al., "Experimental Investigation of the Hydrogen Distribution in the Containment of a Light Water Reactor Following a Coolant Loss Accident,"
Battelle Institute e. V. Frankfurt, NRC Translation 801, 1980.

E-8. G. J. E. Willcutt, Jr. and R. G. Gido, Mixing of Radiolytic Hydrogen Generated Within a Containment Compartment Following a LOCA, NUREG/CR-0304, August 1978.

E-9. D. S. Trent, Mixing of Buoyant Combustibles Gases in BWR Containment Systems, Battelle-Northwest Laboratories report BNWL-B-298, August 1973.

E-10. J. F. van de Vate and A. Plomp, "Atmospheric Stability Inside Containments with a Heated Layer of Liquid on the Floor," Nuclear Science and Engineering, 56, 1975, pp. 196-200.

E-11. J. G. Petri and T. L. Bergman, "Augmentation of Natural Convection Heat Transfer Using Binary Gas Coolants," Int. J. Heat Mass Transfer, 33, No. 7, 1980, pp. 1441-1,449.

E-12. R. C. Reid, J. M. Prausnitz, and T. K. Sherwood, The Properties of Gases and Liquids, Thitd Edition, New York: McGraw-Hill, 1977.

E-13. J. C. Lin, Heat Transfer with Noncondensible Gas, EG\&G Report No. WRNSMD-83-005, January 1983.

E-14. K. E. Carlson et al., RELAP5/MOD3 Code Manual, NUREG/CR-5535, June 1990.

E-15. M. A. Kenton, R. E. Henry, A. Sharon, and M. Epstein, Simulation of the TMI-2 Accident Using the MAAP Modular Accident Analysis Program, Version 2.0, EPRI NP-4292, Final Report, Research Project 2392-15, January 1986. 


\section{Appendix F}

\section{Evaluation of the Capability of RELAP5/MOD3 to Calculate}

Hydrogen Blockage Effects in U-Tube Steam Generators 
.

, 


\title{
Appendix F
}

\section{Evaluation of the Capability of RELAP5/MOD3 to Calculate Hydrogen Blockage Effects in U-Tube Steam Generators}

\begin{abstract}
This appendix documents an evaluation of the capabilities of RELAP5/MOD3 for calculating the buildup of hydrogen during primary side condensation in U-tube steam generators and the blockage of heat transfer resulting from this buildup. Demonstration calculations were performed to illustrate the applicability of RELAP5/MOD3 for calculating hydrogen blockage effects in U-tube steam generators. However, it should be noted that these calculations are not intended to provide a quantitative assessment of RELAP5/MOD3 for calculating detailed thermal-hydraulic behavior, such as the effect of noncondensibles on condensation rates.
\end{abstract}

The behavior calculated by the code was found to exhibit the general trends expected. Introduction of feedwater into a stand-alone steam generator model resulted in condensation of the steam on the primary side, subsequently concentrating hydrogen in the tubes. As the hydrogen concentration increased, condensation rates decreased and the heat transfer to the secondary side of the steam generator was reduced.

The following recommendations are made based on experience gained with the stand-alone models:

- The vertical stratification model should be avoided for applications where interphase energy transfer is an important consideration, until updates are made to correct problems identified with the interphase heat and mass transfer correlations.

- A relatively fine axial nodalization should be used to represent both the primary and secondary sides of the steam generator in order to adequately stimulate reflooding of the secondary side of the steam generator. A nodalization study is recommended in situations where the timing of heat transfer degradation is important.

- A detailed quantitative assessment of RELAP5, to ensure proper calculation of thermal-hydraulic behavior in the presence of hydrogen, is recommended before performing extensive full-plant analyses of hydrogen blockage in U-tube steam generators. 


\section{F-1. PURPOSE}

This appendix documents the development and application of SCDAP/RELAP5/MOD3 (RELAP5) models used to examine the capabilities of RELAP5 for calculating hydrogen blockage effects in U-tube steam generators. Following a severe accident, it has been postulated that hydrogen generated from the oxidation of zirconium cladding will concentrate in the steam generator tubes and limit the heat transfer to the secondary system. Under this scenario, it is assumed that emergency feedwater, or some form. of secondary system cooling, is restored during the late stages of the accident after some amount of core damage and cladding oxidation has occurred. Fluid from the primary system begins to condense in the steam generator tubes as steam generator cooling is restored. As this condensation occurs, noncondensible gases will collect in the steam generator and effectively reduce the ability of the steam generator to remove additional heat from the system.

During portions of severe accident analyses, RELAP5 is calculating the circulation of hydrogen throughout the primary system. The capability of RELAP5 to calculate increased concentration of hydrogen when condensation occurs and its effect on heat transfer is very important to these calculations because of the potential to substantially reduce the effectiveness of natural circulation if water is added to the secondary side of the steam generator.

Two RELAP5 stand-alone steam generator models were developed to demonstrate the applicability of RELAP5 for this type of analysis. These demonstration calculations are designed to evaluate the applicability of RELAP5 for calculating hydrogen blockage effects in U-tube steam generators. However, it should be noted that these calculations are not intended to provide a quantitative assessment of RELAP5 for calculating thermal-hydraulic behavior in the presence of hydrogen.

\section{F-2. MODEL DEVELOPMENT}

Two RELAP5 models were created for this analysis. The first model, illustrated in Figure F-1, was created by removing one set of steam generator tube volumes and their corresponding heat conductors and secondary volumes from the Surry full-plant model ${ }^{\mathrm{F}-1}$ to create a stand-alone RELAP5 model. This base model consists of a set of steam generator tubes modeled with eight volumes with constant and equivalent boundary conditions supplied to both the entrance and exit of the tubes. A five-volume secondary side is modeled, corresponding to the portion of the steam generator containing the tube bundles. A time-dependent junction is used to control feedwater supply to the secondary side.

A somewhat arbitrary set of initial conditions was used for both the primary and secondary volumes. The initial and boundary conditions for the primary side were obtained from a depressurized severe accident calculation. The primary side pressure was approximately $1.31 \mathrm{MPa}$ with about $200 \mathrm{~K}$ superheat and a noncondensible quality of about $1 \%$. Although selection of these conditions was fairly arbitrary, the important characteristic of these conditions is that the fluid be superheated with a relatively small hydrogen concentration. The initial and boundary conditions for the secondary were chosen to represent post-dry-out conditions in a steam generator secondary, with little heat transfer from the primary to secondary fluids. Alternative initial conditions would be expected to change the calculated timing, but not the overall behavior observed in the results.

A $100 \mathrm{~s}$ null transient is used to ensure a stable initial state for the model. At this point, the transient calculation is initiated by supplying feedwater to the secondary side in a 10-s ramp, reaching a flow rate of $1,000 \mathrm{lb} / \mathrm{s}$ at $110 \mathrm{~s}$. This flow rate is then maintained for the remainder of the transient calculation. A feedwater supply temperature of $305 \mathrm{~K}$ is assumed for this analysis.

Control systems are used to calculate some useful parameters that provide an understanding of the overall system response. These include 


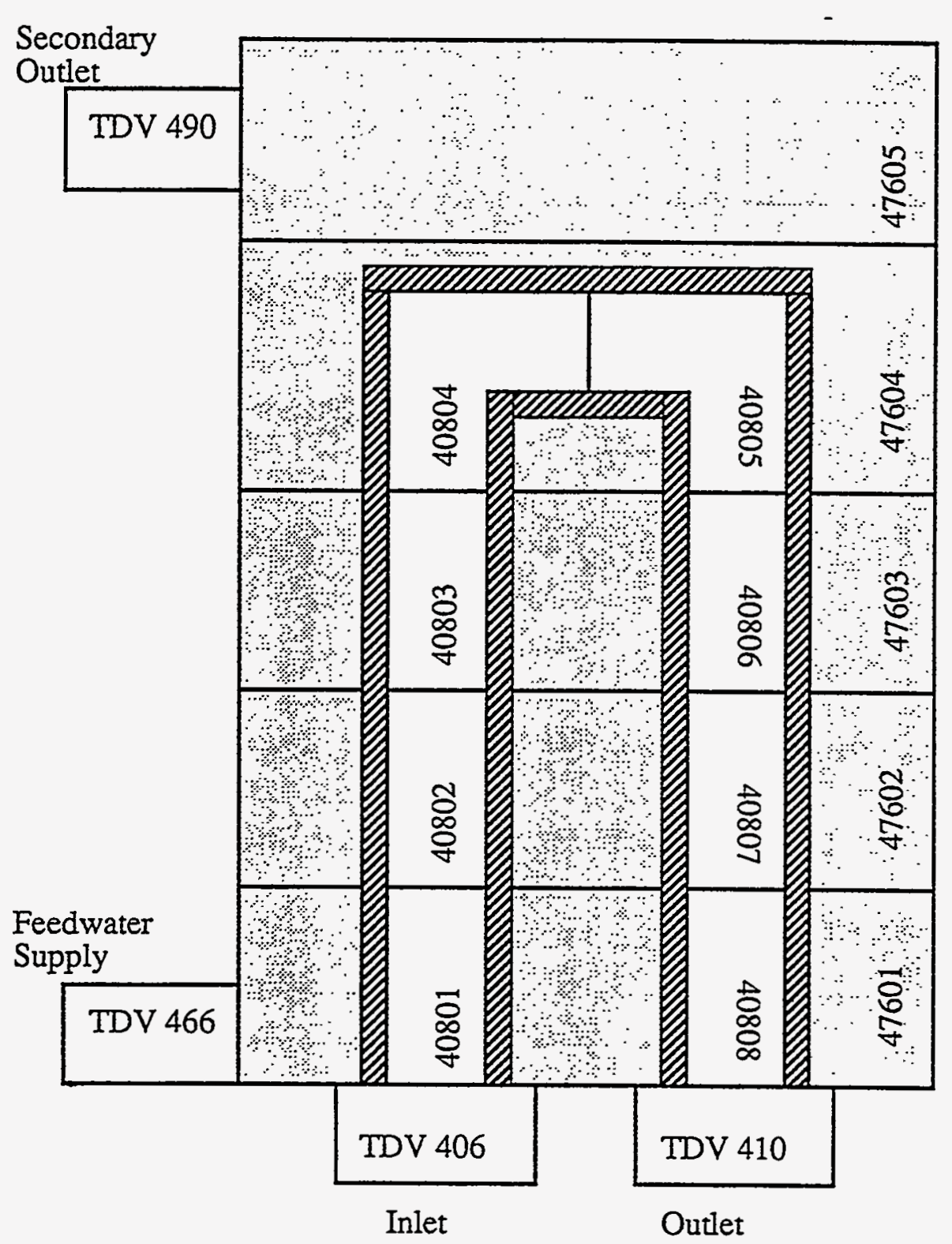

Figure F-1. RELAP5/MOD3 nodalization diagram of base model.

steam generator secondary side water level, total steam generator heat transfer, and average hydrogen concentration in the tubes.

The second model created for this analysis, illustrated in Figure F-2, is a more detailed representation of the steam generator. In this case, a 32-node primary side is used with 17 volumes representing the secondary side. The second model was created by renodalizing the base model with a more detailed mesh in a 4 to 1 ratio.

\section{F-3. RESULTS}

Calculations were performed using SCDAP/ RELAP5/MOD3 Version $80 .^{\text {F-2 }}$ Preliminary calculations identified a code problem in the interphase heat transfer correlation under the vertically stratified flow regime. The error results in very small values of interphase energy and mass transfer to be calculated under this flow regime, allowing superheated vapor to coexist with highly subcooled liquid with very little condensation 


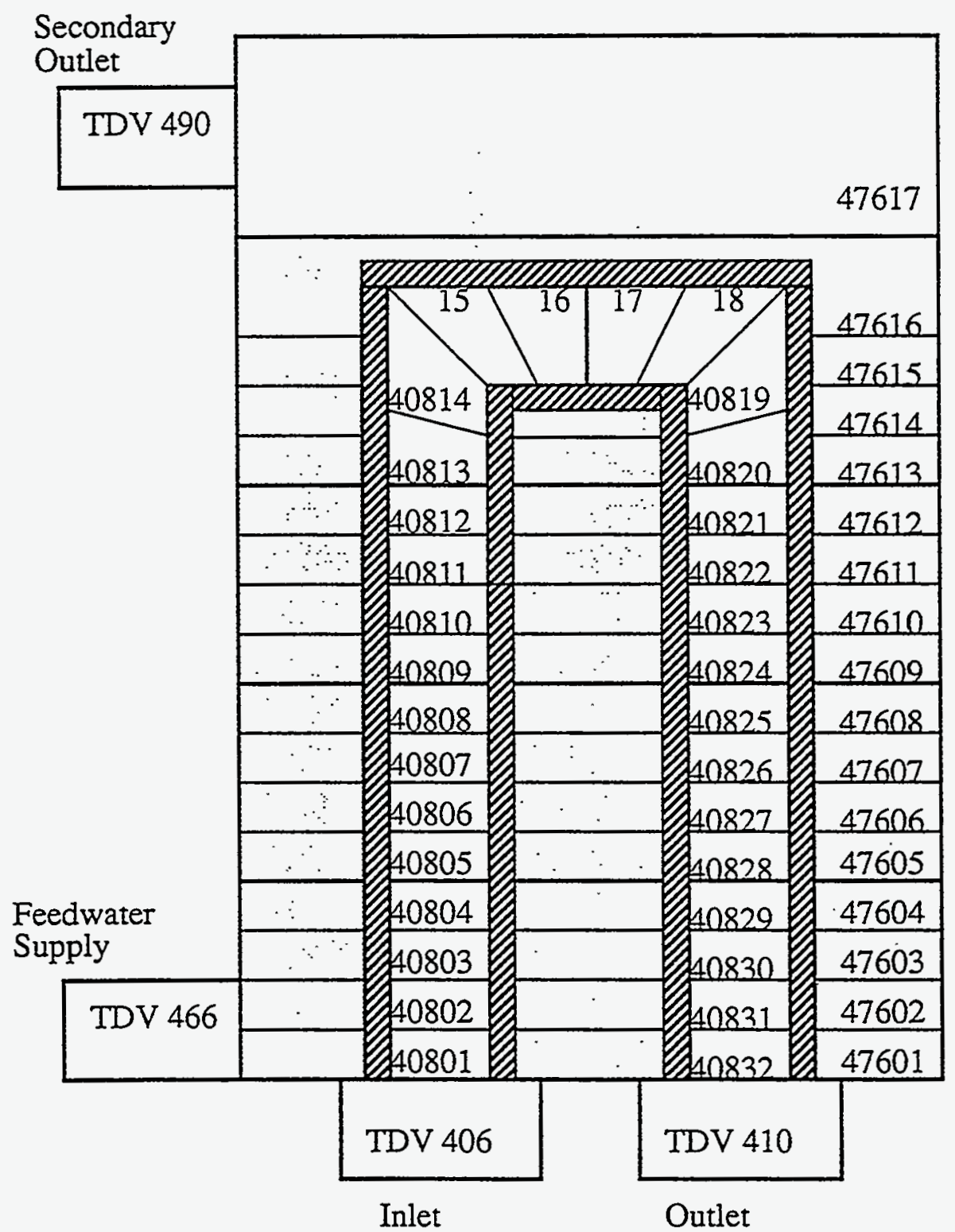

Figure F-2. RELAP5/MOD3 nodalization diagram of detailed model.

taking place. This problem occurs in the secondary side volumes after feedwater flow is restored and has a significant effect on the results during the filling of the secondary side volumes. The problem was corrected for this analysis by turning off the vertical stratification model option through the volume control flags.

Graphical displays were created for each model using the Nuclear Plant Analyzer ${ }^{\mathrm{F}-3}$ (NPA) Version 1.3 software. This software provides a user-defined, computer-animated display of the results calculated by RELAP5.

\section{F-3.1 Results Obtained from the Base Model}

A 100-s null transient was used to initialize each of the cases. At the end of the null transient, the heat transfer from the primary system approached zero, and the hydrogen concentrations remained constant at $1 \%$. At $100 \mathrm{~s}$ the feedwater flow was started with a 10-s ramp, reaching 
a flow of $1,000 \mathrm{lb} / \mathrm{s}$ at $110 \mathrm{~s}$. The flow rate was then held constant at this value for the duration of the calculation. Figures F-3 through F-8 contain plotted results from the base case. The legends on Figures F-5, F-6, and F-8 contain RELAP5 channel names, which end in nine-digit volume numbers. The first five digits of these volume numbers identify the corresponding volume from the nodalization diagram, Figure F-1.

Figure F-3 illustrates the collapsed normalized water level on the secondary side of the steam generator and shows that the secondary side filling time was about $110 \mathrm{~s}$. The total heat transfer rate from the primary system is illustrated in Figure F-4. Little change is seen for the first $25 \mathrm{~s}$ as the lowest secondary side volume is filling. After this point, a rapid rise in heat transfer rate is observed as the lower section of the tubes is quenched and condensation begins to occur on the primary side as evidenced by Figure F-5.

The plot of heat transfer rate develops a sawtooth pattern as each secondary side volume is successively flooded. As condensation begins to occur in the upper volumes on the primary side, the steam-hydrogen mixture from the lower volumes is drawn up into the upper volumes and super-heated steam with a $1 \%$ hydrogen concentration is supplied to the lowest volumes. The result is that the majority of the condensation occurs in the lowest primary side volumes, and the hydrogen tends to build up in the higher volumes. This effect can be seen in Figure F-6, which contains a plot of hydrogen concentrations for the individual volumes on one side of the U-tube. Figure F-7 contains a plot of the average hydrogen concentration for the primary side. The curve shows a fairly smooth buildup of hydrogen reaching a value of about $98 \%$ at $1,000 \mathrm{~s}$. The code does not permit the steam-hydrogen mixture to completely dry out, limiting the maximum hydrogen concentration to that of a steam hydrogen mixture under $100 \%$ humidity conditions. However, this code limitation does not represent a significant problem for this type of analysis since the limiting condition corresponds to the likely end state for the calculation.
Figure F-8 illustrates the average density in the primary side volumes. The oscillations evident in these curves correspond to liquid formed from condensation building up in a volume then flowing down and out of the system. As expected, the final average density in the tubes is significantly less than that of the superheated steam with $1 \%$ hydrogen used as a boundary condition.

\section{F-3.2 Results Obtained from the Detailed Model}

The base model results identified two problems that have been attributed to the fairly coarse nodalization employed. These include a delay of several seconds prior to significant heat transfer occurring, and a sawtooth-shaped behavior for heat transfer and subsequent condensation rates. The detailed model was created to investigate the dependence of the results on nodalization. The model was created by renodalizing the primary side and the portion of the secondary side in contact with the tubes in a 4 to 1 ratio.

Figure F-9 illustrates the collapsed normalized secondary side water level for the detailed case. This case required slightly longer to fill $(\sim 15 \mathrm{~s})$, because of differences in the secondary side interphase mass transfer rates calculated by the two models. Figures F-10 and F-11 illustrate the total heat transfer from the primary side and condensation rates on the primary side, respectively. These two plots exhibit similar response to those of the base case with the exceptions that the sawtooth behavior is eliminated and heat transfer begins much earlier. As before, most of the condensation occurs in the lower tube volumes.

As illustrated by Figure F-12, the hydrogen concentrations increase more rapidly in the smaller volumes of the detailed model. This is to be expected, since condensation starts earlier in this.model and as condensation occurs in the smaller volumes, they tend to pull in higher concentrations of hydrogen from the lower volumes. The average hydrogen concentration also builds in faster in this model, as illustrated in Figure F-13. The density curves shown in Figure F-14 illustrate a more well-behaved model than the base case, with liquid building up 
Appendix $\mathrm{F}$

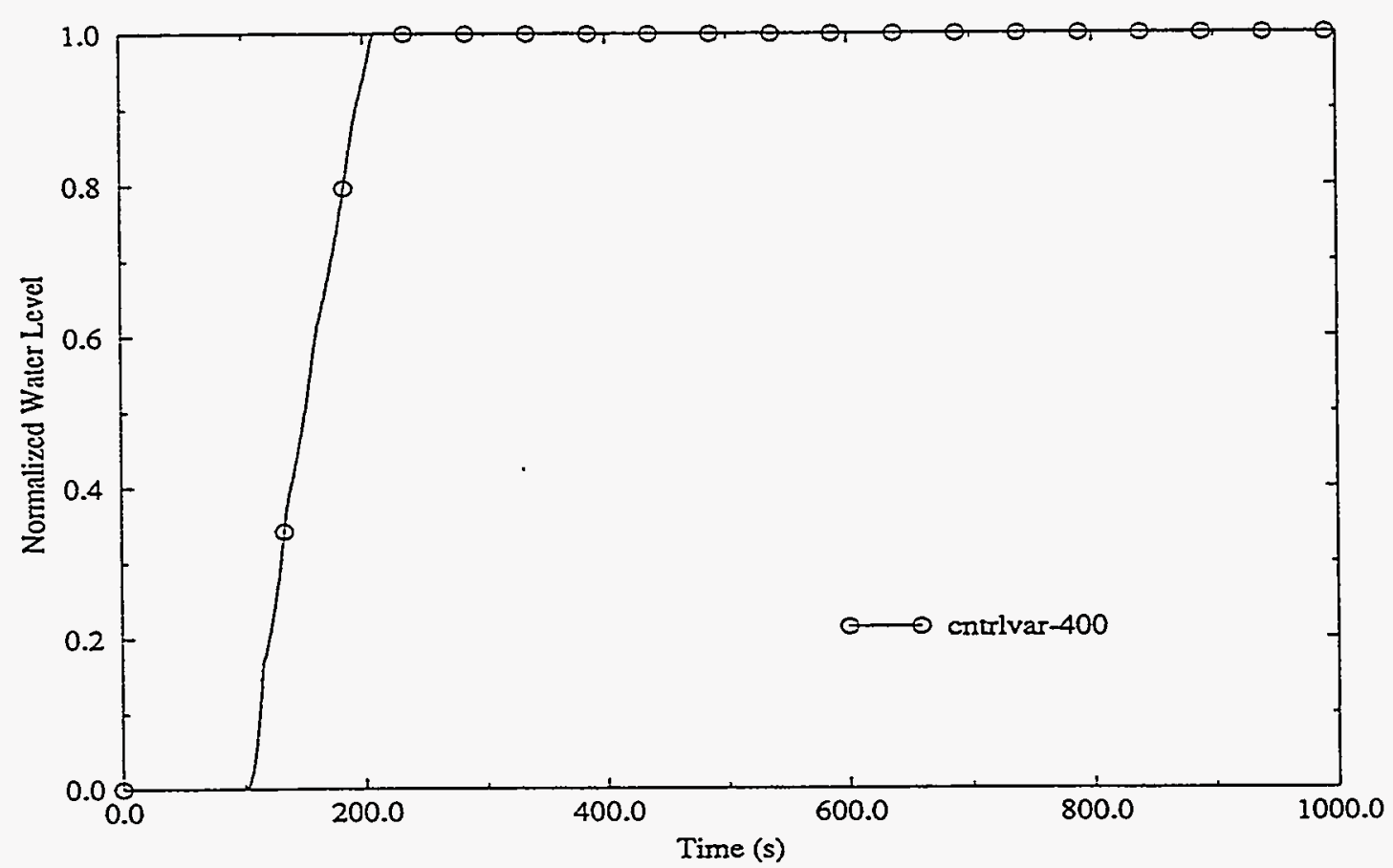

Figure F-3. Normalized secondary side water level for the base case.

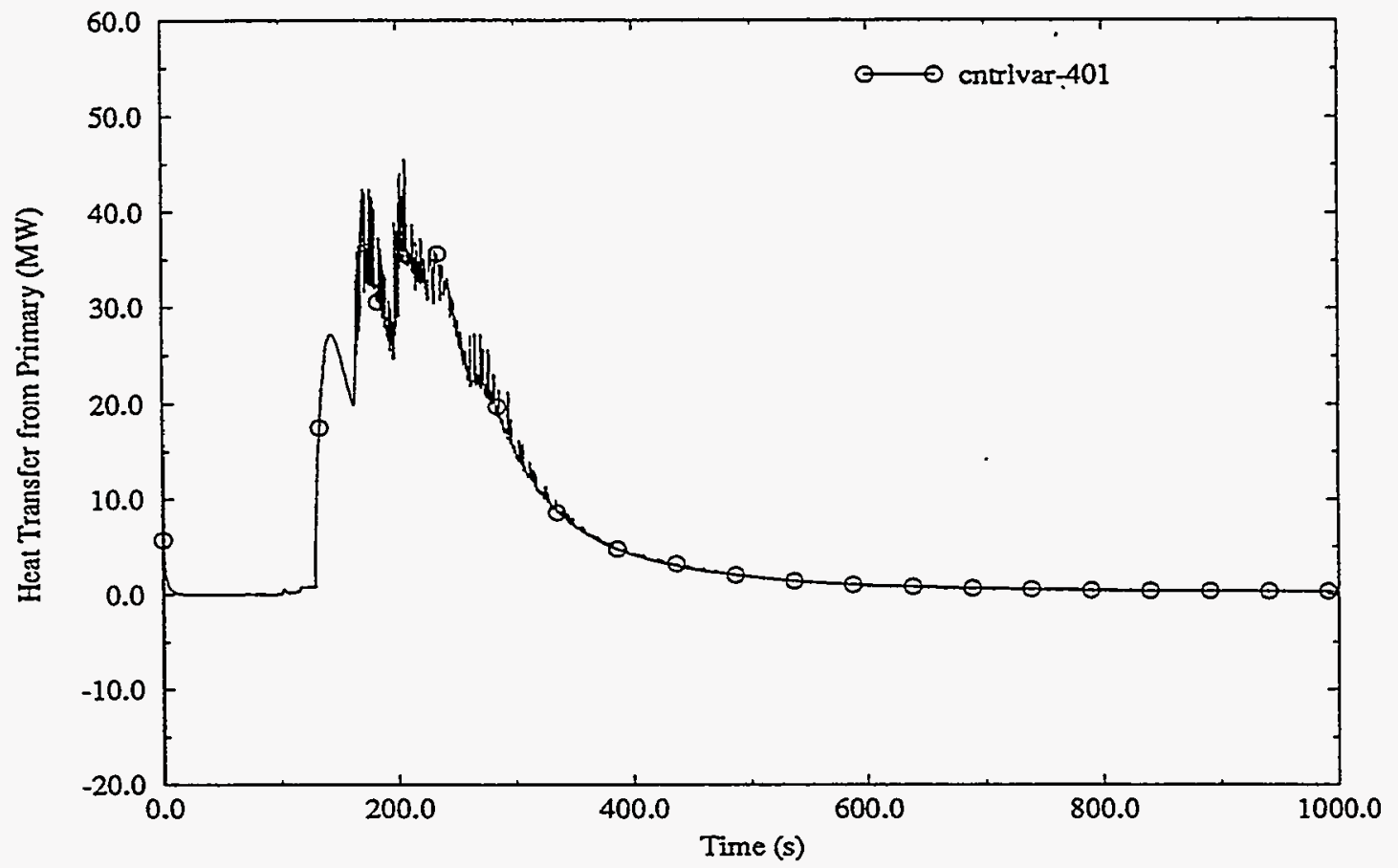

Figure F-4. Total heat transfer from the primary system for the base case. 


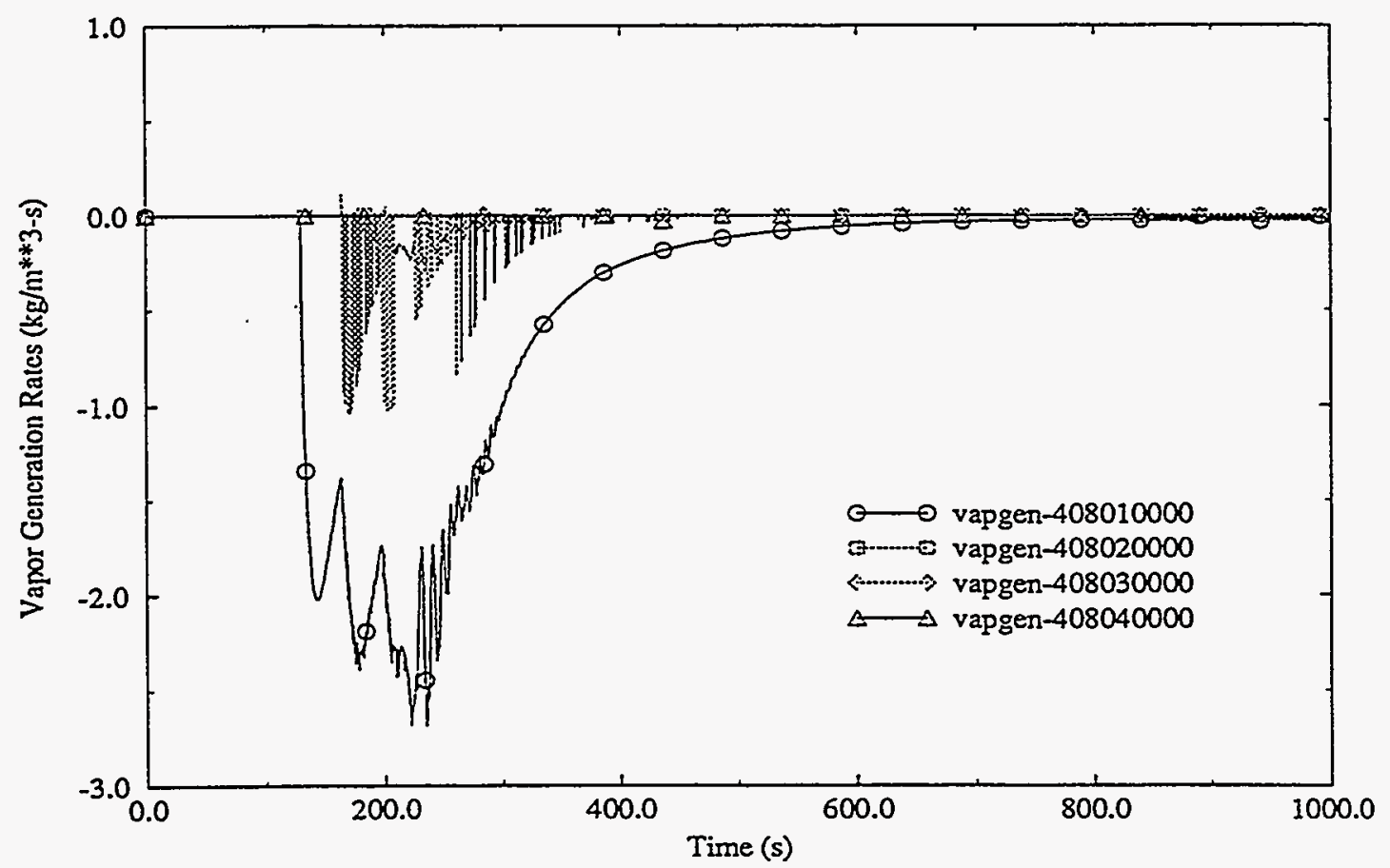

Figure F-5. Vapor generation rates for the base case.

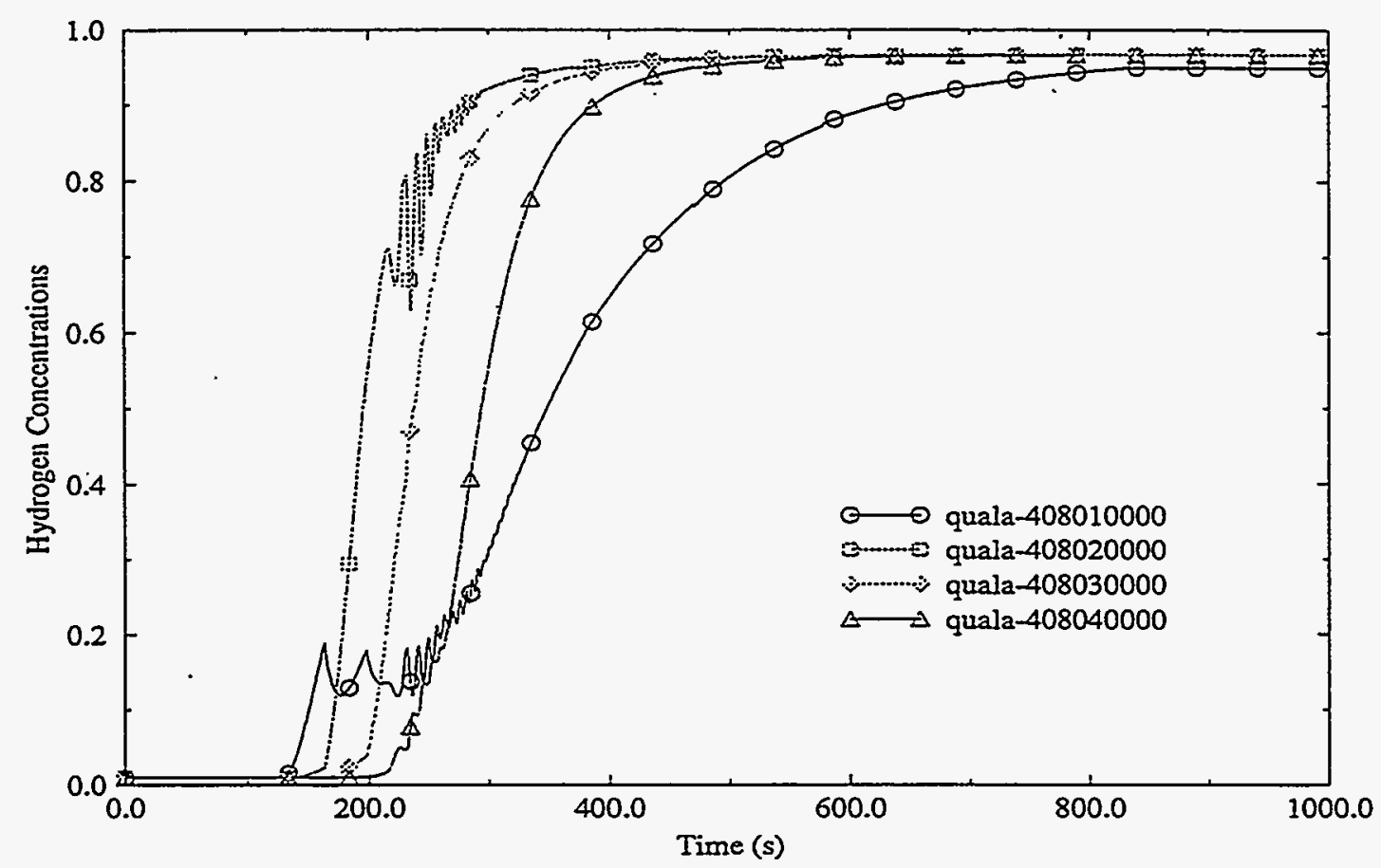

Figure F-6. Hydrogen concentrations for the base case. 
Appendix F

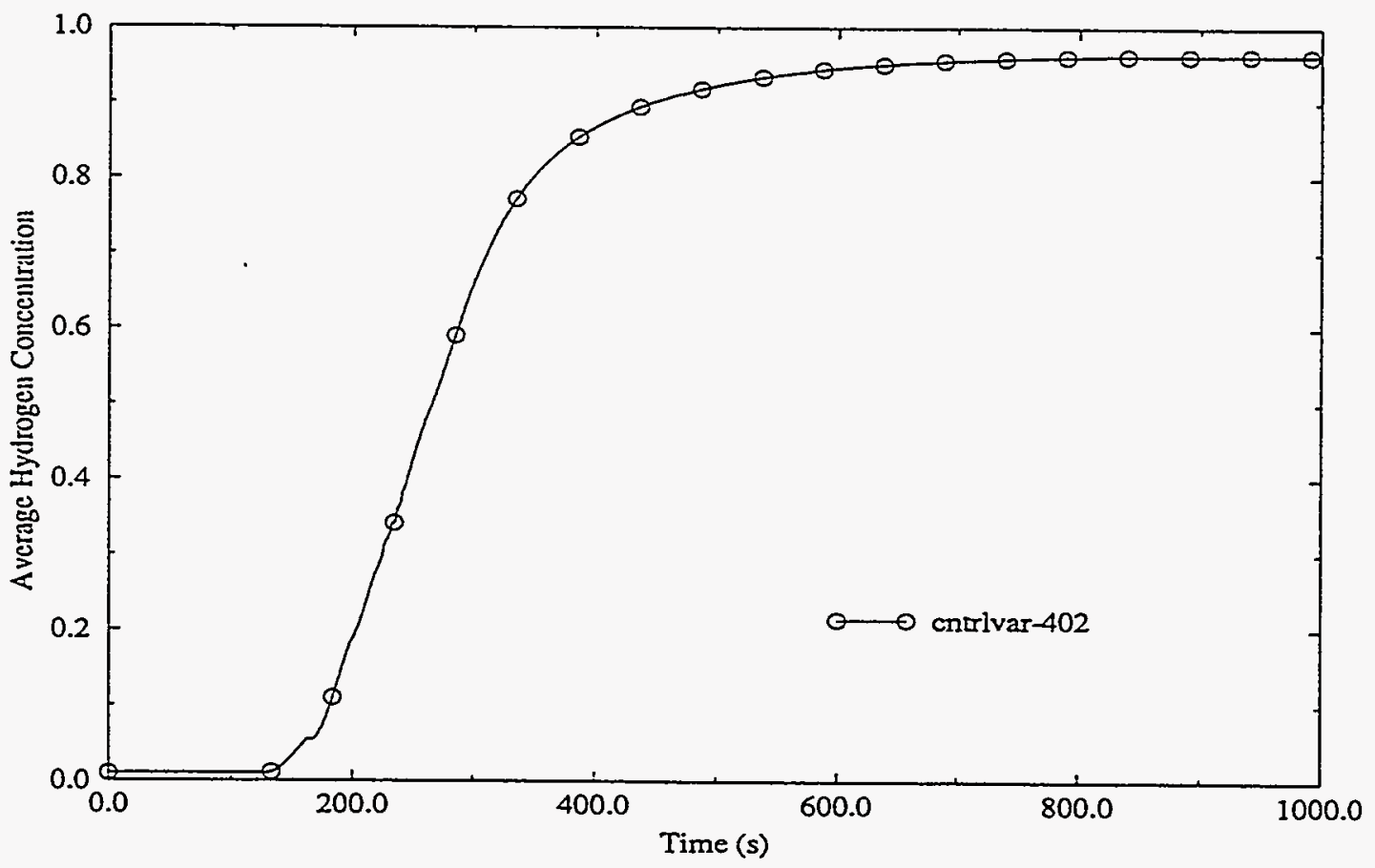

Figure F-7. Average hydrogen concentration for the base case.

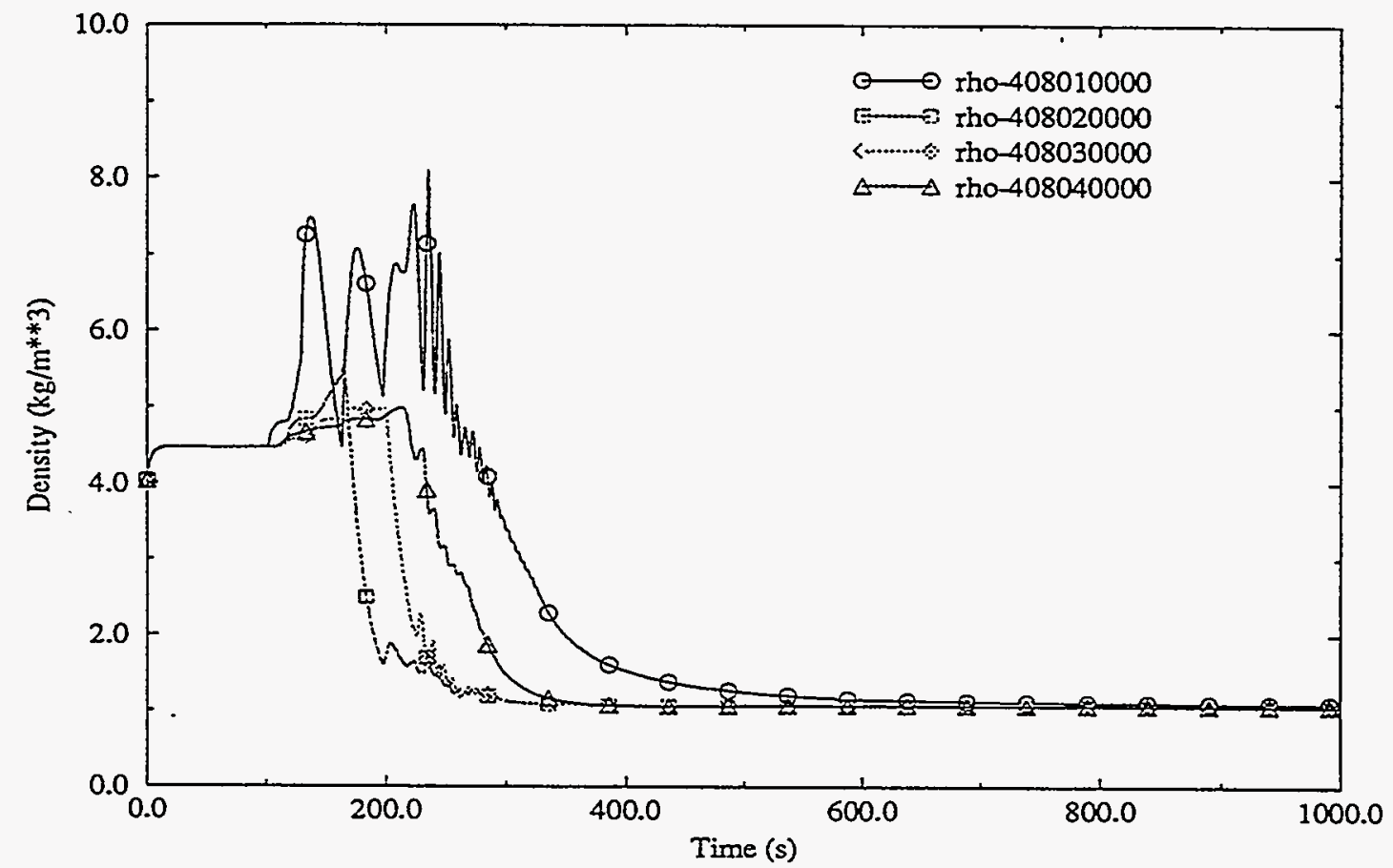

Figure F-8. Primary side fluid density for the base case. 


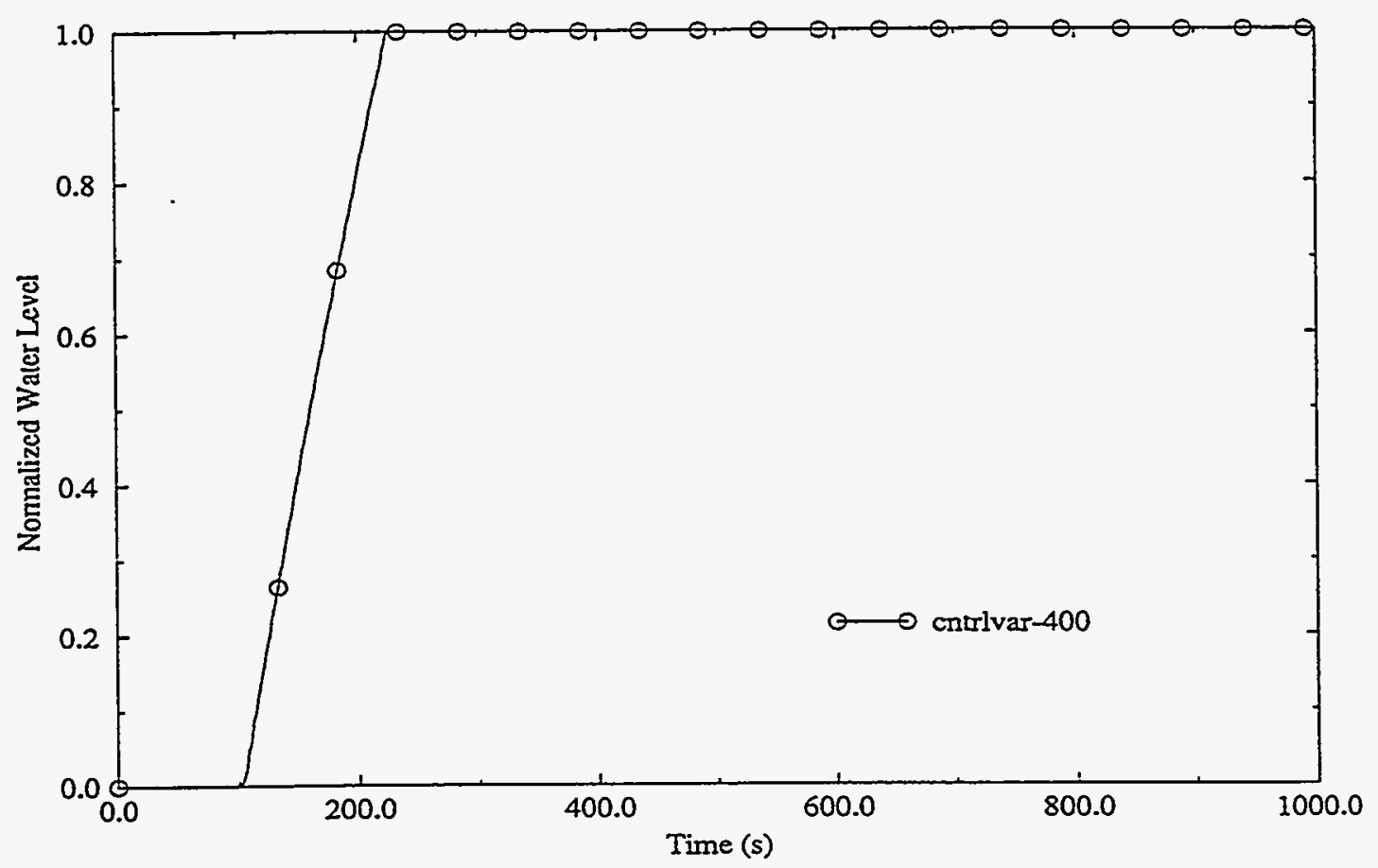

Figure F-9. Normalized secondary side water level for the detailed case.

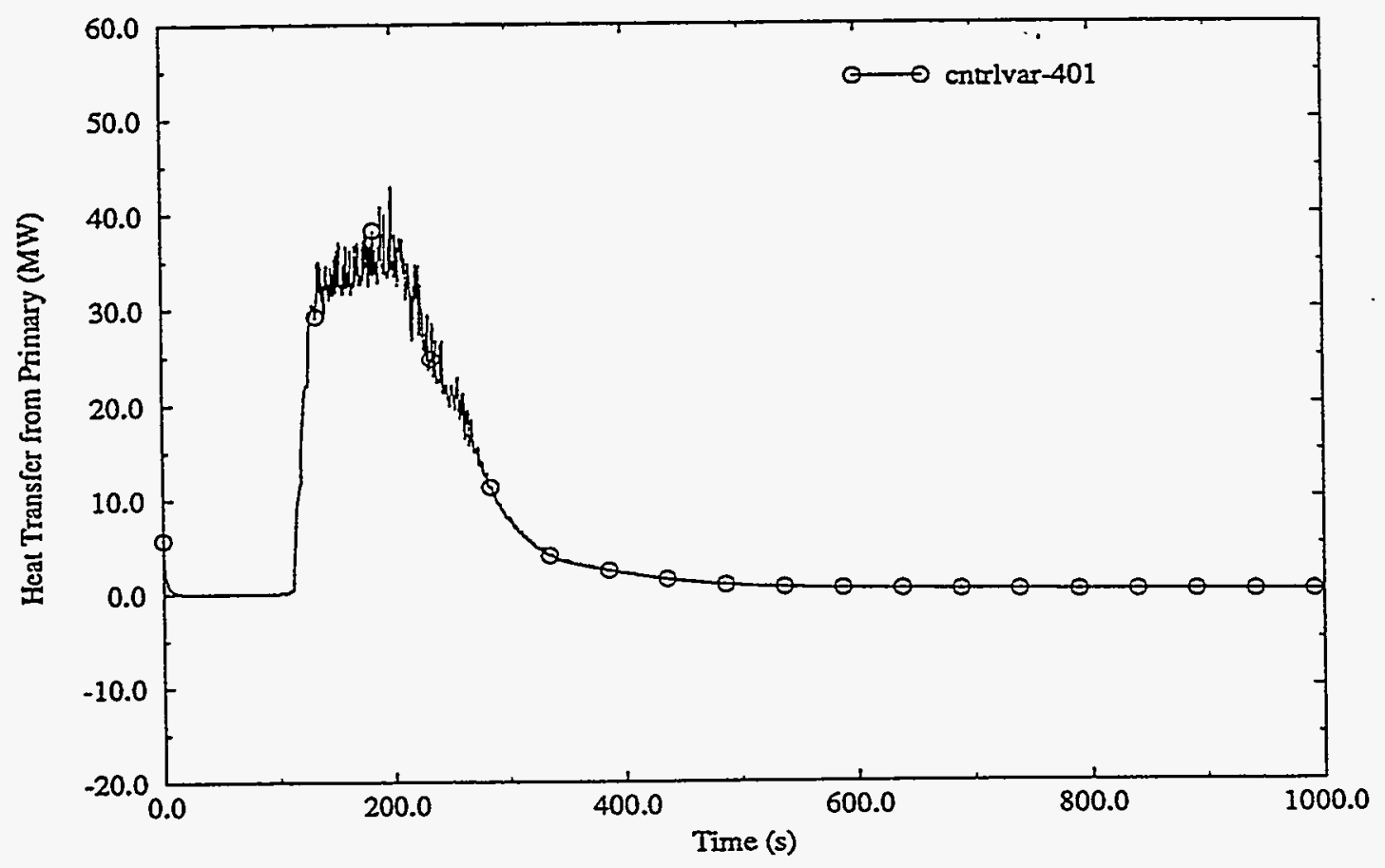

Figure F-10. Total heat transfer from the primary system for the detailed case. 
Appendix F

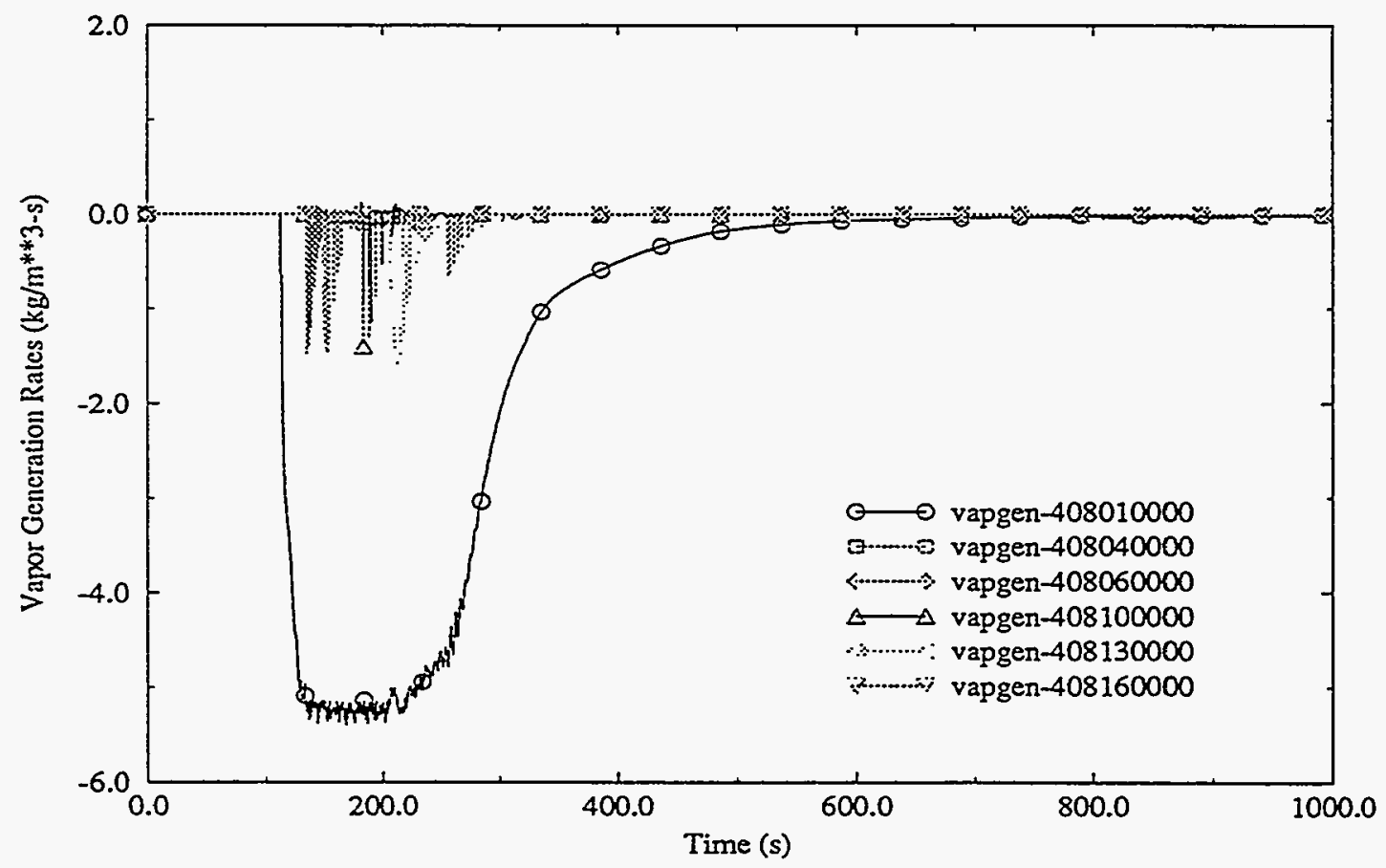

Figure F-11. Vapor generation rates for the detailed case.

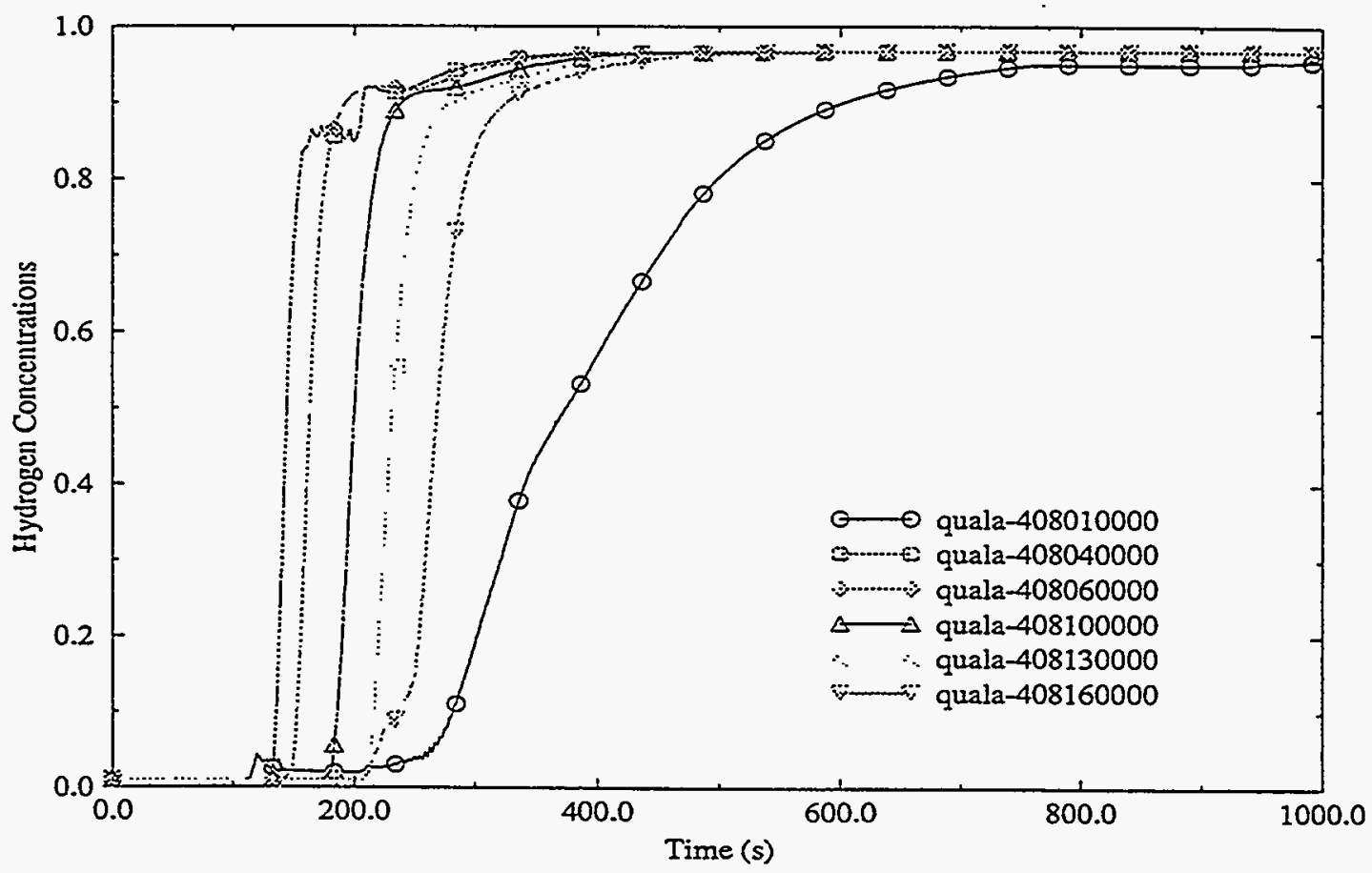

Figure F-12. Hydrogen concentrations for the detailed case. 


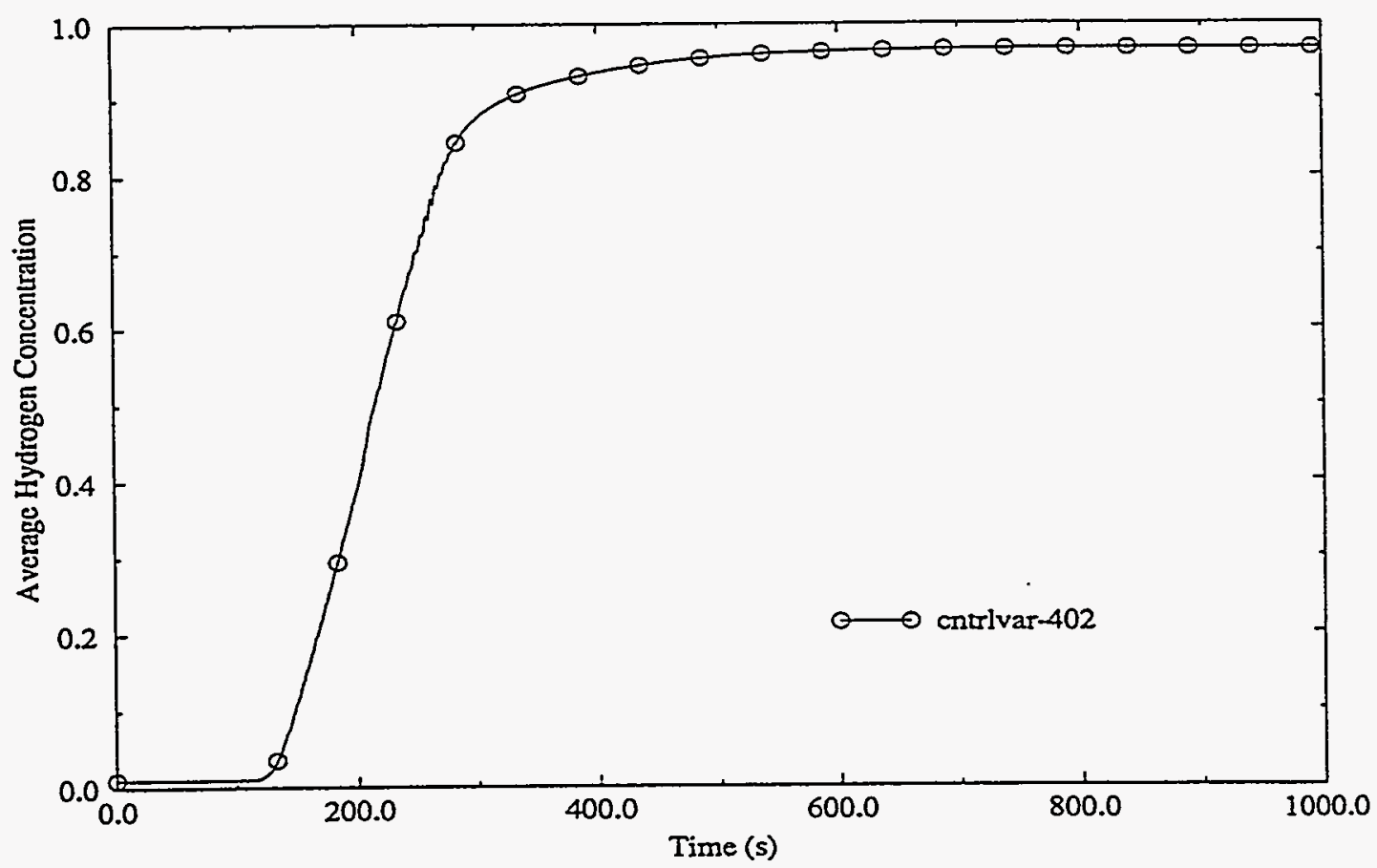

Figure F-13. Average hydrogen concentration for the detailed case.

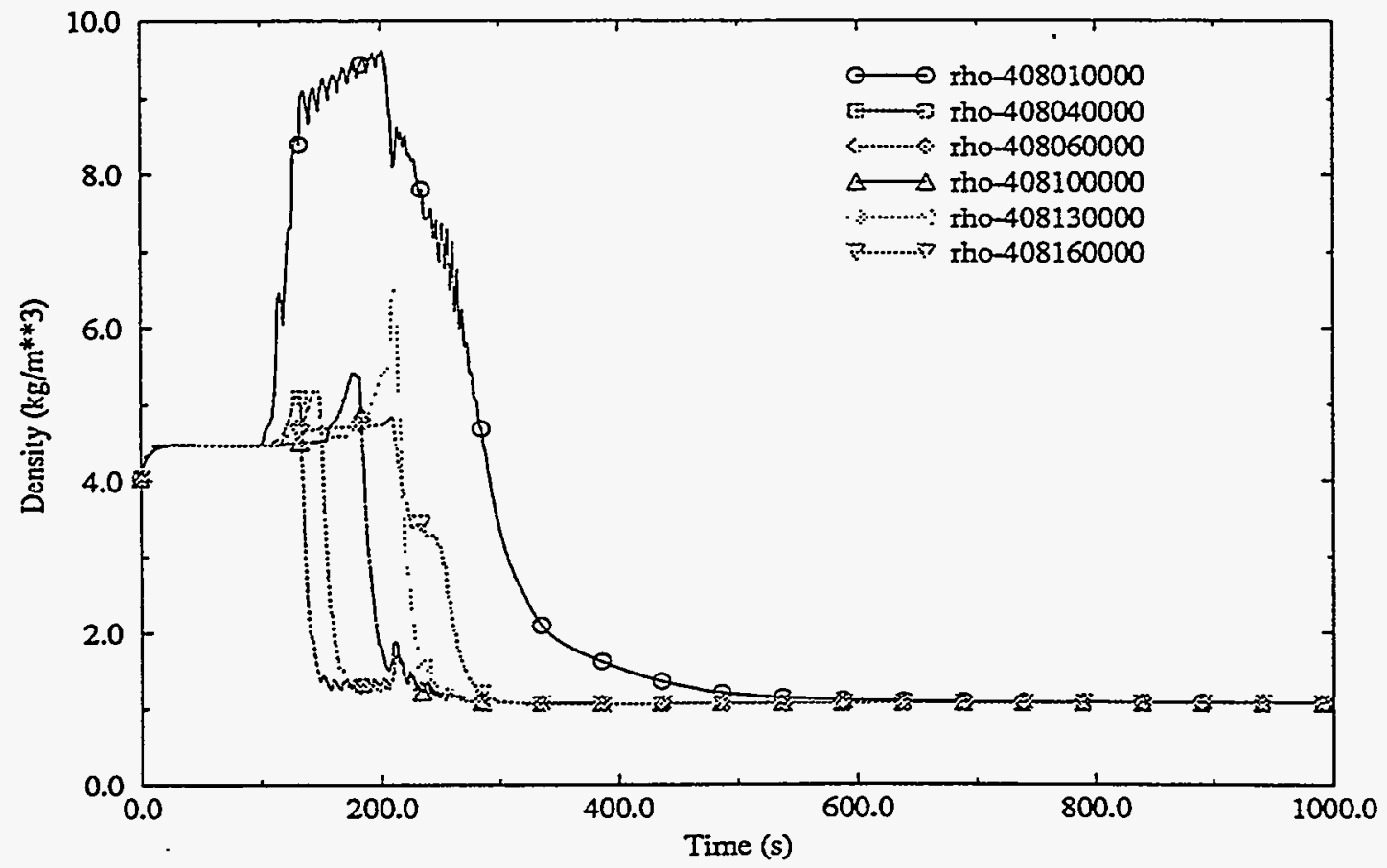

Figure F-14. Primary side fluid density for the detailed case. 
and draining out of the volumes without the oscillations present in the base case.

Both the base and the detailed calculation reach the same final state and, in each case, the expected hydrogen blockage effects are observed. However, the detailed case provides a more wellbehaved solution, eliminating much of the oscillatory behavior observed in the base model that is associated with flooding the secondary side.

\section{F-4. CONCLUSIONS}

The results obtained from this analysis indicate that the SCDAP/RELAP5/MOD3 code is capable of predicting the expected behavior of hydrogen blockage in the U-tube steam generators of pressurized water reactors. It should be noted that this calculation does not include a quantitative assessment of RELAP5 to verify that the correct condensation rates are calculated as a function of hydrogen concentration. However, the behavior calculated by the code does exhibit the general trends expected. Introduction of feedwater into the stand-alone steam generator model results in condensation of the steam on the primary side subsequently concentrating hydrogen in the tubes. As the hydrogen concentration increases, condensation rates decrease and the heat transfer to the secondary side of the steam generator is reduced, eventually to near zero.

The following recommendations are made based on experience gained with the stand-alone models:

- The vertical stratification model should be avoided for applications where interphase energy transfer is an important consideration, until updates are made to correct problems identified with the interphase heat and mass transfer correlations.

- A relatively fine axial nodalization should be used to represent both the primary and secondary sides of the steam generator. In situations where the timing of heat transfer degradation is an important concern, a nodalization study is recommended to ensure a converged solution is obtained. An alternative approach that might prove useful is to implement the reflood option to model the quenching of the hot steam generator tubes as feedwater is restored. The reflood option is designed for modeling hot reactor fuel rods under reflood conditions, but it should be possible to adapt this model to steam generator reflooding.

- A detailed quantitative assessment of RELAP5, to ensure proper calculation of thermal-hydraulic behavior in the presence of hydrogen, is recommended before performing extensive full-plant analyses of hydrogen blockage in U-tube steam generators.

\section{F-5. REFERENCES}

F-1. P. D. Bayless, Analyses of Natural Circulation During a Surry Station Blackout Using SCDAPIRELAP5, NUREG/CR-5214, EGG-2547, October 1988.

F-2. K. E. Carlson et al., RELAP5/MOD3 Code Manual, NUREG/CR-5535, EGG-2596 (Draft), June 1990.

F-3. D. M. Snider et al., Nuclear Plant Analyzer, EGG-EAST-9096, June 1991. 


\section{Appendix G \\ Examination of the Lead Screw Temperatures in the Upper Plenum of TMI-2}





\section{Appendix G}

\section{Examination of the Lead Screw Temperatures in the Upper Plenum of TMI-2}

\section{SUMMARY}

Metallurgical examinations of the lead screws recovered from the upper plenum of TMI-2 indicate that they experienced fairly low temperatures (about $700 \mathrm{~K}$ ) near the top of the upper plenum. However, analyses of the TMI-2 accident or similar scenarios using SCDAP/RELAP5 or MELPROG yield fluid temperatures as high as $1,800 \mathrm{~K}$ in the upper plenum when natural circulation is present. This appendix examines several mechanisms that may influence the lead screw temperature in the upper plenum to reconcile the difference between the relatively low observed lead screw temperature and the higher predicted fluid temperatures in the upper plenum. A wide range of potential mechanisms are examined, including axial conduction from the hot lower section to the cooler top section of the lead screw, radiation exchange in the enclosure between the guide tube and the lead screw, and recirculation in the enclosure, which is set up by a temperature difference between the guide tube and the lead screw.

The effects of axial conduction and radiation are examined in a bounding analysis that compares the calculated time required for the lead screw to reach the observed temperature with the timescale of the TMI-2 accident. Following is a summary of the results of this bounding analysis.

- Axial Conduction-The time required for the lead screws to reach the observed temperatures of about $700 \mathrm{~K}$ is between 75 and 219 hours, when only axial conduction is considered. This is a very long time compared to the timescale of the heatup period during the TMI- 2 accident. Therefore, axial conduction can be ruled out as a factor influencing the observed temperature of the lead screws in the upper plenum.
- Radiation-If the fluid within the enclosure between the guide tube and the lead screw is assumed to be transparent and if the shielding (between the guide tube and the lead screw) provided by the C-tubes and slotted tubes is neglected, the estimated time for the lead screws to reach the observed temperature is found to be from 0.49 to 4.9 minutes. These times are relatively short compared to the TMI-2 timescale. Consequently, radiation may have a significant effect in the determination of the lead screw temperature. It was also found that the effect of radiation is at least as important as that of convection even at a relatively low temperature of $700 \mathrm{~K}$. Moreover, the conditions are such that the optically thick approximation can be used, resulting in an effective heat transfer coefficient that combines both radiation and convection.

A cell of recirculating flow may be set up in the enclosure between the guide tube and the lead screw by buoyancy resulting from a temperature difference between the lead screw and the guide tube. The effects of radiation are included in the analysis of this recirculating flow by using the optically thick approximation, which essentially yields a higher convective heat transfer coefficient to account for radiative heat transfer between the wall and the fluid. In examining the effect of the recirculating flow, two different approaches have been taken:

- First, the steam temperature in the upper plenum is calculated based on the lead screw temperatures deduced by a metallurgical examination. Results indicate that the steam temperature can be very high (on the order of $1,300-1,500 \mathrm{~K}$ ) in comparison with temperatures experienced by the lead screws. Therefore, it can be concluded that the shielding (between the upper plenum steam 
and the lead screw) provided by the guide tube is quite effective.

- Next, the steam temperature obtained by a thermal-hydraulic calculation of TMI-2 using MELPROG is used to calculate the lead screw temperatures. The calculated lead screw temperature is consistent with the temperature obtained by a metallurgical examination.

Both of these cases indicate that the lead screw temperatures determined from metallurgical examinations are consistent with the high steam temperature predicted by severe core damage computer codes. 


\section{NOMENCLATURE}

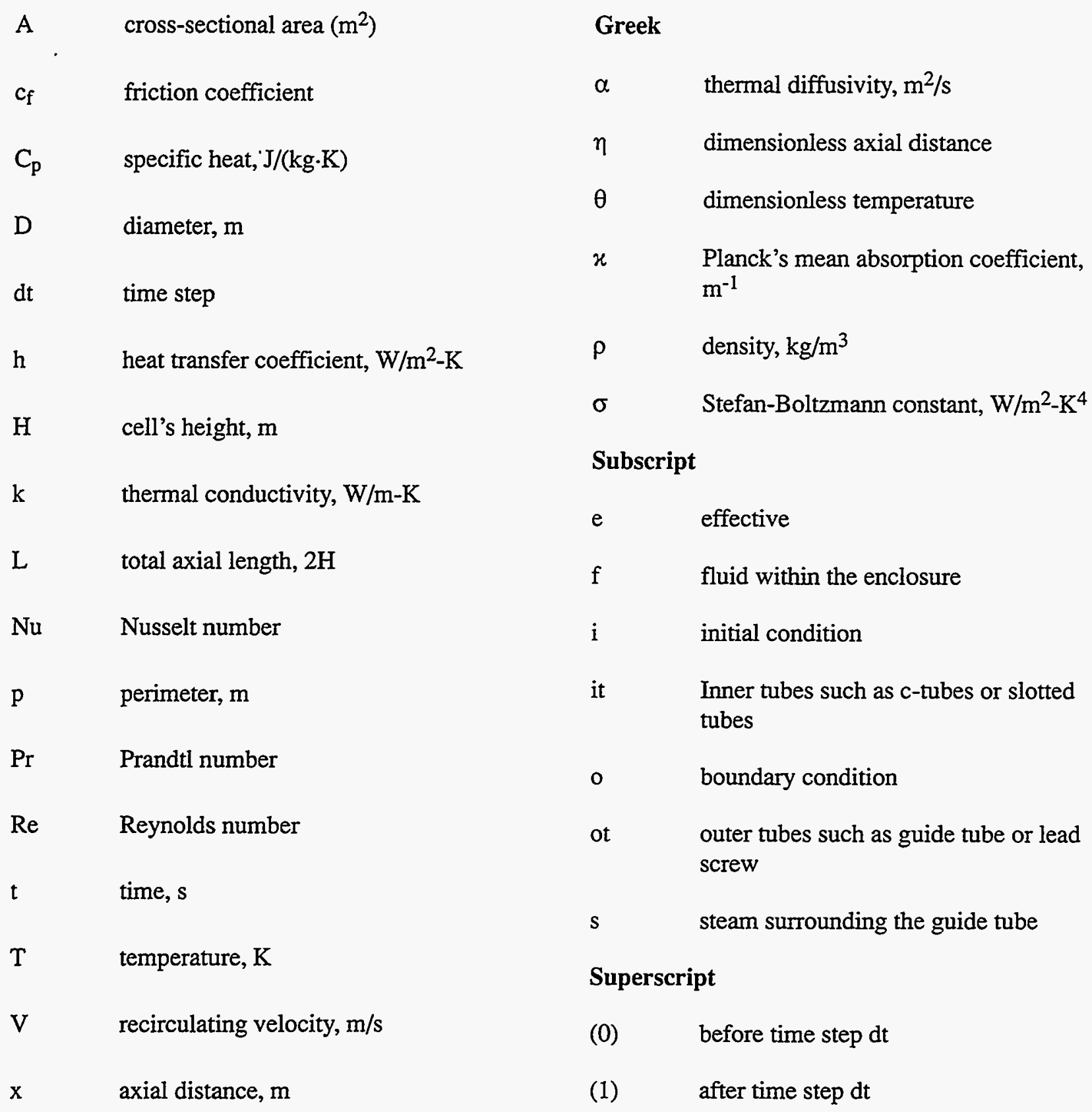




\section{G-1. INTRODUCTION}

During an extended nuclear reactor accident, natural circulation can transfer energy from the core to other parts of the system, such as the upper plenum, hot leg, and steam generator. The magnitude and regional distribution of the natural circulation phenomenon and its heat transfer efficiency are of fundamental importance in assessing subsequent failure modes. Such natural circulation flows have been observed experimentally G-1,G-2 and predicted by several codes such as SCDAP/RELAP5 ${ }^{\mathrm{G}-3}$ and MELPROG. ${ }^{\mathrm{G}-4}$

Analyses of the TMI- 2 accident ${ }^{\mathrm{G}-4}$ or similar scenarios, ${ }^{\mathrm{G}-3}$ however, predict fluid temperatures as high as $1,800 \mathrm{~K}$ in the upper plenum when these natural circulation flows are present. Moreover, the predicted fluid temperature shows little variation in either the axial or the radial direction. These predicted temperatures appear to be incongruent with the temperatures deduced by a metallurgical examination of the lead screws recovered from the upper plenum of TMI-2. G-5 As shown in Figure G-1, these temperatures range from 666 to $1,255 \mathrm{~K}$, with the bottom of the lead screws experiencing a much higher temperature than the top. Not only are these temperatures much lower than those predicted by the codes, but they could also be interpreted as an indication of the existence of some stratification in the upper plenum. Such stratification, however, has been discounted by O'Brien (Appendix E) because of the relatively short mixing time.

In this appendix, an analysis will be performed to reconcile the inconsistencies between the lead screw temperatures reported in Reference G-5 and the fluid temperatures in the upper plenum reported in References G-3 and G-4. Several different mechanisms are examined to determine their influence on lead screw temperatures. Axial conduction from the bottom part of the lead screws to the upper part is examined as a possible influence. However, a more important consideration is the possibility that the guide tube provides an intervening shield between the lead screw and the fluid in the upper plenum. Initially, the guide tube is heated (via a combination of radiation and convection) by the hot fluid in the upper plenum. Subsequently, the temperature difference between the guide tube and the lead screw sets up a convective current that serves as a heat transport mechanism from the guide tube to the lead screw. If such a transport mechanism is not very efficient, the shield provided by the guide tube is fairly effective and a large temperature difference between the lead screw and the fluid temperatures in the upper plenum can be rationalized.

Section G-2 of this report contains bounding analyses on mechanisms such as axial conduction and radiation. It also examines the relative importance of radiation and convection and the possibility of combining these two modes of heat transfer by a simplifying approximation. Results in this section may be used subsequently to exclude unimportant mechanisms from a more detailed analysis and to simplify the resulting energy equations.

Sections G-3 and G-4 examine heat transfer between the lead screw and the steam in the upper plenum. Radiation and convection are combined using the optically thick approximation. The primary transport mechanism in the enclosure formed by the guide tube and the lead screw is the recirculating flow set up by a temperature difference between these two components. Two approaches will be taken in these sections:

1. The steam temperature in the upper plenum will first be calculated based on the lead screw temperatures deduced in Reference G-5. The steam temperature calculated in this fashion can be compared with that predicted by the codes to detect any inconsistency.

2. The upper plenum steam temperature calculated by MELPROG in Reference G-4 will be used to calculate the lead screw temperature. The resulting lead screw temperatures will be compared with those obtained by metallurgical examinations in Reference G-5 to explain the large temperature difference between the upper plenum steam and the lead screw. 


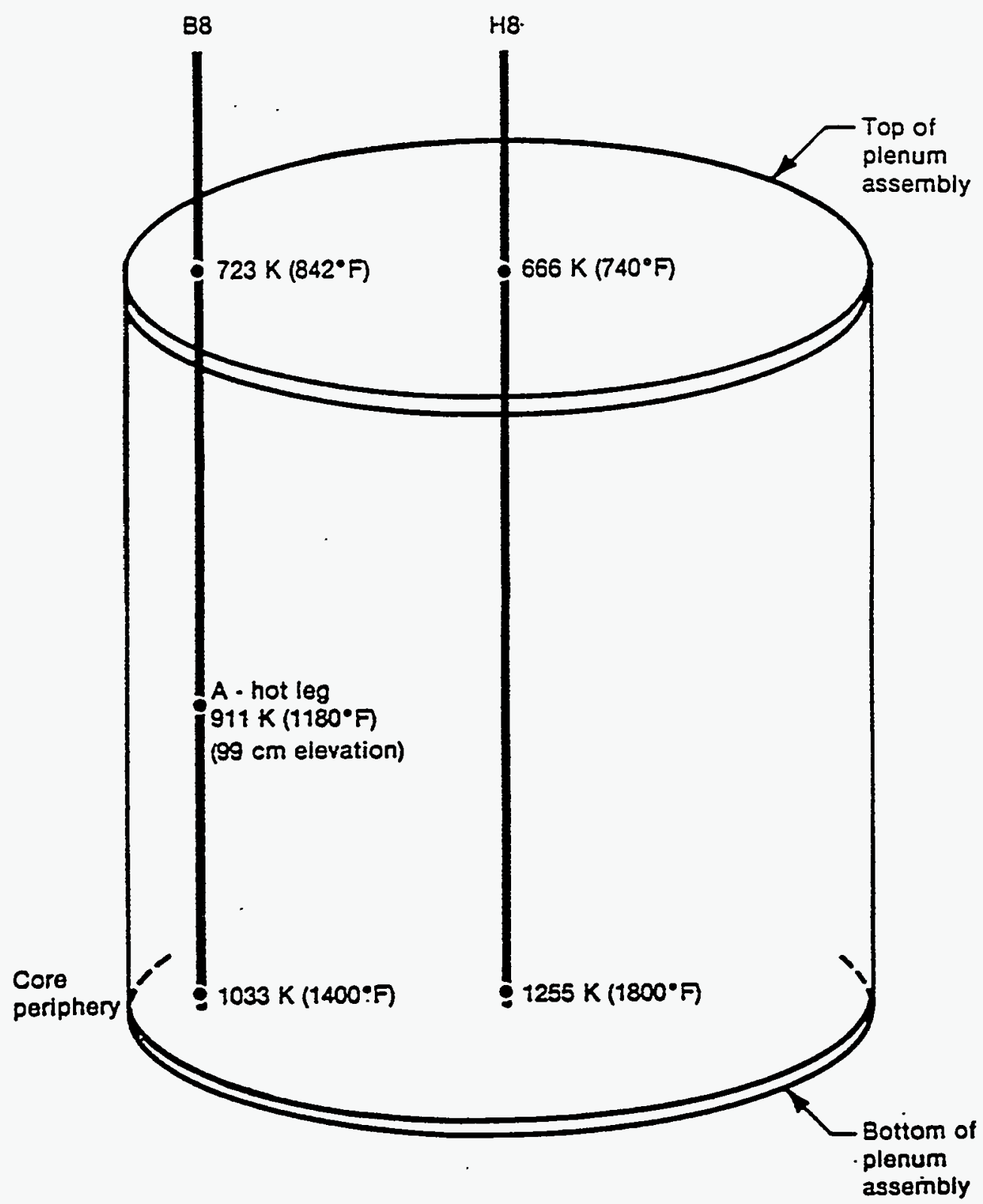

Figure G-1. Lead screw temperatures in the upper plenum.

\section{G-2. BOUNDING ANALYSES}

The bounding analyses in this section examine the extent to which mechanisms such as axial conduction and radiation influence the temperatures of the lead screws in the upper plenum. Results from these bounding analyses may then be used to exclude irrelevant mechanisms from a more detailed analysis.

\section{G-2.1 Upper Bound of Axial Conduction}

Axial conduction has been identified as a potentially important mechanism that can influence the temperature of the lead screw near the top of the upper plenum. This section presents a bounding analysis on the effect of axial conduction and its influence on the temperatures in the 
upper part of the lead screw. In the analysis, the following assumptions have been made:

- . The cross-section of the lead screw is uniform $^{\mathrm{a}}$ and it is treated as a semi-infinite solid

- The lead screw is initially at a saturation temperature of $560 \mathrm{~K}$ corresponding to a pressure of $6.9 \mathrm{MPa}^{\mathrm{b}}$ and the temperature at the bottom end is stepped up to the temperature deduced ${ }^{\mathrm{a}}$ in Reference G-5

- The surface of the lead screw is insulated ${ }^{\mathrm{a}}$

- Properties of stainless steel are taken at a temperature of $900 \mathrm{~K}$.

The transient solution for the temperature of the lead screw then can be given by the classical error function solution

$\theta=\frac{T-T_{i}}{T_{o}-T_{i}}=\operatorname{erfc}(\eta) ;$

$\eta=\frac{x}{2 \sqrt{a t}}$.

The time required for the upper part of the lead screw to reach the temperature deduced in Reference G-5 is shown in Table G-1. The times shown in Table G-1 are very long (75-219 hours) compared to the timescale in TMI-2. Therefore, axial conduction can be ruled out as a factor influencing the lead screw temperatures in the top part of the upper plenum.

\section{G-2.2 Upper Bound of Radiation}

Since the temperatures of the guide tube and lead screw are expected to be quite high, radiative

a. This assumption is conservative since it magnifies any effect of axial conduction on the temperature at the upper part of the lead screws.

b. Between 20 and 80 minutes into the accident, Figure 17 in MAAP 3.OB Simulation of the First 174 Minutes of the TMI-2 Accident, EPRI NP-6206. exchange in the enclosure formed by the guide tube and the lead screw may be significant. An upper bound of this radiative heat transfer is examined in this section to evaluate its potential influence on the temperature of the lead screws in the upper plenum.

A cross-section of the enclosure is shown in Figure G-2 while dimensions are provided in Table G-2. The lead screws are surrounded by a set of C-tubes and slotted tubes as shown in Figure G-2. The whole assembly is enclosed within the guide tube. To establish an upper bound for radiative heat transfer between the guide tube and the lead screws, the following assumptions will be made:

- The gas in the enclosure is transparent

- The shielding provided by the C-tubes and slotted tubes in the enclosure is ignored

- The guide tube is assumed to be at the fluid temperature in the upper plenum

- All surfaces are black $(\varepsilon=1)$, and the lumped capacity approximation can be used for the lead screw.

With these assumptions, the radiative exchange between the guide tube and the lead screw can be modeled as that between two infinitely long concentric cylinders such that

$Q=p_{1} F_{1-2}\left(\sigma T_{2}^{4}-\sigma T_{1}^{4}\right)$

where subscript 1 refers to the lead screw, subscript 2 refers to the guide tube, $p$ is the perimeter and the shape factor $F_{1-2}$ is unity. This radiative heat exchange then must be used to raise the temperature of the lead screw

$\varrho_{1} C_{p 1} A_{1} \frac{d T_{1}}{d t}=Q$

By defining a dimensionless temperature $\theta=\mathrm{T}_{1} / \mathrm{T}_{2}$, one can combine Eqs. (G-2) and (G-3) as 
Table G-1. Estimated heatup time based on axial conduction.

\begin{tabular}{lll}
\hline & B8 lead screw & H8 lead screw \\
\hline$\alpha\left(\mathrm{m}^{2} / \mathrm{s}\right)$ & $6.37 \mathrm{E}-06$ & $6.37 \mathrm{E}-06$ \\
$\mathrm{~T}_{\mathrm{i}}(\mathrm{K})$ & 560 & 560 \\
$\mathrm{~T}_{\mathrm{o}}(\mathrm{K})$ & 1,033 & 1,255 \\
$\mathrm{x}(\mathrm{m})$ & 0.99 & 2.3 \\
$\mathrm{~T}(\mathrm{~K})$ & 911 & 710 \\
$\theta$ & 0.7421 & 0.2158 \\
$\eta$ & $0.233^{\mathrm{a}}$ & $0.877^{\mathrm{a}}$ \\
$\mathrm{t}(\mathrm{hr})$ & 197 & 75 \\
$\mathrm{x}(\mathrm{m})$ & 3.0 & 3.0 \\
$\mathrm{~T}(\mathrm{~K})$ & 723 & 666 \\
$\theta$ & 0.3446 & 0.1525 \\
$\eta$ & $0.670^{\mathrm{a}}$ & $1.013^{\mathrm{a}}$ \\
$\mathrm{t}(\mathrm{hr})$ & 219 & 96 \\
& &
\end{tabular}

\section{a. F.M. White, Heat Transfer, 1sted., 1984, p. 538.}

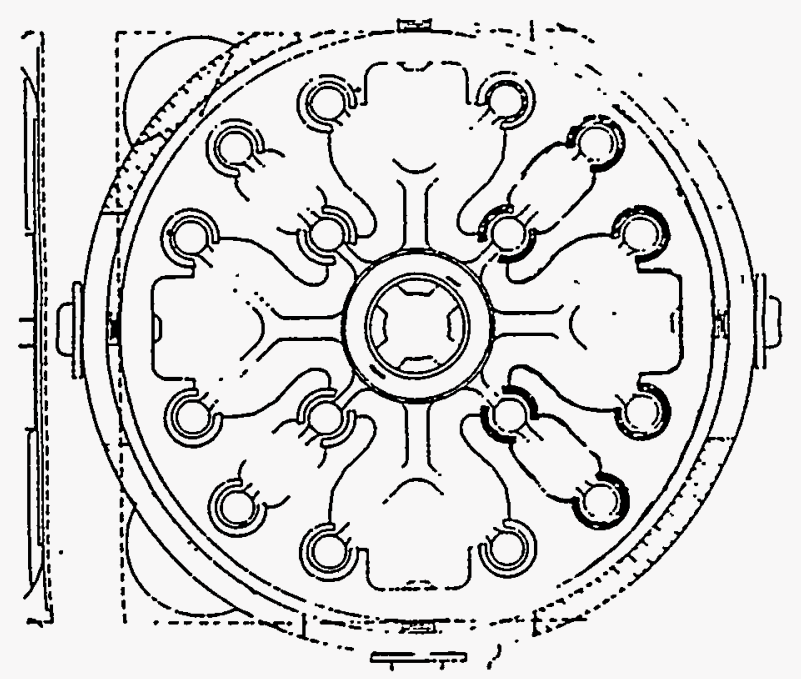

Figure G-2. Enclosure between the lead screw and the guide tube.

$$
\frac{4 d \theta}{1-\theta^{4}}=\frac{16 \sigma T_{2}^{3}}{\varrho_{1} C_{p 1} D_{1}} d t=d \tau
$$

where

$$
\tau=\frac{16 \sigma T_{2}^{3} t}{\varrho_{1} C_{p 1} D_{1}} .
$$

The above equation can be integrated to yield

$$
\begin{aligned}
& {\left[\ln \left(\frac{1+\theta}{1-\theta}\right)+2 \tan ^{-1} \theta\right]} \\
& -\left[\ln \left(\frac{1+\theta_{o}}{I-\theta_{o}}\right)+2 \tan ^{-1} \theta_{o}\right] \\
& =\tau .
\end{aligned}
$$

If we pick a temperature $T_{2}$ for the guide tube, the temperature ratio $\theta=T_{1} / T_{2}$ can be calculated using the temperatures deduced in Reference G-5 for $T_{1}$ (as shown in Figure G-1). Also, by using $560 \mathrm{~K}$ as the initial temperature of the lead screw, the temperature ratio $\theta_{0}$ can be calculated. The left-hand side of Eq. (G-5) then yields the dimensionless time. Substituting this dimensionless time into the second part of Eq. (G-4) then yields the time required for the lead screw to rise from $560 \mathrm{~K}$ to $\mathrm{T}_{1}$ (the temperature determined from metallurgical examination). Such times are tabulated in Table G-3. It should be pointed out that the temperature of the guide tube, $T_{2}$, has been taken to be the measured temperature at the bottom of the lead screws. This is a conservative approach, and radiative heat transfer between the lead screws and the guide tube will be over-estimated. The times shown in Table G-3 are relatively short $0.49-4.9$ minutes). As such, the effects of radiative heat transfer from the guide tube to the lead screw cannot be ruled out.

\section{G-2.3 Radiation Versus Convection}

Even though radiation has been asserted as a potentially important heat transfer mechanism, its relative importance with respect to convection still must be determined. This section examines such a comparison between the two mechanisms and the possibility of combining these two modes of heat transfer by a simplifying approximation. 
Appendix G

Table G-2. Dimensions for Figure 2.

\begin{tabular}{lclcc}
\hline $\begin{array}{c}\text { Item } \\
\text { (No.) }\end{array}$ & $\begin{array}{c}\text { Outside diameter } \\
(\mathrm{m})\end{array}$ & \multicolumn{1}{c}{$\begin{array}{c}\text { Wall } \\
(\mathrm{m})\end{array}$} & \multicolumn{1}{c}{$\begin{array}{c}\text { Section } \\
\left(\mathrm{m}^{2}\right)\end{array}$} & $\begin{array}{c}\text { Perimeter } \\
(\mathrm{m})\end{array}$ \\
\hline Slotted tube (4) & $1.905 \mathrm{E}-02$ & $2.286 \mathrm{E}-03$ & $2.686 \mathrm{E}-04$ & $3.990 \mathrm{E}-02$ \\
C-tubes (12) & $1.905 \mathrm{E}-02$ & $2.286 \mathrm{E}-03$ & $2.768 \mathrm{E}-04$ & $4.987 \mathrm{E}-02$ \\
Lead screw (1) & $3.810 \mathrm{E}-02$ & N/A & $1.140 \mathrm{E}-03$ & $1.197 \mathrm{E}-01$ \\
Guide tube (1) & $2.159 \mathrm{E}-01$ & $7.938 \mathrm{E}-03$ & $3.142 \mathrm{E}-02$ & $6.284 \mathrm{E}-01$ \\
\hline
\end{tabular}

Table G-3. Estimated heatup time based on upper bound of radiation.

\begin{tabular}{lll}
\hline & \multicolumn{1}{c}{$\mathrm{B} 8$} & \multicolumn{1}{c}{$\mathrm{H} 8$} \\
lead screw & lead screw \\
\hline $\begin{array}{l}\rho_{1} \mathrm{C}_{\mathrm{p} 1} \\
\left(\mathrm{~J} / \mathrm{m}^{3}-\mathrm{K}\right)\end{array}$ & $3.77 \mathrm{E}+06$ & $3.77 \mathrm{E}+06$ \\
$\mathrm{D}_{1}(\mathrm{~m})$ & & \\
$\sigma$ & $3.90 \mathrm{E}-2$ & $3.90 \mathrm{E}-02$ \\
$\left(\mathrm{~W} / \mathrm{m}^{2}-\mathrm{K}^{4}\right)$ & $5.67 \mathrm{E}-8$ & $5.67 \mathrm{E}-08$ \\
$\mathrm{~T}_{2}(\mathrm{~K})$ & & \\
$\theta_{0}$ & 1,033 & 1,255 \\
$\mathrm{x}(\mathrm{m})$ & 0.5421 & 0.4462 \\
$\mathrm{~T}_{1}(\mathrm{~K})$ & 0.99 & 2.3 \\
$\theta$ & 911 & 710 \\
$\tau$ & 0.8819 & 0.5657 \\
$\mathrm{t}(\mathrm{min})$ & 2.01 & 0.513 \\
$\mathrm{x}(\mathrm{m})$ & 4.9 & 0.70 \\
$\mathrm{~T}_{1}(\mathrm{~K})$ & 3.0 & 3.0 \\
$\theta$ & 723 & 666 \\
$\tau$ & 0.6999 & 0.5307 \\
$\mathrm{t}(\mathrm{min})$ & 0.748 & 0.359 \\
\hline & 1.8 & 0.49 \\
\hline
\end{tabular}

The Planck mean absorption coefficient, $x$, for water vapor at $1 \mathrm{~atm}$ is about $13 \mathrm{~m}^{-1}$ at $700 \mathrm{~K}$ and $3.2 \mathrm{~m}^{-1}$ at $1,300 \mathrm{~K} .^{\mathrm{G}-6}$ Since this coefficient is approximately proportional to pressure, the values at $6.9 \mathrm{MPa}$ can be obtained as: $x=885 \mathrm{~m}^{-1}$ at $700 \mathrm{~K}$, and $218 \mathrm{~m}^{-1}$ at $1,300 \mathrm{~K}$.

This means that most of the radiant energy will be absorbed by the vapor after a distance of
$1 / x=1.1$ to $4.6 \mathrm{~mm}$. Since this distance is very short compared to the gap between the lead screw and the guide tube $(\sim 83 \mathrm{~mm})$, the optically thick approximation can be invoked to combine the effect of radiation and convection in the gap. The effective Prandtl number then can be found as

$\frac{\operatorname{Pr}_{e}}{\operatorname{Pr}}=\left(1+\frac{4}{3 N}\right)^{-1}$,

where

$N=\frac{k \varkappa}{4 \sigma T^{3}}$.

Using a system pressure of $6.9 \mathrm{MPa}$, the ratio $\mathrm{Pr}_{\mathrm{e}} / \mathrm{Pr}$ is found to be 0.32 at $700 \mathrm{~K}$ and 0.038 at $1,300 \mathrm{~K}$. These values indicate that the effect of radiation is at least as important as that of convection even at a relatively low temperature of $700 \mathrm{~K}$.

\section{G-3. GRAVITY-DRIVEN FLOW IN THE GUIDE TUBE}

The shielding provided by the guide tube has been proposed as one reason why the lead screw temperature as deduced in Reference G-5 is relatively cool compared to the upper plenum fluid temperatures predicted by existing codes. It is believed that the steam in the upper plenum must first heat up the guide tube. The temperature difference between the guide tube and the lead screw then will promote a gravity-driven recirculating flow in the enclosure between the lead screw and the guide tube. The flow configuration is such that the hot fluid adjacent to the guide tube will 
rise and the cool fluid adjacent to the lead screw will fall. Such a recirculating flow can serve as a heat transfer mechanism from the guide tube to the lead screw and will be examined in this section. In the upper plenum, the geometry of the enclosure is shown in Figure G-2 while dimensions are provided in Table G-2. In addition to dimensions shown in Table G-2, there are other parameters of importance, such as $\mathrm{D}_{\mathrm{i}}$ and $\mathrm{H}$. $\mathrm{D}_{\mathrm{i}}$ is the diameter $(1.389 \mathrm{E}-01 \mathrm{~m})$, which evenly divides the open flow area for the fluid within the enclosure (one half adjacent to the guide tube is for hot upflow while the other half adjacent to the lead screw is for cool downflow). The total height of one cell, $\mathrm{H}=2.578 \mathrm{E}-01 \mathrm{~m}$, is determined by the spacing of the plates supporting the C-tubes and the slotted tubes shown in Figure G-2.

\section{G-3.1 Analysis}

The present analysis will be outlined as follows in terms of the mechanism involved and the approach to be used. It should be pointed out that the recirculating flow velocity within the cell, the fluid temperature, the lead screw temperature, and the guide tube temperature are all known at the beginning of a time step.

1. Heat Transfer Outside the Guide TubeThis will be analyzed as a convection problem between the upper plenum gas (outside the guide tube) at high temperature and the outer surface of the guide tube. Radiation will be included via the use of the effective Prandtl number defined by Eq. (G-6).

2. Heat Transfer Inside the Guide Tube-This will again be analyzed as a combined radiation/convection problem to yield the surface heat flux from the inside of the guide tube to the fluid.

3. Heat Transfer to the C-Tubes, Slotted Tubes and Lead Screw-This problem is similar to Step 2 and will be analyzed similarly. It yields the surface heat flux from the fluid to the tubes, and the surface heat flux at the lead screw.

4. Temperatures-Once all these heat fluxes are known, the change in temperature after a time step dt is found by an energy balance for each component using the lumped capacity approximation. Fluid temperatures at each point of the flow will also be determined.

5. Buoyancy Term-The buoyancy term in the momentum balance can then be found by integration over the height of the cell.

6. Friction Term-The total frictional resistance of the flow can be found by integrating the surface shear stress over the height of the cell.

7. Flow Velocity - The flow velocity after a time step dt can then be found by applying the buoyancy force and friction force to the mass of recirculating steam in the cell. Once this velocity has been updated, one can go back to Step 1 to begin a new time step.

G-3.1.1 Heat Transfer Outside the Guide Tube. The natural circulation velocity in the upper plenum was calculated by SCDAP/ RELAP5 to be approximately $0.5 \mathrm{~m} / \mathrm{s}^{\mathrm{c}}$ (upflow) near the $\mathrm{H} 8$ lead screw and $0.2 \mathrm{~m} / \mathrm{s}^{\mathrm{c}}$ (downflow) near the B8 lead screw. ${ }^{\text {G-3 }}$ Similar natural circulation velocities were also obtained in MELPROG and FLOW3D simulations of TMI-2. G-4 The vapor temperatures at these locations are unknown, however. For this analysis, these temperatures will be varied parametrically. The vapor flow outside the guide tube will be treated as flow over a flat plate at zero incidence. Assuming that

c. Scaled from Figure 11 on page 17 of Reference $\mathrm{G}-3$. 
the flow can be considered laminar, ${ }^{d}$ the Nusselt number is given bye

$N u_{\dot{x}}=f\left(\operatorname{Pr}_{e}\right) \cdot \sqrt{\operatorname{Re}_{x}} \quad$,

where

$$
f\left(\operatorname{Pr}_{e}\right) \approx \frac{0.564 \sqrt{\operatorname{Pr}_{e}}}{\left(1+127 \operatorname{Pr}_{e}+450 \operatorname{Pr}_{e}^{2}\right)^{1 / 12}}
$$

The function $\mathrm{f}\left(\mathrm{Pr}_{\mathrm{e}}\right)$ has been chosen to cover a wider range of Prandtl number. It satisfies both asymptotic limits: $\operatorname{Pr} \rightarrow 0\left(0.564 \mathrm{Pr}^{1 / 2}\right)$ and $\mathrm{Pr} \rightarrow$ $\infty\left(0.339 \operatorname{Pr}^{1 / 3}\right)$. The average heat transfer coefficients (at $6.9 \mathrm{MPa}$ ) outside the guide tube are tabulated in Table G-4 for temperatures of 700 and $1,300 \mathrm{~K}$.

Using the maximum heat transfer coefficient $(h=117)$ in Table $G-4$, the Biot number based on the thickness of the guide tube is about 0.04 . This Biot number is small enough such that the lumped capacity approximation can be applied to the guide tube wall. It should also be pointed out that, for the same temperature, the heat transfer coefficient on the B8 lead screw is higher than that calculated for the $\mathrm{H} 8$ lead screw. This is because a point in the upper part of the plenum will be near the trailing edge for upflow and near the leading edge for downflow. Also, radiation heat transfer has been included in the heat transfer coefficients through the use of the effective Prandtl number, $\mathrm{Pr}_{\mathrm{e}}$, defined by Eq. (G-6).

G-3.1.2 Heat Transfer Inside The Guide Tube. Given the recirculating flow velocity

d. Even though O'Brien (Appendix E) calculated a Rayleigh's number on the order of $10^{11}$, a laminar boundary layer along the surface of the guide tube may still exist despite free stream turbulence in the bulk flow.

e. Using laminar flow correlation for flow over a flat plate on page 166 of Reference G-7 with the effective Prandtl number in Eq. (G-6). within the guide tube, the heat transfer coefficient on any surface in the enclosure can be found by a procedure similar to that used for the outside of the guide tube. Again this will be approximated as laminar flow over a flat plate and Eq. (G-7) will be used. However, the heat transfer coefficient will be averaged over the cell's height $(2.578 \mathrm{E}-01 \mathrm{~m})$ and $\mathrm{f}\left(\mathrm{Pr}_{\mathrm{e}}\right)$ must be doubled to reflect this averaging process. Radiation will be included through the use of $\mathrm{Pr}_{\mathrm{e}}$ defined by Eq. (G-6). Using a maximum velocity of $0.05 \mathrm{~m} / \mathrm{s}$ (based on conditions in the guide tube), the maximum Biot number for the lead screw is about 0.10 , which also supports the lumped capacity approximation for the lead screw. Heat transfer to the C-tubes and the slotted tubes is also similar to that between the recirculating steam and the lead screw. The Biot number for these tubes is also very small compared to unity. Consequently, the lumped capacity approximation can also be applied to these $\mathrm{C}$-tubes and slotted tubes.

G-3.1.3 Temperature Calculations. Given a mass flow rate or velocity within the guide tube, the temperatures of each component can be calculated after a time step dt by integrating the following one-dimensional energy equations (axial conduction is neglected and radiation is included in the heat transfer coefficients):

$$
\begin{aligned}
\frac{\partial T_{f}}{\partial t}+V \frac{\partial T_{f}}{\partial x}= & \frac{(h p)_{i t}}{\left(\varrho C_{p} A\right)_{f}}\left(T_{i t}-T_{f}\right) \\
& +\frac{(h p)_{o t}}{\left(\varrho C_{p} A\right)_{f}}\left(T_{o t}-T_{f}\right) \\
\frac{\partial T_{i t}}{\partial t}= & -\frac{(h p)_{i t}}{\left(\varrho C_{p} A\right)_{i t}}\left(T_{i t}-T_{f}\right) \\
\frac{\partial T_{o t}}{\partial t}= & -\frac{(h p)_{o t}}{\left(\varrho C_{p} A\right)_{o t}}\left(T_{o t}-T_{f}\right) \\
& -\frac{(h p)_{s}}{\left(\varrho C_{p} A\right)_{o t}}\left(T_{o t}-T_{s}\right),
\end{aligned}
$$

where $\mathrm{p}$ is the perimeter in contact with the fluid and $\mathrm{A}$ is the cross section. The above equation involves three temperatures, namely: $T_{f}, T_{i t}$, and $\mathrm{T}_{\text {ot }}$. All other variables including $\mathrm{T}_{\mathrm{s}}$ are known. Using the following coefficients 
uoụenba

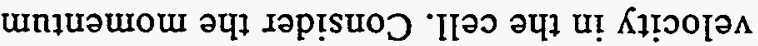

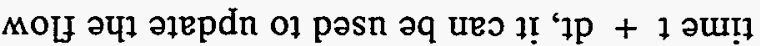

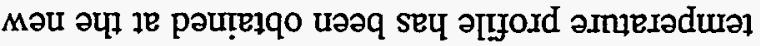

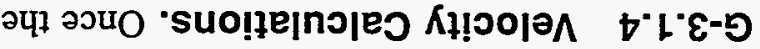

(0)L SəIml

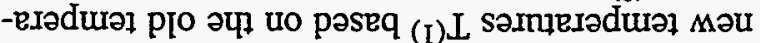

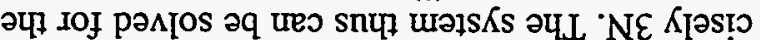

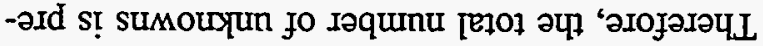

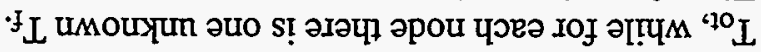

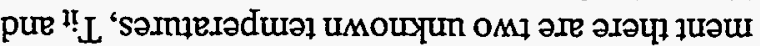

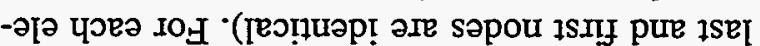

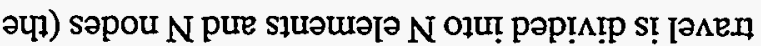

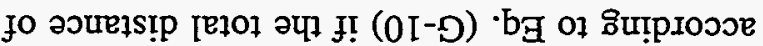

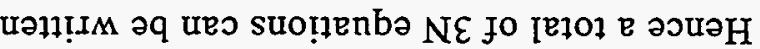

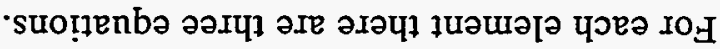

$(0[-D)$

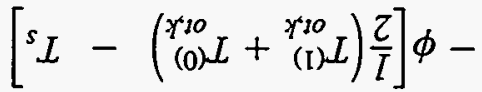

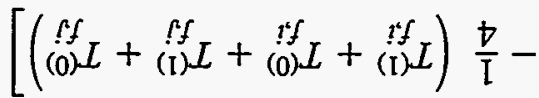

$$
\begin{aligned}
& \left.\left(\begin{array}{c}
x^{310} \\
(0) L
\end{array}+\underset{(\mathrm{I})}{x^{2}} L\right) \frac{Z}{\mathrm{I}}\right] \mathrm{U}-=
\end{aligned}
$$

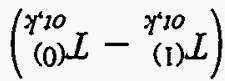

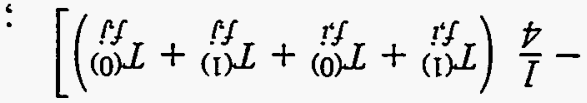

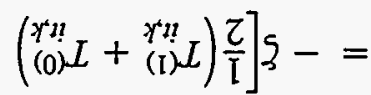

$$
\begin{aligned}
& \left(\begin{array}{l}
y^{\prime} n \\
(0)
\end{array} L-\stackrel{y^{\prime} n}{(1)} L\right)
\end{aligned}
$$

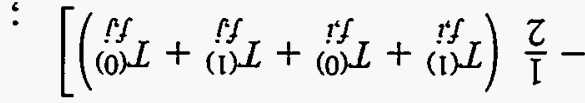

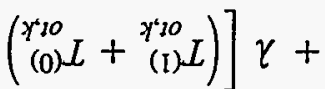

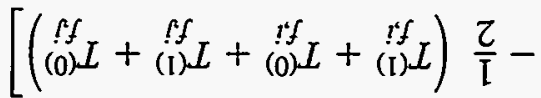

$$
\begin{aligned}
& \left.\left(\begin{array}{c}
y^{\prime} n ! \\
(0)
\end{array} L+\stackrel{y^{\prime} n}{(1)} L\right)\right] \mathcal{L}=
\end{aligned}
$$

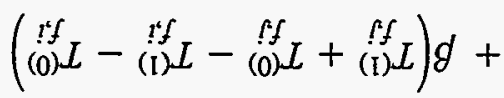

$$
\begin{aligned}
& (\stackrel{\varphi f}{(0)} L-\stackrel{r f}{(0)} L-\underset{(\mathrm{I})}{(f)} L+\stackrel{? f}{(\mathrm{I})} I)
\end{aligned}
$$

[ pue ! səpou Kq pəpunoq

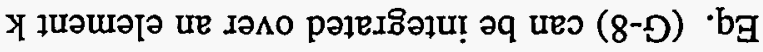

$$
\begin{aligned}
& \text { - } \frac{{ }^{10}\left(\nabla^{d} \partial^{\partial}\right)}{s(d y)+p}=\phi \\
& : \frac{{ }^{10}\left(\nabla^{d} \partial^{\partial}\right)}{{ }^{10}(d y)+p}=u: \frac{{ }^{n !}\left(\nabla^{d} \partial^{\partial}\right)}{{ }^{1 !}(d y)+p}=\xi \\
& \frac{f\left(V^{d} \partial \partial\right)}{{ }^{o}(d y) t p}=\gamma \\
& : \frac{f\left(\nabla^{d} \partial \partial\right)}{{ }^{\eta}(d y) t p}=\ell \quad: \quad \frac{x p}{\not p \Lambda}=d
\end{aligned}
$$

\begin{tabular}{|c|c|c|}
\hline & \\
\hline $\mathrm{e} L \mathrm{II}$ & 89 & $\left(X^{-} \tau^{\mathrm{W} / M}\right)^{4}$ \\
\hline - & $\$ 9$ & $\mathrm{n}_{\mathrm{N}}$ \\
\hline$\downarrow 0+\exists t 6 \sigma^{\circ} \tau-t 0 \div G 8 \mathrm{~S}^{\cdot} \mathrm{I}$ & $S 0+B \subseteq 6^{\circ} \varepsilon$ & oy \\
\hline S0ーヨ0ヤ゙ャ & so-anot't & $(s-u / \delta \bar{y}) \eta$ \\
\hline $9^{\circ}$ II & $9 \cdot$ II & $\left({ }_{\varepsilon} \mathrm{w} / \bar{\delta} y\right) d$ \\
\hline$\downarrow \varepsilon 0^{\circ} 0$ & $\downarrow \mathcal{E} 0^{\circ} 0$ & $\partial_{I_{d}}$ \\
\hline $00 \varepsilon^{\prime} I$ & $00 \varepsilon^{\prime} I$ & (X) I \\
\hline 892 & $\varsigma I$ & $\left(\mathrm{X}^{-} \tau^{\mathrm{W} / M}\right)$ ч \\
\hline- & 092 & $\mathrm{n}_{\mathrm{N}}$ \\
\hline$+0+\mathrm{G}\left[8^{\circ} 6-t 0+\mathrm{B} 8 \mathrm{Z}^{\circ} \mathrm{S}\right.$ & $90+B Z \varepsilon^{*} I$ & əy \\
\hline SO- $\mathrm{BS} 9^{\circ} Z$ & so- $\mathrm{s} s 9^{\circ} \tau$ & $(s-w / z=y) \gamma$ \\
\hline$\varepsilon \cdot \varepsilon 乙$ & $\varepsilon^{\prime} \varepsilon 乙$ & $\left({ }_{\varepsilon} w / \delta y\right) d$ \\
\hline I $\varepsilon^{*} 0$ & I $\varepsilon^{*} 0$ & $\partial_{\mathbf{I d}}$ \\
\hline $00 L$ & $00 L$ & (X) $\perp$ \\
\hline $2 \cdot 0$ & $\varsigma^{*} 0$ & $(\mathrm{~s} / \mathrm{w}) \Lambda$ \\
\hline $8 L S S^{\circ} 0-\varepsilon 0$ & $0{ }^{\circ} \varepsilon$ & (wi) $x$ \\
\hline MəIOs peəI $8 \mathrm{q}$ & $\begin{array}{l}\text { MəIOS } \\
\text { prəI } 8 \mathrm{H}\end{array}$ & นəฑI. \\
\hline
\end{tabular}

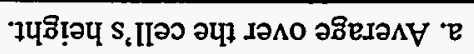




$$
\begin{aligned}
\bar{\varrho} A_{f}\left(\frac{\partial V}{\partial t}+V \frac{\partial V}{\partial x}\right) \\
=\bar{\varrho} A_{f} g_{V}\left[1-\beta\left(T_{f}-\bar{T}_{f}\right)\right] \\
\quad-\frac{1}{2} \bar{\varrho} V^{2} \cdot c_{f} \cdot p,
\end{aligned}
$$

where gV is the component of gravitational acceleration in the direction of the flow. Integrating Eq. (G-11) over the entire length (both hot and cold sides) while assuming that the steam behaves as an ideal gas yields

$$
\begin{aligned}
\bar{\varrho} A_{f} L \frac{\partial \bar{V}}{\partial t}= & -\bar{\varrho} A_{f} \int_{0}^{L} g_{V} \frac{T_{f}}{\bar{T}_{f}} d x \\
& -\frac{1}{2} \bar{\varrho} \bar{V}^{2} \cdot \overline{c_{f}} \cdot A_{w},
\end{aligned}
$$

where $A_{w}$ is the total wall surface area within the cell and $\mathrm{L}$ is the total axial flow distance (twice the height). By defining $x^{*}=x / L, E q$. (G-12) becomes

$$
\begin{aligned}
\frac{\partial \bar{V}}{\partial t}= & g\left[\int_{0}^{1 / 2} \frac{T_{f}}{\bar{T}_{f}} d x^{*}-\int_{1 / 2}^{1} \frac{T_{f}}{\bar{T}_{f}} d x^{*}\right] \\
& -\frac{1}{2} \cdot \overline{c_{f}} \cdot \frac{\bar{V}^{2}}{L} \cdot \frac{A_{w}}{A_{f}} .
\end{aligned}
$$

The first term in Eq. (G-13) represents buoyancy and can be integrated easily once the temperature profile has been obtained. The second term involves friction and can be calculated using the geometry in Figure G-2 and Table G-2. The friction coefficient, $\mathrm{c}_{\mathrm{f}}$, is modeled as

$$
\overline{c_{f}}=1.328 / \sqrt{\operatorname{Re}_{H}} \text {. }
$$

Such a friction coefficient accounts only for flow parallel to the inner tubes. To account for the resistance caused by cross-flow at the top and bottom of the cell, the friction coefficient is modified by assuming that the cross-flow velocity at the top and bottom of the enclosure is the same as the recirculating velocity to yield $\overline{c_{f .}}=\frac{1.328}{\sqrt{\mathrm{Re}_{H}}}+\frac{32}{\pi} \frac{A_{f}}{A_{w}} \frac{D_{i t}}{D_{i}}\left[1+\frac{10}{\operatorname{Re}_{D_{i r}}^{2 / 3}}\right]$.

For the remainder of this appendix, solutions obtained with the friction coefficient in Eq. (G-14) will be referred to as the "low friction" cases while those obtained with Eq. (G-15) will be referred to as the "high friction" cases. These "low" and "high" friction cases are essentially lower and upper bounds of friction encountered by the recirculating flow in the enclosure.

In any case, the right-hand side of Eq. (G-13) can be evaluated at both times $t$ and $t+d t$. The recirculating velocity at time $t+d t$ can then be found by the trapezoidal rule. This calculation closes the procedure for stepping from time $t$ to time $t+d t$. The procedure can then be started again for another time step as described in the beginning of Section G-3.1.

\section{G-3.2 Convergence Tests}

Tests of convergence with respect to time step and element length have been carried out with the system temperature and pressure maintained at constant values of $1,100 \mathrm{~K}$ and $6.9 \mathrm{MPa}$, respectively. With a fixed number of elements per side (hot upflow or cold downflow) the solution converges linearly with a reduction in time step. When the time step is fixed and the number of elements is increased, the solution appears to converge quadratically with a reduction in the element length.

\section{G-3.3 Plate Flow Assumption}

The heat transfer coefficients and friction coefficients in Section G-3.1 have been obtained with the assumption that the flow along a cylinder (e.g., the guide tube or the inner tubes) can be treated as flow over a flat plate with zero incidence. Such an assumption, however, must be justified by examining the thickness of the boundary layer in comparison with characteristic lengths of the geometry. Such a comparison is carried out in this section. 
G-3.3.1 Flow Outside the Guide Tube. The flow outside the guide tube is Iaminar throughout most of its length in the upper plenum based on the calculated Reynolds numbers. For laminar flow over a flat plate, the momentum thickness is given by

$\frac{\delta_{m}}{x}=\frac{5}{\sqrt{\operatorname{Re}_{x}}}$.

The thermal boundary layer thickness can be found by examining the Nusselt number in Eq. (G-7). By assuming that $\delta_{t}$ is given by $\mathrm{k}_{\mathrm{e}} / \mathrm{h}$, one can rearrange Eq. (G-7) to yield $\delta_{t}$ as

$\frac{\delta_{t}}{x}=\frac{1}{f\left(\mathrm{Pr}_{e}\right) \sqrt{\operatorname{Re}_{x}}}$.

A comparison between Eq. (G-16) and (G-17) yields

$\begin{aligned} \frac{\delta_{t}}{\delta_{m}} & =\frac{0.2}{f\left(\operatorname{Pr}_{e}\right)}=2.3 \text { maximum at } \operatorname{Pr}_{e} \\ & =0.032 .\end{aligned}$

Taking the largest elevation ( $x=3 \mathrm{~m}$ ) with the corresponding smallest Reynolds number $(3.95 \mathrm{E}+05), \delta_{\mathrm{m}}$ can be found to be $2.4 \mathrm{~cm}$ and $\delta_{\mathrm{t}}$ is about $5.5 \mathrm{~cm}$. These are much smaller than the outside diameter of the guide tube $(21.6 \mathrm{~cm})$. As such, the boundary layers have not grown sufficiently large to be influenced by the transverse curvature of the guide tube.

G-3.3.2 Flow Inside the Guide Tube. Inside the guide tube, the flow velocity is on the order of a few $\mathrm{cm} / \mathrm{s}$. Taking the maximum calculated value of $5 \mathrm{~cm} / \mathrm{s}$, the highest Reynolds number can be calculated to be about 1.13E+04. Therefore, the flow is laminar if one considers this as flow over a flat plate. The boundary layer thicknesses can then be found by Eqs. (G-16 through G-18) to be $\delta_{\mathrm{m}}=1.2 \mathrm{~cm}$ and $\delta_{t}=2.7 \mathrm{~cm}$. These are comparable to the diameter of the slotted and C-tubes $(1.9 \mathrm{~cm})$. The curvature of these tubes then may influence the drag and heat transfer over their surfaces. The influence, however, is believed to be minimal since the ratio $\delta / D$ is not far from unity. Moreover, these tubes do not participate directly in the heat transfer from the guide tube to the lead screws and their effect should be of secondary importance. The diameter of the lead screw and the guide tube, however, is much larger than these boundary layer thicknesses. Their curvatures thus should have little influence on the plate flow assumption.

\section{G-3.4 Outside Steam Temperature}

The actual temporal variation of the steam temperature outside the guide tube is an unknown for the TMI-2 accident. A SCDAP/RELAP5 simulation of a Surry station blackout transient ${ }^{\mathrm{G}-3}$ indicated that, for a 40-minute period of natural circulation, the temperature of the fuel cladding at the top of the fuel assembly rises almost linearly. As an approximation, a linear variation of steam temperature outside the guide tube can also be assumed for TMI-2 during the period of natural circulation (139-174 minutes). Between 110 and 139 minutes, however, the steam temperature near the top of the upper plenum is expected to rise more slowly since steam is escaping through the surge line in TMI-2 and thus may not readily reach the top of the upper plenum. If we assume that the steam temperature near the top of the upper plenum varies parabolically with time from 110 to 139 minutes and linearly from 139 to 174 minutes, only the maximum temperature at 174 minutes is needed to completely characterize the steam temperature over the excursion between 110 and 174 minutes:

$$
\begin{aligned}
& \frac{T_{s}-560 K}{T_{\max }-560 K} \\
& =\left\{\begin{array}{cl}
\frac{t^{* 2}}{2,871} & t *=t-110<29 \mathrm{~min} \\
\frac{2 t^{*}-29}{99} & t *=t-110>29 \mathrm{~min}
\end{array}\right\} .
\end{aligned}
$$

The assumed steam temperature's temporal variation shown in Eq. (G-19) is not unique, however. Even though the actual temporal variation may come close to that shown in Eq. (G-19), there are an infinite number of functional 
relationships between time and temperature. Another candidate can be obtained by examining the maximum core temperature calculated for TMI-2 by SCDAP/RELAP5. G-8 Assuming that the steam temperature follows the same pattern it can be approximated by

$$
\begin{aligned}
& \frac{T_{s}-560 \mathrm{~K}}{T_{\max }-560 \mathrm{~K}} \\
& =\left\{\begin{array}{c}
7.532 E-03 \cdot t * \\
6.460 E-02 \cdot t^{*}-2.6822 \\
1.0
\end{array}\right. \\
& 0 \text { min }<t *<4 \text { min } \\
& 47 \min <t *<57 \min \} \\
& 57 \text { min }<t^{*}<64 \text { min }
\end{aligned}
$$

Given a maximum steam temperature, either Eqs. (G-19) or (G-20) can be used to find the steam temperature as a function of time. This steam temperature then can be used to calculate the lead screw temperature. A plot of the dimensionless steam temperatures defined by Eqs. (G-19) and (G-20) is shown in Figure G-3.

\section{G-3.5 Sensitivities}

Results have been obtained with various combinations of time step, spatial discretization and external steam temperature. To establish sensitivities with respect to each individual parameter, comparisons will be made between different cases. From this point on, the term "low friction" will be used to denote the cases where friction is calculated by Eq. (G-14). Likewise, the term "high friction" will be used to denote the cases where Eq. (G-15) is used instead.

A typical time history of the recirculation velocity within the cell for a high-friction case is shown in Figure G-4. The steam temperature and system pressure are assumed to remain constant for the duration of this run. Results indicate that the recirculating flow oscillates near the beginning of the calculation. This oscillation, however, decays with time as friction increases with velocity. The oscillation is caused by alternating inter- vals of acceleration and deceleration of the flow. In one period, the flow is first accelerated by increasing buoyancy. This is followed by an interval when friction overcomes buoyancy, resulting in deceleration of the fluid. The mean value of the recirculating velocity will rise initially as shown in Figure G-4, while the flow is being established by a temperature difference between the guide tube and the lead screw. Upon reaching a peak, the recirculating flow will decay as this temperature difference (and hence buoyancy) begins to diminish.

A typical recirculating velocity near the beginning of the calculation is shown in Figure G-5. The differences in velocity between the two cases (0.5-s and 0.05-s time steps) are relatively small. As such, solutions obtained with 0.5 -s time steps are probably accurate enough for our purpose. Furthermore, the period of oscillation is about $25 \mathrm{~s}$, which is much longer than the time steps used. Consequently, numerical instability can be ruled out as the cause of the oscillations.

Figure G-6 shows a comparison of the recirculating velocities obtained for both high- and lowfriction cases with a time step of $0.5 \mathrm{~s}$. As anticipated, lower friction results in higher velocity and higher oscillation frequency. It also produces less damping and hence slower decay for the oscillations.

A complete time history of recirculation velocity, guide tube temperature, and lead screw temperature is shown in Figure G-7 for both highand low-friction cases. For the sake of clarity, the first 15 minutes of oscillation in velocity has been deleted from the graph. It can be observed that, generally, the recirculation velocity is much higher for the low-friction case. The guide tube temperature, however, is relatively unaffected by the flow rate within the cell. This is perhaps because heat transfer from the outside steam to the guide tube dominates its temperature history. With lower friction, higher heat transfer from the guide tube to the lead screw results in a slightly lower temperature for the guide tube and a higher 


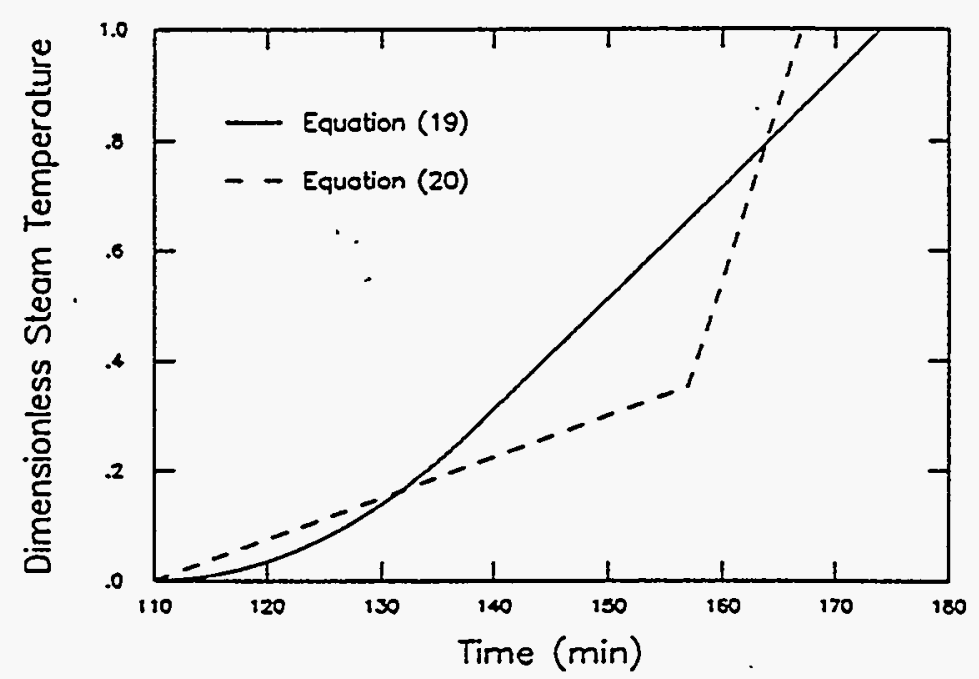

Figure G-3. Assumed dimensionless steam temperature in the upper plenum.

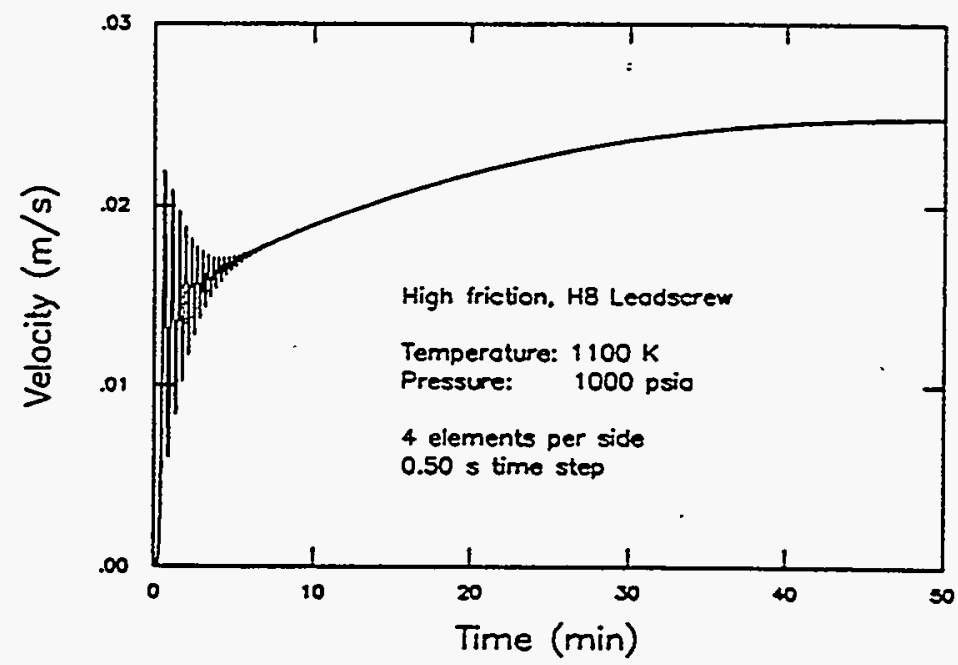

Figure G-4. Typical recirculating vapor velocity.

temperature for the lead screw. The relative difference, however, is much less than that observed for the recirculating velocity. For example, the time it takes for the lead screw to reach $800 \mathrm{~K}$ is about 52 minutes at low friction and 57 minutes at high friction, a difference of only $10 \%$.

\section{G-4. RESULTS OF GRAVITY-DRIVEN FLOW}

Two approaches will be taken in this section. First, the steam temperature in the upper plenum 


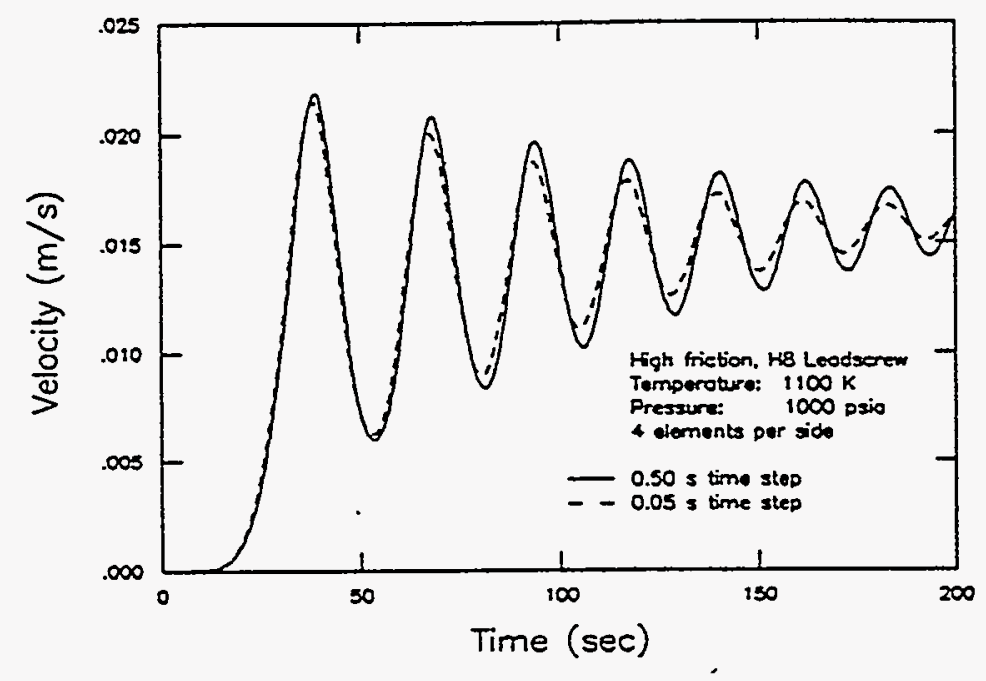

Figure G-5. Recirculation near the beginning-different time steps.

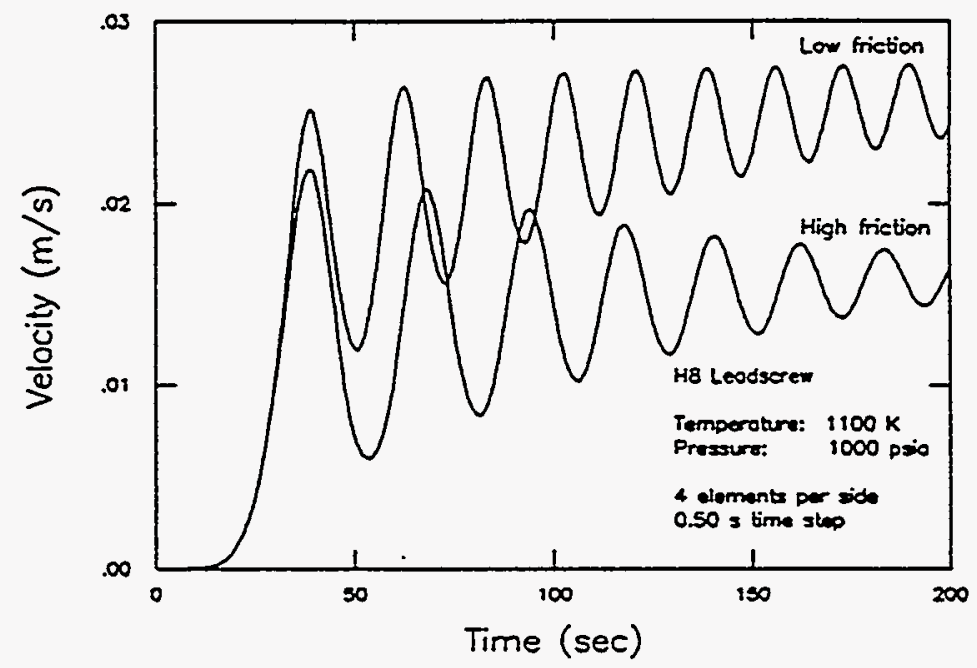

Figure G-6. Recirculation near the beginning-high and low friction.

is calculated based on the lead screw temperatures observed in TMI-2. Results can then be compared with the steam temperature predicted by severe core damage computer codes. Next, the steam temperature obtained by a thermalhydraulic calculation of the TMI- 2 accident ${ }^{\mathrm{G}-4}$ is used to calculate the lead screw temperatures. The resulting lead screw temperatures are then compared with temperatures deduced in a metallurgical examination of the lead screws recovered from the upper plenum of TMI-2. Such a comparison can be used to explain the large temperature difference between the upper plenum steam and the lead screw.

\section{G-4.1 Calculation of Steam Temperature Using $\mathrm{H} 8$ Lead Screw Temperature}

As mentioned earlier, given a maximum steam temperature (at 174 minutes), either Eq. (G-19) or (G-20) can be used to calculate the temporal variation of the steam temperature near the top of the upper plenum. This steam temperature then can be used to calculate the lead screw temperature as a function of time. The maximum lead screw temperature will be the instantaneous 


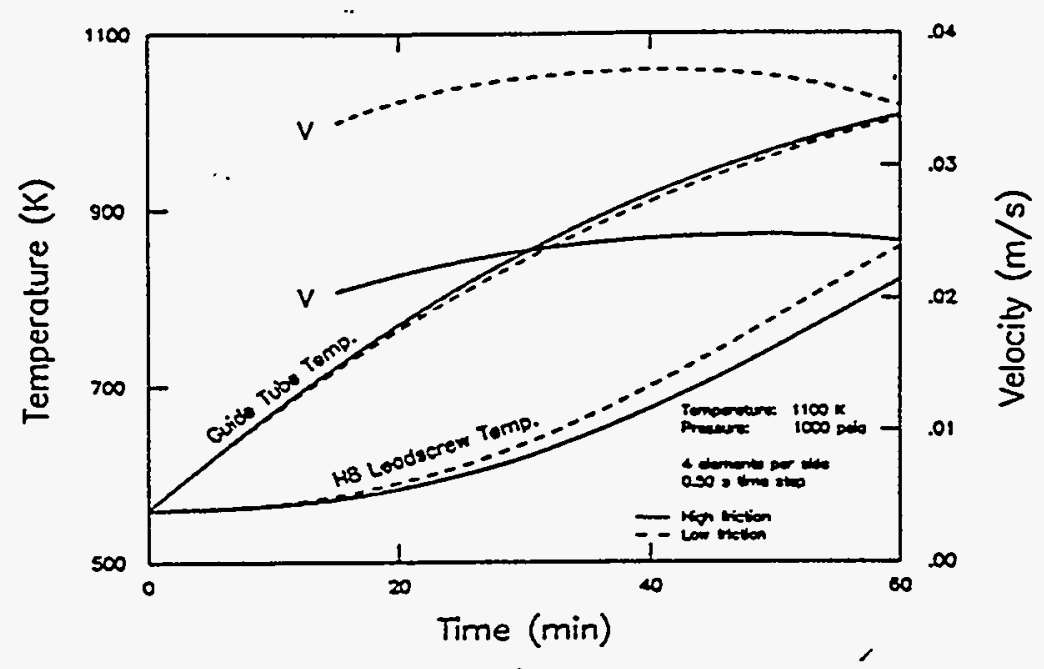

Figure G-7. Comparison between high- and low-friction cases.

temperature at 174 minutes. Figures G-8 and G-9 show the maximum lead screw temperature as a function of maximum steam temperature using both Eqs. (G-19) and (G-20). Using the maximum temperature experienced by the $\mathrm{H} 8$ lead screw $(666 \pm 28 \mathrm{~K})$ deduced in Reference G-5, Figures G-8 and G-9 yield maximum steam temperatures of $1,385 \pm 151 \mathrm{~K}$ and $1,528 \pm 175 \mathrm{~K}$ using Eqs. (G-19) and (G-20), respectively. Because of the uncertainty in the temporal variation of the steam temperature in the upper plenum, these maximum steam temperatures are of limited value. However, they do indicate that the upper plenum steam temperature can be much higher than the maximum temperature experienced by the lead screws.

\section{G-4.2 Calculation of Steam Temperature Using B8 Lead Screw Temperature}

Figure G-10 shows the maximum B8 lead screw temperature as a function of the maximum steam temperature using both Eqs. (G-19) and (G-20). Using the same procedure as that for the H8 lead screw, the peak steam temperature can be found from Figure G-10 to be

$$
\mathrm{T}_{\max }=1,289 \pm 91 \mathrm{~K} \text { using Eq. (G-19) }
$$

$$
\begin{aligned}
& \mathrm{T}_{\max }=\frac{1,424 \pm 100 \mathrm{~K} \text { using }}{\text { Eq. }(\mathrm{G}-20) .} \\
& \text {. }
\end{aligned}
$$

Even though the B8 lead screw's temperature is higher than that of the $\mathrm{H} 8$ lead screw (723 versus $666 \mathrm{~K}$ ), the steam temperature is found to be slightly lower. This is due to the higher heat transfer coefficient between the steam and the guide tube that exists for the B8 lead screw. A point near the top part of the upper plenum in the center channel is at the trailing edge of the upflow, while the same point in the outer channel will be near the leading edge of the returning downflow. This different relative location with respect to the flow results in a higher heat transfer coefficient for the outer channel (B8) compared to the center channel (H8). Moreover, a lower temperature in the outer channel is also consistent with the expected flow pattern for natural circulation, since the steam that goes up the center channel must lose heat to the upper head before returning to the upper plenum via the outer channel.

\section{G-4.3 MELPROG and FLOW3D Results}

Thermal-hydraulic calculations of TMI-2 using MELPROG and FLOW3D ${ }^{\mathrm{G}-4}$ indicate that the steam temperature in the upper plenum is fairly uniform axially and radially. According to this calculation, the steam temperature remains at about $560 \mathrm{~K}$ until 110 minutes. Thereafter, an 


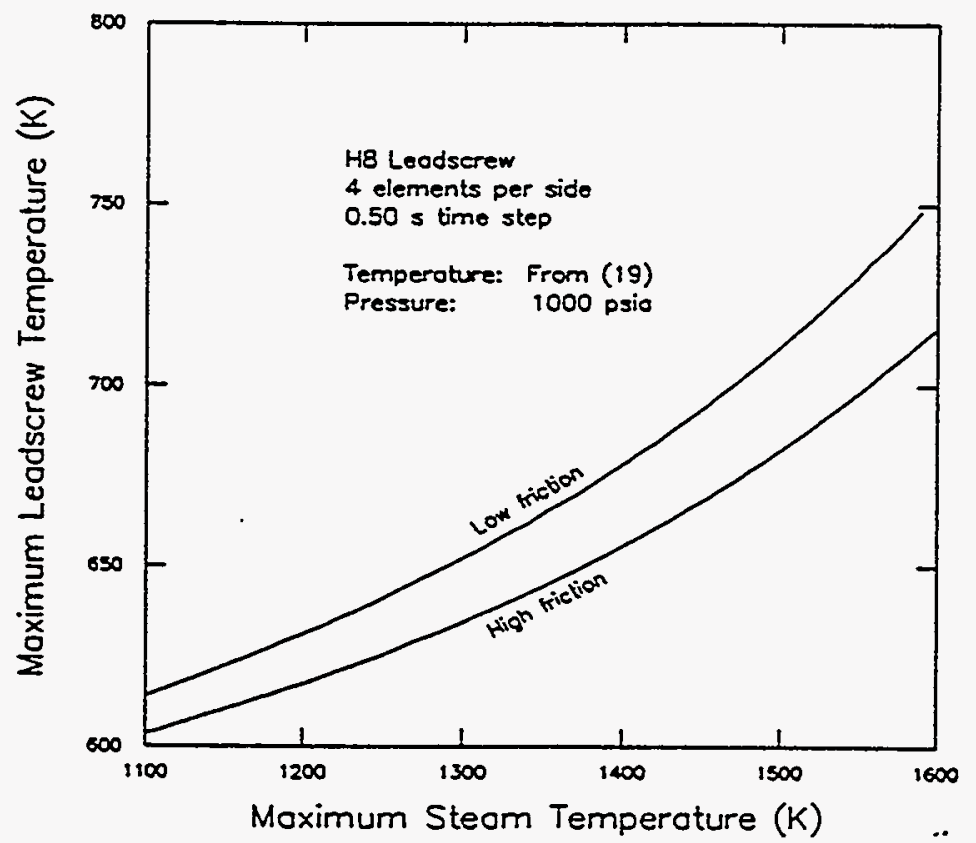

Figure G-8. Maximum lead screw temperature (H8)- $\mathrm{T}_{\mathrm{s}}$ from Eq. (G-19).

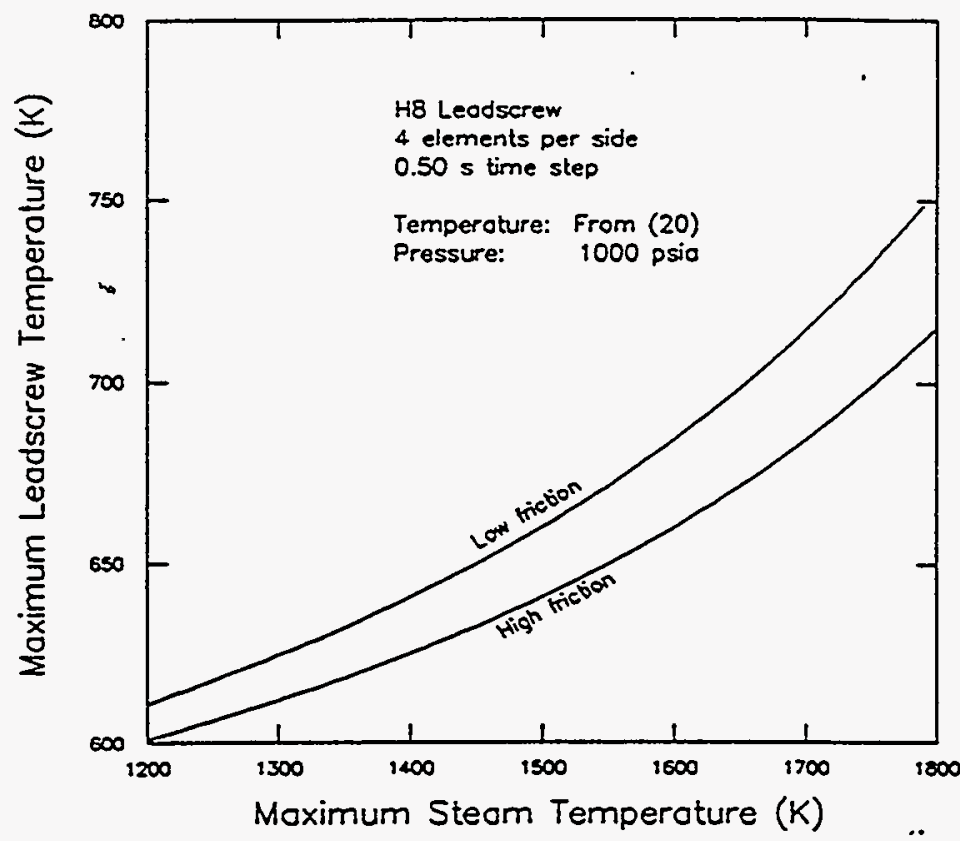

Figure G-9. Maximum lead screw temperature (H8)- $\mathrm{T}_{\mathrm{s}}$ from Eq. (G-20).

approximately linear temperature rise is calculated until the temperature reaches about $1,450 \mathrm{~K}$ at 157 minutes. At this time, a very steep rise brings the steam temperature to about $1,800 \mathrm{~K}$ (because of the zirconium-steam reaction).
Because of numerical difficulties, the calculation in Reference G-4 is terminated at 159 minutes, and it is not clear how the steam temperature in the upper plenum varies after this point even though the calculation does indicate a rate of 


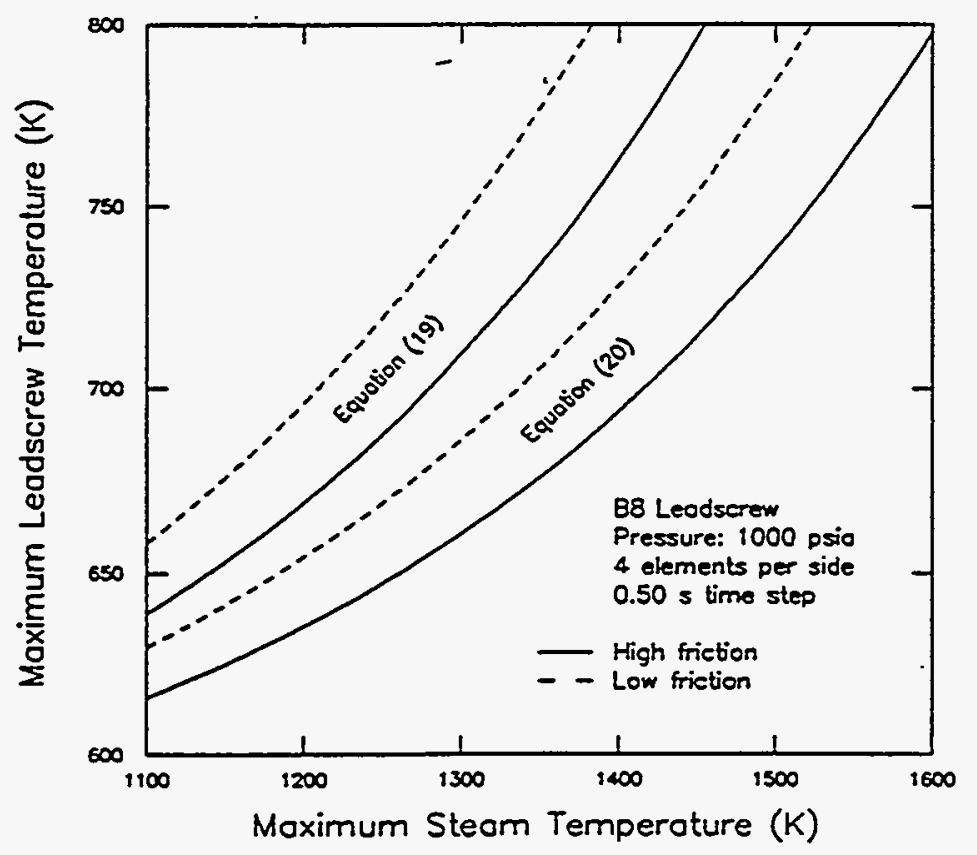

Figure G-10. Maximum lead screw temperature (B8).

decrease of about $1 \mathrm{~K} / \mathrm{s}$ between 157 and 159 minutes because of mixing with relatively cooler steam from below as the zirconium-steam reaction diminishes. As an estimate, the following steam temperature in the upper plenum is used in the present work

$$
\left.\begin{array}{rl}
T_{s}= & \left\{\begin{array}{l}
560+18.94 \cdot t^{*} \\
4,620-60 \cdot t^{*} \\
560+18.94 \cdot t^{*}
\end{array}\right. \\
& 0 \min \leq t * \leq 47 \min \\
& 47 \min <t *<51.43 \min \\
& 51.43 \min \leq t * \leq 64 \min
\end{array}\right\},
$$

which is essentially a linear temperature rise with a sharp peak at around 157 minutes. Such a variation is also consistent with SCDAP/RELAP5 calculations of the TMI-2 accident. ${ }^{\text {G-9 }}$ Another complication is the flow velocity in the upper plenum after 157 minutes. The steep rise in temperature is a result of rapid oxidation of the fuel cladding, which might be accompanied by partial relocation of the core. Thereafter, the flow velocity in the upper plenum may decrease because of a change in the geometry of the core (such as the formation of blockages) in addition to a reduction in the boiloff rate. Therefore, heat transfer from the steam in the upper plenum to the guide tube should be maximum at around 157 minutes. Since information on flow velocity is not available in Reference G-4 after 157 minutes, a conservative estimate of the lead screw temperature will be obtained here by assuming that there is no change in the flow velocity after this time. The lead screw temperature thus obtained is plotted in Figure G-11 as a function of time. The temperatures after 157 minutes are shown as dashed lines, since both the natural circulation velocity and the steam temperature are expected to be lower than the values used in the calculation. From Figure G-11, the temperature of the $\mathrm{H} 8$ lead screw is found to be about $950 \mathrm{~K}$ at around 170 minutes. This is considerably higher than the temperature deduced in Reference G-5 (about $700 \mathrm{~K}$ ). However, because of uncertainties in the steam temperature and natural circulation flow rate mentioned earlier, the actual lead screw temperature must be much lower than the value of $950 \mathrm{~K}$ predicted here. In fact, the maximum temperature experienced by the lead screw is most likely to occur near the point of rapid oxidation (157 minutes), where the lead screw temperature is predicted to be about $660 \mathrm{~K}$, which is consistent with that deduced in Reference G-5. 


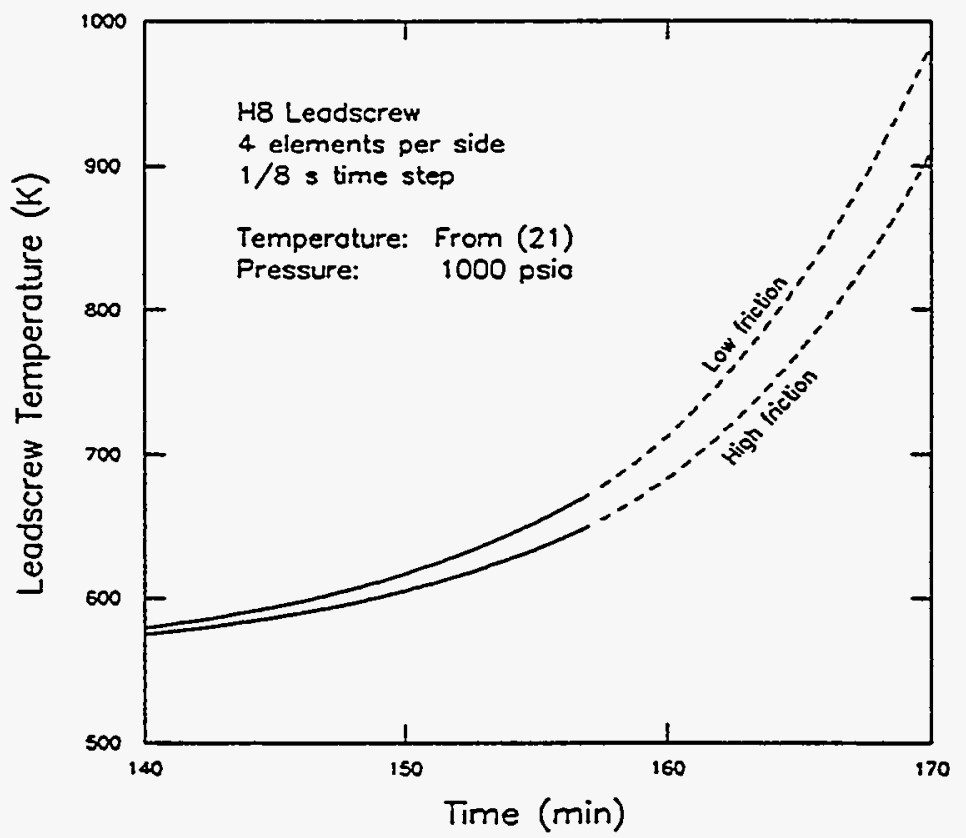

Figure G-11. Lead screw temperature from the MELPROG calculation.

\section{G-5. CONCLUSIONS}

The following are conclusions drawn from this study on the temperature of the lead screw recovered from the upper plenum of TMI-2:

1. Even though the actual temporal variation of the steam temperature in the upper plenum is unknown for the TMI-2 accident, results obtained in this study indicate that the maximum steam temperature can be very high (on the order of $1,300-1,500 \mathrm{~K}$ ) compared to temperatures experienced by the lead screws (666-723 K).

2. The steam temperature obtained by a thermal-hydraulic calculation of TMI-2 using MELPROG produces maximum lead screw temperatures that are consistent with those observed in TMI-2.

3. Axial conduction in the lead screw is unimportant in determining the lead screw temperature for locations near the top of the upper plenum.
4. Radiative exchange between the guide tube and the lead screw may be important and must be considered as a heat transfer mechanism.

5. A gravity-driven recirculating flow can be set up in the enclosure bounded by the lead screw and the guide tube. The buoyancy term for such a flow arises from the temperature difference between the guide tube and the lead screw.

\section{G-6. REFERENCES}

G-1. W. A. Stewart et al., Experiments on Natural Circulation in a Pressurized Water Reactor Model for Degraded Core Accidents. Final Report, EPRI Project No. RP2177-5, 1990.

G-2. W. A. Stewart et al., Experiments on Natural Circulation in a Pressurized Water Reactor Model With High Pressure SF $_{6}$, Draft EPRI Report, 1990. 
G-3. P. D. Bayless, Analyses of Natural Circulation During a Surry Station Blackout Using SCDAPIRELAP5, NUREG/CR-5214, 1988.

G-4. J. N. Lillington, A. J. Lyons, I. M. Lovely, Thermal-Hydraulic Calculation in TMI-2 Accident Analysis, Reactor Systems Analysis Division, AEE Winfrith, Report No. AEEW-R 2434, January 1989.

G-5. K. Vinjamuri, D. W. Akers and R. R. Hobbins, Examination of $H 8$ and $B 8$ Leadscrews From Three Mile Island Unit 2, GEND-INF-052, September 1985.

G-6. E. M. Sparrow and R. D. Cess, Radiation Heat Transfer, Hemisphere Publishing Company, 1978.
G-7. D. K. Edwards, V. E. Denny and A. F. Mills, Transfer Processes, Hemisphere Publishing Company, 2nd edition, 1979.

G-8. R. R. Hobbins, A. W. Cronenberg, S. Langer, D. E. Owen and D. W. Akers, "Insights On Severe Accident Chemistry From TMI-2," Proceedings of the Symposium on Chemical Phenomena Associated With Radioactive Releases During Severe Nuclear Plant Accidents, NUREG/ CP-0078, September 1986.

G-9. D. W. Golden and N. Ohnishi, SCDAP/ RELAP5 Demonstration Calculation of the TMI-2 Accident, EGG-TMI-8473, March 1989. 


\section{Appendix $\mathrm{H}$}

\section{Evaluation of Heat Transfer Uncertainties for Hot Leg Natural Circulation}




\section{Appendix $\mathrm{H}$}

\section{Evaluation of Heat Transfer Uncertainties for Hot Leg Natural Circulation}

\section{H-1. INTRODUCTION}

Hot leg countercurrent natural circulation flow is driven by the ex-vessel heat transfer to structures, which provides the buoyancy difference between the hot and cold streams. Additionally, reactor coolant system (RCS) piping failures that result from hot leg countercurrent natural circulation are a strong function of the heat transfer rate from the superheated steam to the piping structure. Uncertainties inherent in the heat transfer between the steam and structures and between the hot and cold streams via radiation could change the natural circulation flow, the structure heatup rate, and the predicted structure failure time. To quantify the effect of the heat transfer uncertainties, a series of analyses was performed where the heat transfer rates and mechanisms were varied to determine whether the variations significantly affect the prediction of ex-vessel RCS piping failures prior to core relocation and lower head failure.

A postulated TMLB' station blackout sequence in the Surry pressurized water reactor (PWR) was calculated, using the analytical methodology employed for the direct containment heating (DCH) analyses described in Reference $\mathrm{H}-1$. The following sections provide a brief description of the Base Case analytical methodology, the modifications made to vary the heat transfer, the results obtained from the analyses, and the conclusions drawn from these results.

\section{H-2. ANALYTICAL METHODOLOGY}

The calculations performed for the heat transfer uncertainty study were performed with version $8 \mathrm{~b}$ of the SCDAP/RELAP5/MOD3 computer code. ${ }^{\mathrm{H}-2}$ The Surry input decks used for the TMLB' station blackout calculation are described in detail in Appendix B of Reference H-1. The following is a brief overview of the transient and the input model used for the Base Case analyses, followed by a discussion of the modifications made to the Base Case model for the heat transfer sensitivities.

The TMLB' station blackout sequence is initiated by the loss of offsite power. Onsite ac power is also unavailable because the diesel generators fail to start or fail to supply power. The steamdriven auxiliary feedwater pumps are also assumed to fail so that decay heat removal through the steam generators cannot be maintained. The transient starts with a reactor scram and closure of the main feedwater and turbine stop valves. The inventory in the steam generators is boiled off through the secondary relief valves and the.RCS begins to heat up and pressurize to the pressurizer power-operated relief valve (PORV) setpoint. After the RCS saturates, a highpressure boiloff begins, ultimately leading to core uncovery and heatup. Without recovery of power, the transient proceeds to severe core damage, melting, relocation to the lower head, and reactor vessel failure.

The Surry model used SCDAP/RELAP5 to simulate the thermal-hydraulics of the reactor vessel, the piping in all three primary coolant loops, the pressurizer, all three steam generators, and selected parts of the secondary systems. The reactor vessel nodalization used is shown in Figure $\mathrm{H}-1$. As indicated, three parallel flow channels extend from the lower plenum through the core to the reactor vessel upper head. If the appropriate conditions exist, this arrangement will allow development of in-vessel natural circulation. Heat structures, which are shown as shaded areas, represent the structural mass of the reactor vessel walls, the core barrel and baffle, the thermal shield, the upper and lower core support 


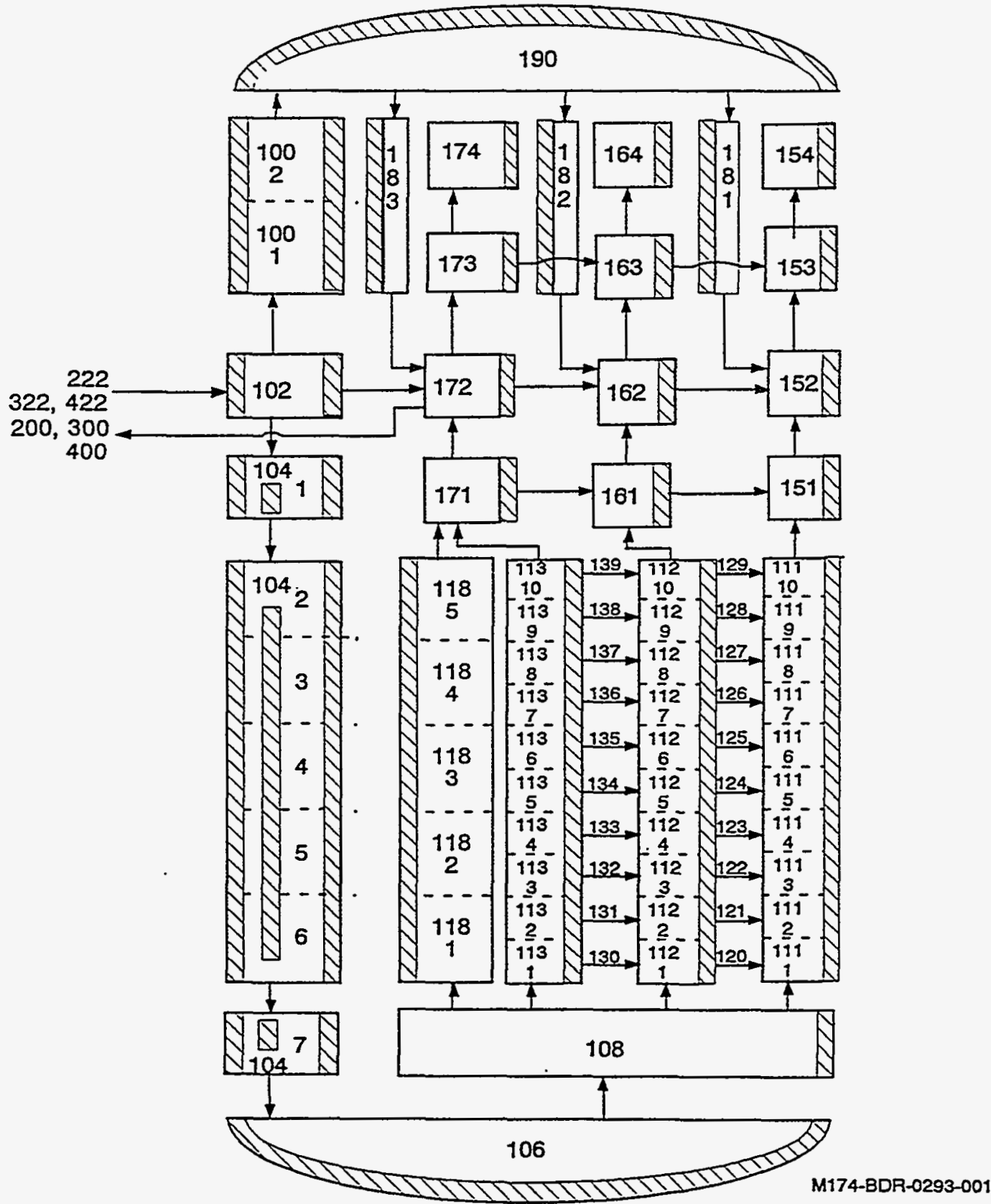

Figure H-1. Surry PWR reactor vessel nodalization with provisions for in-vessel natural circulation.

plates, and structures in the upper and lower plena. External surfaces of all heat structures were assumed to be adiabatic.

Nodalizations of the primary coolant loop containing the pressurizer are shown in Figures $\mathrm{H}-2$ and $\mathrm{H}-3$. With the exception of the pressurizer and associated surge line piping, similar nodalizations were included in the model to separately represent the other two primary coolant loops in the Surry plant.

The nodalization shown in Figure $\mathrm{H}-2$ was used in conjunction with the reactor vessel nodalization from TMLB' initiation to core heatup. (In this assessment, it was assumed that the onset of core heatup coincided with a core exit vapor superheat of $2.8 \mathrm{~K}$.) During this portion of the transient, full loop natural circulation of 


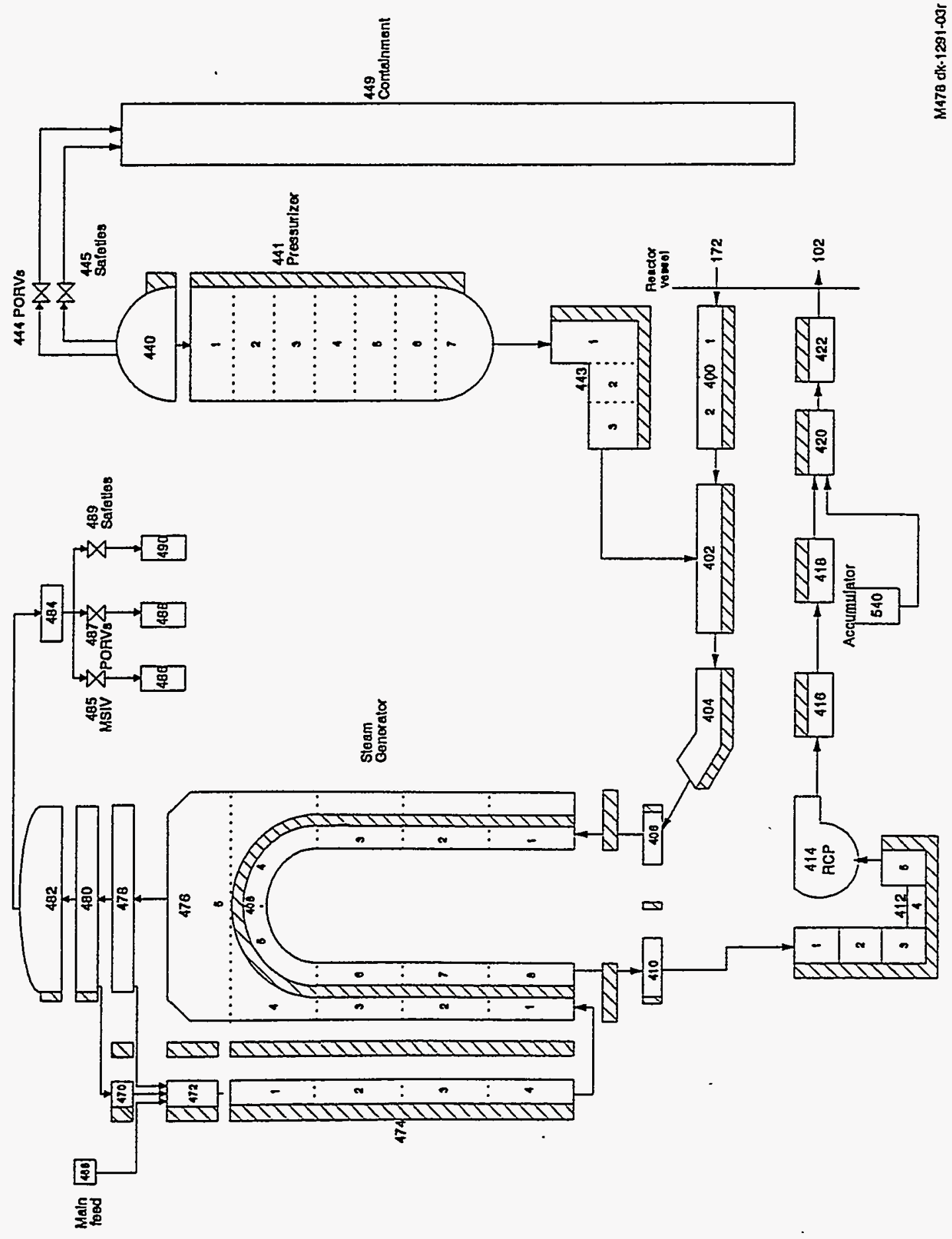

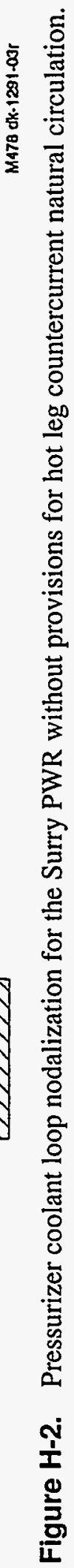


Appendix $\mathrm{H}$

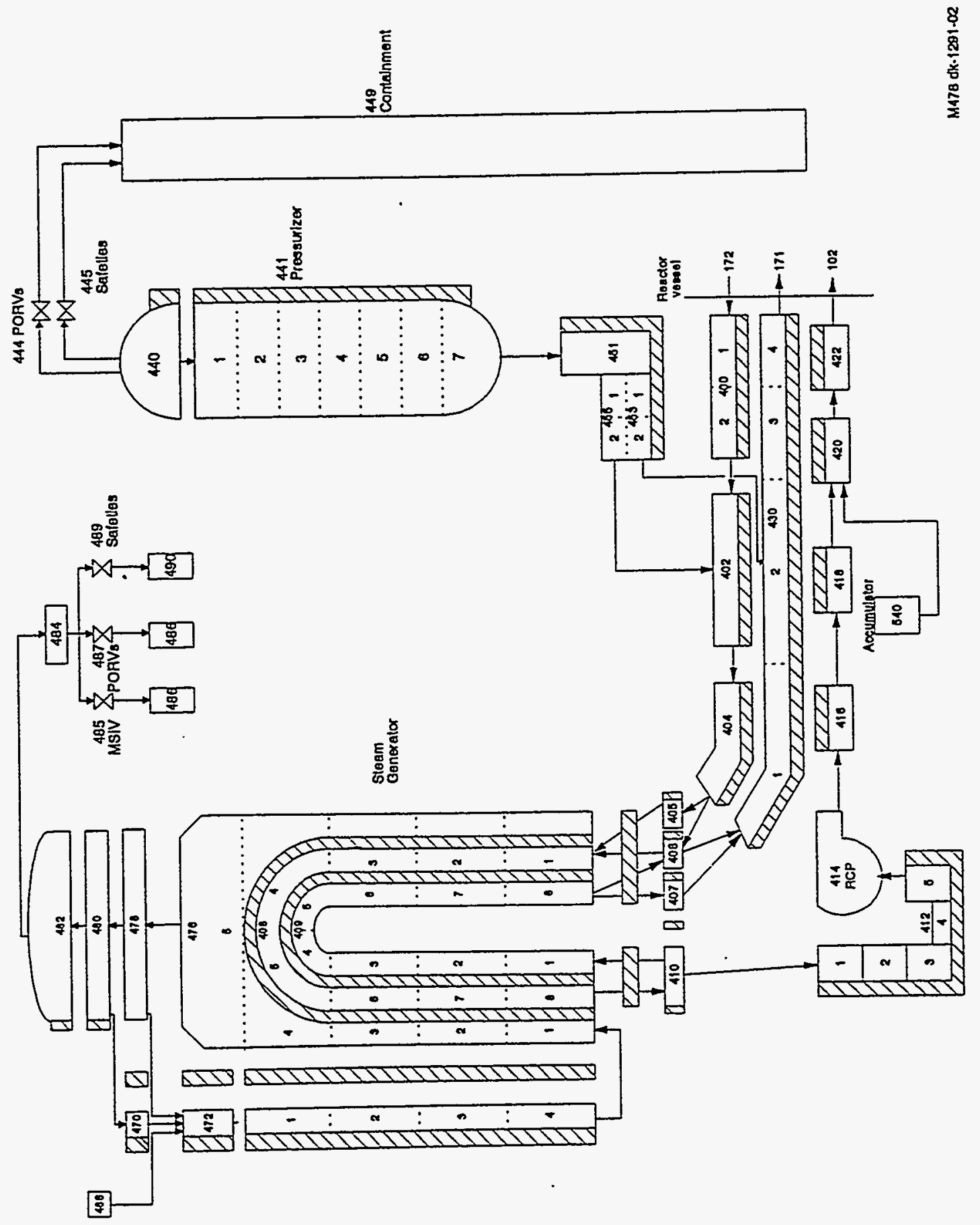

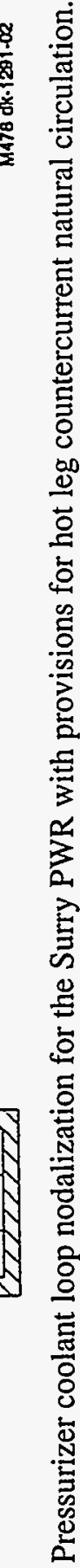

$\frac{\text { Ṗ }}{\frac{1}{1}}$ 
subcooled and saturated liquid can develop. As the core heats the primary coolant toward saturation, however, voids begin to form and collect at the top of the steam generator U-tubes. Once that occurs, full loop natural circulation of liquid is interrupted.

At the onset of core heatup, the Figure H-2 nodalization was replaced by the nodalization shown in Figure $\mathrm{H}-3$ for the Base Case calculation and was the starting point for all the heat transfer sensitivity analyses. This substitution provides the flow paths needed to represent hot leg countercurrent natural circulation. Hot leg countercurrent natural circulation becomes possible after saturated liquid in the hot legs drains to the vessel and/or flashes. At that time, temperature gradients from the core to the steam generator U-tubes can drive steam flow along the top half of the hot leg (represented by components 400,402 , and 404), through a portion of the steam generator U-tubes (represented by component 408), and back to the vessel through a cooler portion of the steam generator U-tubes and the lower half of the hot leg (represented by components 409 and 430). During this portion of the transient, simple structural models of the exvessel piping were included to track the potential for creep rupture failures induced by the combined effects of elevated temperature and pressure. Although RCS piping failures were predicted to occur, no RCS blowdown was simulated. Instead, the code calculations were allowed to continue to provide timing differences between failure events.

The Surry model used the SCDAP code models to simulate the fuel assemblies in the three core channels. The three core flow channels shown in Figure $\mathrm{H}-1$ were selected so that similarly powered fuel assemblies would be grouped together. A cross-section of the resulting three-channel model is shown in Figure $\mathrm{H}-4$. The number of fuel assemblies in each channel and their relative power are indicated. SCDAP represents the fuel and control rods as separate components and computes the thermal-mechanical response of these components to the core heatup.
The heat transfer sensitivity studies consisted of five calculations that varied the heat transfer coefficients for the heat structures in contact with the hot leg natural circulation flow. The first two calculations varied the heat transfer coefficient for the upper plenum structures (inside surface of the core barrel, control rod guide tubes, support columns, and bottom surface of the upper support plate). The heat transfer coefficient was changed by $\pm 20 \%$ by assigning a multiplier of $0.8(-20 \%)$ and $1.2(+20 \%)$ on the RELAP5-calculated heat transfer coefficient for these structures at the beginning of the hot leg countercurrent flow phase of the transient.

The third calculation varied the heat transfer coefficient in the piping heat structures representing the three hot legs and the surge line by $-20 \%$. The Surry TMLB' Base Case calculation described in Reference $\mathrm{H}-1$ showed that exvessel RCS piping failures occurred in the surge line and hot leg nozzles well in advance of lower head failure. Since increasing the heat transfer coefficient would only accelerate the RCS failure time for these structures, the $+20 \%$ case was not of interest. As with the first two calculations, the sensitivity was achieved by applying a 0.8 multiplier to the RELAP5-calculated heat transfer coefficient on the inside surface of the hot leg and surge line piping structures.

The next two calculations varied the heat transfer coefficient on the primary side of the steam generator tubes by $\pm 20 \%$. As with the upper plenum structure sensitivity, this was accomplished by applying a multiplier of 0.8 and 1.2 on the RELAP5-calculated heat transfer coefficient.

The final calculation was performed to simulate radiation heat transfer between the hot steam flow in the top of the hot leg (Components 400 through 404 in Figure $\mathrm{H}-3$ ) and the cooler return steam flow in the bottom of the hot leg (Component 430 in Figure H-3). The Base Case calculation reported here and in Reference $\mathrm{H}-1$ assumed that these two streams did not mix or thermally interact. The radiation heat transfer between the streams was simulated by placing a very thin heat structure $(0.024 \mathrm{~m})$ with a high thermal conductivity $(6.23 \mathrm{e} 9 \mathrm{~W} / \mathrm{m}-\mathrm{K})$ and a low 


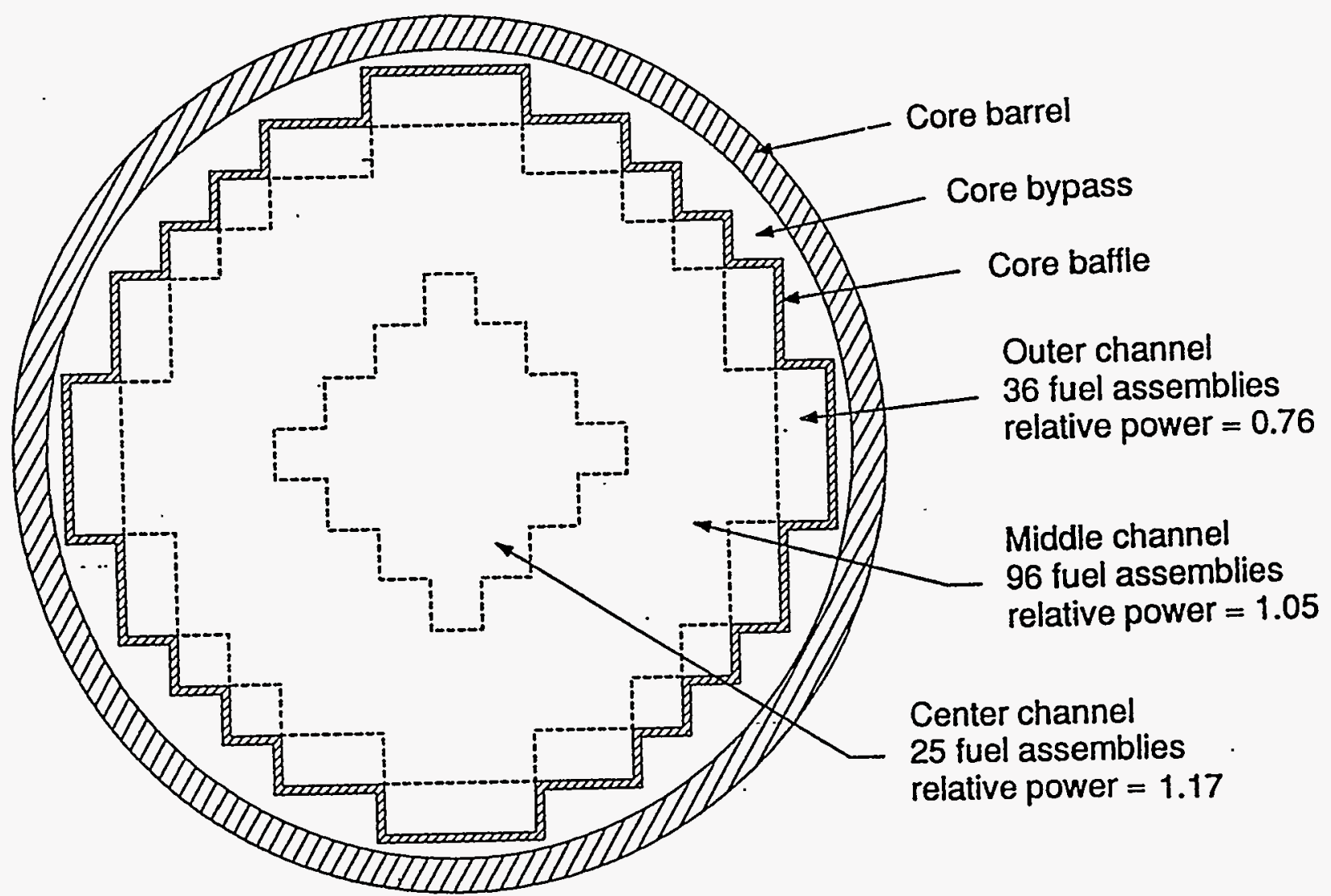

Figure H-4. A cross-section of the three-channel core region.

heat capacity $\left(6.71 \mathrm{e} 5 \mathrm{~J} / \mathrm{m}^{3}-\mathrm{K}\right)$ between the two vapor streams in each component (four structures per hot leg). A high heat transfer coefficient $\left(2.04 \mathrm{e} 6 \mathrm{~W} / \mathrm{m}^{2}-\mathrm{K}\right)$ was applied to the side in contact with the hot stream, and a temperaturedependent heat transfer coefficient representative of black body radiation potential was applied to the side in contact with the cooler flow stream. The values for the latter heat transfer coefficient were derived from the Base Case temperature difference between the streams and ranged from $0.0 \mathrm{~W} / \mathrm{m}^{2}-\mathrm{K}$ at $866 \mathrm{~K}$ to $245.3 \mathrm{~W} / \mathrm{m}^{2}-\mathrm{K}$ at or above a hot stream vapor temperature of $1,275 \mathrm{~K}$. The upper limit represents the highest temperature difference observed in the Base Case.

\section{H-3. ANALYTICAL RESULTS}

The following provides the analytical results of the heat transfer sensitivity studies. The results of the Base Case calculation are presented first to provide an overview of the Surry TMLB' transient results. Next, comparisons between the Base Case results and those obtained by modifying the heat transfer coefficients as described in the previous section are provided.

The sequence of events for the Base Case calculation is shown in Table H-1. Following transient initiation, decay heat was transported from the core to the steam generators by full loop natural circulation in all three coolant loops. As the water in the steam generators boiled off, the energy removed from the RCS by the steam generators dropped below the decay energy being added in the core, and the RCS began to heat up and pressurize. The pressurizer PORVs controlled the RCS pressurization by cycling between the opening and closing setpoints of 16.2 and $15.7 \mathrm{MPa}$, respectively. Vapor generated by boiling in the core collected in the top of the steam generator U-tubes, terminating full loop natural circulation at 126.4 minutes. Venting of coolant by the 
Table H-1. Sequence of events for the Base Case.

\begin{tabular}{|c|c|}
\hline Event & $\begin{array}{l}\text { Time } \\
(\min )\end{array}$ \\
\hline TMLB' initiation & 0 \\
\hline Steam generator dryout (pressurizer/nonpressurizer loops) & $80.0 / 81.1$ \\
\hline Initial cycle of pressurizer PORV & 81.1 \\
\hline Pressurizer filled with liquid & 99.0 \\
\hline Full loop natural circulation ends & 126.4 \\
\hline Reactor vessel liquid level drops below top of fuel rods & 148.1 \\
\hline Core exit superheat; hot leg countercurrent circulation begins & 150.1 \\
\hline Reactor vessel liquid level drops below bottom of fuel rods & 180.4 \\
\hline Onset of fuel rod oxidation & 184.3 \\
\hline Surge line creep rupture failure & 222.8 \\
\hline Hot leg creep rupture failure (pressurizer/nonpressurizer loops) & $241.8 / 244.5$ \\
\hline End of calculation & 296.7 \\
\hline
\end{tabular}

pressurizer PORVs reduced the RCS liquid inventory, which uncovered the top of the core at 148.1 minutes, initiating core heatup and superheating of RCS vapor. The core was completely uncovered by 180.4 minutes, with oxidation of the fuel cladding commencing at 184.3 minutes. Cyclic flow through the pressurizer PORV (to control RCS pressure) and hot leg countercurrent natural circulation removed energy from the reactor vessel, producing a heatup of the pressurizer and surge line piping. This ex-vessel heatup resulted in a predicted creep rupture failure of the surge line piping at 222.8 minutes. As previously explained, a blowdown was not modeled following surge line failure. The calculation was allowed to proceed without RCS depressurization, resulting in creep rupture failure of the hot leg nozzles between 241.8 and 244.5 minutes. Since these were the results to be compared in the sensitivity studies, the calculation was terminated at 296.7 minutes.

The RCS pressure response during the TMLB' transient is shown in Figure $\mathrm{H}-5$. The pressure initially decreased from the operating pressure of 15.5 $\mathrm{MPa}$ because the steam generators removed more energy than was being added by the core. Following steam generator dryout, the pressure increased to the PORV opening pressure. The pressure then cycled between the PORV opening and closing setpoints for the remainder of the transient.

The collapsed liquid level in the reactor vessel is shown in Figure H-6. Following RCS saturation, the vessel water level boiled down rapidly to the bottom of the fuel rods. The flattening of the boiloff at about 130 minutes was caused by the liquid in the coolant loops draining into the vessel through the hot and cold leg nozzles. When the level dropped below the core, the boiloff became more gradual because heat transfer from the core to the liquid was through recirculating superheated vapor. As shown by the peak cladding surface temperature in Figure $\mathrm{H}-7$, the core heated up rapidly following uncovery, reaching the initiation temperature for rapid cladding oxidation of $1,850 \mathrm{~K}$ at about 220 minutes.

The mass flow rate in the top of one of the nonpressurizer loop hot legs is shown in Figure H-8. After the hot leg countercurrent flow renodalization was introduced at 150.1 minutes, a natural circulation pattern was established. The mass flow rate decreased steadily throughout the transient, as the vapor temperature increased and the density decreased. The cycling of the PORV 
Appendix $\mathrm{H}$

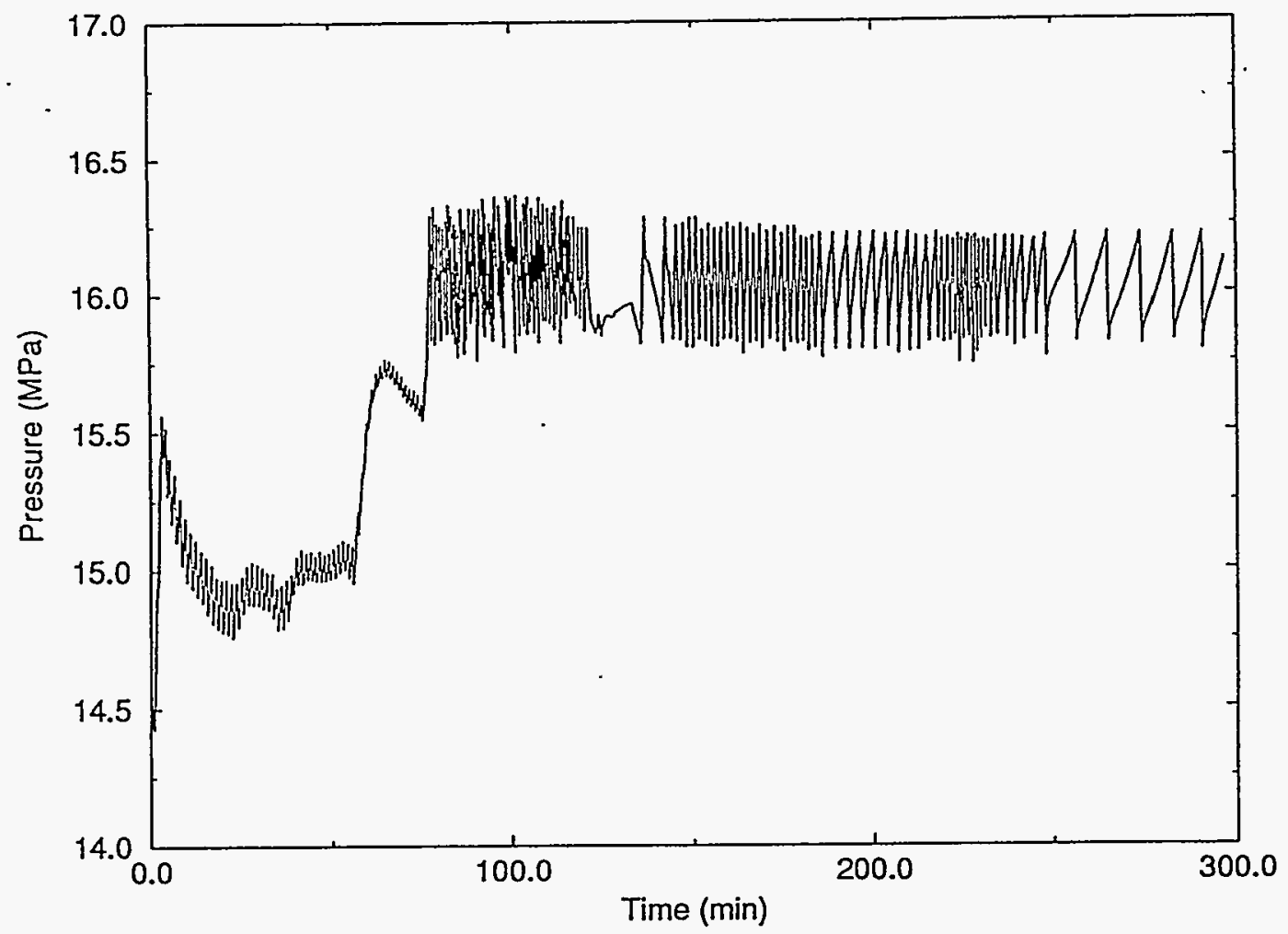

Figure H-5. Pressurizer pressure for the Base Case.

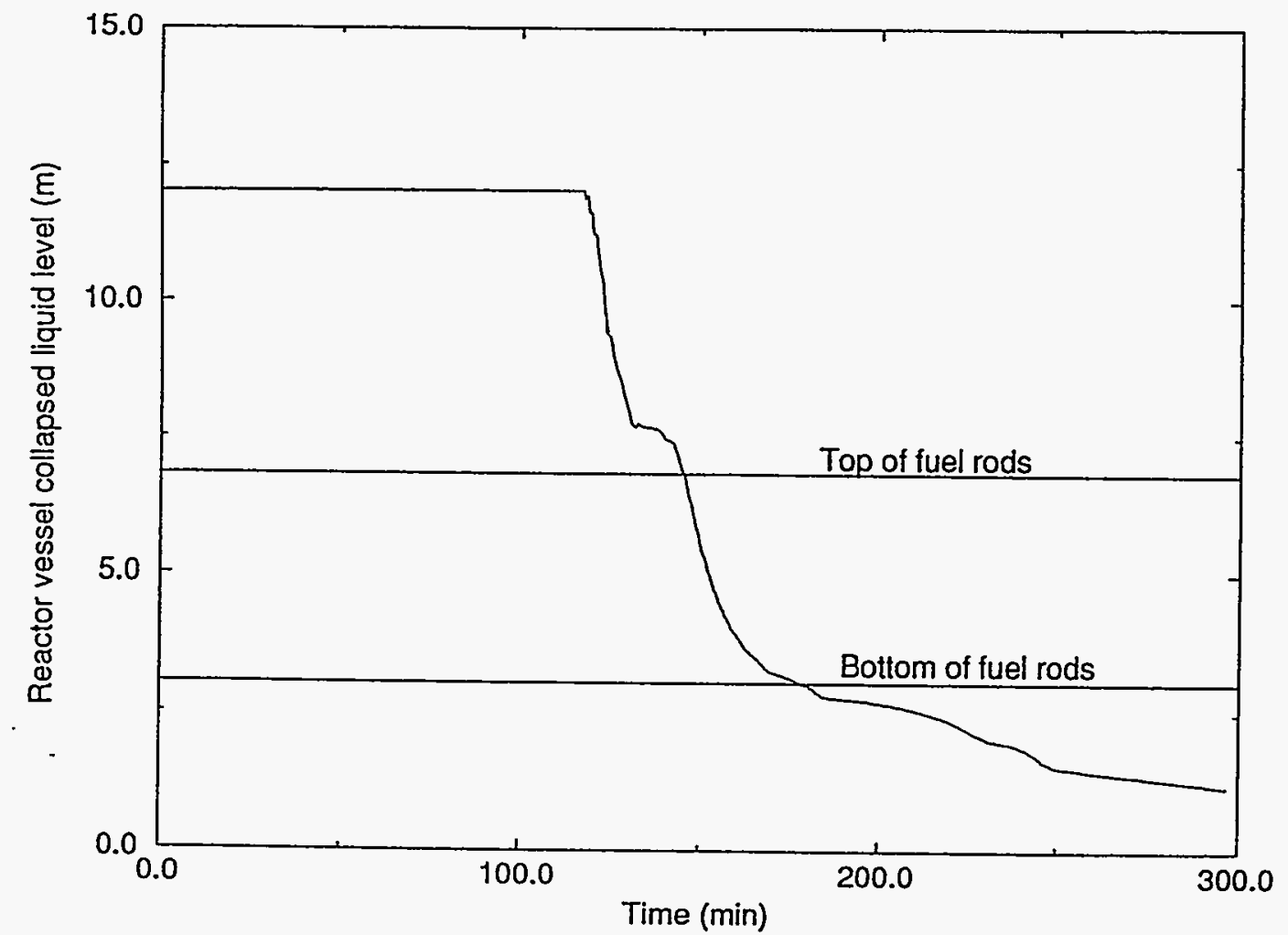

Figure H-6. Reactor vessel collapsed liquid level for the Base Case. 


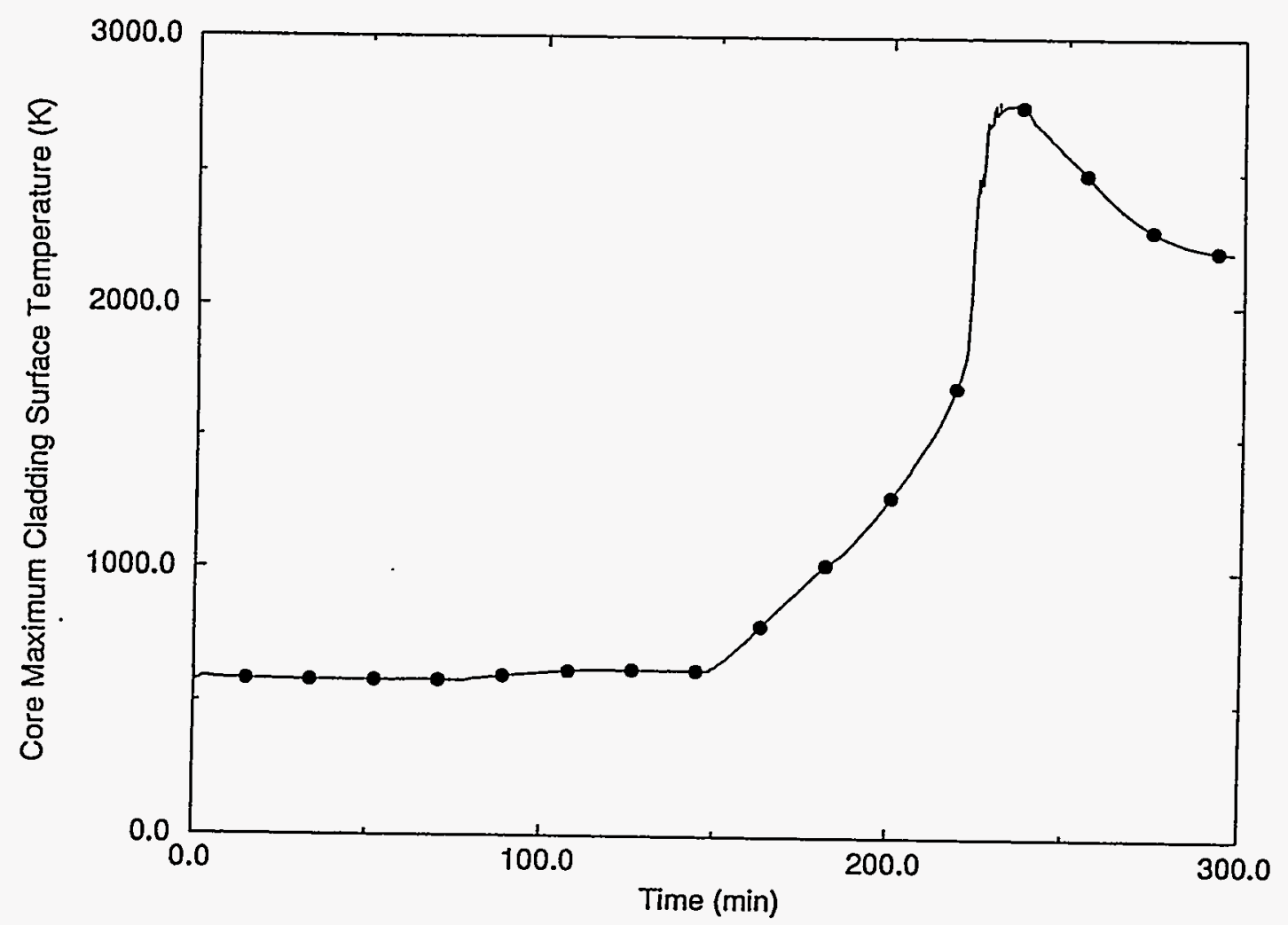

Figure H-7. Core maximum cladding surface temperature for the Base Case.

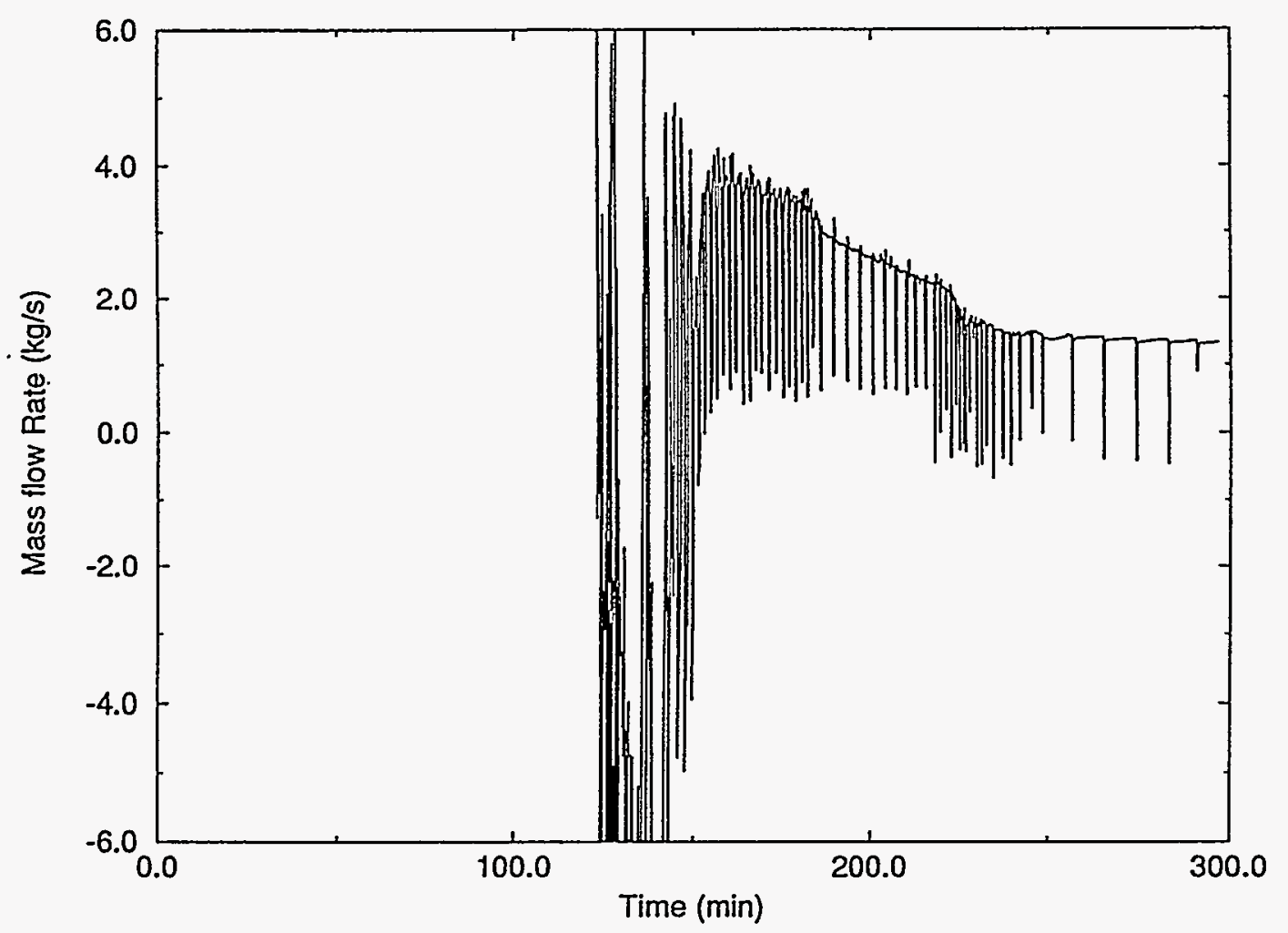

Figure H-8. Mass flow rate in the top of a nonpressurizer loop hot leg (A) for the Base Case. 
momentarily reversed the natural circulation flow, as vapor was drawn toward the pressurizer surge line. When the PORV closed, however, the natural circulation pattern was quickly reestablished. Vapor temperatures in the top and bottom of the hot leg nozzle for this same loop are shown in Figure H-9. A large, sustained temperature gradient across the hot leg nozzle was maintained from 150.1 minutes to the end of the calculation. Vapor temperatures increased rapidly when the cladding oxidation rate increased at about 220 minutes.

Temperatures of the hottest structure in the upper plenum, the pressurizer surge line at the hot leg connection, the top of the pressurizer loop hot leg at the nozzle, and the hottest steam generator tube in the pressurizer loop are shown in Figure $\mathrm{H}-10$. Because of its smaller thermal mass, the pressurizer surge line heated up faster and was predicted to fail earlier than the hot leg. The steam generator tubes remained relatively cool because most of the energy in the circulating steam was lost in the steam generator inlet plenum, where the hotter steam mixed with the cooler return flow steam before entering the tubes. There were large margins before any steam generator tube failures from creep rupture could be expected to occur.

The comparisons between the Base Case failure times and those predicted for the heat transfer sensitivity calculations are shown in Table H-2. The calculations were initiated at 150.1 minutes via restart from the Base Case results. As indicated by Table $\mathrm{H}-2$, none of the heat transfer sensitivities produced a significant change in the Base Case predicted failure times. What this indicates is that the hot leg nozzle differential temperature, the driving potential for the buoyancy-driven hot leg natural circulation flow, is not significantly affected over the range of heat transfer sensitivities investigated.

The sensitivity study on upper plenum heat transfer produced a slight delay in RCS piping failures with the higher heat transfer coefficients and somewhat faster RCS piping failures with the lower heat transfer coefficients. Because the upper plenum structures have fairly large surface areas and relatively small thermal masses, they respond rapidly to vapor temperature changes and don't store a large amount of energy. Figure H-11 shows the comparison for vapor temperature in the top of a nonpressurizer loop (A) hot leg for the Base Case and the two upper plenum sensitivities. The figure shows that increasing the heat transfer coefficient in the upper plenum structures slightly reduced the inlet temperature to the hot leg, while decreasing the heat transfer coefficient produced a minimal increase. The temperature change was not large enough to affect the natural circulation flow rate or significantly alter the RCS piping failure time in either of the sensitivity calculations.

Decreasing the heat transfer coefficient in the hot leg structures had the expected result of delaying the failure times for the structures, as shown in Table H-2. Figure $\mathrm{H}-12$ shows the comparison for volume-averaged temperatures in a nonpressurizer loop hot leg top and the surge line nozzle top for the Base Case and the hot leg heat transfer sensitivity. Since the heat transfer modification does not change the vapor temperature in the hot leg nozzle, the natural circulation flow was the same as observed in the Base Case. The only effect was that the decrease in the heat transfer coefficient produced a decrease in the structure volume-average temperature.

The steam generator tube sensitivity study produced almost no difference in RCS piping failure times between the two extremes and only a slight delay when compared to the Base Case. The recirculating hot leg countercurrent flow comes into a quasi-equilibrium with the steam generator secondary side before returning to the hot leg. By adjusting the heat transfer coefficient in the tubes, the point in the tubes where the two temperatures equilibrate changes, as does the primary temperature at equilibration. Figure $\mathrm{H}-13$ shows the comparison for vapor temperatures in the top and bottom of a nonpressurizer loop (A) hot leg for the Base Case and the two steam generator sensitivities. The temperature variation in the cooler return flow was amplified somewhat in the core, producing a larger change in the vapor 


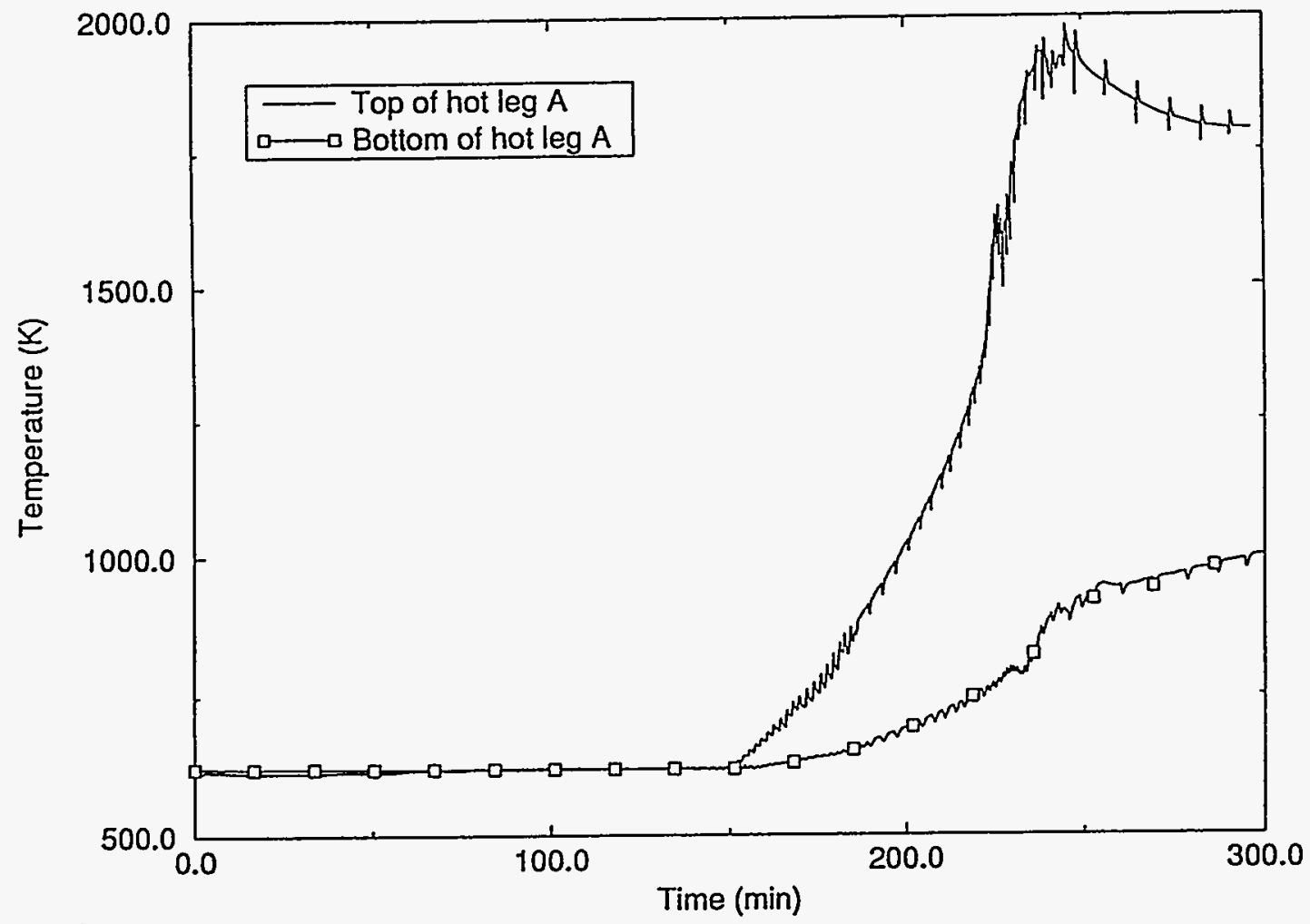

Figure H-9. Vapor temperatures in the hot leg nozzle of a nonpressurizer loop hot leg (A) for the Base Case.

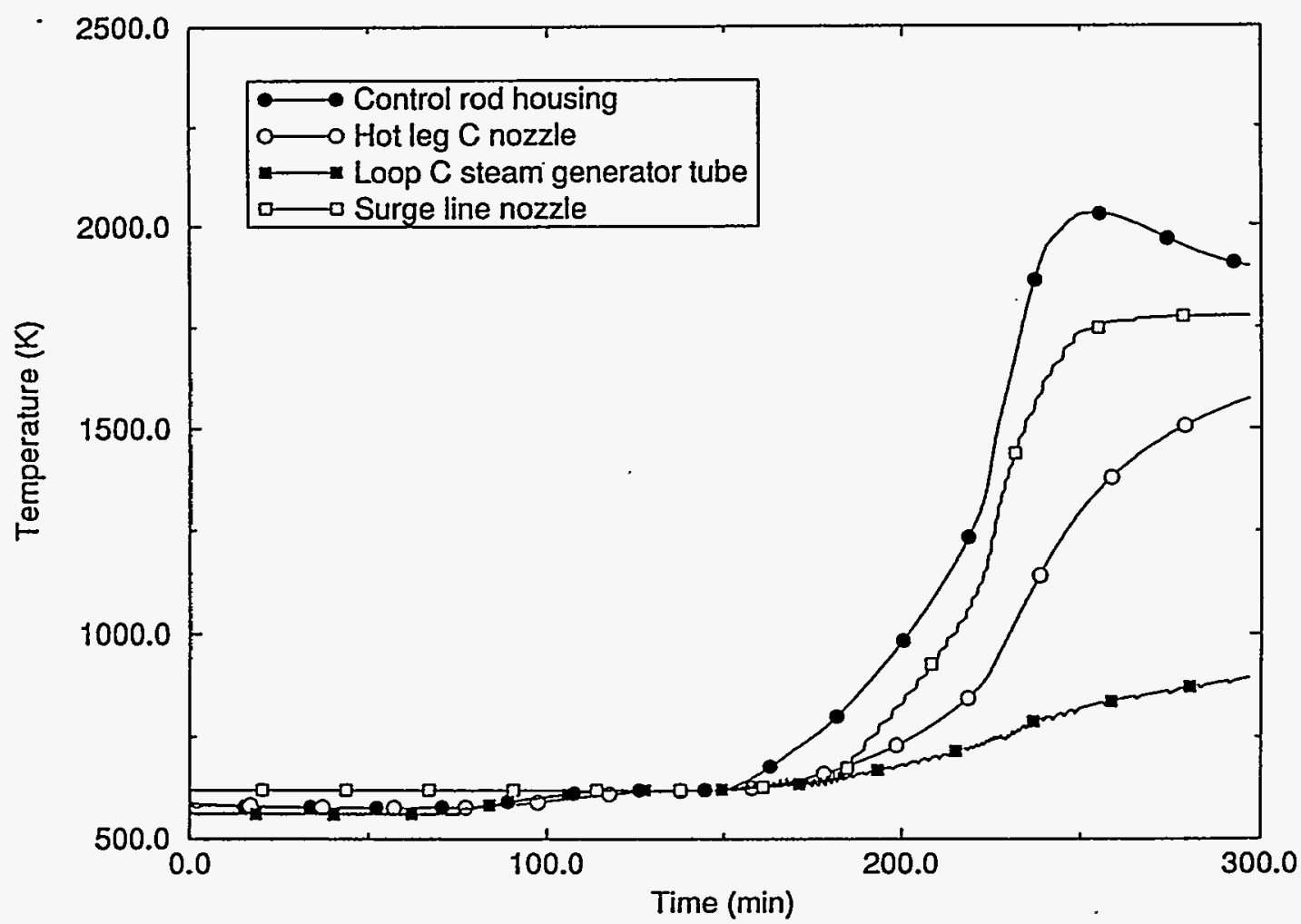

Figure $\mathbf{H - 1 0}$. Volume-averaged temperatures of various structures in the pressurizer loop (C) and the reactor vessel for the Base Case. 
Appendix $\mathrm{H}$

Table H-2. RCS failure times for the heat transfer sensitivity studies.

\begin{tabular}{lccc} 
& \multicolumn{3}{c}{$\begin{array}{c}\text { Failure time } \\
\text { (min) }\end{array}$} \\
\cline { 2 - 4 } \multicolumn{1}{c}{ Sensitivity study } & Surge line & Loop C hot leg & Loops A \& B hot leg \\
\hline Base Case & 222.8 & 241.8 & 244.5 \\
Upper plenum * 1.2 & 223.5 & 242.9 & 245.6 \\
Upper plenum * 0.8 & 222.1 & 240.9 & 243.6 \\
Hot legs *0.8 & 223.3 & 246.8 & 249.9 \\
Steam generator tubes * 1.2 & 223.1 & 242.7 & 245.4 \\
Steam generator tubes * 0.8 & 223.2 & 242.9 & 245.8 \\
Hot leg radiation & 221.8 & 241.0 & 244.3 \\
\hline
\end{tabular}

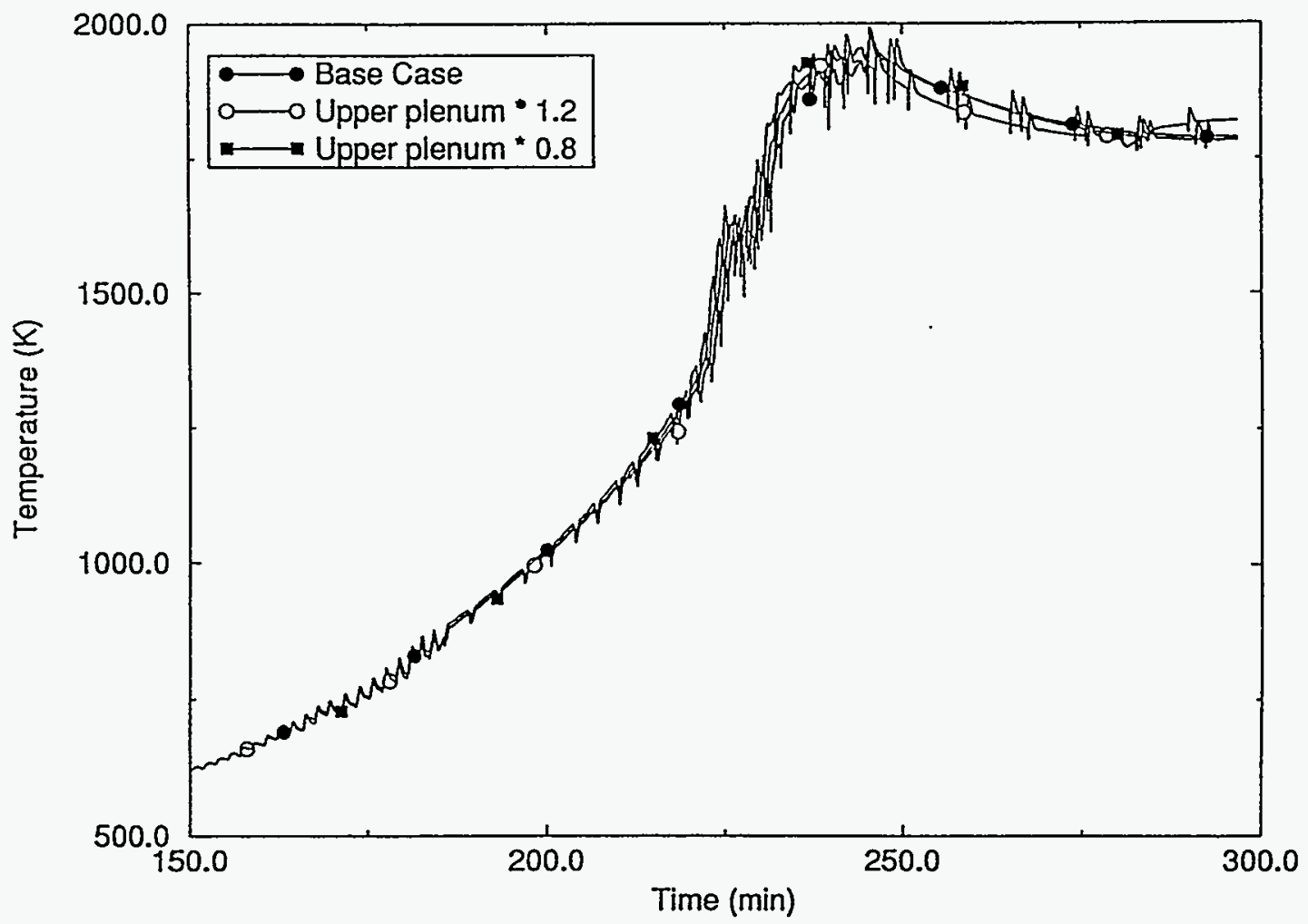

Figure H-11. Vapor temperatures in the top of a nonpressurizer loop hot leg (A) for the Base Case and the upper plenum heat transfer uncertainty cases. 


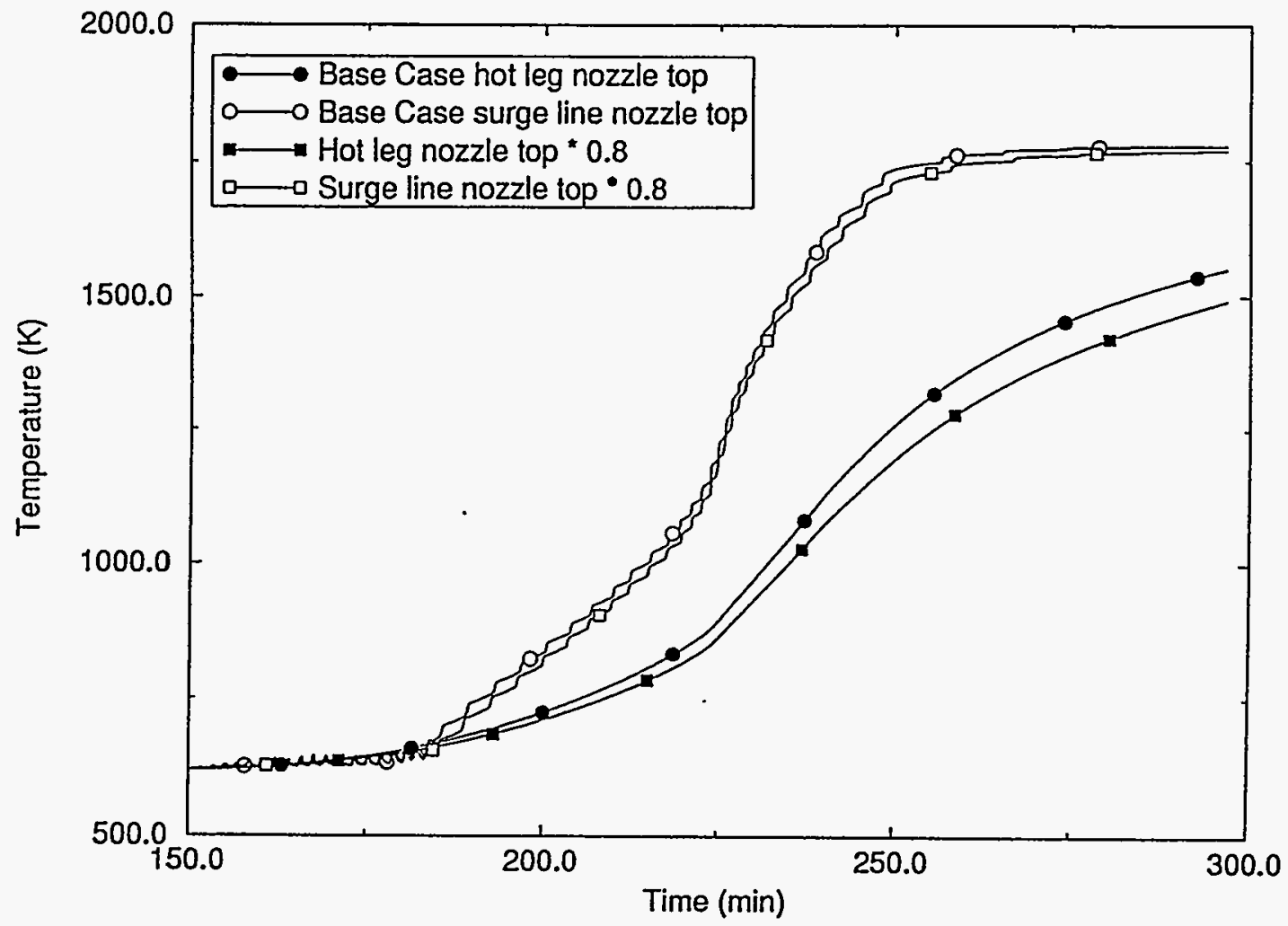

Figure H-12. Volume-averaged temperatures in a nonpressurizer loop hot leg nozzle top and the surge line nozzle top for the Base Case and the hot leg heat transfer sensitivity case.

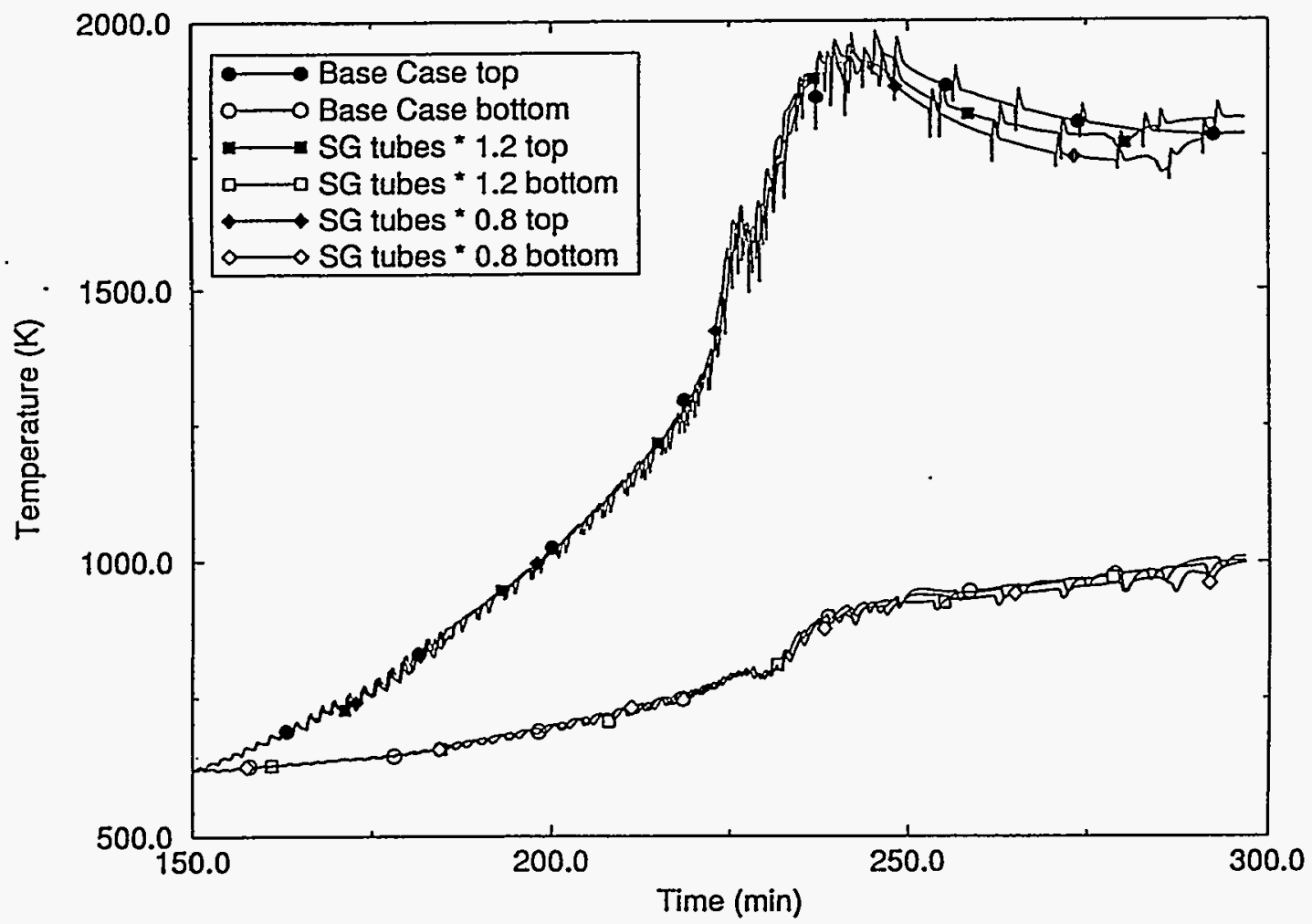

Figure H-13. Vapor temperatures in the hot leg nozzle of a nonpressurizer loop hot leg (A) for the Base Case and the steam generator sensitivity cases. 
temperature in the top of the hot leg nozzle. The difference in temperature observed in the hot leg nozzles produced almost no change in the hot leg natural circulation flow rates compared to the Base Case, as shown in Figure H-14.

The hot leg radiation heat transfer sensitivity study results also showed a negligible change in the RCS piping failures. As shown in Table $\mathrm{H}-2$, the changes relative to the Base Case were within a minute for all the structures. This is because the creep rupture failure temperature for these structures occurs before radiation heat transfer becomes dominant. Figure H-15 shows the comparison for vapor temperatures in the top and bottom of a nonpressurizer loop (A) hot leg for the Base Case and the radiation sensitivity case. The radiation heat transfer rate peaks at about 235 minutes, after surge line failure and just before hot leg failure. The effect on RCS piping failure was therefore minimal.
As the results show, the hot leg countercurrent natural circulation flow and resultant piping heatup and failure were not affected by reasonable variations in the heat transfer rates or mechanisms. Therefore, uncertainty in the heat transfer is not a concern for predicted RCS piping failures if the uncertainties are within the bounds examined in these studies.

\section{H-4. REFERENCES}

H-1. D. L. Knudson and C. A. Dobbe, Assessment of the Potential for High-Pressure Melt Ejection Resulting from a Surry Station Blackout Transient, NUREG/CR-5949, EGG-2689, November 1993.

H-2. C. M. Allison et al., SCDAP/RELAP5/MOD3.1 Code Manual, NUREG/ CR-6150, EGG-2720, Volumes 1-5, October 1993.

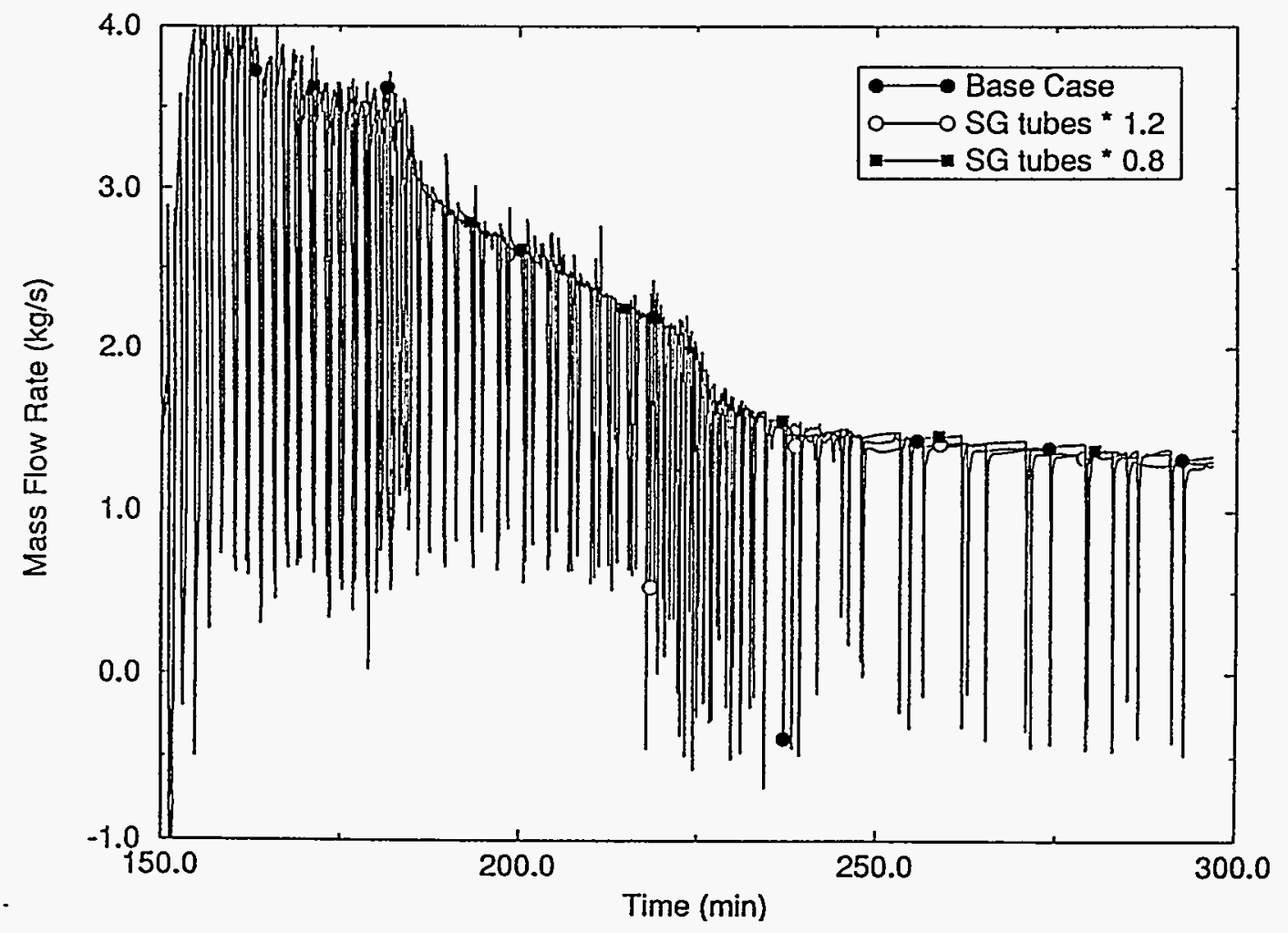

Figure H-14. Mass flow rate in the top of a nonpressurizer loop hot leg (A) for the Base Case and the steam generator sensitivity cases. 


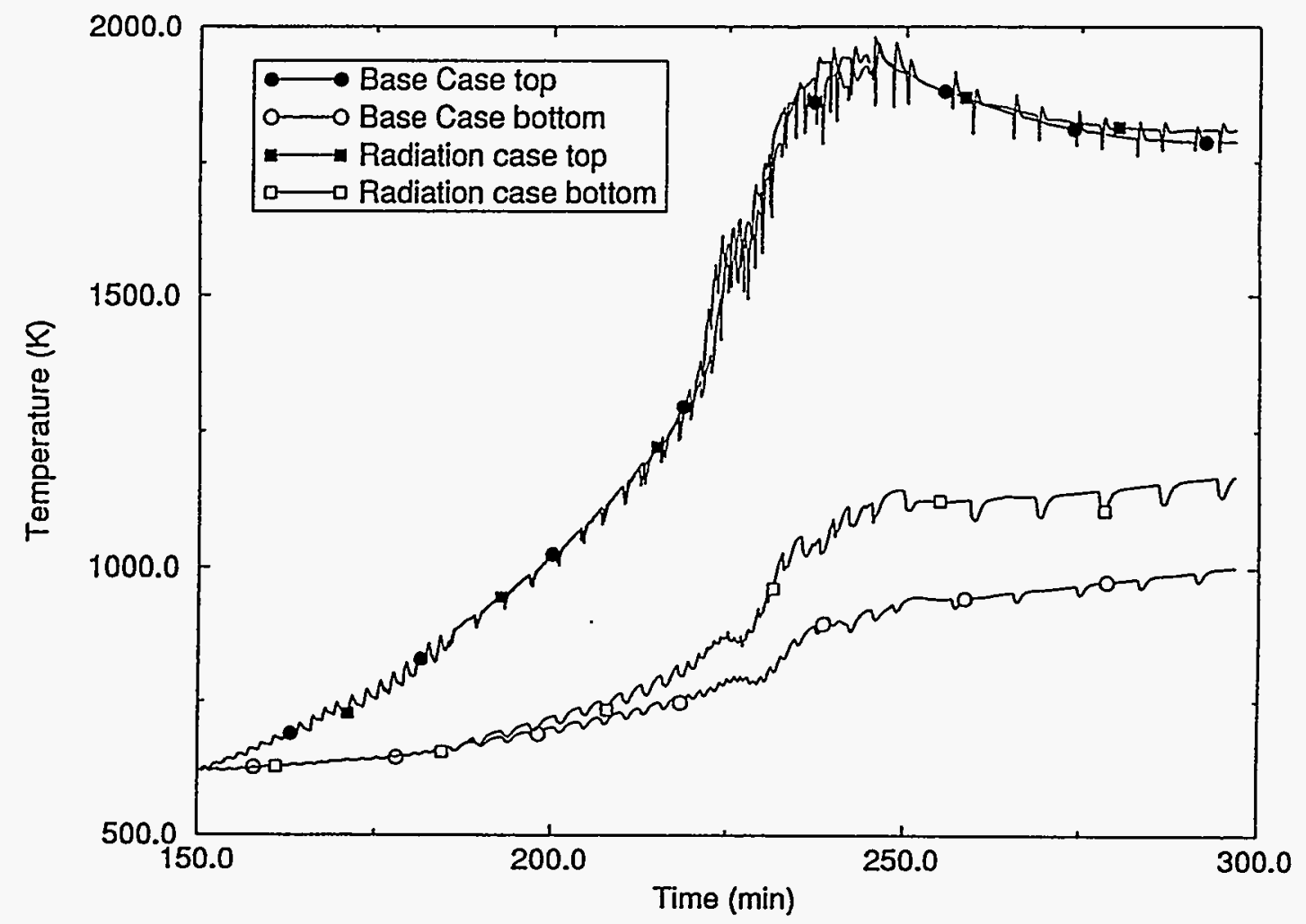

Figure H-15. Vapor temperatures in the hot leg nozzle of a nonpressurizer loop hot leg (A) for the Base Case and the radiation heat transfer sensitivity case. 


\section{Appendix I \\ Plant Categorization Based on the Potential for Unintentional Depressurization Resulting from Failure of Ex-Vessel Components}





\section{Appendix 1}

\section{Plant Categorization Based on the Potential for Unintentional Depressurization Resulting from Failure of Ex-Vessel Components}

\section{l-1. INTRODUCTION}

A study of intentional depressurization of the reactor coolant system (RCS) of pressurized water reactors (PWRs) was conducted by Brownson. ${ }^{\mathrm{I}-1, \mathrm{I}-2} \mathrm{He}$ developed a categorization scheme for PWRs that could be used to indicate the likelihood that a plant could be intentionally depressurized under certain severe accident conditions. The success of that study provided incentive to examine the possibility of categorizing plants according to their potential to unintentionally depressurize. The objective of this study is to determine if a method can be developed to categorize plants based on their potential for unintentional depressurization resulting from the temperature-induced failure of ex-vessel components during severe accidents.

Ex-vessel component failures can occur during certain severe accidents when structures are exposed to high temperature fluids that originate in the reactor vessel. Temperature-induced failures that are large enough to depressurize the RCS during a severe accident would most likely occur in one of the hot legs, the pressurizer surge line, or the steam generator tubes. Failure of the cold leg piping is generally not considered because hot fluids from the core region would raise the temperature of other structures, such as the hot leg piping, more rapidly before affecting the cold leg piping. In addition, full-loop natural circulation flow is unlikely without some form of secondary system cooling or unless the loop seals clear. Then there could be significant flow through the loops. Failure of the ex-vessel components would likely be caused by

- Forced flow of hot gases-Flow of hot gases during the latter stages of a severe accident could cause the RCS ex-vessel structures to reach high temperatures and fail. Forced RCS flows could be induced by (a) small ruptures in the hot legs, pressurizer, cold legs, or pump seals, or (b) open or cycling relief valves in the pressurizer.

- Natural circulation of hot gases-Natural circulation during the latter stages of a severe accident can transfer large amounts of energy to the plant ex-vessel structures. Since forced flow circulation in the RCS will tend to overwhelm natural circulation flows, natural circulation behavior is most important for accidents that occur when the system pressure is below the relief valve setpoints. However, natural circulation is also very important for a TMLB' station blackout scenario with the relief valves cycling. Natural circulation may take one of several forms ranging from full-loop circulation of hot steam and hydrogen mixtures to the countercurrent circulation of high-temperature gases in the hot leg.

A more specialized type of ex-vessel temperature-induced failure could also occur in the seals of a reactor coolant pump. This failure would occur when the fluid in the RCS reaches the saturation temperature, which leads to the pump seals failing. The seals of certain pump manufacturers are likely to fail catastrophically under these conditions. Relatively large failures must occur in a reactor coolant pump for the leak rates to be high enough to depressurize the RCS sufficiently to minimize the effects of direct containment heating (DCH).

Categorization of PWRs on their potential for unintentional depressurization through ex-vessel component failures is much more complex than intentional depressurization. During intentional depressurization, the pressure behavior of the system is dominated by flow out of the relief 
valves. System pressure under these conditions is dependent-on a relatively few, well-characterized parameters. In addition, flow out of the relief valves is a dominant influence on the flows and heat transfer in the remainder of the system, including the ex-vessel structures. In contrast, flows and temperatures from conditions expected prior to unintentional depressurization can vary significantly and are dependent on a wide range of plant conditions and system variables. The temperature of the ex-vessel structure depends on the temperature of the fluid exiting the reactor vessel, the flow conditions in the ex-vessel components, and the material properties and characteristics of the ex-vessel structure itself. The larger number of influential parameters makes categorization of plants much more difficult for unintentional depressurization. As an example, the temperature of the fluid exiting the reactor vessel is influenced by many parameters, including core decay heat levels, core materials, core geometry, upper plenum materials, and upper plenum geometry. These parameters vary among many of the PWR plants. Changes in some of these parameters can strongly influence vessel exit fluid temperatures. A difference in the core bypass geometry between the Surry and Zion plants significantly changes the predicted temperature behavior of the core, which influences the temperature behavior of the ex-vessel structures.

Section I-2 describes the approach taken in examining methods for categorizing plants, and Section I-3 describes the results. Section I-4 presents conclusions and recommendations. References are provided in Section I-5.

\section{I-2. APPROACH}

Several different approaches could be used to categorize plants. One approach would be to develop simple, conservative, first-principle models of natural circulation, power-operated relief valve (PORV)-induced flow, and lower head failure phenomena, and to either develop failure maps or apply the simple models to all plants. This approach was not used because it would require resources that were beyond the scope of this study. A second approach would be to use scaling methods and simple models of selected behavior to extrapolate results from code calculations for a small number of plants to categorize all plants. We chose the second approach for this work. The categorization work of Brownson $^{\mathrm{I}-1, \mathrm{I}-2}$ for intentional depressurization will be relied on extensively for results that are applicable for unintentional depressurization cases.

The success of unintentional depressurization depends on the timing of the failure of the exvessel structure. This timing is influenced by the temperature of the various ex-vessel structures and the RCS pressure. The temperature of the exvessel structures primarily depends on the dimensions and material characteristics of the structures and on the temperature and flow rate of the fluid passing within them. The approach was to examine system parameters that affect the structure temperature for a range of severe accident conditions and to identify dominant parameters that can be used to categorize plants. Results from computer code calculations can then be used to relate the plant categories to the timing of exvessel failures.

A single categorization of plants is not practical for all possible unintentional depressurization conditions because there are several very different mechanisms that can cause ex-vessel structure failures. To accommodate these different mechanisms, four failure modes have been identified for the categorization. These failure modes are

1. Failure of the hot leg or surge line resulting from flow through the relief valves.

Periods of forced flow in the ex-vessel piping during a severe accident would occur if the pressurizer relief valves were cycling or were open or possibly if there was a break in the RCS. The conditions where break flows would cause ex-vessel failure were not examined because the break flow rates would have to be in a narrow range (small enough to prevent substantial depressurization but large enough to overwhelm natural circulation) and the range of flows would be influenced by the location of the break. 
These conditions are too broad and complex to be categorized by an evaluation of scaling.

Periods of relatively high flow and heat transfer in the hot leg and surge line occur when the relief valves are open, followed by periods of hot leg countercurrent natural circulation when they are closed. Accidents that would result in this phenomenon are those that remain at relatively high RCS pressures and have frequent cycling of the relief valves, or accidents where the flow out the break or the relief valves is not sufficient to depressurize the system to levels where the effects of $\mathrm{DCH}$ would be mitigated.

Using the work of Brownson, categorization criteria that may be successful include: the core power density, the safety relief valve (SRV) and PORV flow capacities, the characteristics of the hot leg and surge line, and the failure time of the lower head. Accounting for differences in the lower head failure time is difficult when extrapolating between vendor designs and could cause the minimum number of categories to be equivalent to the number of reactor system vendors.

Calculations have been identified that could aid in the categorization process by providing a baseline behavior that other plants could reference. The calculations where relief valve flow dominates are (a) the Surry TMLB' calculations $^{\mathrm{I}-3}$ for accidents where the PORV cycles throughout the accident, and (b) the Surry, Sequoyah, Calvert Cliffs, and Oconee calculations ${ }^{\mathrm{I}-2, \mathrm{I}-4}$ for accidents where the relief valve is open for long periods of time. There are numerous small-break loss-of-coolant accident calculations that will have to be examined when the characteristics important to unintentional depressurization are identified.

2. Failure of the hot leg or steam generator tubes resulting from natural circulation flow.
This failure mode would likely be the result of accidents in which the RCS pressure is generally below the pressurizer relief valve setpoints and which do not depressurize the RCS low enough before lower head failure to mitigate the effects of DCH. Failure of the steam generator tubes can depressurize the RCS, although failure of additional equipment in the steam generator (such as the steam generator atmospheric dump valves or safety relief valves failing in an open position) is necessary for the RCS to depressurize to levels where DCH would be mitigated.

Calculations have been identified that could be used in the categorization process. These include the Surry TMLB' calculations ${ }^{\mathrm{I}-3}$ for accidents where the pump seal leaks occur once the system reaches saturation temperature. Categorization criteria could be based on the core power density, the characteristics of the hot leg and steam generators, and the lower head failure time.

3. Failures of relief valves that would depressurize the RCS to low pressures.

The failure of the plant PORVs or SRVs in an open position may depressurize the RCS, depending on the capacity of the relief valves and how they fail. Failure in an open position would likely occur as a result of valve cycling in the presence of high temperature fluid. Flow after failure must be sufficient to depressurize the RCS. For some plants this would mean that the valve would have to fail in a fully open position, while for other plants the degree of opening could be less. Possible criteria for categorization would be the number and capacity of relief valves and the likelihood of failure of the valve when exposed to hot fluid. The likelihood of failure would strongly depend on the valve design and the qualification temperature of its components.

4. Failures of reactor coolant pump seals that will depressurize the RCS. 
Studies, for example NUREG-1150, ${ }^{\mathrm{I}-5}$ have shown that reactor coolant pump seal leak rates may be sufficiently large that their failure can cause the RCS to depressurize to levels that would mitigate the effects of $\mathrm{DCH}$. The likelihood of failure of the seals depends on the design of the seal and the capability of the plant support systems to maintain cooling for the seal. The possible range of leak rates is also dependent on the seal design, which is different for the various manufacturers of reactor coolant pumps.

Categorization of plants for this area would be beneficial since there is the potential that some manufacturers' pumps could experience seal leaks large enough to depressurize the plant prior to lower head failure. Pump seal leak calculations for Surry ${ }^{\mathrm{I}-3}$ can be used to estimate the sizes of leaks that will depressurize the RCS. The categorization criteria would be based on the size of the leak possible for the pump type installed at each plant. For those plants that do not depressurize to sufficiently low pressures to mitigate the effects of $\mathrm{DCH}$, the categorization produced for natural circulation (Failure Mode 2) should be examined to determine how the plant would respond.

Since there is interest in plants that are not expected to depressurize the RCS to a sufficiently low pressure to mitigate the effects of $\mathrm{DCH}$, relationships between the four failure modes must be considered. For example, the inability of failed reactor coolant pump seals to depressurize the RCS will not necessarily result in DCH if natural circulation would cause a failure in the hot leg piping sufficiently prior to lower head failure. Consequently, if categorization is to be practical, results will have to be correlated between failure modes to identify those plants that have a higher potential to experience $\mathrm{DCH}$.

\section{I-3. RESULTS}

An evaluation of plant categorization based on the potential for unintentional depressurization is presented in this section. Results are presented for each of the four failure modes identified in Section I-2. Categorization for all four failure modes was found to be difficult because the temperature of the ex-vessel structures is influenced by a wide variety of complex parameters.

\section{I-3.1 Ex-Vessel Failures Caused by Relief Valve Flow}

The hot leg or surge line may fail from high temperature creep rupture if there is sufficient flow through the relief valves or if flow through the relief valves is periodic and natural circulation occurs between the cycles. Failure of steam generator tubes is not considered in this categorization because, although some flow through the tubes will occur during relief valve operation, it is unlikely that the temperature of the flow will be sufficiently high to cause tube failure.

Hardware or accident characteristics that can be used to categorize plants according to their potential for failures in the hot leg or surge line are considered in two parts:

- Characteristics influencing hot leg or surge line failure resulting from PORV or SRV cycling

- Characteristics influencing hot leg or surge line failure resulting from an open relief valve (for this condition to be of concern, flow through the valve would need to be too low to fully depressurize the RCS).

I-3.1.1 PORV or SRV Cycling. Many other parameters would also influence the temperatures of the fluid and structures or the pressure in the RCS. Evaluating the relative importance of the large number of parameters led to the conclusion that categorization based on a single or simple groups of parameters is not reasonable. For example, an evaluation of the effects of differences in length, pipe diameter, and wall 
thickness was performed for the hot leg pipes. Although relationships could be derived to relate the temperatures of pipes from different reactors, these relationships were highly dependent on assumptions on the temperature of the fluid entering the pipes. The heat transfer in the core and upper plenum regions is also difficult to characterize based on a few parameters. This makes categorization of plants based on system parameters not possible for this failure mode.

I-3.1.2 Stuck Open PORV or SRV. Having the PORV or SRV stuck open would simplify the flow conditions in the ex-vessel structures as most flow would tend to be towards the pressurizer. (This would depend on the amount of flow going out the valves because lower flow rates may not be sufficient to overcome natural circulation patterns.) However, the parameters influencing the ex-vessel structure temperature would continue to be very complex and would not differ appreciably from the discussion in Section I-3.1.1. After careful examination, it was concluded that categorization would not be possible for this failure mode.

\section{I-3.2 Potential for Natural Circulation}

Natural circulation during the latter stages of some severe accidents may cause the hot legs or surge line to reach failure temperatures. Possible natural circulation modes that could circulate hot gases are

1. Countercurrent circulation of steam or a steam-hydrogen mixture in the hot leg

\section{Reflux natural circulation}

3. Loop circulation of steam or a steamhydrogen mixture.

Following is a brief description of each mode and the plant and accident characteristics that would be important in categorizing plants for unintentional depressurization.
1. Countercurrent circulation of steam or a steam-hydrogen mixture in the hot leg.

This circulation mode is possible during the latter stages of some severe accidents where the steam or steam-hydrogen mixture in the vessel is heated to high temperatures and the primary system piping and steam generator act as heat sinks. For these conditions, there is generally no water in the secondary side of the steam generators and, consequently, there is no condensation occurring on the primary side of the steam generator tubes. This mode of natural circulation is important for severe accidents at high and intermediate pressures. For accidents that remain at high pressure, such as the TMLB' station blackout scenario, natural circulation may be present but the periodic flow out of the relief valves would strongly influence fluid flow through the hot leg and surge line and would be the dominant factor in determining the failure time of these structures. In addition, natural circulation would likely be the dominant mode of heat transfer for accidents where the steam generators contained little or no water and the relief valves were not cycling, such as in some small-break scenarios.

Parameters that could be important influences in the categorization of plants for their potential to fail the ex-vessel structure include ex-vessel structure characteristics (material properties, diameter, and thickness), steam generator type (U-tube or oncethrough), mass of metal on the steam generator secondary side, and the geometry of the attachment point of the surge line.

The steam generators are much more effective heat sinks than the hot leg pipes. As a result, plants with steam generators that are directly in the hot leg countercurrent natural circulation flow path would be expected to have strong natural circulation flow rates. Experiments conducted by Westinghouse in a 1/7-scale model of a PWR indicate that 
plants with U-tube steam generators would have strong natural circulation flows.

The geometry of the hot leg piping and the configuration of the steam generator varies most for plants with once-through steam generators when compared with plants that have U-tube steam generators. The large vertical run of hot leg piping and the elevation and geometry of the once-through steam generator do not promote strong hot leg natural circulation flows. Plants that have once-through steam generators should be in a different category than plants that have U-tube steam generators. The remaining categorization items would indicate whether there are enough differences in U-tube steam generator designs that further categorization between plants with U-tube steam generators can be made.

Additional parameters, such as steam generator tube metal mass or the dimensions of the tubes, would be important but could not be used to discriminate between plants. The volume of the steam generator secondary side and its metal mass could affect the timing of a severe accident progression, but its effect on the mass flow rate in the hot leg is difficult to determine directly.

Orientation of the pressurizer surge line where it attaches to the hot leg may influence the timing of a failure in the surge line. If the surge line is attached to the top of the hot leg pipe, natural convection cells may develop when the PORV is not cycling that will enhance heat transfer to the surge line. Surge lines entering the side of the hot leg would not have natural convection cells develop. Currently there is not sufficient information to evaluate side-mounted surge lines. Computational fluid dynamic calculations of side-mounted surge lines would need to be made to examine the potential for the development of natural convection cells in this configuration.
In summary, plants could be categorized based on their steam generator type. Plants with U-tube steam generators would experience higher hot leg natural circulation rates and would have a higher potential for exvessel failures than plants with oncethrough steam generators. Other parameters, such as surge line orientation, were evaluated, but do not provide sufficient discrimination criteria to be used for plant categorization.

2. Reflux natural circulation.

Condensation in the steam generators could draw superheated steam into the hot leg from the vessel. This circulation mode is possible only if secondary system cooling is available. For plants with U-tube steam generators, the condensate would return to the vessel either along the bottom of the hot leg or through the cold leg. For plants with once-through steam generators, condensate would return to the vessel through the cold leg.

Reflux natural circulation may be less likely to cause hot leg failure for plants with U-tube steam generators because the condensate flowing along the bottom of the pipe would provide some cooling. The presence of hydrogen in the mixture being condensed would tend to concentrate hydrogen in the steam generator tubes for a U-tube steam generator and in the top of the "candy cane" for the once-through steam generators. In either case, the flow in the loops would decrease substantially. It is not clear that there are features that would provide enough discrimination of these phenomena to categorize plants for reflux natural circulation.

3. Loop circulation of steam or a steamhydrogen mixture.

Hot steam or a mixture of steam and hydrogen could follow the normal flow pattern around the loop (upper plenum-hot legsteam generator-inactive reactor coolant 
pump-cold leg-downcomer-core) if the inventory in the reactor coolant system was very low and the reactor coolant pump loop seals have been cleared.

The depth of the loop seal varies greatly between and among PWR vendor designs. However, there is not sufficient understanding of the phenomena that cause loop seal clearing to use loop seal depth as a means for categorizing plants.

\section{I-3.3 Failure of PORVs and SRVs in an Open Position}

During high-pressure accident scenarios, the PORVs and SRVs will cycle to relieve RCS pressure. This allows hot gasses to pass through these valves. The possibility that these valves will fail in an open position and result in an unintentional depressurization of the RCS is most strongly influenced by the design of the valves. Plants could be categorized based on their valve designs, but there are insufficient data for valve operation under conditions expected during severe accidents to identify the failure modes of any of the valve designs. Consequently, categorizing plants by valve design would not be beneficial for this failure mode.

\section{I-3.4 Categorization for Pump Seal Failures}

The likelihood of a reactor coolant pump seal failure under high temperature conditions is considered to be higher for plants with Westinghouse pumps because they must rely on continuous seal cooling. Since Combustion Engineering and Babcock \& Wilcox plants use other manufacturers' pumps [(Bingham International, Byron Jackson, or Klein, Schanzlin, and Becker (KSB)], unintentional depressurization as a result of pump seal failure is considered to be less likely.

However, Westinghouse has recently developed a pump seal design that would be less likely to fail under high-temperature conditions. As a result, some Westinghouse PWRs may now be using, or are planning to use, the new pump seal design. Plants could be categorized into two groups, those with Westinghouse pumps that have the old seal design and those that have the new design or that do not have Westinghouse pumps. Plants with the old design would be more likely to experience unintentional depressurization.

\section{1-4. CONCLUSIONS AND RECOMMENDATIONS}

The likelihood that an ex-vessel failure mode occurs in a PWR is influenced by plant hardware and accident characteristics. Ex-vessel failures can occur during certain severe accidents when structures are exposed to high-temperature fluid that originates in the reactor vessel. If relief valves are operating, forced flow in the hot legs or surge line will strongly influence the heat transfer from the hot fluid to the piping. If the pressure is below the setpoint for relief valve operation, or during periods when the relief valves are closed, natural circulation flow will influence heat transfer to the piping or steam generator tubes. In both of these situations, many system parameters influence the reactor vessel exit temperature of fluid that is in contact with the pipe or tubes, the fluid flow rate, and the structure energy storage capability. Consequently, a simple set of parameters could not be identified that would characterize PWRs according to their potential for unintentional depressurization resulting from temperature-induced creep rupture failure of the hot leg, surge line, or steam generator tubes.

Failure of relief valves in an open position may occur if hot fluid passing through the valve heats valve components above their failure limits. The potential for failure of relief valves would depend strongly on their design and their temperature qualifications. Consequently, PWR plants could be categorized according to the potential for failure of relief valves based on the valve type installed in the plant. However, there are no data on the failure modes of relief valves under conditions similar to those that would be expected during severe accidents. Therefore, categorization of PWRs based on valve type would not provide insights into which plants would be more likely to experience unintentional depressurization. Without extensive failure mode testing 
and analysis of the data, categorization of plants according to the potential for failure of their relief valves would not be beneficial.

The likelihood that a reactor coolant pump seal will fail because of high temperature conditions is considered to be higher for plants with Westinghouse pumps because they must rely on continuous seal cooling. Since Combustion Engineering and Babcock \& Wilcox plants use other manufacturers' pumps, unintentional depressurization as a result of the failure of pump seals is considered to be less likely. However, Westinghouse has recently developed a pump seal design that would be less likely to fail under hightemperature conditions. As a result, there may be some Westinghouse PWRs that are now using or are planning to use the new pump seal design. Plants could be categorized into two groups, those with Westinghouse pumps that have the old seal design and those that have the new seal design or that do not have Westinghouse pumps. Plants with the old seal design would be more likely to experience unintentional depressurization.

\section{1-5. REFERENCES}

I-1. D. A. Brownson, Extension of Surry Late Depressurization Strategy Results to Commercially Operating Pressurized Water Reactors, EGG-EAST-9717, October 1991.

I-2. D. A. Brownson, Intentional Depressurization Accident Management Strategy for Pressurized Water Reactors, NUREG/ CR-5937, EGG-2688, April 1993.

I-3. D. L. Knudson and C. A. Dobbe, Assessment of the Potential for High-Pressure Melt Ejection Resulting from a Surry Station Blackout Transient, NUREG/CR-5949, EGG-2689, November 1993.

I-4. D. J. Hanson et al., Depressurization as an Accident Management Strategy to Minimize the Consequences of Direct Containment Heating, NUREG/CR-5447, EGG-2547, October 1990.

I-5. U.S. Nuclear Regulatory Commission, Reactor Risk Reference Document, NUREG/CR-1150, December 1990. 
Severe Accident Natural Circulation Studies at the INEL

\section{AUTHOR(S)}

P. D. Bayless, D. A. Brownson,

C. A. Dobbe, K. R. Jones,

J. E. O'Brien, D. J. Pafford,

L. D. Schlenker, V. X. Tung
3. DATE REPORT PUBLISHED

February 1995

4. FIN OR GRANT NUMBER

\section{L1675}

6. TYPE OF REPORT

Technical

7. PERIOD COVERED IInCIUSUre DatesI

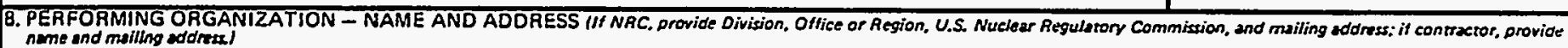

Idaho National Engineering Laboratory

Lockheed Idaho Technologies Company

P.O. Box 1625

Idaho Falls, Idaho 83415

9. SPOINSORING ORGANIZATION - NAME AND ADORESS (II NRC, tvDe "Same ss sbove", il eontractor, provide NRC Divisian, Office or Region, U.S. Nuclear Regulazon Commission.

Division of Systems Research

Office of Nuclear Regulatory Research

U.S. Nuclear Regulatory Commission

Washington, D.C. 20555-0001

10. SUPPLEMENTARY NOTES

\section{ABSTRACT 1200 words or tess)}

Severe accident natural circulation flows have been investigated at the Idaho National Engineering Laboratory to better understand these flows and their potential impacts on the progression of a pressurized water reactor severe accident. Parameters affecting natural circulation in the reactor vessel and hot legs were identified and ranked based on their perceived importance. Reviews of the scaling of the 1/7-scale experiments performed by Westinghouse were undertaken. RELAP5/MOD3 calculations of two of the experiments showed generally good agreement between the calculated and observed behavior. Analyses of hydrogen behavior in the reactor vessel showed that hydrogen stratification is not likely to occur, and that an initially stratified layer of hydrogen would quickly mix with a recirculating steam flow. An analysis of the upper plenum behavior in the Three Mile Island, Unit 2 reactor concluded that vapor temperatures could have been significantly higher than the temperatures seen by the control rod drive lead screws, supporting the premise that a strong natural circulation flow was likely present during the accident. SCDAP/RELAP5 calculations of a commercial pressurized water reactor severe accident without operator actions showed that the natural circulation flows enhance the likelihood of ex-vessel piping failures long before failure of the reactor vessel lower head.

12. KEY WORDS/DESCR!PTORS (List words or phrases ethat will essist researchers in locating the report.)

Natural circulation

Severe accidents

Code assessment

Code applications
13. AVAILABILITY STATEMENT

Unlimited

14. SECUAITY CLASSIFICATION

This Pagel

Unclassified

Tris Reoon
Unclassified

15. NUMBER OF PAGES 